\title{
Joint U.S./Russian Study on the Development of a Decommissioning Strategy Plan for RBMK-1000 Unit \#1 at the Leningrad Nuclear Power Plant
}

\section{RECEIVED \\ FFR 191998 \\ OSTI}

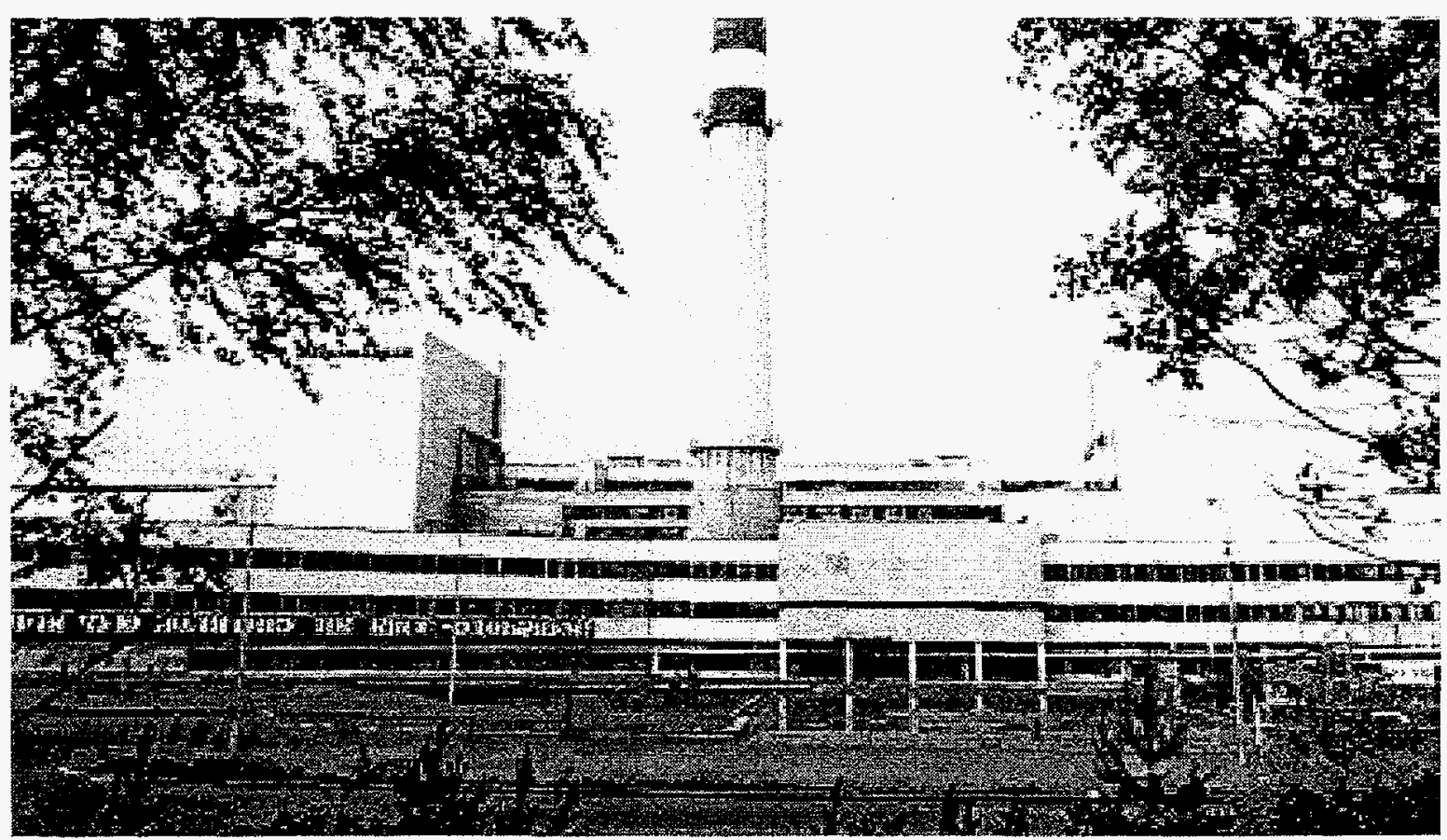

December 1997

Prepared by

Joint U.S./Russian Study Team

Pacific Northwest National Laboratory

Brookhaven National Laboratory

RRC Kurchatov Institute

for the

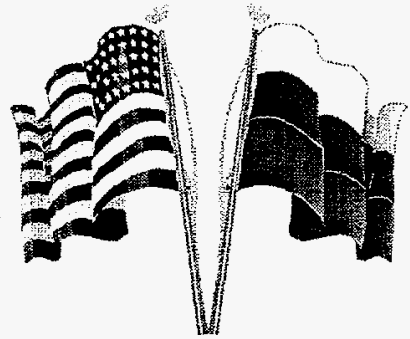

United States Department of Energy and the Russian Federation Ministry of Atomic Energy 
Printed in the United States of America

Available to DOE and DOE contractors from the Office of Scientific and Technical Information,

P.O. Box 62, Oak Ridge, TN 37831

Prices available from (615) 57688401.

Available to the public from the National Technical Information Service

U.S. Department of Commerce 5285 Port Royal Rd. Springfield, VA 22161 


$$
\text { PNNL- }-11769
$$

\section{Joint U.S./Russian Study on the Development of a Decommissioning Strategy Plan for RBMK-1000 Unit \#1 at the Leningrad Nuclear Power Plant}

December 1997

Prepared for

U.S. Department of Energy

Office of Nuclear Energy, Science and Technology

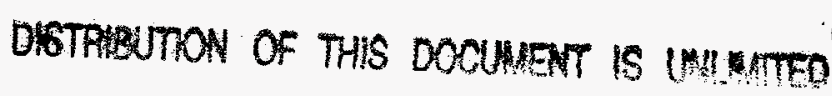

Pacific Northwest National Laboratory

International Nuclear Safety Program

Richland, Washington 99352 


\section{DISCLAIMER}

Portions of this document may be illegible electronic image products. Images are produced from the best available original document. 


\section{DISCLAIMER}

This report was prepared as an account of work sponsored by an agency of the United States Government. Neither the United States Government nor any agency thereof, nor any of their employees, makes any warranty, express or implied, or assumes any legal liability or responsibility for the accuracy, completeness, or usefulness of any information, apparatus, product, or process disclosed, or represents that its use would not infringe privately owned rights. Reference herein to any specific commercial product, process, or service by trade name, trademark, manufacturer, or otherwise does not necessarily constitute or imply its endorsement, recommendation, or favoring by the United States Government or any agency thereof. The views and opinions of authors expressed herein do not necessarily state or reflect those of the Unjted States Government or any agency thereof. 


\title{
Participating Organizations
}

\author{
United States
}

United States Department of Energy (DOE)

Pacific Northwest National Laboratory (PNNL)

Brookhaven National Laboratory (BNL)

\section{Russian Federation}

Ministry of Atomic Energy (Minatom)

Leningrad Nuclear Power Plant (LNPP)

Russian Research Center Kurchatov Institute (RRC KI) 


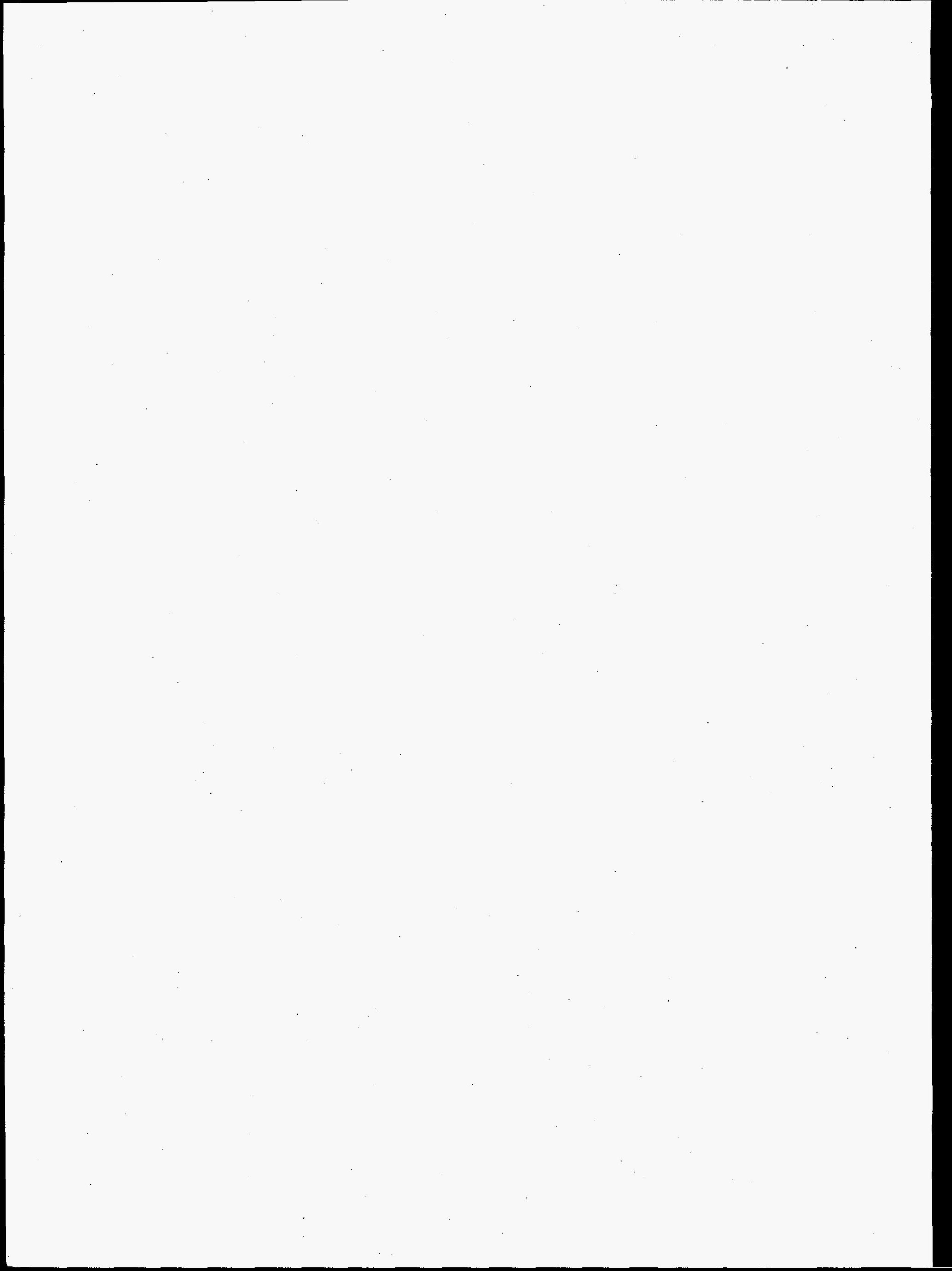




\section{Study Leaders}

United States Project Manager

Task Manager

Russian Federation Leader

Russian Federation Deputy Leader

Russian Federation Deputy Leader

Russian Federation Project Manager

Russian Federation Project Manager
Ms. S.M.K. Garrett

Pacific Northwest National Laboratory

Mr. R.F. Lavelle

Brookhaven National Laboratory

Dr. N.E. Kukharkin

RRC Kurchatov Institute

Dr. Yu.V. Garusov

Leningrad Nuclear Power Plant

Dr. Yu.F. Chernilin

RRC Kurchatov Institute

Dr. B.K. Bylkin

RRC Kurchatov Institute

Dr. Yu.A. Zverkov

RRC Kurchatov Institute 


\section{Participants - United States}

M.G. Cowgill (Brookhaven National Laboratory, New York, NY)

G.R. Eidam (Bechtel Hanford Inc., Richland, WA)

S.M.K. Garrett (Pacific Northwest National Laboratory, Richland, WA)

R.F. Lavelle (Brookhaven National Laboratory, New York, NY)

S.M. Short (Pacific Northwest National Laboratory, Richland, WA) 


\section{Participants - Russian Federation}

N.I. Ampelogova (VNIPIET, St. Petersburg)

M.I. Abramov (NIKIET, Moscow)

A.I. Berela (Volgodonsk branch, VNIIAM, Volgodonsk)

E.V. Burlakov (Kurchatov Institute, Moscow)

B.K. Bylkin (Kurchatov Institute, Moscow)

Yu.V. Garusov (Leningrad Nuclear Power Plant, Sosnovy Bor)

G.B. Davydova (Kurchatov Institute, Moscow)

Yu.A. Egorov (AtomEnergoProyekt, Moscow)

N.V. Zhukov (NIKIET, Moscow)

Yu.A. Zverkov (Kurchatov Institute, Moscow)

N.N. Kalyazin (Leningrad Nuclear Power Plant, Sosnovy Bor)

E.P. Kozlov (Leningrad Nuclear Power Plant, Sosnovy Bor)

I.D. Kulikov (VNIPIET, St. Petersburg)

N.E. Kukharkin (Kurchatov Institute, Moscow)

M.I. Miroshnitchenko (Gosatomnadzor, Moscow)

D.A. Michailov (Kurchatov Institute, Moscow)

A.A. Noskov (Rosenergoatom, Moscow)

M.A. Pavlov (Leningrad Nuclear Power Plant, Sosnovy Bor)

B.A. Paytunin (NIKIMT, Moscow)

V.G. Romanov (Leningrad Nuclear Power Plant, Sosnovy Bor)

V.N. Ryzhkova (VNIIAES, Moscow)

B.M. Tishkov (Leningrad Nuclear Power Plant, Sosnovy Bor)

V.I. Cheremiskin (Leningrad Nuclear Power Plant, Sosnovy Bor)

O.G. Chernikov (Leningrad Nuclear Power Plant, Sosnovy Bor)

Yu.F. Chernilin (Kurchatov Institute, Moscow)

V.A. Shaposhnikov (Leningrad Nuclear Power Plant, Sosnovy Bor)

V.Ya. Shpitser (VNIIAM, Volgodonsk)

T.D Shepetina (Kurchatov Institute, Moscow)

A.A. Etingen (VNIIAM, Volgodonsk) 


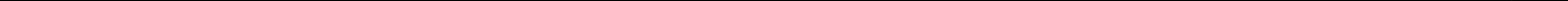




\section{Summary}

The objective of this joint U.S./Russian study was to develop a safe, technically feasible, economically acceptable strategy for decommissioning Leningrad Nuclear Power Plant (LNPP) Unit \#1 as a representative first-generation RBMK-1000 reactor. The ultimate goal in developing the decommissioning strategy was to select the most suitable decommissioning alternative and end state, taking into account the socioeconomic conditions, the regulatory environment, and decommissioning experience in Russia. This study was performed by a group of Russian and American experts led by Kurchatov Institute for the Russian efforts and by the Pacific Northwest National Laboratory for the U.S. efforts and for the overall project.

\section{Current Status of NPP Unit Decommissioning in Russia}

Russian nuclear power plant (NPP) units commissioned in the ' 60 s and early ' 70 s have already reached or are approaching the end of their design operating life. Since 1981 the two Phase I units at Beloyarsk, which have AMB-100 and AMB-200 graphite-water pressure tube reactors similar to the RBMK-1000 and two VVER-210 and VVER-365 pressure vessel reactors, have been shut down. By 2006 the design operating life of 10 NPP units will end. By 2020, Russia must solve the problem of decommissioning 24 NPP units with a total electrical output of 12,565 MWe, including units at Kursk, Leningrad, and Smolensk NPPs with RBMK-1000 reactors and the units at Bilibino NPP with EGP-6 graphite-water reactors.

Current regulations in Russia define NPP unit decommissioning as the process performed after nuclear fuel has been removed from the unit to prevent its use and to ensure the safety of personnel, the population, and the environment. According to this definition, Russian organizations operating nuclear power plants should be ready to carry out the full scope of work to decommission their units as well as to process, transport, and bury the large amounts of resulting radioactive wastes.

Russia does not have experience in full-scale decommissioning of NPP units because the shutdown Russian units have not been dismantled. These units are being prepared for decommissioning. However, Russia does have experience repairing and rebuilding plutonium-production graphite-uranium reactors, including those with graphite stacks. The reconstruction of Leningrad Units \#1 and \#2 has almost been completed, including large-scale replacement of fuel channels in the reactors. This experience, as well as that acquired on the shutdown units at Beloyarsk NPP, will be used to plan and decommission RBMK units.

\section{Basic Tasks of the Joint Study}

The analyses performed included an analysis of fundamental regulatory and technical requirements for the decommissioning of NPP units and the technological infrastructure for decontaminating and dismantling radioactive structures. A strategy was developed considering the specific features (location, construction, and operation) of Leningrad NPP Unit \#1, current regulatory requirements, technical approaches to the decommissioning of NPP units, and the socioeconomic conditions in Russia. The study therefore included analyses of the current Russian and U.S. legislative and regulatory environment governing NPP unit decommissioning; 
experiences repairing and rebuilding graphite-uranium nuclear reactors; and problems related to ensuring the safety of personnel, the population, and the natural environment during decommissioning. The analyses listed made it possible to identify. with greater certainty technologies for decontamination and dismantling (D\&D) and for spent nuclear fuel and radwaste handling that are being successfully used in the West and to determine the possibility of transferring these technologies to the Russian Federation.

\section{Description of Leningrad NPP and Its Site}

Leningrad NPP is a representative plant for NPPs built with RBMK-1000 reactors. This NPP was designed and built in compliance with the regulations of the 1960s.

The NPP was built in two phases. Units \#1 and \#2 are the Phase I units, and Units \#3 and \#4 are the Phase II units. Construction of Leningrad NPP started in 1967, and startup of Unit \#1 took place in December 1973. Unit \#2, the other Phase I unit, was commissioned in 1975 . Unit \#3 was commissioned in the summer of 1979 and Unit \#4 in the fall of 1981.

Leningrad NPP is located in the Lomonosov Region of Leningrad Oblast $80 \mathrm{~km}$ west of St. Petersburg on the southern coast of the Gulf of Finland, about 6-8 km southwest of the town of Sosnovy Bor, which has a population of about 62,400. There are about 700 large and small industrial and other enterprises in the area around Leningrad NPP and Sosnovy Bor.

\section{Features of the Construction of Leningrad Unit \#1}

The Phase I units, Units \#1 and \#2, like the Phase II units, are individual structures with separate reactor sections. The units in each phase share a common turbine hall. LNPP Phases I and II were laid out and built to ensure the maximum sharing of process equipment and auxiliary systems. This was accomplished by having the two units of a phase use common systems in common halls. Later when the NPP was in operation, the main systems of the Phase I units were separated for safety.

LNPP units are equipped with the RBMK-1000 reactor, a heterogeneous channel-type thermal neutron nuclear power reactor. The reactor uses graphite as the moderator, boiling water as the coolant, and uranium dioxide $\left(\mathrm{UO}_{2}\right)$ weakly enriched with $\mathrm{U}-235$ isotope as fuel.

The reactor structure includes metal structures (support structure, bottom and top load-bearing structures, circular tanks, cylindrical liner, and top plate floor) which perform load-bearing and protective functions; a graphite reactor stack; and a set of vertical fuel and special channels. The graphite stack consists of columns of graphite blocks and is surrounded by a thin-walled cylindrical housing (shell). All reactor structures are housed inside a special concrete shaft with massive concrete walls that provide biological protection. Coolant circulates through the reactor core through a multiple forced circulation (MFC) circuit that consists of two independent loops. The MFC has much piping and includes a large amount of equipment.

\section{Operational Features and Current Status of Leningrad Unit \#1}

On September 30,1975, there was an accident at Leningrad NPP Unit \#1 that led to the rupture of one of the fuel channels. As a result of this accident, a portion of the fuel elements and the fuel in them entered the reactor graphite stack. At the time it was impossible to determine the 
amount of nuclear fuel which entered the graphite stack, but estimates showed that it was not large. During repair, the damaged fuel assembly was removed, the emergency channel tube was repaired, and assemblies in the adjacent fuel channels were replaced. To dismantle the reactor graphite stack blocks safely, it will be necessary to inspect the graphite stack to determine the level of radioactivity and the amount and local distribution of nuclear fuel and fission products.

\section{Factors Influencing Leningrad Unit \#1 Decommissioning}

The major factors influencing the decommissioning of Unit \#1 are the availability of financing; personnel safety; initial outlay of expenditures; the layout of the units (e.g., the fact that some systems and equipment are shared between Units \#1 and \#2); the timely removal of spent nuclear fuel; the processing, storage, and/or burial of decommissioning radwastes; and the status of technological support for the D\&D of RBMK-1000 reactors. Also, the short time between the commissioning of each phase's units at LNPP (averaging two years) must be considered in planning their decommissioning.

\section{Alternative Strategies Analyzed}

Three decommissioning alternatives were evaluated during this study: SAFESTOR, DECON, and ENTOMB. These alternatives are based on U.S. Nuclear Regulatory Commission definitions:

- SAFESTOR is the method by which a facility is placed and maintained in a condition that allows it to be safely stored and subsequently decontaminated to levels that permit its release for unrestricted use.

- ENTOMB is the method by which radioactive contaminants are encased in a structurally long-lived material. The entombed structure is maintained, and surveillance is performed until the radioactivity decays to a level permitting unrestricted use of the site.

- DECON is the method by which the facility and its associated equipment, systems and site, are decontaminated (e.g., contaminated portions removed or cleaned) to a level that permits unrestricted use of the site.

The definitions of the alternatives were modified for conditions in Russia. Examples of the modifications include

- In the United States, D\&D is done to unrestricted levels, while in Russia, D\&D will be done to restricted levels because the site will continue to be used as a nuclear site.

- In the United States, entombment would last until radiation levels reach background, but in Russia, the site is dedicated for nuclear power generation and it may be recovered before radiation levels reach even restricted use levels. 


\section{Recommended Leningrad Unit \#1 Decommissioning Alternative}

The SAFESTOR alternative is recommended for LNPP Unit \#1. Analyses showed the unit should be held in long-term storage for approximately 70 years in order to dismantle the reactor structures with a minimum of special equipment. The recommended alternative provides time to develop regulations, complete necessary research and development, and build storage facilities and repositories. The SAFESTOR alternative also results in less radwaste, lower personnel dose rates, and reduced initial expenditures.

Decommissioning Leningrad Unit \#1 according to the recommended alternative requires basic research. Basic research is needed for substantiation of the long-term strength of metal and concrete structures during storage; development of technologies for final handling of irradiated graphite; development of equipment for real-time monitoring of low-level beta and gamma radiation and detection of hot aerosol particles.

\section{End State of Leningrad Unit \#1}

To increase the cost-effectiveness of the proposed Unit \#1 decommissioning alternative, various ways to accomplish it were analyzed. Decommissioning of the two Phase I units or the entire NPP was investigated. As a result it is proposed that a processing and long-term storage complex for radwastes (both operational and those created during decommissioning) be built in Unit \#1 facilities.

\section{List of Required Tasks to Achieve the End State for Unit \#1}

In order to bring Leningrad Unit \#1 to the recommended end state, some steps will need to be taken:

- partial dismantling of turbine hall equipment to make room for the specialized radwaste processing complex

- localization of the reactor and graphite stack in a concrete cavity

- conversion of the unit's main building into storage for processed radwastes

- dismantling of the remaining turbine hall equipment to make room for processed radwastes and dismantled equipment.

\section{Conclusions and Remarks}

The results of this study may be used as the basis for developing a decommissioning program for Leningrad NPP Unit \#1. The results may also be used as the basis for planning the decommissioning of other NPP units with RBMK reactors.

Estimates of the financing required for decommissioning LNPP Unit \#1 (SAFESTOR alternative) and to achieve the recommended end state have not been considered at this stage but will be developed in a follow-on study.

The amount of process equipment and auxiliary systems shared by the Phase I units makes it worthwhile to consider the concurrent decommissioning of the Phase I units, thereby reducing costs. 


\section{Proposed Projects}

The following projects are proposed for achieving the longer-term goal of this workdevelopment of the Leningrad Unit \#1 decommissioning strategy that is optimal in terms of safety, technical feasibility, and economic acceptability:

- Detailed analysis of the proposed decommissioning alternative and Unit \#1 end state in order to estimate costs.

- Development of a technical and economic database for preparing cost estimates and for optimizing costs to decommission units with RBMK- 1000 reactors.

- Development of a standard plan for decommissioning RBMK-1000 units.

- Development of a decommissioning project for Leningrad NPP Unit \#1 considering its construction as part of Phase I and using the document outlines presented in Appendix D.

- Analysis of the design basis accidents that may occur during long-term storage and decommissioning of units with RBMK-1000 reactors.

- Development of a strategy for the combined decommissioning of first-generation units with RBMK-1000 reactors at Leningrad and VVER-440 reactors at Kola, both of which are in the northwestern region of Russia.

Also, while performing the analyses for this study, it became evident that several issues related to RBMK-1000 reactors in general need to be addressed at the Russian Federation level:

- Continuation of the development of regulations for decommissioning and handling of SNF.

- Analysis of the possibility of non-safety threatening decommissioning activities (e.g., general cleanup and dismantling of non-safety related equipment and systems) after shut down but prior to licensing, and the modification of current regulations.

- Construction of state radwaste sites for management of NPP operational and decommissioning waste.

- Initiation of a program for joint NPP funding of basic research and development required for decommissioning of units with RBMK-1000 reactors (currently each NPP will perform its own research and development). 


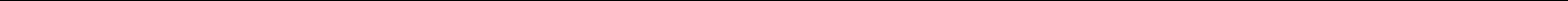




\section{Table of Contents}

Participating Organizations ...................................................................................... iii

Study Leaders...................................................................................................................... $\quad$ v

Participants - United States....................................................................................... vi

Participants - Russian Federation ............................................................................ vi

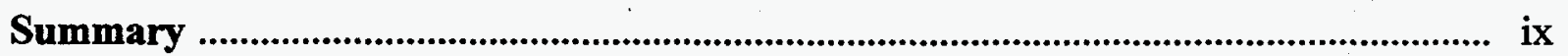

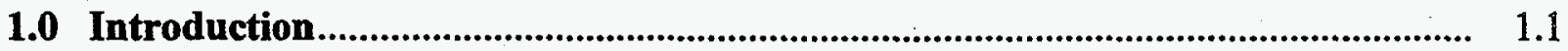

1.1 Background ............................................................................................ 1.1

1.2 Efforts of the U.S: Department of Energy, RF Minatom and Leningrad NPP to Organize the Joint Study .................................................................... 1.1

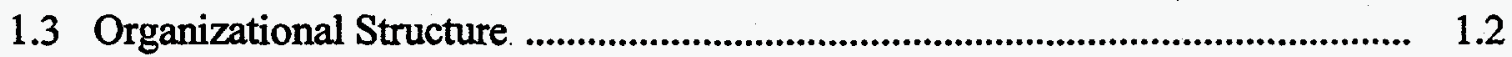

1.4 General Assumptions and Goals ................................................................ 1.2

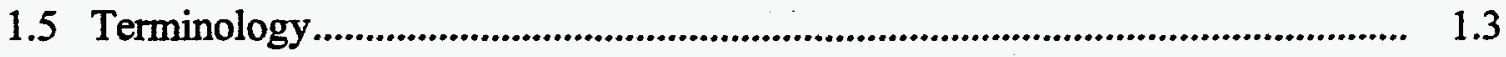

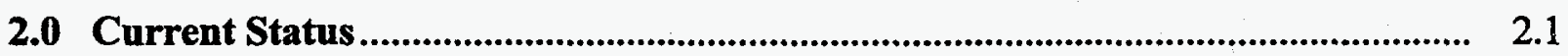

2.1 Current Status in the Nuclear Power Sector in Russia........................................... 2.1

2.2 Current Status of Decommissioning in Russia ................................................ 2.2

2.3 Current Status of the Legislative and Regulatory Environment in Russia .......... 2.5

2.4 Current Technological Status........................................................................ 2.6

2.5 Current Conditions at Leningrad NPP ............................................................ 2.7

3.0 Description of the Leningrad NPP and Features of Its Site.................................... 3.1

3.1 Overview of the Construction and Development of the Leningrad NPP ............ 3.1

3.2 Main Characteristics of the Leningrad NPP Site ............................................... 3.1

4.0 Description of the Construction and Design Features of Leningrad Unit \#1 ........ 4.1

4.1 Design and Main Characteristics of the RBMK Reactor ....................................... 4.1

4.2 Leningrad NPP Unit \#1 Design Features............................................................... 4.9

4.3 RBMK-1000 Reactors' Major Parameters......................................................... 4.13

4.4 Specific Features of a Unit with an RBMK-1000 Reactor Influencing Its Decommissioning

4.5 Operational Features of LNPP Unit \#1 to be Considered at Decommissioning. 
5.0 Actions Necessary to Organize and Carry Out NPP Unit Decommissioning....... 5.1

5.1 The Procedure for Licensing an NPP Unit Decommissioning ........................... 5.1

5.2 Features of the Procedure for Licensing NPP Unit Decommissioning................ 5.2

5.3 Documents Required for Application for an NPP Unit Decommissioning License

5.4 Recommendations for LNPP Administration Actions During Unit \#1 Decommissioning

6.0 Estimation of Radioactivity Accumulated at the LNPP Unit \#1 and NPP Site..... 6.1

6.1 Classification of Radioactivity Sources at Leningrad Unit \#1 .............................. 6.1

6.2 Estimation of the Radioactivity of Reactor Structures ....................................... 6.1

6.3 Radioactivity of the Multiple Forced Circulation Circuit..................................... 6.11

6.4 Radioactivity of LNPP Unit \#1 as a Function of Long-Term Storage ............... 6.13

6.5 Estimation of Radioactivity at Leningrad NPP ................................................. 6.15

7.0 Spent Nuclear Fuel Handling ...................................................................................... 7.1

7.1 Spent Nuclear Fuel Handling Facilities ............................................................ 7.1

7.2 Development of Dry Storage Casks for Spent Nuclear Fuel ............................... 7.2

7.3 Spent Nuclear Fuel Handling During Decommissioning of LNPP Unit \#1 ........ 7.3

8.0 Decontamination Activities During Decommissioning of Leningrad Unit \#1 ....... 8.1

8.1 RBMK-1000 Decontamination Experience ...................................................... 8.1

8.2 Problems Decontaminating RBMK-1000 Units ................................................. 8.5

8.3 Recommendations on Decontaminating Equipment, Systems, and Process Circuits

9.0 Radwaste Handling at LNPP .................................................................................. 9.1

9.1 Concept of Radwaste Handling at Russian NPPs ................................................ 9.1

9.2 Operational Radwaste at the LNPP........................................................... 9.2

9.3 Radwaste Handling Program ............................................................................ 9.7

9.4 Radwaste Handling Strategy During the Decommissioning of LNPP Unit \#1 ... 9.10

10.0 Safety Assurance During Decommissioning Leningrad Unit \#1 ........................... 10.1

10.1 Safety Assurance for Spent Nuclear Fuel ........................................................ 10.1

10.2 Radiological Safety Assurance …................................................................. 10.2

10.3 Environmental Safety Assurance ..................................................................... 10.8 
11.0 Decommissioning Alternative Proposed for Leningrad Unit \#1

11.1 Possible Decommissioning Alternatives.

11.2 Substantiation of the Proposed Decommissioning Alternative and Final Condition

11.3 Main Stages and Activities Performed During Leningrad Unit \#1 Decommissioning

11.4 Certain Problems to be Solved During Implementation of the Unit \#1 Decommissioning Alternative

12.0 Summary

13.0 General Conclusions and Recommendations

13.1 Results of the Study

13.2 Proposed Projects 


\section{Figures}

3.1 General Layout of the Leningrad NPP 3.2

3.2 Layout of Units \#1 and \#2 of the Leningrad NPP 3.3

3.3 Geographic Location of the Leningrad NPP 3.4

3.4 Site of the Leningrad NPP. 3.5

4.1 Locations of the Core, Equipment, and Structures of the RBMK-1000 Reactor. 4.2

4.2 Graphite Stack Blocks of the RBMK-1000. 4.3

4.3 Metal Structures of the RBMK-1000 4.4

4.4 Basic Diagram of the Forced Circulation Circuit Loop .

4.5 Layout of Components in One Forced Circulation Loop at the Section from Drum-Separator to Distribution Group Header

4.6 Drum-Separator 4.9

9.1 Main Stages in NPP Radwaste Handling . 9.2

10.1 Diagram of Ecological Monitoring in NPP Region 10.13

10.2 Diagram of Preparation for Decommissioning of Nuclear Power Plant Unit 10.14

\section{Tables}

2.1 List of Nuclear Power Plant Units in the Russian Federation 2.2

4.1 Major Technical Parameters for the Main Building of a Unit. 4.13

4.2 Equipment and Equipment Weights for an RBMK-1000 Unit. 4.14

4.3 Weights and Sizes of Major Systems in the Reactor Section of Unit \#1 4.15

5.1 List of Required Planning Activities in the Preliminary Stage 5.8

5.2 List of Activities During the Preparation Stage for Unit Decommissioning. 5.10

6.1 Sources of Radioactivity in RBMK-1000 Reactor Structure Elements 6.2

6.2 Composition of Steel 10XN1M 6.2

6.3a Radioactivity of the Reactor Shell as a Function of Long-Term Storage 6.4

6.3b Radioactivity of the Inner Wall of Water Biological Shield Tank as a Function of Long-Term Storage

6.4a Radioactivity of Steel Top Protection Blocks as a Function of Long-Term Storage

6.4b Radioactivity of the Bottom Plate of the Top Load-Bearing Structure as a Function of Long-Term Storage. 
6.5a Radioactivity of Bottom Plate Steel Support Blocks as a Function of Long-Term Storage

6.5b Radioactivity of the Top Plate of the Bottom Load-Bearing Structure as a Function of Long-Term Storage.

6.6 Chemical Composition of Zirconium Alloy 125 ............................................ 6.6

6.7 Radioactivity of Fuel Channel Material .......................................................... 6.7

6.8 Weight Distribution of Graphite in an RBMK-1000 Reactor ................................ 6.9

6.9 Estimate of the Specific Radioactivity of a Graphite Stack as a Function of Long-Term Storage

6.10 Estimate of the Specific Radioactivity of Graphite Sleeves as a Function of Long-Term Storage

6.11 Estimated Total Radioactivity of Structural Elements of an RBMK-1000 Reactor and MFC Circuit as a Function of Long-Term Storage, Ci

6.12 Estimated Radioactivity of Corrosion Products on MFC Circuit Equipment Surfaces (outside the core) as a Function of Long-Term Storage, $\mathrm{Bq}$.

6.13 Specific Radioactivity of Cobalt-60 in Structural Elements of an RBMK-1000 Reactor and the Dose Rate near the Structural Elements

8.1. Parameters for and Efficiency of Chemical Decontamination of the MFC Circuits at LNPP.

8.2 Effectiveness of Reagent-Free Decontamination on the Leningrad MFC Circuits

8.3 Chemical Composition of Corrosion Deposits in the MFC Circuit for Units with RBMK-1000 Reactors

8.4 Comparison of Efficiency Parameters for Reagent-Free and Chemical

Decontamination of the MFC Circuit in Units with RBMK-1000 Reactors

9.1 Radwaste Handling Technology Needs

9.2 Liquid Radwaste Volumes at Russian NPPs with Water-Cooled Graphite-Moderated Reactors

9.3 Liquid Radwaste Volumes at Russian NPPs with Water-Cooled Graphite-Moderated Reactors

9.4 Classification of Liquid Radwaste

9.5 Classification of Solid Radwaste.

9.6 Characteristics of Operational Radwaste Deliveries from One NPP Unit with an RBMK-1000 Reactor.

9.7 Liquid Radwaste Deliveries from LNPP Units 9.6 
9.8 Solid Radwaste Deliveries from LNPP to Lenspetskombinat................................. 9.7

9.9 Estimated Volume of Operational Radwaste Created over 30 Years for an NPP Unit with an RBMK-1000 ....................................................................... 9.10

9.10 Estimate of Solid Radwaste Created During the Dismantling of an NPP Unit with an RBMK-1000.

9.11 Construction Quantities for an NPP Unit with an RBMK-1000 ............................... 9.12

10.1 Radiological Situation in MFC Circuit Areas During Major Overhaul of LNPP Unit \#1

11.1 List of Work Required to Prepare Unit \#1 for Safe Storage

11.2 List of Work Required During Long-Term Storage of Leningrad Unit \#1 11.11

11.3 List of Required Work During Dismantling of Unit \#1 Reactor Structures. 


\subsection{Introduction}

\subsection{Background}

In 1993, at meetings of the Russian-American Joint Committee on Economic and Technological Cooperation, Russian Prime Minister Chernomyrdin and U.S. Vice President Gore agreed to combine efforts to study alternatives to the development of Russian electric power in accordance with joint actions under the electric power development plan. The result of this agreement was the Russian-American joint electric power alternatives study (JEPAS) conducted in 1993-1995, under which the joint parallel nuclear power alternatives study (JPNAS) was performed simultaneously.

The JPNAS provided the required data on nuclear power engineering for modeling comprehensive plans for resource use and for defining investment programs for developing electric power in Russia. Cost estimates were developed for the following nuclear power plant scenarios: continued operation with safety upgrades, complete construction of NPPs that had been begun but not finished, restructure NPPs into cogeneration plants, build new-generation NPPs, and decommission first-generation NPPs with RBMK-1000 and VVER-440 reactors.

One of the conclusions of the JPNAS was that the process of decommissioning NPPs in Russia is still in the initial stage. Russia is not ready to decommission NPPs because it lacks comprehensive laws and regulations and has problems disposing of spent nuclear fuel and radwastes. Thus it may be difficult to plan and implement the optimal policy for decommissioning NPPs. As a followup to the JPNAS, Russian and American participants proposed a joint development of the decommissioning program for one Russian first-generation unit designated among the first to be decommissioned.

\subsection{Efforts of the U.S. Department of Energy, RF Minatom, and Leningrad NPP to Organize the Joint Study}

To develop a decommissioning strategy for Russian units with first-generation RBMK-1000 reactors, the U.S. Department of Energy (DOE) selected a team from the Pacific Northwest National Laboratory (PNNL) and Brookhaven National Laboratory (BNL) to coordinate with the Russians to organize this study, select a specific Russian first-generation unit, and conduct the research. The Russian Ministry of Atomic Power (Minatom) selected the Kurchatov Institute to support this study in Russia.

Minatom supported this study and selected the Leningrad NPP (LNPP) Unit \#1, as the subject. LNPP Unit \#1 was the first of 11 RBMK-1000s built in Russia. The LNPP Administration and U.S. DOE consented to the Russian Minatom proposal and cooperated in the organization and conduct of this joint study for LNPP Unit \#1. 


\subsection{Organizational Structure}

Among the Russian participants were experts from organizations under the Russian Minatom, namely LNPP; Research and Development Institute of Power Engineering (NIKIET, Moscow), the designer of the RBMK reactor; the All-Russian Design and Research Institute of Power Technology (VNIPIET, St. Petersburg), the designer of LNPP; the Research and Design Institute of Installation Technology (NIKIMT, Moscow); AtomEnergoProyekt (AEP, Moscow), the designer of nuclear power plants with VVER and RBMK reactors; Rosenergoatom Concern; the All-Russian Research Institute for Nuclear Power Plant Operation (VNIIAES, Moscow); RF Gosatomnadzor (GAN RF, Moscow); the Scientific-Technical Center for Nuclear and Radiation Safety (NTC YaRB, Moscow); and a branch of the All-Russian Research Institute of Nuclear Power Engineering (VNIIAM, Volgodonsk).

Experts from the Kurchatov Institute coordinated the study for the Russian side. The U.S. DOE delegated coordination of the study for the American side to PNNL. BNL was responsible for a major portion of the technical work.

\subsection{General Assumptions and Goals}

The major goal of the study is the joint development of recommendations on a strategy for decommissioning a first-generation unit. The LNPP Unit \#1 with RBMK-1000 reactors was chosen as the representative unit for this joint study.

The analysis for a safe, technically feasible, cost-effective decommissioning strategy for LNPP Unit \#1 was based on the results of a preliminary analysis of fundamental regulatory and technical requirements for decommissioning. This study took into account the conditions under which Russian nuclear power engineering functions; specific features of the site, structure, and operations of LNPP Unit \#1; and current requirements and technical approaches to decommissioning a nuclear power plant.

The study therefore included a survey and analysis of the current status of Russian and foreign laws and regulations on decommissioning and an analysis of safety of personnel, the population, and the natural environment.

The study also included a survey and analysis of practical decommissioning experience and the current situation concerning nuclear reactor decommissioning in Russia and the United States. This will make it possible to identify with greater certainty technologies required for decontamination and dismantling reactor structures and handling spent nuclear fuel and radwastes that are being successfully used in the West, and to determine the possibility of transferring these technologies to the Russian Federation. 


\subsection{Terminology}

Throughout this report, the term "track" refers to horizontal channels, and "channels" refers to vertical channels. The "reactor bottom room" is an equipment room below a reactor. 


\subsection{Current Status}

\subsection{Current Status of the Nuclear Power Sector in Russia}

On January 1, 1997, there were 29 nuclear power units with a total installed capacity of 21,242 MWe operating at nine NPPs in Russia. As Table 2.1 shows, units are operating with the following types of nuclear reactors:

- an installed 440 MWe capacity with VVER-440 water-water reactors (modifications V-179, $\mathrm{V}-230$, and V-213)

- an installed 1,000 MWe capacity with VVER-100 water-water reactors (modifications $\mathrm{V}-187, \mathrm{~V}-338$, and V-320)

- an installed 1,000 MWe capacity with RBMK-1000 graphite-uranium pressure tube reactors.

There are also four low-power $12.0 \mathrm{MWe}$ units with EPG-6 graphite-water pressure tube reactors operating at the Bilibino NPP and a unit with a BN-600 fast reactor with sodium coolant at the Beloyarsk NPP.

In 1996, Russian NPPs generated 108.8 billion $\mathrm{kWh}$ of electricity, which accounted for $13.1 \%$ of the electricity generated in Russia. In 1996, NPPs generated $10.9 \%$ more of the total electricity output than in the previous year. By region, NPPs accounted for the following percentage of electric power generation in 1996: Urals, 2.1\%; Central Volga, 21.6\%; Center, 25.6\%; Northwest, $39.9 \%$. The capacity factor, which describes the efficiency with which generated capacities are used, was as follows: the average for all NPPs, $58.3 \%$, for VVER reactors, $54.6 \%$, and for RBMK reactors, $60.7 \%$.

In 1996, the Russian side reported that the total number of violations in NPP unit operation and their seriousness according to the seven-point International Event Scale (INES) declined. The number of reactor shutdowns due to scrams dropped. In 1996, Russian NPPs logged 83 violations subject to investigation and reporting in compliance with the National Incident Reporting System. The violations included unplanned shutdowns, unit disconnections from the grid, equipment and system malfunctions, contamination of equipment and rooms, etc. Only two of the violations were significant in terms of safety and were ranked as level 1 on the INES scale. There were no violations higher than level 1 .

First-generation units (Units \#3 and 4 at Novovoronezh, Units \#1 and 2 at Kola, Units \#1 and \#2 at Leningrad, Units \#1 and \#2 at Kursk, Units \#1-4 at Bilibino) have been operated under a special regime since 1990. This includes annual safety analysis and receipt of Gosatomnadzor permits to continue operation. Despite current financial difficulties, in 1996 work was done to rebuild LNPP Units \#1, 2, and 3, and Kursk Unit \#1 was shut down for reconstruction. Design and construction work increased for the VVER-640 unit in Sosnovy Bor and replacement capacities at Kola Unit \#2 and Novovoronezh Unit \#2. Construction of units at Kaliningrad and Kursk NPPs continued. This work is basically financed by the two Russian independent operating organizations (Table 2.1): 1) Rosenergoatom, which includes Balakovo, Beloyarsk, Bilibino, Kalinin, Kola, Kursk, Novovoronezh, and Smolensk NPPs; and 2) LNPP, which has four units with RBMK-1000 reactors. 
Table 2.1. List of Nuclear Power Plant Units in the Russian Federation

\begin{tabular}{|c|c|c|c|c|c|c|c|c|}
\hline No. & $\begin{array}{l}\text { NPP and Unit } \\
\text { Denomination }\end{array}$ & Reactor Type & $\begin{array}{l}\text { Project } \\
\text { Code }\end{array}$ & $\begin{array}{c}\text { Capacity } \\
\text { (gross), } \\
\text { MWe }\end{array}$ & $\begin{array}{c}\text { Safety } \\
\text { Generation }\end{array}$ & Utility & $\begin{array}{l}\text { Year of } \\
\text { Start-Up }\end{array}$ & $\begin{array}{c}\text { Planned } \\
\text { Shutdown Date }\end{array}$ \\
\hline \multirow[t]{4}{*}{1} & Balakovo-1 & VVER-1000 & $V \cdot 320$ & 1000 & 2 & Rosenergoatom & 1985 & 2015 \\
\hline & Balakovo-2 & VVER-1000 & $V-320$ & 1000 & 2 & Rosenergoatom & 1987 & 2017 \\
\hline & Balakovo-3 & VVER-1000 & $V-320$ & 1000 & 2 & Rosenergoatom & 1988 & 2018 \\
\hline & Balakovo-4 & VVER-1000 & $V-320$ & 1000 & 2 & Rosenergoatom & 1993 & 2023 \\
\hline \multirow[t]{3}{*}{2} & Beloyarskaya-1 & AMB-100 & - & 100 & 1 & Rosenergoatom & 1963 & shutdown 1980 \\
\hline & Beloyarskaya-2 & AMB-160 & - & 160 & 1 & Rosenergoatom & 1967 & shutdown 1989 \\
\hline & Beloyarskaya-3 & BN-600 & - & 600 & 1 & Rosenergoatom & 1980 & 2010 \\
\hline \multirow[t]{4}{*}{3} & Bilibino-1 & EGP-6 & $=$ & 12 & 1 & Rosenergoatom & 1974 & 2004 \\
\hline & Bilibino-2 & EGP-6 & - & 12 & 1 & Rosenergoatom & 1974 & 2004 \\
\hline & Bilibino-3 & EGP-6 & - & 12 & 1 & Rosenergoatom & 1975 & 2005 \\
\hline & Bilibino-4 & EGP-6 & - & 12 & 1 & Rosenergoatom & 1976 & 2006 \\
\hline \multirow[t]{2}{*}{4} & Kalinin-1 & VVER-1000 & V-338 & 1000 & 2 & Rosenergoatom & 1984 & 2014 \\
\hline & Kalinin-2 & VVER-1000 & V-338 & 1000 & 2 & Rosenergoatom & 1986 & 2016 \\
\hline \multirow[t]{4}{*}{5} & Kola-1 & VVER-440 & $\mathrm{V}-230$ & 440 & 1 & Rosenergoatom & 1973 & 2003 \\
\hline & Kola-2 & VVER-440 & $V-230$ & 440 & 1 & Rosenergoatom & 1974 & 2004 \\
\hline & Kola-3 & VVER-440 & V-213 & 440 & 2 & Rosenergoatom & 1981 & 2011 \\
\hline & Kola-4 & VVER-440 & $V-213$ & 440 & 2 & Rosenergoatom & 1984 & 2014 \\
\hline \multirow[t]{4}{*}{6} & Kursk-1 & RBMK-1000 & $\overline{-}$ & 1000 & 1 & Rosenergoatom & 1976 & 2006 \\
\hline & Kursk-2 & RBMK-1000 & - & 1000 & 1 & Rosenergoatom & 1978 & 2008 \\
\hline & Kursk-3 & RBMK-1000 & - & 1000 & 2 & Rosenergoatom & 1983 & 2013 \\
\hline & Kursk-4 & RBMK-1000 & - & 1000 & 2 & Rosenergoatom & 1985 & 2015 \\
\hline \multirow[t]{4}{*}{7} & Leningrad-1 & RBMK-1000 & $\overline{-}$ & 1000 & 1 & LNPP & 1973 & 2003 \\
\hline & Leningrad-2 & RBMK-1000 & - & 1000 & 1 & LNPP & 1975 & 2005 \\
\hline & Leningrad-3 & RBMK-1000 & - & 1000 & 2 & LNPP & 1979 & 2009 \\
\hline & Leningrad-4 & RBMK-1000 & - & 1000 & 2 & LNPP & 1981 & 2011 \\
\hline \multirow[t]{5}{*}{8} & Novovoronezh-1 & VVER-213 & $=$ & 210 & 1 & Rosenergoatom & 1964 & shutdown 1984 \\
\hline & Novovoronezh-2 & VVER-365 & - & 365 & 1 & Rosenergoatom & 1970 & shutdown 1990 \\
\hline & Novovoronezh-3 & VVER-440 & $V-179$ & 417 & 1 & Rosenergoatom & 1971 & 2001 \\
\hline & Novovoronezh-4 & VVER-440 & V-179 & 417 & 1 & Rosenergoatom & 1972 & 2002 \\
\hline & Novovoronezh-5 & VVER-1000 & $V-187$ & 1000 & 2 & Rosenergoatom & 1980 & 2010 \\
\hline \multirow[t]{3}{*}{9} & Smolensk-1 & RBMK-1000 & - & 1000 & 2 & Rosenergoatom & 1982 & 2012 \\
\hline & Smolensk-2 & RBMK-1000 & - & 1000 & 2 & Rosenergoatom & 1985 & 2015 \\
\hline & Smolensk-3 & RBMK-1000 & - & 1000 & 2 & Rosenergoatom & 1990 & 2020 \\
\hline
\end{tabular}




\subsection{Current Status of Decommissioning in Russia}

As Table 2.1 shows, NPP units commissioned in the ' 60 s and early ' 70 s have reached or are approaching the end of their design operating life. Since 1981, the two Phase I units at Beloyarsk, which have AMB-100 and AMB-200 graphite-water pressure tube reactors similar to the RBMK-1000 and two VVER-210 and VVER-365 pressure vessel reactors, have been shut down.

By 2006, the design operating life of 10 NPP units will end, and the design service life of several more units will end by 2020. During this period Russia must solve the problem of decommissioning 24 nuclear power plant units with a total electrical output of $12,565 \mathrm{MWe}$, including some units at Kursk, Leningrad, and Smolensk with RBMK-1000 reactors and the units with EPG-6 graphite water reactors at Bilibino.

In 1991, the Ministry for Atomic Power Engineering and the Atomic Power Industry of the former USSR prepared and approved a "Concept for Decommissioning NPP Units" to organize and plan decommissioning. This concept sets forth the following basic assumptions that define the strategy and general approaches to solving problems related to decommissioning NPP units:

1. Units or NPPs should be decommissioned after their design service life has ended or if it is technically infeasible to ensure further safe operations.

2. Unit decommissioning should be planned on the basis of renovation (complete restoration) or replacement of the capacities being retired with new upgraded or safer units.

3. Existing NPP sites should be used for building new units to replace those being decommissioned.

4. A goal should be to maximize the use of buildings, civil structures, and equipment of the unit or NPP being decommissioned to study safety improvement and to demonstrate new design approaches for operational or planned NPPs.

5. The possibility of restructuring (converting) NPP units to be decommissioned should be evaluated.

Current regulations in Russia define NPP unit decommissioning as carrying out a set of organizational and technical procedures after nuclear fuel has been removed from the unit to prevent the use of the reactor and to ensure the safety of personnel, the population, and the environment. Russian and foreign experience indicates that shutting down a unit does not necessarily make it safe. Yet, Russian organizations operating NPPs are not ready to carry out the full scope of work to decommission their units or to process, transport, and bury the large amounts of radwastes associated with decommissioning.

Analyzing the decommissioning of shutdown NPP units in Russia and assessing the current condition of these units in its 1995 annual report, RF Gosatomnadzor (GAN) cited the following factors as delaying organization and completion of full-scale decommissioning work:

- inadequate legislation to ensure public safety when radioactive materials and radioactive substances are handled 
- no regulatory requirements for several specific aspects of safety assurance during decommissioning

- uncertainty in organizing the processing and subsequent safe long-term storage of spent nuclear fuel from RBMK-1000 reactors

- no available technologies and equipment to ensure safe dismantling

- no appropriate repositories for burying large amounts of radwastes formed during decommissioning

- plans to carry out and finance work preparatory to decommissioning are rarely carried out.

On the basis of its inspections, GAN has established compulsory compliance with the required system for servicing shutdown units. Since the spent nuclear fuel has not been removed from Phase I units at Beloyarsk, only work related to operational servicing of these units was permitted. Dismantling of reactor equipment and structures of Phase I units at Novovoronezh is prohibited.

In view of the actual condition of operating NPPs, Russia's current lack of regional storage facilities or repositories for radwastes, and foreign and domestic experience decommissioning research and commercial reactors, GAN recommends the following basic phases in the unit decommissioning process:

1. Shut down the unit.

2. Discharge nuclear fuel from the reactor and remove it from the unit.

3. Put the shut-down unit in a state of temporary hold (conservation).

4. Dismantle nonradioactive and partially dismantle low-level radioactive systems and equipment.

5. Put the unit in a state of safe long-term storage.

6. Completely dismantle and bury the reactor of the units being decommissioned.

7. Restore the unit site to the required state.

At present, the technical approaches to decommissioning NPP units in Russia are oriented toward long-term safe storage under surveillance or conservation. The reactor structure of shutdown NPP units is not being dismantled, but work is being done to prepare them for decommissioning. Specifically, comprehensive inspections of shutdown units with VVER reactors at Novovoronezh and those with AMB graphite-water reactors at Beloyarsk have been completed, and the induced radioactivity of structural materials has been analyzed.

Moreover, Russia has gained experience repairing and rebuilding plutonium-production graphiteuranium reactors, including those with graphite stacks. Most of the work to rebuild LNPP Units \#1 and \#2 with RBMK-1000 reactors has been completed, including large-scale replacement of fuel channels in the reactor, installation of emergency steam dump systems, and cutting in twoway valves on group distribution headers. This experience, along with that gained at Phase I units at Beloyarsk, may be analyzed and used in decommissioning RBMK-1000 units. 


\subsection{Current Status of the Legislative and Regulatory Environment in Russia}

Current Russian codes regulating nuclear power engineering activity to a large extent still reflect the legal and regulatory documents developed within the nuclear power complex of the former USSR, in which there was no law on the use of nuclear energy.

The federal law "On Use of Nuclear Energy," enacted in Russia on October 20, 1995, laid the foundation for creating a system for legal and regulatory governance of nuclear power engineering activities, including decommissioning of NPP units, and gave precedence to the laws of the Russian Federation and federal codes. The federal law "On Use of Nuclear Energy" states that all non-defense nuclear facilities, including NPPs, are federal property. Therefore, the government of the Russian Federation makes the decision to decommission them. This same law establishes that the operating organizations are totally responsible for the safety at nuclear facilities, including decommissioning and handling of nuclear materials and radwastes. One criterion for decommissioning safety is compliance with radiological limits (permissible irradiation dose limits) established by the Russian Federation (RF) law, "On Public Radiation Safety," enacted in December 1995.

Operating organizations must have the appropriate powers and material and other resources, including financial, to perform their functions. For this purpose, operating organizations and the appropriate agencies controlling the use of nuclear energy are obliged to create a special fund to finance the decommissioning of NPP units.

To decommission NPP units, an operating organization must obtain a license from GAN, and the decommissioning plan must undergo environmental (state and public) review. If conditions for ensuring safety during decommissioning of an NPP unit do not meet the regulatory limits and do not ensure environmental safety, the decommissioning will not be permitted, and the license for this kind of activity will not be issued.

Russian codes governing NPP unit decommissioning are based primarily on regulations used in the former USSR. Therefore they must be brought into full compliance with the laws of the Russian Federation. Russia has no experience in decommissioning NPP units. Therefore, the current regulations governing decommissioning are primarily based on experience repairing and dismantling operating NPP units and plutonium production, research, and transportation of nuclear reactors and on the results of research on shutdown nuclear facilities.

Regulations governing NPP unit decommissioning in Russia have the following features:

- Regulations state that until nuclear fuel is removed an NPP unit must meet operating requirements.

- Plans for decommissioning an NPP unit must include a report demonstrating the safety of the work and estimating its effect on the natural environment. However, regulations do not address other aspects of decommissioning, including safety assurance problems.

- There is no requirement to justify the time required to complete decommissioning if it is to be done after long-term storage and surveillance. The possibility of decommissioning NPP units with immediate dismantling is not considered in the regulations. 
- Like Western regulations, Russian regulations define requirements and deadlines (5 years before the end of the design service life) for developing, substantiating, and submitting the NPP unit decommissioning plan to GAN for review and performing a comprehensive (radiation and engineering) inspection of the NPP unit. However, requirements for their content are not defined in sufficient detail.

- Furthermore, current regulations do not reflect the difference in the designs of different types of Russian reactors. They ignore the fact that nuclear power plants have multiple units and are built in phases consisting of two units, and therefore some systems, rooms, and structures are shared. Consequently, when one unit is decommissioned, the operation of other units on the NPP site must be taken into account.

- So far, Russia has not analyzed the concept, criteria, or requirements for handling and (limited and unlimited) reuse of low-level radioactive materials in the national economy. Significant amounts of these materials will be formed when NPP units are decommissioned.

- The lack of appropriate storage facilities or repositories for NPP radwastes necessitates planning for their long-term storage at the plants. However, requirements for organizing storage sites and the procedure for long-term storage of radwastes at NPPs have not been defined. Also, a concept for handling irradiated graphite has not been formulated.

- The inability to solve the problem of processing spent nuclear fuel accumulated in large quantities at units and storage facilities at NPPs with RBMK-1000 reactors requires further analysis of regulations in relation to long-term storage of spent nuclear fuel at plants when they are decommissioned.

- GAN is developing a unified set of regulations for various activities, including those related to decommissioning NPP units with various types of nuclear reactors. It is assumed that foreign experience will be considered in formulating these regulations.

\subsection{Current Technological Status}

Russia has borrowed from foreign experience in its efforts to begin decommissioning NPP units with RBMK reactors to a limited extent since no pressure tube reactors like the RBMK are operated abroad —except for those built in the former USSR at Chornobyl (Ukraine) and Ignalinsk (Lithuania).

Russia does have experience in repairing, rebuilding, and replacing equipment and systems in high-level radiation fields at operating nuclear facilities and in partially dismantling equipment and systems at shutdown nuclear facilities. This experience has demonstrated the complexity of undertaking and completing full-scale dismantling because of both the radiation hazards and the technical and structural approaches used in building first-generation reactor facilities without regard for problems that might be encountered when these facilities are decommissioned.

Russian repair and reconstruction experience and its experience in dismantling equipment and systems are based on the use of existing technologies. Special repair services are now operating at each NPP in Russia. These services have a specific set of tools and devices to carry out a rather wide variety of work necessary at the final stage of the life cycle of NPP units. Obviously, 
depending on the time required to decommission units at a specific NPP, finances, and other factors, each power plant will try first to use technologies at its disposal to achieve the ultimate goal (the final condition of a unit and/or its site) of decommissioning.

Recently, new methods for fragmenting metal and concrete structures, including thermite, hot gas jet, explosive, plasma, resistance-arc and abrasive steam cutting, thermal shock, and others, have been developed, tested, and proven. Advanced fragmentation methods such as laser are now being tested. Final choices for specific tools will be made in individual decommissioning projects, because each project may have unique requirements.

So far Russia has made little use of robotics and other remote technologies in repair and dismantling work at plutonium-production graphite-uranium reactors and at NPPs with RBMK-1000 reactors. This has affected the total collective irradiation dose of personnel doing the work. The collective dose for rebuilding a graphite-uranium plutonium-production reactor has reached about 1000 man-rems (10 man-Sv).

Analysis of radiation conditions at NPP units with RBMK-1000 reactors shows that the most complicated and time-consuming work in dismantling equipment and structures is cutting and removing the radioactive reactor metal structures (items 6, 7,8 and 9 in Figure 4.3) and dismantling and removing the graphite stack. Analysis of the drop in the radioactivity of these metal structures over time shows that, in the next 30 to 70 years, dismantling these reactor structures will require specialized equipment, including remote-controlled systems. Dismantling and removing graphite stack blocks from RBMK- 1000 reactors may also require remote-controlled devices or other simpler, but equally effective, technologies. Russia does have certain expertise in these technologies.

Analysis of the development of remote-controlled systems in Russian shows that, in addition to their main purpose (dismantling highly radioactive equipment), they can be used for other technological operations. Therefore, refining the design of remote-controlled systems and other dismantling technologies is a significant problem. Solving it requires research, planning, and design work and attention to training personnel with the required skills.

It seems reasonable that existing Russian methods, technologies, and design studies for dismantling work would be used to solve problems related to decommissioning reactor units and other nuclear facilities. Organizing and participating in such international projects will enable both Russia and other countries developing nuclear technologies to maintain their practical experience and scientific and technical potential and to lay the necessary scientific, technical, and regulatory groundwork for ensuring the safe and environmentally and economically acceptable decommissioning of NPP units, including those with RBMK reactors.

\subsection{Current Conditions at Leningrad NPP}

Leningrad Nuclear Power Plant is representative of NPPs built with RBMK reactors. The design and construction of LNPP complied with the regulatory codes of the ' 60 s and '70s. The NPP was therefore designed without regard for safety requirements imposed on NPPs by current regulations. 
It seems natural that, because of the long operation of NPP units and the increase in the strictness of regulations for safety over time, operations eventually will not meet new safety requirements, although the equipment is not anywhere near the end of its service life. For this reason, the main systems of NPPs must either be upgraded or rebuilt to meet newer safety requirements, or equipment and piping inspection must be increased to compensate for the lack of other equipment.

As the first commercial RBMK-1000, LNPP was the first to be faced with the need to modernize technological systems and equipment and the first to near the end of its life. Therefore, throughout the entire operating life of LNPP, its equipment and technological systems and control and protection systems have been upgraded according to changes in requirements for reliability and safety. In terms of its technical and economic indicators, LNPP occupies a noteworthy place among both Russian and foreign NPPs.

Analysis reveals three phases of the operation of LNPP:

- 1973 to 1981 - commissioning and attainment of design unit capacity. (This stage is characterized by slightly lower capacity factors and a relatively large number of unit shutdowns.)

- 1982 to 1988 - stable operation of units, introduction of more advanced procedures for operation, and elimination of design omissions and deficiencies in equipment performance. (This stage is characterized by high technical and economic indicators and a small number of unscheduled unit shutdowns; the plant's capacity factor was above $80 \%$ and exceeded $90 \%$ for individual units.)

- 1989 to the present - a period of large scale reconstruction of first-generation units, i.e., the plant's first and second units. (This work required long down times for units being rebuilt. Therefore, there were decreases in the total amount of power generated and in the plant's capacity factor.)

On November 20, 1992, LNPP was granted the status of an operating organization. Although LNPP personnel were fully responsible for safe operation as of that date, the plant gained the ability to solve its organizational, technical, and economic problems independently.

\subsubsection{Reconstruction and Safety Upgrading at LNPP Units}

In 1989 LNPP began preparations for the phased modernization of its units. To maximize compliance with current nuclear power safety requirements, a unit reconstruction plan was developed and started in 1990.

A large amount of the planned reconstruction work has been completed at both Units \#1 and \#2, since these units are both first-generation units with RBMK reactors.

Several systems and structures at Units \#3 and \#4, which are in greater compliance with modern regulations, are also slated to be replaced and upgraded. LNPP is supposed to carry out a series of procedures to be completed according to the reconstruction plan.

As an operating organization, LNPP submits an annual report to GAN evaluating the current status of operational safety for each NPP unit. According to the most recent findings, the status of operational safety at all LNPP units is satisfactory. 


\subsubsection{Leningrad NPP's Role in Supplying Power to the Northwest Economic Region of Russian and Leningrad Oblast}

LNPP is part of the power system of the Lenenergo Joint Stock Company, which supplies central power and heat to users in St. Petersburg and Leningrad Oblast. Lenenergo's territory, which is part of the unified power system of Northwest Russia, covers 85,900 square kilometers and serves a population of about 6.7 million.

Annual electricity output by the region's power stations is $50-52$ billion $\mathrm{kWh}$, which is about 10 billion $\mathrm{kWh}$ more electricity than the Leningrad region needs. The average annual growth rate of power consumption in the Leningrad region unit by 2010 is estimated to be $1.8,2.9$ and $3.3 \%$ for three five-year periods, respectively. Power surpluses are transferred to the Northwest and Central Power Systems. The Leningrad Power System now exports about 4.8 billion $\mathrm{kWh}$ of electricity to Finland.

Over its life, until the end of 1996, LNPP has supplied the Russian power system with about 474 billion $\mathrm{kWh}$ of electricity. It supplies electricity to the power system at voltages of 110,330 , and $750 \mathrm{kV}$. The design electricity output at LNPP is 28 billion $\mathrm{kWh} / \mathrm{year}$. NPP uses $8-8.5 \%$ of the power it generates for its own needs. From 1982 to 1988 inclusive, electricity output at LNPP exceeded its design output. In 1985-1986 it reached 29.4 billion $\mathrm{kWh}$, and the capacity factor during this period was $84 \%$.

Despite the fact that LNPP's electricity output dropped in 1989 because of unit reconstruction, the power plant continues to play an important role in the electrical supply of both the Leningrad region and the entire Northwest. LNPP supplies about $50 \%$ of the Lenenergo System load and, together with the Kola NPP, provides more than $40 \%$ of the Northwest Unified System load. LNPP accounts for $26 \%$ of the installed power generating capacity of the Northwest Region. In addition, LNPP is the main source of heat for the Sosnovy Bor industrial zone and the city of Sosnovy Bor, which is $6 \mathrm{~km}$ from the plant.

\subsubsection{Factors Influencing the Decommissioning of LNPP Unit \#1}

Financing the decommissioning work. LNPP, which has the status of an independent operating organization, is a state enterprise, but it is completely self-financed and does not receive any financial support from the state, even for reconstruction to provide required safety. Because it does not receive budget allocations, LNPP finances capital construction, reconstruction, and reequipment basically from its own funds.

As of 1991, the NPPs annually send a specific amount of money to a special unified decommissioning fund to finance the decommissioning of NPP units at the end of their design lives. Money accumulates in this fund from surcharges on the main activity of the NPPs $(1.3 \%$ of the cost of the NPP's saleable products-electricity and heat).

According to a government resolution dated June 16,1997, a special decommissioning fund was set up to finance decommissioning for LNPP units with expired design service life. This fund will accumulate money from fees on the primary operation of NPPs (the value of the salable product of nuclear power plants-electricity and heat). However, the mechanism for forming, accumulating, and spending money in the specialized decommissioning fund does not take into 
account possible requirements for decommissioning NPP units or the financial, political, and economic aspects of the current situation in Russia.

One of the currently serious problems in Russian nuclear power is that consumers do not pay for the electricity generated by NPPs. This has a negative effect on the financial position of LNPP. Therefore, even material procurements to support operation are not fully satisfied.

The current problem of non-payment for electricity and the instability of the NPPs' financial status make it impossible to accumulate the needed money in the specialized fund. This threatens not only the financial backing for future decommissioning work but also the completion of research and experimental design work required to support decommissioning work. The problem of financing decommissioning work at LNPP Unit \#1 is rather pressing and requires special attention and a search for acceptable solutions.

Analysis of replacement may be worthwhile from the standpoint of the power supply requirements for the Leningrad region and of solving social problems that will inevitably arise when Unit \#1 is decommissioned. In view of the fact that the design life of Unit \#1 ends in 2003 and it usually takes 8-10 years to build replacement nuclear capacities, the LNPP administration is studying the feasibility of extending its operating life in order to accumulate the money required to build replacement capacities.

Operating experience and the completion of the necessary scope of reconstruction work ensure an acceptable level of safety in compliance with modern requirements. All work to rebuild Unit \#1 must be completed in 2001.

Features of Construction of LNPP Units. LNPP was designed and built in two phases of two units each. The time between the commissioning of the units in each phase averages two years. In building and configuring Phase I and Phase II units, LNPP used the principle of maximum sharing of equipment and auxiliary systems. Some of the systems and equipment have since been separated for safety reasons. LNPP units will probably be decommissioned in the same order as they were commissioned. Considering the relatively short interval between the decommissioning of units in one phase and the specific nature of the layouts used to build the units, decommissioning work should be planned for each phase to minimize total costs. This can be done by extending the service life of Unit \#1 of each Phase, as a minimum, up to the time of shutdown of the second unit of that Phase.

Removing spent nuclear fuel from a unit. The inability to solve the problem of processing and/or burying spent nuclear fuel from LNPP units makes it necessary to store it in cooling ponds and in permanent plant storage facilities whose design capacities are being fully used. Therefore, special attention must be given to solving the problem of timely removal of spent nuclear fuel from Unit \#1. when its decommissioning is planned and executed.

Storing and/or Burying Radwastes. Russia's lack of regional storage facilities or repositories for radwastes may require that these wastes be placed in long-term storage at the plant when Unit \#1 decommissioning is planned. 
Technological Support for Dismantling of the RBMK-1000 Reactors. The current lack of specialized equipment for dismantling highly radioactive reactor structures, including the graphite stack, and the uncertainty that it will be available in the foreseeable future, may influence the choice of a Unit \#1 decommissioning plan. 


\subsection{Description of the Leningrad NPP and Features of Its Site}

\subsection{Overview of the Construction and Development of the Leningrad NPP}

The trend toward pressure tube reactors originated in the former USSR at the end of the 1940s, when development of the first reactors of this design began. The nuclear reactor at the world's first NPP in Obninsk was developed and commissioned first. The next stage in the development of pressure tube reactors was the commissioning of the plutonium production channel-type reactor at the Siberian NPP (in Seversk) in 1958. Two AMB channel-type pressure tube reactors with electrical outputs of 100 and $200 \mathrm{MW}$ were then built and commissioned at the Beloyarsk NPP.

The LNPP became the prototype plant for the construction of a series of NPPs with RBMK reactors. About another 10 units with RBMK-1000s are operating at other NPPs, and two units with RBMK-1500 reactors with an electrical output of $1500 \mathrm{MW}$ each are operating at the Ignalinsk NPP (Lithuania).

Construction of the LNPP began in 1967. Its units were built in two phases: Units \#1 and \#2 (Phase I) and Units \# 3 and \#4 (Phase II). The startup of Unit \#1 of the LNPP, the first RBMK pressure tube reactor, took place in December 1973. Reactor management work continued for about a year, and on November 1, 1974, Unit \#1 reached its design electrical output of 1000 MW. In 1975 Unit \#2 was commissioned.

Construction of the Phase II units at the LNPP began after.Phase I construction was completed. Phase II was built and commissioned more quickly than Phase I because, by this time, the appropriate construction infrastructure had been developed in the area of the LNPP, plants had begun to manufacture the needed equipment, and Phase I had provided construction and installation experience. Unit \#3 at the LNPP was built and commissioned in the summer of 1979; Unit \#4 in the fall of 1981 . The four units, each with an electrical output of $1000 \mathrm{MW}$, are now operating at the LNPP.

\subsection{Main Characteristics of the Leningrad NPP Site}

\subsubsection{General Layout of the Leningrad NPP}

Units \#1 and \#2 and Units \#3 and \#4 are individual structures with separate reactor rooms. The units in each phase share a turbine hall. Figure 3.1 shows the general plan of the LNPP and the location of buildings and structures at the site. Figure 3.2 shows the layout of the LNPP Phase I units and the location of Unit \#1 and Unit \#2 main equipment.

\subsubsection{Geographic Location}

The LNPP is located in the Lomonosov Part of the Leningrad Region $80 \mathrm{~km}$ west of St. Petersburg on the southern coast of the Gulf of Finland in the Baltic Sea. The Gulf of Finland is the source of cooling water for the LNPP. 


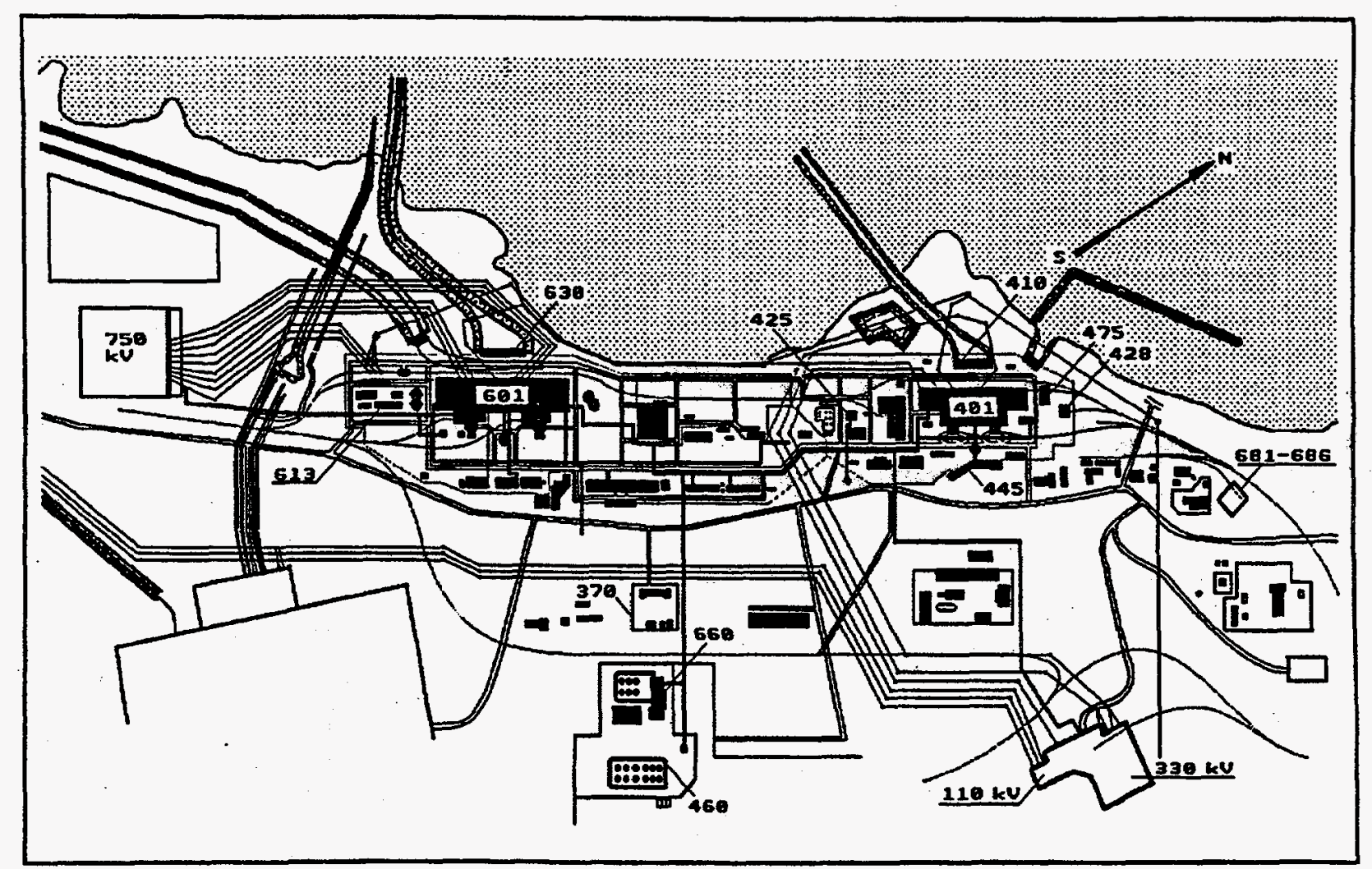

370 - Fire station

401 - Units 1 \& 2

410 - Sea water pumping station of Units 1 \& 2

425-Diesel building of Unit 1

428- Spent fuel storage

445 - Administrative building

460 - Liquid waste storage
475 - Diesel building of Unit 2

601 - Units 3 \& 4

613 - Diesel building of

Units 3 \& 4

630 - Sea water pumping station of Units $3 \& 4$

660 - Liquid waste storage

681/686 - Oil storage

Figure 3.1. General Layout of the Leningrad NPP

Units \#1 and \#2 of the LNPP are about $6 \mathrm{~km}$ southwest of the town of Sosnovy Bor; Units \#3 and \#4 are two kilometers farther southwest. Figure 3.3 shows the geographic location of the LNPP. Figure 3.4 shows the location of the LNPP relative to the town of Sosnovy Bor.

\subsubsection{Geological Engineering Conditions}

LNPP is located in the pre-clintal lowland on the first and second marine terraces. The surfaces of the terraces are level with a gentle slope toward the Gulf of Finland. The absolute elevations of the first terrace are from 0 to $10 \mathrm{~m}$; of the second, from 13 to $18 \mathrm{~m}$. The site of the LNPP was once traversed by four streams, which are now channeled and discharged into the Gulf of Finland. 


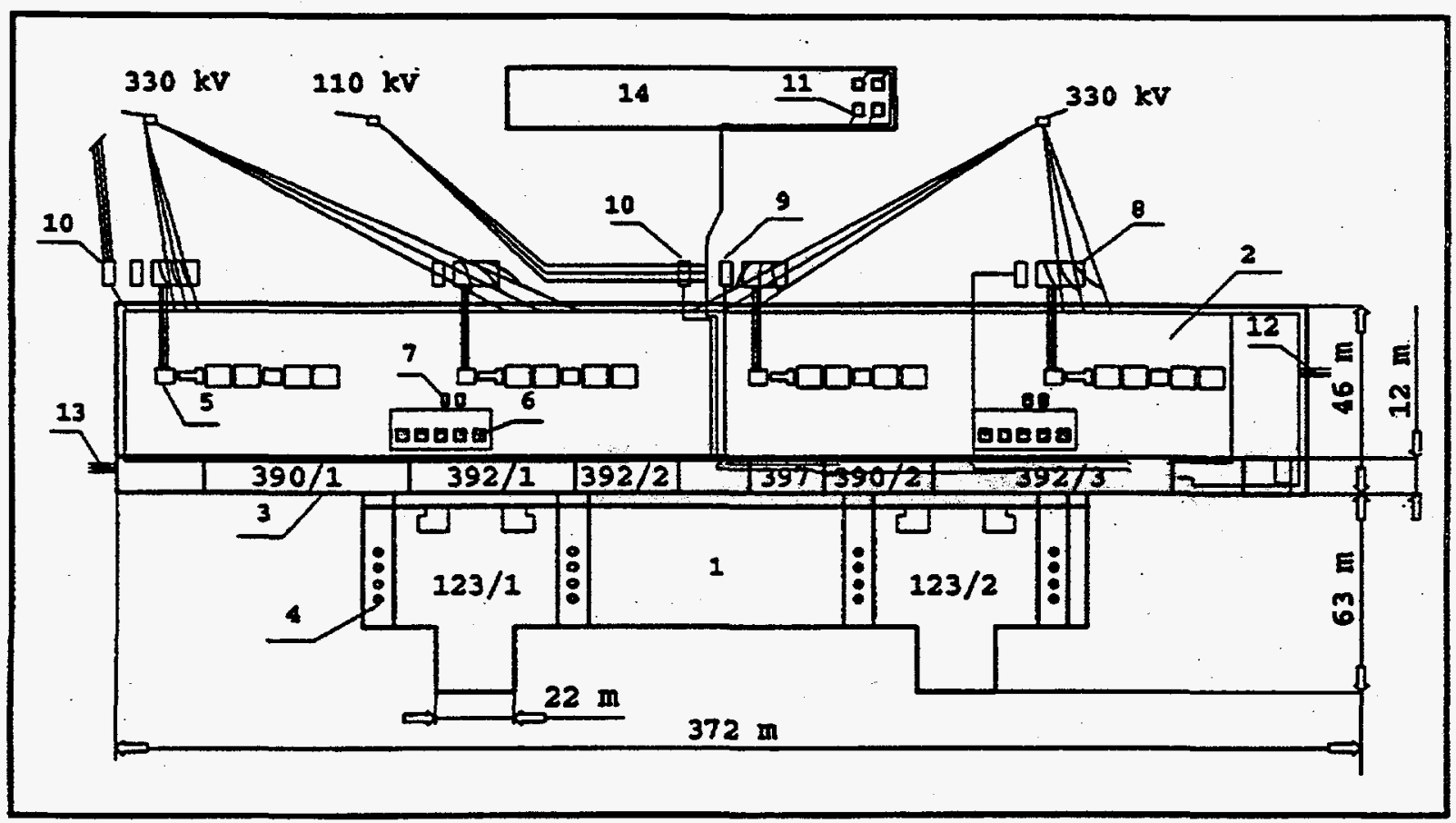

1 - Auxiliary building

2 - Common turbine ball

3 - Intermediate building

4 - Main circulation pump

5 - Generator

6 - Main feed water pump

7 - Auxiliary feed water pump

8 - Main transformer
9 - Auxiliary transformer

10 - Start-up transformer

11 - NA-pump, service water system

12 - Cables to diesel building of Unit 2

13 - Cables to diesel building of Unit 1

14 - Sea water pumping station

$123 / 2$ - Reactor hall of Unit 2

123/1 - Reactor hall of Unit 1
$392 / 1$ - Control room of Unit 1

$392 / 3$ - Control room of Unit 2

$392 / 2$ - Electrical equipment (SUZ, reactor instrumentation)

390/1,2 - Electrical equipment (SKALA computer)

97 - Central control room (external grid, fire detection)

Figure 3.2. Layout of Units \#1 and \#2 of the Leningrad NPP

Widely distributed Quaternary formations and Lower Cambrian and Proterozoic deposits are part of the geological structure. The hydrological conditions of the site are characterized by groundwaters with free surface in the Quaternary deposits and pressure water in the Lower Cambrian and Proterozoic rocks. The general slope of the groundwater surface is toward the Gulf of Finland.

The geological engineering conditions at the industrial site of the LNPP have now been studied in detail and are rated as entirely favorable. Specifically, in 1989, the site of the LNPP was microseismographed, and the results were incorporated into the raw data used in designing the replacement units and the structures associated with plant safety assurance. The results of this study show that dense Proterozoic clays are the base for the foundations of most of the existing structures at the LNPP site. 


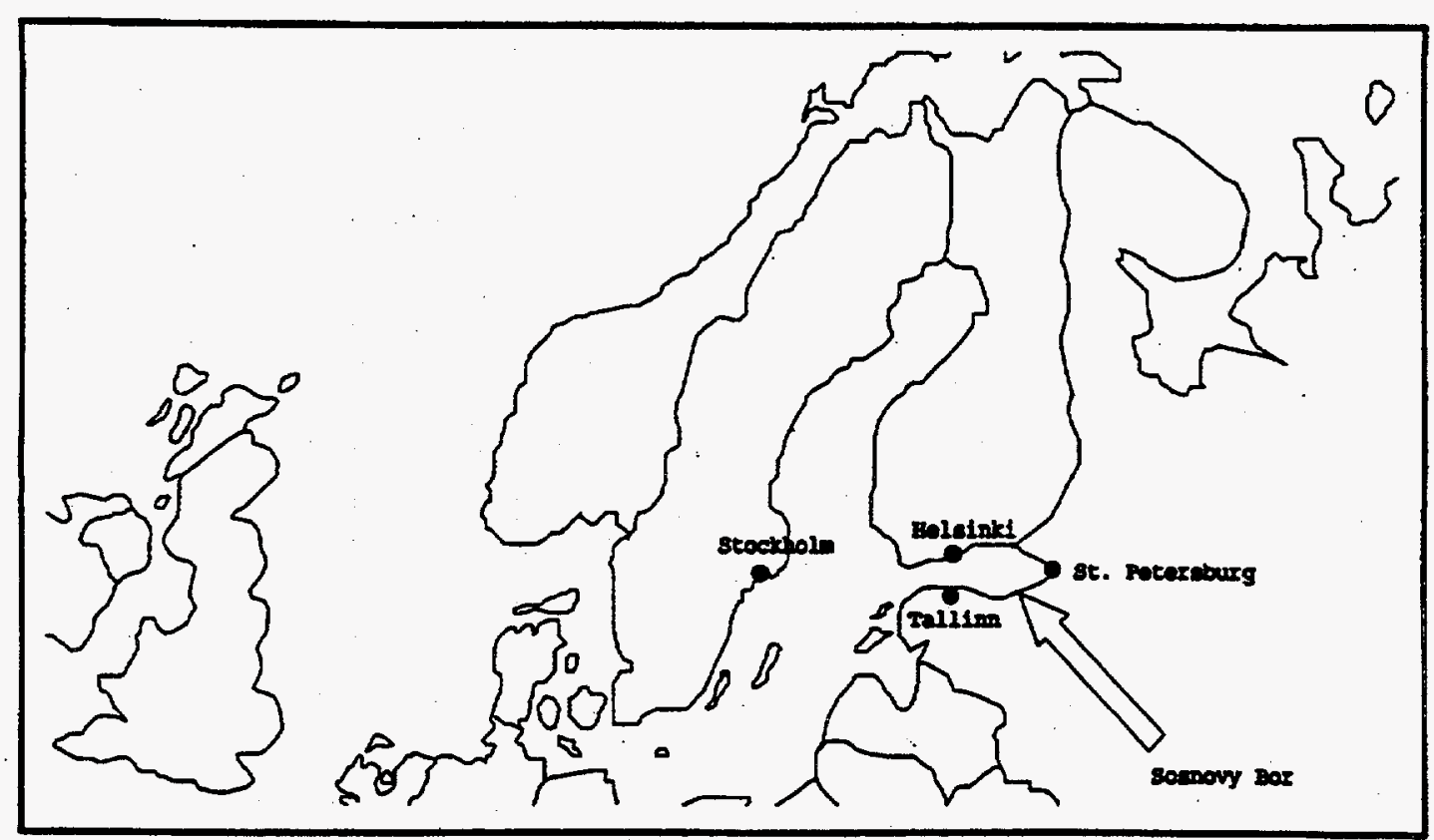

Figure 3.3. Geographic Location of the Leningrad NPP

\subsubsection{Hydrological Conditions}

The multiyear average water level in the Gulf of Finland, which is the source of cooling water for the LNPP, corresponds to zero on the Kronstadt tide gauge. Multiyear variations in the average annual level range from -18 to $+21 \mathrm{~cm}$. The most significant variations in the level of the Gulf of Finland result from the action of the wind. Rising water levels are generally caused by winds from the north, northwest, and west; falling levels by winds from the south and southeast.

According to data from St. Petersburg Gidroproyekt, the water level in the Gulf of Finland have had the following elevations since protective structures were erected near the city of St. Petersburg.

High Level

\begin{tabular}{|l|c|c|c|c|}
\hline \multirow{2}{*}{} & \multicolumn{4}{|c|}{ Frequency, \% } \\
\cline { 2 - 5 } & 0.01 & 0.1 & 1 & 10 \\
\hline Level, $\mathrm{m}$ & 4.66 & 4.12 & 2.91 & 1.67 \\
\hline
\end{tabular}

Low Level

\begin{tabular}{|l|c|c|c|c|}
\hline \multirow{2}{*}{} & \multicolumn{4}{|c|}{ Frequency, \% } \\
\cline { 2 - 5 } & 99 & 97 & 95 & 90 \\
\hline Level, $\mathrm{m}$ & -1.42 & -1.28 & -1.20 & -1.12 \\
\hline
\end{tabular}




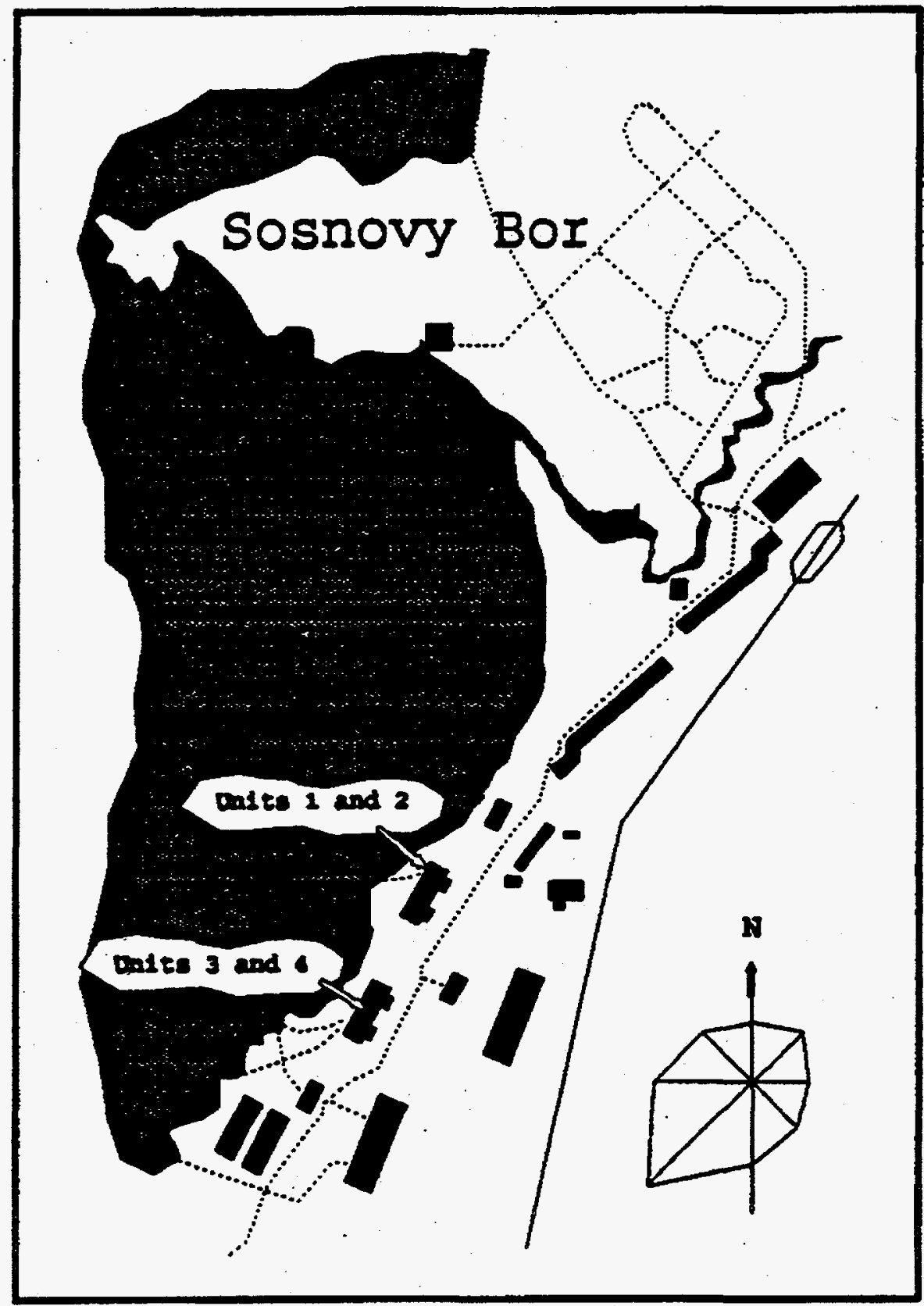

Figure 3.4. Site of the Leningrad NPP

\subsubsection{Climatic and Meteorological Conditions}

The area of the LNPP has a middle-latitude sea climate, intense cyclone activity, comparatively small air temperature variations during the seasons and over a day, high humidity, cloudiness, and a rather large amount of precipitation. The average annual wind speed is $4.1 \mathrm{~m} / \mathrm{s}(9 \mathrm{mph})$. The average annual partial vapor pressure is $7.8 \mathrm{gPa}$. Average monthly vapor pressure reaches maximum in June and minimum in February. Monthly variations are $3.2-14.7 \mathrm{gPa}$. 
Relative humidity is high throughout the year, ranging from 72 to $86 \%$. The annual average relative air humidity is $80 \%$. Relative humidity is at its maximum in December-January and its minimum occurs in May. There are 150 days a year when the relative humidity over a 24-hour period is more than $80 \%$; there are $4-10$ days per year when it is $30 \%$ or lower. The relative humidity at 3:00 pm in the warmest month of the year is $66 \%$; in the coldest month, $85 \%$.

The annual variation in atmospheric pressure may be described with its average monthly multiyear values. According to the Sosnovy Bor Weather Station, the average multiyear atmospheric pressure by month is as follows; the change in the average atmospheric pressure from month to month is negligible.

\begin{tabular}{|c|c|c|c|c|c|c|c|}
\hline Month & I & II & III & IV & V & VI & VII \\
\hline Pressure, gPa & 1006.9 & 1019.5 & 1014.3 & 1012.6 & 1015.2 & 1011.7 & 1011.0 \\
\hline Month & VIII & IX & X & XI & XII & Year & \\
\cline { 1 - 6 } Pressure, gPa & 1010.6 & 1011.1 & 1007.1 & 1007.4 & 1005.6 & 1011.1 & \\
\hline
\end{tabular}

The normal precipitation in the region averages $748 \mathrm{~mm} / \mathrm{yr}$ (29.5 in./yr); about $461 \mathrm{~mm}$ (18.1 in./yr) falls during the summer. Maximum precipitation intensity is $36 \mathrm{~mm} / \mathrm{hr}$. There are an average of 69 days with precipitation.

No dust or sand storms or typhoons have been observed in the area of the LNPP. Tornadoes are rare, and the probability of a tornado in the area of the LNPP is $0.007 \%$, or once every 1400 years. Tornadoes occur mostly in June and July. Two recorded tornadoes (in 1925 near Leningrad and in 1981 near Luga) were rated at zero intensity on the Fujita scale (the intensity category is determined by the nature of the destruction caused by the tornado). The zero class is characterized by minor damage: broken tree branches, some damage to television antennas on rooftops. According to data from the Hydrometeorological Service, there were eight wind squalls with gusts to $30-32 \mathrm{~m} / \mathrm{s}$ from 1967 through 1983 . Wind squalls usually occur in the warm season during thunderstorms. The phenomenon lasts a few minutes.

Storm and hurricane winds with speeds of $20-30 \mathrm{~m} / \mathrm{s}$ or more occur in the transitional seasons and are associated with cyclones. Estimated winds with different frequencies are given below. The estimated maximum wind speed with a frequency of once every 100,000 years (averaged over 10-min. intervals) is $31 \mathrm{~m} / \mathrm{s}$. Individual gusts at maximum wind speed with a frequency of once every 100,000 years (averaged over 3 seconds) are $40 \mathrm{~m} / \mathrm{s}$. The rated wind pressure (as per SNiP [construction code] 2.01.07-85 "Loads and Forces") is $0.30 \mathrm{kPa}$ or $30 \mathrm{kgf} / \mathrm{m}^{2}$.

\begin{tabular}{|c|c|c|c|c|c|c|}
\hline Frequency & $1 \mathrm{yr}$ & $5 \mathrm{yr}$ & $10 \mathrm{yr}$ & $15 \mathrm{yr}$ & $20 \mathrm{yr}$ & $50 \mathrm{yr}$ \\
\hline $\begin{array}{c}\text { Wind speed, } \\
\mathrm{m} / \mathrm{s}\end{array}$ & 20 & 23 & 24 & 25 & 26 & 30 \\
\hline
\end{tabular}


The absolute maximum air temperature is $33^{\circ} \mathrm{C}$, the absolute minimum, $-40^{\circ} \mathrm{C}$. The average air temperature is $-28^{\circ} \mathrm{C}$ on the coldest days and $-12^{\circ} \mathrm{C}$ during the coldest period.

There are an average of 29 days with fog in this region during a year. In some years the number of foggy days may vary from 10 to 53 depending on atmospheric circulation. Conditions most conducive to the development of fog occur during the cold season (from October to March), which accounts for $72 \%$ of the annual fog days. The number of foggy days during the warm half of the year varies from 0.5 to 3, and there is no fog whatsoever in June and July in $60-70 \%$ of the years. On a foggy day, fog lasts an average of 3.7 hours. Fog totals 107 hours a year. December has the most fog $(18 \mathrm{hr})$; June the least $(0.7 \mathrm{hr})$. During the cold half of the year, fog occurs from 6:00 am to 12:00 noon; in the warm half of the year, before dawn. Fog lasts the longest at night and in the morning.

Hail is rare. It is most likely to occur in June and September. The maximum number of days with hail is six. On an hourly basis, hail falls primarily in the early afternoon, with maximum frequency from 12 noon to $2 \mathrm{pm}$. In most cases hail falls for a period from a few minutes up to 15 minutes. The hailstones are basically small; no hail larger than $20 \mathrm{~mm}$ has been noted.

Ice and frost also occur in this area. There are an average of 31 days with some sort of glazing in a season. The most common type of frost is crystal rime. There are an average of 18 days per season with crystal rime, but there was a season with 41 days of rime (over the period from 1953 through 1977 during which instrument measurements were taken). Moreover, in one season the number of days with deposits of some sort was 57 , twice the average multiyear figure.

For overhead power transmission lines $(10 \mathrm{~mm}$ in diameter at a height of $10 \mathrm{~m})$, the maximum load is $210 \mathrm{~g} / \mathrm{m}$ once every 10 years. For tall structures, the ice load at a height of $100 \mathrm{~m}$ is estimated to reach $1.5 \mathrm{~kg} / \mathrm{m}$ once every 10 years; this figure doubles and triples for heights of 300 and $500 \mathrm{~m}$. As per SNiP 2.01.07-85, "Loads and Forces," this area is one in which ice thickness in $\mathrm{mm}$ (exceeded once every $5 \mathrm{yr}$ ) on round-section elements $10 \mathrm{~mm}$ in diameter $10 \mathrm{~m}$ above the ground equals $5 \mathrm{~mm}$; at a height of 200,300 and $300 \mathrm{~m}$, it is 15,35 , and $35 \mathrm{~mm}$, respectively.

The ground freezes to a maximum depth of $139 \mathrm{~cm}$ and an average depth $50 \mathrm{~cm}$. The snow cover lasts an average of 132 days. In warm winters there may be no lying snow, but the probability of these winters is no more than $5 \%$ (once every 20 years). The average snow cover depth over the winter is $32 \mathrm{~cm}$ (12.6 in) along the shore, $39 \mathrm{~cm}$ (15.4 in) in the forest. The maximum snow cover depths are $51 \mathrm{~cm}$ and $67 \mathrm{~cm}(26 \mathrm{in})$. Average snow density is $0.20-0.22 \mathrm{~g} / \mathrm{cm}^{3}$; it varies slightly over the winter from $0.13 \mathrm{~g} / \mathrm{cm}^{3}$ to $0.29 \mathrm{~g} / \mathrm{cm}^{3}$. As per SNiP 2.01.07-85, "Loads and Forces," this territory is classified as one in which the rated weight of snow cover per square meter of horizontal land surface should be $1.0 \mathrm{kPa}$ or $100 \mathrm{kgf} / \mathrm{cm}^{2}$.

The heating season lasts 225 days. The average temperature during this period is $-1.7^{\circ} \mathrm{C}$. The estimated temperature of the coldest five-day period is $-23^{\circ} \mathrm{C}$; of the coldest day, $-28^{\circ} \mathrm{C}$. The winter ventilation temperature is $-12^{\circ} \mathrm{C}$. The period with an average daily temperature above $15^{\circ} \mathrm{C}$ starts in the first half of June. The warmest period lasts 60 days. 


\subsubsection{Ecological Features}

According to data from January 1, 1993, industrial facilities and several other small organizations (see Section 3.2.7) near the LNPP discharge roughly 16,000 tonnes/yr of pollutants (including 12,700 tonnes from automobiles) into the atmosphere. These pollutants include sulfur anhydride, carbon monoxide, nitrous oxides; ammonia; acetone, ash; welding aerosols; paint aerosols; butyl acetate; acid vapors; magnesium oxide; fluorine and fluorides; xylene; toluene; white spirit and alcohols; lead; silicon compounds, heavy metal vapors and salts, gasoline, and the like.

The atmosphere contains small amounts (from 0.003 to $0.25 \mathrm{mg} / \mathrm{m}^{3}$ ) of carbon monoxide, ozone, nitrous oxides and ammonia along with 0.5 to $1.5 \mathrm{mg} / \mathrm{m}^{3}$ of hydrogen and methane. All other compounds (solids, liquids, and gases that alter the natural composition of the atmosphere) entering the air from various sources (basically anthropogenic) are classified as pollutants. These include oxides of carbon, sulfur, and nitrogen; hydrocarbons; metal aerosols; solid particles (dust, ash, organic aerosols); and radioactive substances.

Toxic chemical compounds enter the atmosphere and are significantly altered by ultraviolet radiation, moisture, ozone, and oxygen in the air. According to information from the Armed Forces, military facilities in the area of the LNPP produce no harmful chemical and toxic emissions or effects on nature.

Pollutants from mineral fertilizers, pesticides, and organic wastes of animal husbandry from agricultural operations enter the soil, groundwater, and the water of the gulf. In addition, if there is a ship accident (primarily tankers) in the channel of the Gulf of Finland, pollutants may enter Koporsk Bay.

The primary enterprises influencing the radiation situation of the region are the LNPP, the NITI, and Radon Works (Lenspetskombinat). Radioactive contamination of the atmosphere affects most living organisms and plants and has a tremendous influence on the composition and atmospheric reactions of nonradioactive air pollutants.

Various types of radiation - from space and nuclear radiation to optical frequency radiationcause excited molecules and ions to form in the atmosphere. These molecules and ions have a considerable effect on changing meteorological factors, on processes associated with atmospheric electricity and the propagation of radio waves, and on other geophysical and meteorological phenomena.

The degree of atmospheric pollution varies in time and space. These variations are related to the features of the sources emitting the pollutants (the type of source, the nature and properties of the pollutants, the volume of the emission) and to the effect of meteorological and topographical factors (wind speed and direction, temperature inversions, atmospheric pressure, humidity, the topographical relief, and the distance to the source of pollution). Pollutants in the atmosphere contribute to the destruction of outside objects made of metal and other construction materials. 


\subsubsection{Description of the Residential Town and Industrial Infrastructure in the Region of the LNPP}

Sosnovy Bor, the closest town, is $6 \mathrm{~km}$ from the LNPP site. The town has a population of 120,000. There are about 700 large and small enterprises around the LNPP and Sosnovy Bor. About 650 of these are small businesses. The agricultural operations of the Lomonosov, Kingisepp, and Volosov Regions, Armed Forces installations, and transportation routes (railroads, motor roads, and a sea channel) are within a $25-\mathrm{km}$ radius of the plant.

The LNPP, the NITI, Radon Works (Lenspetskombinat); and the "Mashinostroitelny zavod are the main industrial enterprises of the Sosnovy Bor region. Others are Opytno-eksperimentalny zavod" Company, the Northern Construction Administration with its internal subdivisions, the Ruchevsky rybokombinat Company; "Kalishchekhleb" Company; the Vavilov State Optical Research Institute; a branch of the VNIPIET; a branch of the Khlopin Radium Institute; a subsidiary of the Central Machine Building Design Office; the Motor Transport Administration; the Municipal Motor Transport Administration; the "MSU-90" Company; "Sosnovoborelektromontazh" Company; and "Sosnovoborspetskhimmontazh" Company.

Facilities planned or under construction which may have a specific effect on the natural environment around Sosnovy Bor include the new LNPP units, which will replace those to be decommissioned; the NITI Atomic Energy Scientific Industrial Center; radwaste collection, processing, and storage facilities at the LNPP; the NITI; Radon Works; and the seaport at Batareynaya; and a calcium carbide plant. 


\subsection{Description of the Construction and Design Features of Leningrad Unit \#1}

\subsection{Design and Main Characteristics of the RBMK Reactor}

The RBMK-1000 reactor is a heterogeneous channel-type thermal neutron nuclear reactor. The reactor is graphite moderated with boiling water coolant. Uranium dioxide $\left(\mathrm{UO}_{2}\right)$ weakly enriched with U-235 isotope is used for the fuel. The reactor basically consists of a set of vertical fuel channels inserted into cylindrical holes in columns of the reactor's graphite stack with top and bottom protective plates.

The hollow space in the reactor's graphite stack is surrounded by a thin-walled cylindrical housing (shell). The graphite stack consists of square-section graphite blocks assembled in columns with cylindrical holes in the center. The stack rests on the bottom plate, which transfers the reactor's weight to the concrete cavity. The fuel channels and control rod channels pass through bottom and top metal structures. The control rod drives are located above the core near the top protective structure of the reactor hall.

The reactor core is a vertical cylinder with a diameter of $1.18 \mathrm{~m}$ and a height of $7 \mathrm{~m}$. The $3.64 \mathrm{~m}$-long fuel elements are assembled into fuel bundles (FB), cylindrical bundles of 18 fuel elements each. Two bundles, one above the other and assembled around one central rod, form a fuel assembly (FA), which is installed in each fuel channel (FCH).

Nuclear fuel in the form of $\mathrm{UO}_{2}$ pellets is placed in a zirconium and niobium alloy fuel cladding (grade E-110). Fuel is loaded into the reactors by a fuel-handling machine (FHM) located in the central reactor hall (CRH).

About $95 \%$ of the energy released in the fission reaction in the reactor core is transferred to the coolant. About 5\% of the reactor's output is released in the graphite from moderating the neutrons and absorbing gamma rays. To lower thermal resistance and prevent graphite oxidation, the cavity of the stack is filled with a circulating mixture of helium and nitrogen gases. This mixture is also used to check the integrity of the channels as the moisture content and temperature of the gas change. Under the bottom and above the top plates are spaces for water lines (WL) from the distribution header to each channel and steam-water lines (SWL) from each fuel channel to the drum-type steam separator.

The reactor's control and protection system (CPS) is based on the movement of solid absorber rods in specially designated channels cooled by water from a self-contained circuit. The main characteristics and working parameters of the RBMK-1000 reactor are summarized in the following subsections.

\subsubsection{Graphite Stack Blocks of the Reactor}

The reactor's graphite stack (Figure 4.2) acts as a moderator and reflector. The stack is located inside the reactor zone (RZ) in the form of a vertical cylinder assembled from 2,488 columns of graphite blocks. The graphite blocks are rectangular prisms $250 \times 250 \mathrm{~mm}$ in square section and $200,300,500$, and $600 \mathrm{~mm}$ high with a center hole $114 \mathrm{~mm}$ in diameter. 


\begin{tabular}{|ll|}
\hline Reactor output, $\mathrm{MW}$ & \\
$\quad$ - thermal & 3,200 \\
$\quad$ - electrical & 1,000 \\
Coolant flow rate through the reactor, tonne/hr & 37,500 \\
Steam capacity, tonne/hr & 5,600 \\
Steam pressure in drum-separator, $\mathrm{MPa}$ & 7.0 \\
Pressure in pressure headers, MPA & 8.6 \\
Average mass steam content at exit from the reactor, \% & 14.5 \\
Coolant temperature, ${ }^{\circ} \mathrm{C}$ & \\
- at entry to the core & 270 \\
- at exit from the core & 284 \\
Maximum channel output, $\mathrm{kW}$ & 3,000 \\
Coolant flow rate in maximum output channel, tonne/hr & 29.4 \\
Core height, mm & 7,000 \\
Core diameter, mm & 11,800 \\
Fuel lattice spacing, mm & $250 \times 250$ \\
Number of fuel channels & 1,693 \\
Fresh fuel enrichment, $\%$ & 2.4 \\
Average fuel burnup fraction, $\mathrm{MW} /$ day $/ \mathrm{kg}$ & 22.5 \\
Maximum temperature of reactor graphite stack, ${ }^{\circ} \mathrm{C}$ & 700 \\
Maximum temperature of the surface of a zirconium fuel & 325 \\
channel tube, ${ }^{\circ} \mathrm{C}$ & \\
\hline
\end{tabular}

Figure 4.1. Locations of the Core, Equipment, and Structures of the RBMK-1000 Reactor

The graphite stack columns are assembled mostly from graphite blocks $600 \mathrm{~mm}$ high resting on support plates with seats mounted on the metal load-bearing structure (bottom load-bearing structure). The four outside rows of columns form a side reflector ring $800 \mathrm{~mm}$ thick along the periphery of the stack. The top and bottom courses of stack graphite $500 \mathrm{~mm}$ high act as end reflectors. The tops of the columns are covered with protective plates. The shorter, 200-, 300-, and 500-mm blocks are set only at the bottom and top leveling courses of the end reflectors to shift the joints between the blocks in adjacent columns vertically.

The through-holes (114 mm in diameter) in the graphite stack blocks form tracks for fuel, steam generating, and special channels in the 1,888 columns. The holes in 444 of the side reflector columns are filled with solid graphite rods. A graphite stack is secured against radial displacement by 156 rods placed in the holes of the outside layer of the side reflector columns. The graphite's effective density is $1.7 \mathrm{~g} / \mathrm{cm}^{3}$, and the total weight of the graphite stack is about 1,900 tonnes.

\subsubsection{Reactor Metal Structures}

Forces from the weight of reactor internals, assemblies, and service lines are transferred to civil structures, and the internal spaces of the reactor are sealed using special welded metal structures 


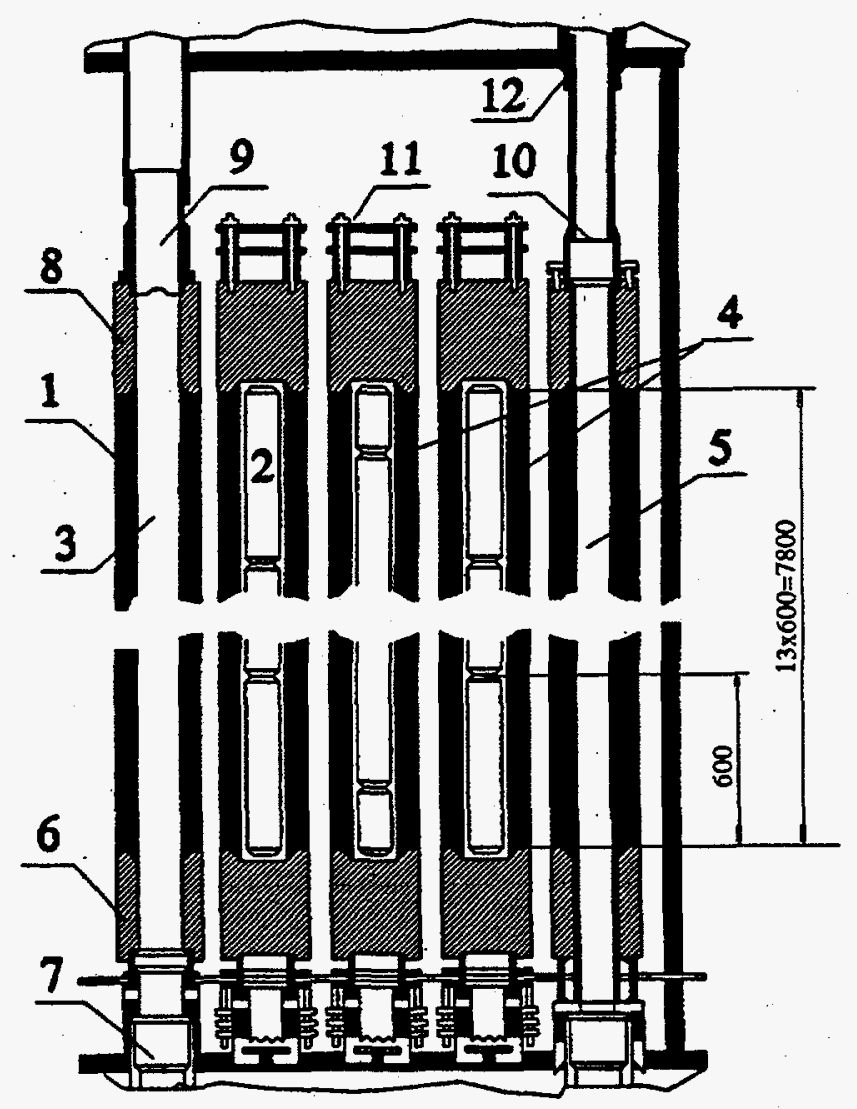

1 - Graphite blocks

2 - Graphite rods

3 - Core columns

4 - Reflector columns

5 - Peripheral reflector columns

6 - Supporting slabs
7 - Supporting cups

8 - Shielding plates

9 - Flanges

10 - Guide branches

11 - Heat shields

12 - Ducts

Figure 4.2. Graphite Stack Blocks of the RBMK-1000 (units in $\mathrm{mm}$ )

that also provide biological protection (Figure 4.3). The reactor's metal structures therefore perform both bearing and biological protection functions. The following describes the numbered metal structures in Figure 4.3.

Item 5 is the reactor's support structure. It takes the form of a cross with stiffeners $5.3 \mathrm{~m}$ high, and it transfers loads from the reactor to the heat-resistant concrete foundation plate at the bottom of the reactor cavity. The cross-shaped structure weighs about 120 tonnes. 


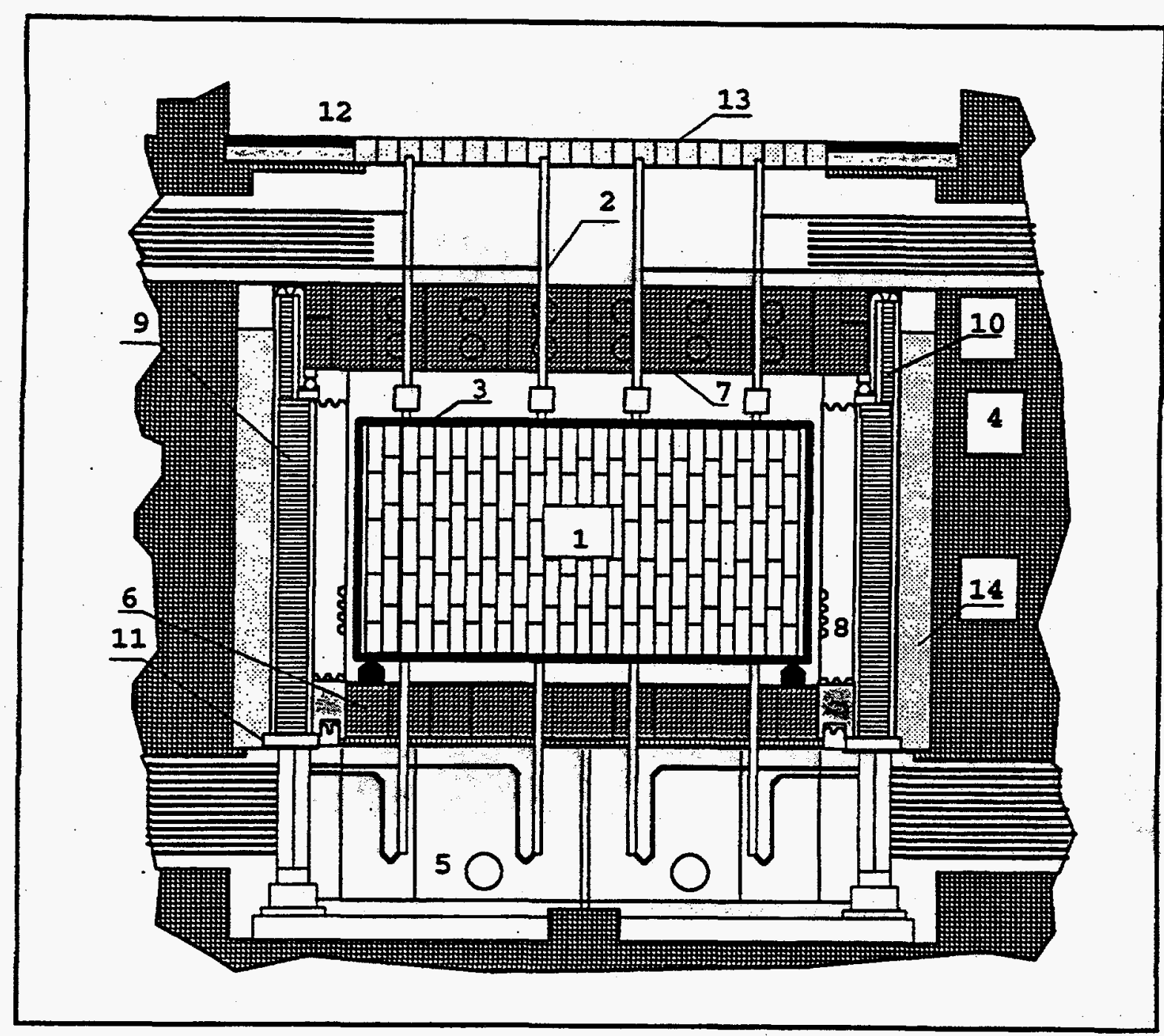

1 - Graphite stack

2 - Pressure tubes

3 - Reactor cavity

4 - Concrete vault

5 - Support Structure

6 - Bottom Load Bearing Structure

7 - Top Load Bearing Structure
8 - Cylindrical Liner

9 - Circular Tank

10 - Circular Tank

11 - "A" Scheme

12 - Top Plate Floor

13 - Plating

14 - Sand fill

Figure 4.3. Metal Structures of the RBMK- 1000

Item 6 is the bottom load-bearing structure of the graphite stack and the bottom water lines (BWL). It consists of a cylindrical shell and a top and bottom lattice. Tracks for the fuel channels and CPS channels are welded into the lattice. The cavity of the structure is filled with loose serpentine. With a diameter of $14.5 \mathrm{~m}$ and a height of $2.0 \mathrm{~m}$, the bottom support structure weighs about 270 tonnes. 
Item 7 shows the top load-bearing structure for channels, fuel assemblies, CPS equipment, steam and water lines, and the plate floor. In terms of layout, the design of this structure resembles that of the bottom load bearing structure and is a cylinder $17 \mathrm{~m}$ in diameter and $3 \mathrm{~m}$ high weighing about 450 tonnes. The cylinder's top and bottom plates are made of 10KhSND-grade steel $40 \mathrm{~mm}$ thick; they are connected to the side shell by sealed pressure welds; there are vertical stiffeners between these plates. As in the bottom load-bearing structure, the space between pipes inside the cylinder contains serpentine fill. Tracks for fuel channels and special channels are welded into the top and bottom load-bearing structures through holes drilled in the plates.

Item 8, the reactor's cylindrical liner with a block of lens compensators, along with top and bottom load-bearing structures, forms a sealed space called the reactor zone (RZ), where the reactor's graphite stacks are placed. The liner is a welded cylinder $14.52 \mathrm{~m}$ in outside diameter and $9.75 \mathrm{~m}$ high. It is made of grade $10 \mathrm{KhSND}$ plate steel $16 \mathrm{~mm}$ thick. The reactor liner weighs 77 tonnes. The lens compensator block compensates for longitudinal temperature expansions in the reactor liner.

Items 9 and 10 are circular reservoirs (tanks) for side biological protection. The reservoirs are divided into 16 sealed vertical compartments filled with water, which is circulated by a pumpheat exchanger unit. Item 9 takes the form of a cylindrical welded reservoir with an outside diameter of $19 \mathrm{~m}$ and an inside diameter of $16.6 \mathrm{~m}$. It is made of low-alloyed carbon steel (grade 10XSND) $30 \mathrm{~mm}$ thick. The metal structure in weighs about 800 tonnes. Item 9 surrounds the reactor's graphite stack liner. The space between the outer surface and the surrounding walls of the concrete reactor cavity is filled with sand. Item 9 is also a support structure for the top loadbearing structure, forces from which are transferred through 16 roller bearings.

Item 11 covers the bottom of the installation opening between the cavity wall and the cylindrical liner and contains sand fill. Together with the plate floor, Item 12 protects the central hall from reactor radiation. The top plate floor covers the opening above the reactor cavity. It is formed from plates and blocks resting on channel tracks. The plates and blocks are metal structures filled with iron-barium-serpentine cement stone.

The covering of the reactor cavity serves as the floor for the central hall. There is an opening in the floor in the central hall for fuel channels and special channels. The diameter of the opening is larger than the diameter of the graphite stack. The opening is covered by a removable floor consisting of individual plates. The plate floor consists of top and bottom plates and blocks resting on pipe tracks (channels).

The plate floor provides biological protection and thermal insulation for the central hall. During normal reactor operation the biological protection ensures dose rates no more than $2.8 \mathrm{mrem} / \mathrm{hr}$ in the central hall and service areas adjacent to the reactor cavity. During fuel loading, the dose rate for gamma radiation near the FHM momentarily reaches $100 \mathrm{mrem} / \mathrm{hr}$. When the reactor is stopped, the radiation situation is such that equipment in unattended areas can be inspected and repaired. 


\subsubsection{Fuel and Special Channels}

Fuel channels (FCH) are intended to hold fuel assemblies (FA) and to direct the coolant flow through the reactor. Fuel channels are welded tubular structures. The top and bottom of a fuel channel is made of corrosion-resistant steel; its middle, $88 \mathrm{~mm}$ in diameter $\times 4 \mathrm{~mm}$, within the core is made of zirconium alloy. The middle portion of a fuel channel is connected to its top and bottom by special steel zirconium adapters made by vacuum diffusion welding.

The fuel channels are attached to the top load-bearing structure by a "tab" weld and to the bottom load-bearing structure through the compensator assembly which compensates for the difference in thermal expansions without disrupting the seal of the reactor's interior space (reactor zone). The design of the joint between the fuel channel and the metal structure makes it possible, using special devices, to remove a damaged fuel channel in a reactor that has been shut down and to replace it with a new one. The fuel channel housing is rated for 20-25 years of trouble-free operation.

To prevent the fuel channels from sticking in the reactor stack and at the same time to improve heat removal from the graphite columns, graphite sleeves and rings are mounted on the middle parts of the fuel channels. This design provides the necessary heat transfer conditions and compensates for the reduction in the diameter of the opening in the graphite stack due to shrinkage.

The reactor's special channels are for the control and protection system (CPS), energy release sensors (ERS), fission ionization chamber (FIC), and reflector cooling (RC).-The CPS, FIC, and ERS channels and their tracks have the same design. They differ from one another only in the devices placed in them. At the top of the channels are heads for attaching actuators and for supplying cooling water. The RC channel is intended to cool the stack's side reflector rod and to reduce heat flow to the liner. Structurally, the RC channel is a field tube (tube within a tube) of corrosion-resistant steel. The Unit \#1 reactor at the LNPP has 1,693 fuel channels, 179 CPS channels, 12 ERS channels, four FIC channels, and 156 RC channels.

\subsubsection{Multiple Forced Circulation Circuit}

The multiple forced circulation circuit (MFC circuit) is intended to provide coolant circulation through the reactor core. It (Figure 4.4) consists of two independent loops, each cools the left or right half of the reactor and includes two drum-type separators; two separator water coffer-dams; two separator steam coffer-dams; 24 downcomers; four main circulation pumps (MCP); one MCP suction header; four MCP suction pipes with fittings; four MCP delivery pipes with fittings; 22 grouped distribution headers (GDH); 847 water lines with stop-actuator valves and flow meters; 847 fuel channels; and 847 steam-water lines.

Saturated water at a pressure of 7.0 MPa travels from the drum-type separator to the downcomers, where it is mixed with feedwater brought from deaerators by electric feedwater pumps. Traveling through the downcomers, the suction header and the MCP suction pipes, the water enters the MCP. Under the pressure developed by the MCP, the water is carried through the delivery lines, MCP pressure header, grouped distribution headers, and water lines into the fuel channels, where it is heated to saturation temperature and partially evaporated. The resulting 


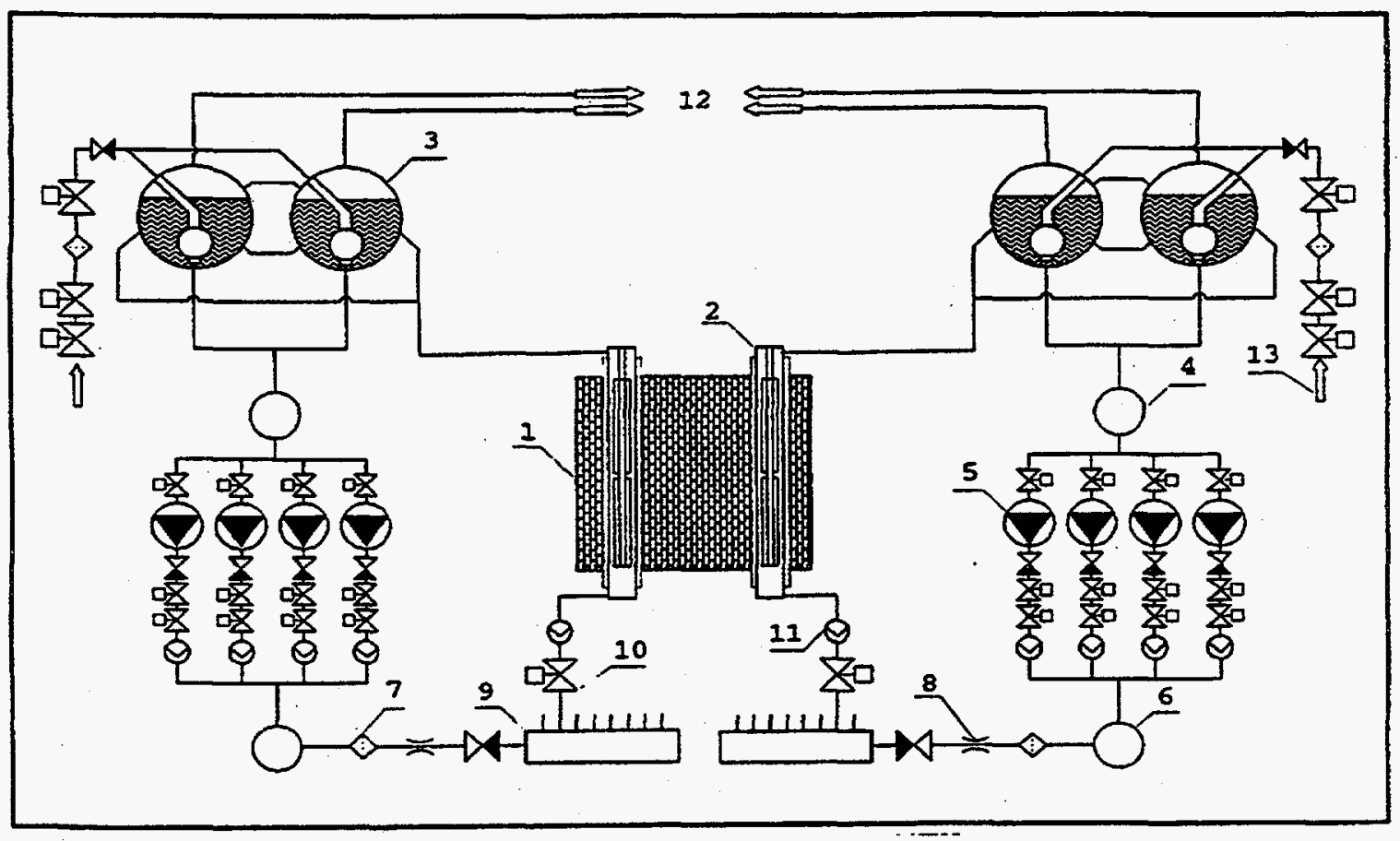

1 - Reactor

2 - Technological channel

3 - Drum-separator

4 - Suction header

5 - Main circulation pump

6 - Pressure header

7 - Mechanical filter
8 - Limiter

9 - Distribution header

10 - Isolation and control valve

11 - Ball-type flowrate meter

12 - Steam lines

13 - Feedwater pipelines

Figure 4.4. Basic Diagram of the Forced Circulation Circuit Loop

steam-water mixture passes through steam-water lines to the drum-type separators, where it is separated into steam and water. The steam is carried through the steam lines to the turbines, the saturated water, to the downcomers. Figure 4.5 is an isometric scheme of the arrangement of the equipment in one loop of the MFC circuit with level marks showing their locations.

In addition to its main function (separating the steam-water mixture into steam and water and producing dry saturated steam at its outlet) the drum-type separator in the MFC circuit mixes the separated circuit water with feedwater and creates the necessary backup water supply.

The separator (Figure 4.6) is a horizontal cylindrical vessel with elliptical bottoms; it weighs about 200 tonnes. For convenience in reloading the core, the separators are shifted aside relative to the reactor's center line.

Coolant is circulated in each loop by three working and one backup MCP. The MCPs are grade TsVN-8 pumps. There are vertical, centrifugal, single-stage pumps with shaft seals. The 


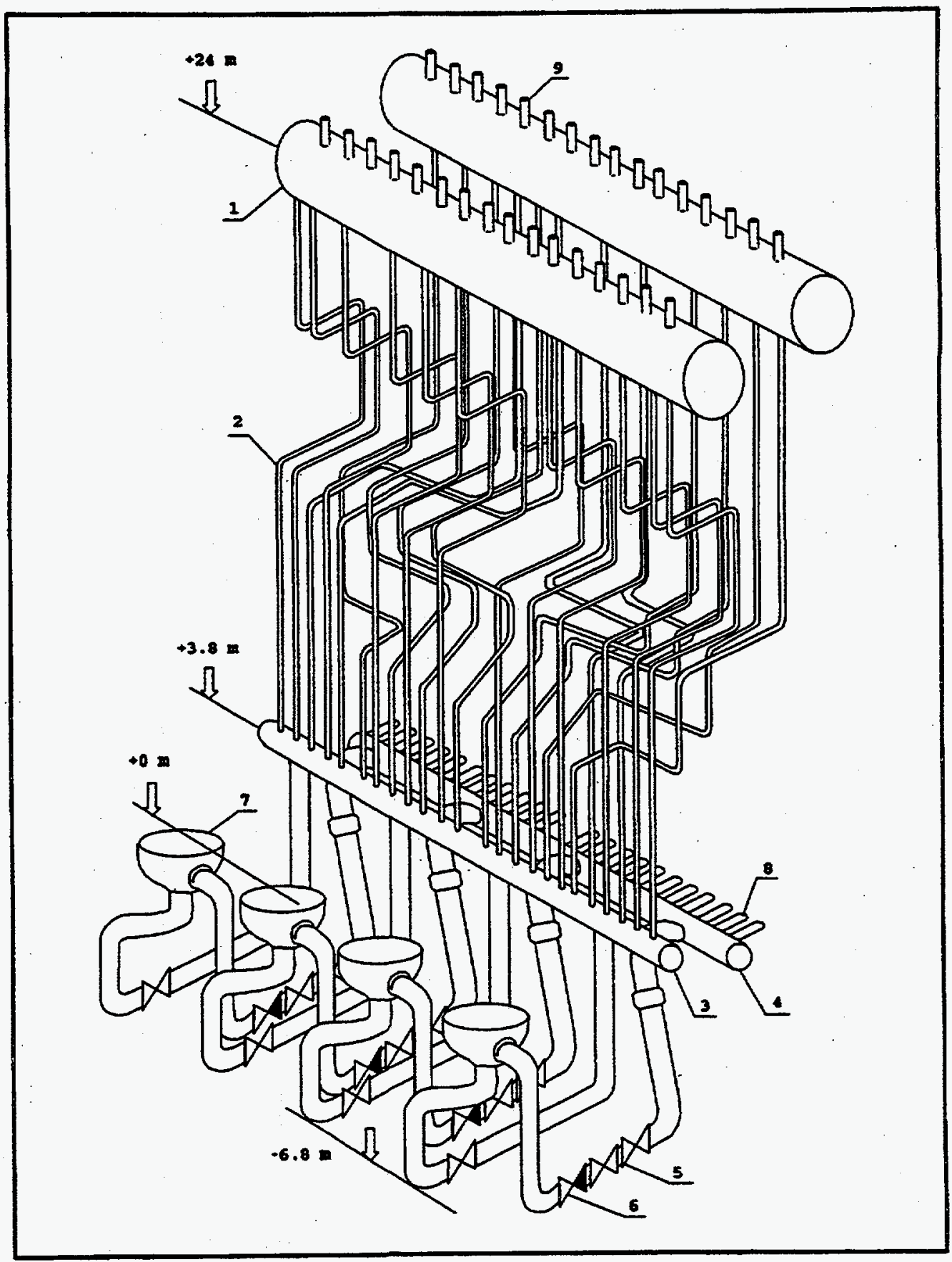

1- Drum-separator 4 - Pressure header

2 - Downcomers

3 - Suction header
5 - Valves

6-Check valve
7 - Main circulation pump

8 - Distribution group header

9 - Steam branch

Figure 4.5. Layout of Components in One Forced Circulation Loop at the Section from Drum-Separator to Distribution Group Header 


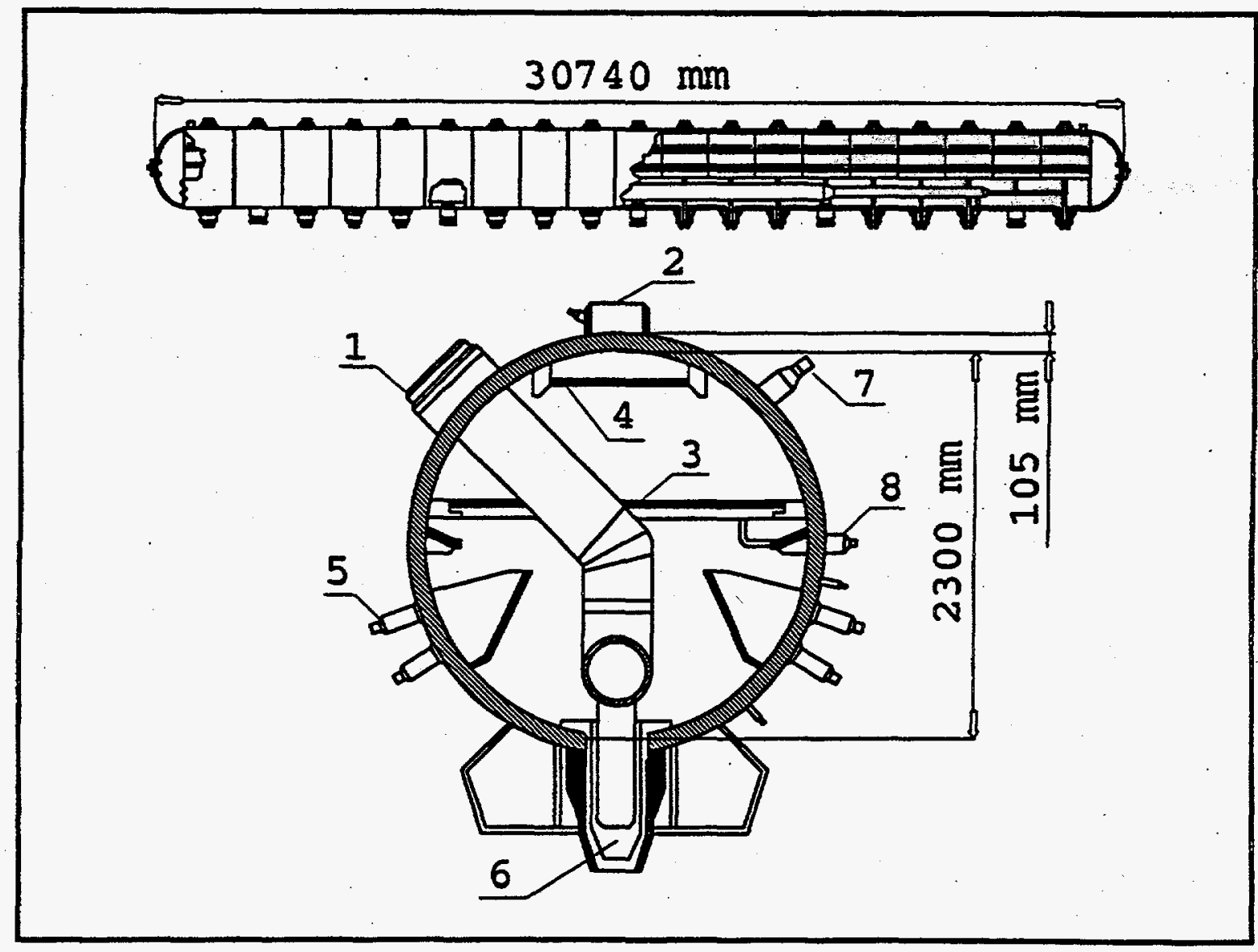

1 - Feedwater branch

2 - Steam branch

3 - Underwater perforated sheet
4-Ceiling perforated sheet

5 - Steam-water branch

6-Downcomer branch
7 - Branch of the level gauge

8 - Branch of the level gauge

Figure 4.6. Drum-Separator

nominal parameters of the MCPs are capacity, $8000 \mathrm{~m}^{3} / \mathrm{hr}$; developed pressure, $200 \mathrm{~mm} \mathrm{H}_{2} \mathrm{O}$; speed, $1000 \mathrm{rpm}$; and motor output, $5,500 \mathrm{~kW}$. The MCPs weigh a total of about 130 tonnes; the electric motors, 30 tonnes.

\subsection{Leningrad NPP Unit \#1 Design Features}

Leningrad NPP Unit \#1, an RBMK-1000 reactor, was built as part of Phase I. A two-unit layout, in which each phase comprises a main building with two units and a set of ancillary and service buildings and structures, was used when NPPs with RBMK reactors were built. Section 3 of this report describes the plan of the buildings for the Phase I units at LNPP and the arrangement of the main equipment for Units \#1 and \#2. The LNPP was laid out to ensure the maximum possible consolidation of process equipment and auxiliary systems. This was accomplished by combining them into one construction activity. 
Main building: In terms of function, the structures of the main building of the NPP Phase I units with RBMK reactors are divided into the reactor sections (two units), deaerator gallery with electrical, gallery, and turbine hall. The main building of LNPP Phase I includes reactor sections with a set of auxiliary systems, a turbine hall with turbogear sets, a deaerator gallery, and an electrical and control systems gallery.

Reactor section: The reactor section consists of a sealed area, including the bottom water lines (BWL), MCP, drum-type separators and quench tanks, and an unsealed area including the reactor hall, spaces for MCP electric drives, and the intake and exhaust ventilation centers.

Nuclear reactor: The nuclear reactor for Unit \#1 of LNPP Phase I, together with the MFC circuit is located in a separate block of the main building. The turbine hall, which is common to both Units \#1 and \#2, adjoins it.

The reactor is placed in a special cavity $21.6 \times 21.6 \mathrm{~m}$ in plane and $25.5 \mathrm{~m}$ deep with massive concrete walls that provide biological protection. To the side of the nuclear reactor are spaces for the BWL and grouped distribution headers (GDH). Behind them are the downcomer shafts and MCP enclosures. The drum-type separators are located above the downcomers. Above the MCP enclosures are spaces with overhead cranes to service the MCP electric motors. The reactor is serviced from the central hall by a fuel-handling machine (FMH) and an overhead crane.

In addition to MFC circuit equipment, the reactor island accommodates some of the main and auxiliary systems, including headers and piping for the main steam supplied to the turbines, feedwater piping with feed controls, the cooling circuit for the CPS, FIC, ERS, and RC channels; a system of balance tanks to control water level in the drum-type separators; systems for powering the hydrostatic bearings and heating, cooling, and discharging the MCPs; the MCP oil systems; emergency steam dump condensation system; fuel channel integrity monitoring (FCIM) systems and an FCIM vacuum pump; fuel cladding seal monitoring system; a system for preparing and storing fresh nuclear fuel; a nuclear fuel transfer system; a spent nuclear fuel (SNF) handling and storage system; the pump-heat exchanger unit for the SNF cooling pond (CP); the pump-heat exchanger unit for the top load-bearing structure; the intermediate circuit expansion tank, piping and pumps for increasing the head in the intermediate loop; the fuel-handling machine support system; drains and vent valves; a system for receiving and transferring sanitary waste water and planned leaks; and others (including piping to systems in the other NPP units).

Turbogenerators: Each unit has two turbogenerators with an electrical capacity of $500 \mathrm{MW}$, consisting of K-500-65 saturated steam turbines and a three-phase TVV-500-2 synchronous generator at $3000 \mathrm{rpm}$. The turbine is a steam condensation single-shaft turbine with one high-pressure cylinder and four low-pressure cylinders. The total length of a turbogenerator is 39.0 (turbo) + 17.8 (generator) meters. A turbogenerator weighs 1,524 tonnes; the condenser, 1,170 tonnes. There is a common turbine hall for the NPP Phase I units, but each turbogear set together with condensers, steam separators, and reheaters is located inside an insulated enclosure.

Turbine hall: The turbine hall houses four turbines with generators (along the center line of the turbine hall), condensate-feedwater track equipment and auxiliary turbine-condensate treatment systems, low- and medium-pressure heaters, electric feedwater pumps (FWP), emergency feedwater pumps (EFWP), clean steam evaporators, oil supply systems, and the like. 
The turbine hall has a span of $51 \mathrm{~m}$, which was governed by the transverse dimensions of the turbine and its auxiliary equipment (separators-steam superheaters, reheaters) and by the requirement to provide passages for equipment maintenance and through passages for vehicles (electric cars). The height of the turbine hall was determined by the total height of a turbogear set and the need to raise the most cumbersome turbine hall equipment components above it during installation and repair.

The length of the turbine hall was determined by the length of the cell for the turbogear set with condensate treatment (four cells each at $96 \mathrm{~m}$ ) and the area of the installation platforms for exterior transport entrances at the ends of the turbine hall. The area occupied by the interior track, which runs between the turbogear sets of the unit and connects the turbine hall with the central machinery repair shop, also had to be taken into account.

In the turbine hall, the basic equipment repair and installation operations during NPP construction are carried out with two 125-tonne overhead cranes, each equipped with a 20-tonne auxiliary hook. When turbines are being installed or undergoing major overhaul, auxiliary gantry cranes may be installed over them. If it is necessary to do a major overhaul of one turbine and routine maintenance or inspection of another at the same time, repair platforms may be built by placing permanent or temporary spans rated for a specific load to $40 \times 10^{3} \mathrm{kN} / \mathrm{m}^{2}$ between the turbine enclosures.

Deaerator gallery: The deaerator gallery is between the reactor block and the turbine hall. The upper floors of the deaerator gallery hold deaerators and pipe corridors. The lower levels hold the central (CPC) and unit (UPC) control panels, dosimetry monitoring panels, distribution gear, storage batteries, cable half-stories, and other electrical systems. The main pedestrian and vehicle routes, stairs and elevators, and passageways and corridors connecting restricted and unrestricted areas of the reactor and turbine sections with the administrative complex are also located within the deaerator gallery.

Auxiliary services: Auxiliary services are combined in a special building between the two reactor sections. These services include the reactor gas circuit, special water treatment with water management panel, an air cleaning and radioactive gas suppression unit, machinery repair services, etc.

Restricted zones: The reactor section, turbine hall, and the upper portion of the deaerator gallery where the deaerators and pipe corridors are located are classified as main building restricted zones. Restricted zones are assigned to different categories: unattended (turbine and condensate treatment enclosures, etc.), in which personnel are not permitted when the equipment is operating; regularly attended (deaerator, feedwater piping areas, etc.), and areas where operating personnel are continuously present. This last category includes local control panels, valve drive and instrumentation areas, most ventilation system areas, the turbine hall, central reactor hall, MCP motor areas, and all types of repair areas.

To enter a restricted zone, personnel must change clothing and pass through personnel air locks. Personnel enter unattended areas through sanitary locks to repair and inspect the equipment and are required to undergo a dosimetry check. Entrances to MFC circuit areas and central reactor halls, where spent fuel cooling ponds are located, are equipped with permanent sanitary locks. 
The surfaces of equipment, walls, and ceilings in restricted areas are protected by special coatings based on epoxy and organosilicate lacquers and enamels that are easy to wash and deactivate.

The central, unit, and backup control panels, CPS and dosimetry monitoring panels, secondary instrumentation, power supply, and electrical distribution gear are in the unlimited access area of the main building. The ventilation systems for the entire building are categorized according to how the main building is divided into unrestricted and restricted zones.

Ventilation systems: Ventilation in the unrestricted zone complies with public health codes for air temperature, humidity, and dust content. Spaces where control systems and unit control panels are located are equipped with an air conditioning system that includes a refrigeration chamber. The ventilation systems for the reactor section and the turbine hall are handled separately. Incoming air enters the turbine hall through ventilation chambers along the outside wall. Incoming air is heated in the cold season and cooled in the warm season.

All areas in the reactor section (except sealed MFC circuit areas) are served by separate intake ventilation systems in which heated or cooled outside air undergoes dust removal, after which it flows through the duct system through service corridors to the appropriate spaces through isolation valves. All reactor section exhaust systems are equipped with special filters that reduce radioactive gases and aerosols to safe concentrations.

The MFC circuit sealed areas, where air temperature should not exceed $70^{\circ} \mathrm{C}$, is cooled by a recirculating system made up of induced-flow coolers with water coolant. The MCP circuit sealed areas are evacuated under normal operating conditions by special exhaust systems that suck part of the air or steam-air mixture from them.

Fuel-handling system: When RBMK NPPs were designed, a great deal of attention was given to the fuel-handling cycle, which was tied in with the equipment repair. This system is rather complicated and is in the multistory building of the reactor section, where most of the equipment is in isolated areas.

NPP Phase I units are turned toward one another, facing the fuel handling units that supply fresh nuclear fuel to and remove spent nuclear fuel from the central reactor halls. These units are connected to two railroad approaches, one of which extends into the turbine hall and runs between the turbogear sets of the power units.

At an elevation of $12.5 \mathrm{~m}$, there are horizontal fuel handling connections along the entire outside perimeter of the reactor section. Equipment and materials from all floors can be brought to this elevation through transportation hatches and installation openings.

Nuclear fuel storage: Fuel assemblies with fresh nuclear fuel are stored in sealed containers at the fresh fuel store at the NPP site. The fresh fuel store is above the zero elevation in an unflooded zone at the LNPP. Fresh fuel assemblies represent no radiation hazard to NPP personnel or the environment.

Each unit has two cooling ponds in the central hall next to the nuclear reactor to store spent fuel assemblies. The cooling ponds have a pump-heat exchanger unit to remove residual heat from the spent nuclear fuel. Fuel assemblies are stored in sealed tanks under water. The capacity of 
both cooling ponds makes it possible to store the full fuel charge of a nuclear reactor all at once. This corresponds to the number of fuel assemblies removed from the reactor over four years of operation at full capacity.

Fuel assemblies are kept in the cooling pond for about two years. At the end of this period the fuel assemblies are transferred to the spent nuclear fuel storage on site. Before the fuel assemblies are transported, they are separated from their special mount by a cutting mechanism. After deactivation the mounts are reused, and the fuel assemblies are loaded into the cooled container of a special container car. In the receiving area of the spent nuclear fuel storage facility to which the container cars are sent, the fuel assemblies are placed in containers and put into long-term storage in water-filled compartments.

\subsection{RBMK-1000 Reactors' Major Parameters}

The major parameters of the RBMK-1000 reactors are presented in the following tables: Table 4.1 provides the major technical parameters for the Phase I main building units; Table 4.2 provides the makeup and weight of equipment for Unit \#1; and Table 4.3 provides the makeup, weight, and size of the Unit \#1 major systems in the reactor section.

\subsection{Specific Features of a Unit with an RBMK-1000 Reactor Influencing Its Decommissioning}

NPP units with RBMK reactors have several specific features that must be reflected and clarified in design materials or requirements of regulatory documentation when decommissioned. First is lack of RBMK spent fuel storage. Nuclear fuel is loaded in a RBMK reactor core, and spent nuclear fuel assemblies are immediately removed and placed in a short-term cooling pond near the reactor to reduce residual heat.

Because it is no longer cost-effective to reprocess RBMK spent nuclear fuel, and there are no centralized sites for storing or burying RBMK spent nuclear fuel assemblies, it was decided that spent nuclear fuel assemblies would be stored on site at NPPs.

As noted previously, specialized spent nuclear fuel storage facilities have been erected at NPPs with RBMK reactors. Spent nuclear fuel assemblies from units operating at a NPP are placed in the specialized storage facilities after cooling for a time in the ponds near the reactors.

Table 4.1. Major Technical Parameters for the Main Building of a Unit

\begin{tabular}{|l|l|}
\hline \multicolumn{1}{|c|}{ Parameter } & Amount \\
\hline Construction volume of the building, $\mathrm{m}^{3} / \mathrm{kW}$ & 1.14 \\
Volume of concrete and reinforced concrete, $\mathrm{m}^{3} / \mathrm{kW}$ & 0.25 \\
Weight of metal structures, $\mathrm{kg} / \mathrm{kW}$ & 38.0 \\
Weight of process equipment, $\mathrm{kg} / \mathrm{kW}$ & 36.6 \\
Stainless steel consumed, $\mathrm{kg} / \mathrm{kW}$ & 10.24 \\
\hline
\end{tabular}


Table 4.2. Equipment and Equipment Weights for an RBMK-1000 Unit

\begin{tabular}{|l|c|}
\hline \multicolumn{1}{|c|}{ Item } & $\begin{array}{c}\text { Weight, } \\
\text { tonnes }\end{array}$ \\
\hline Reactor with fuel handling machine and plate floors & 8,200 \\
Reactor section equipment & 4,940 \\
Turbine units & 11,320 \\
Turbine hall and deaerator gallery equipment & 3,420 \\
Main building low-pressure piping & 4,250 \\
Main building high-pressure piping & 3,460 \\
Special water treatment system equipment & 1,820 \\
Special ventilation system equipment & 1,630 \\
Equipment linking to outside structures & 5,575 \\
TOTAL & 44,615 \\
\hline
\end{tabular}

The situation regarding RBMK spent nuclear fuel storage at NPPs has become serious. RBMK spent nuclear fuel cooling ponds are overfilled, but the NPP design did not provide the capability for emergency core discharging. Therefore, filled cooling ponds may cause a premature shutdown of NPP units with RBMKs. Moreover, the design capacities for RBMK spent nuclear fuel storage facilities are more than two-thirds used.

Therefore, efforts are being made to increase the capacity of RBMK fuel cooling ponds and RBMK spent nuclear fuel storage facilities by increasing the density of fuel assemblies. However, the engineering approaches used did not take into account either the need to discharge and store RBMK spent nuclear fuel in the case of decommissioning or the need to continue the longterm operation of RBMK spent nuclear fuel storage facilities after decommissioning. This situation is aggravated by the fact that RBMK spent nuclear fuel storage facilities were built almost at the same time as the nuclear power plants, and the design service life of these fuel stores, like that of the nuclear power plant, is 30 years. Long-term storage of spent nuclear fuel is not addressed in current regulations but must be addressed by regulations prior to extending storage facility life.

Second, a typical feature of the decommissioning of RBMKs is the existence of a large amount (about 1,800 tonnes per unit) of radioactive graphite. This graphite contains a large quantity of environmentally hazardous radionuclides such as tritium and carbon-14. Therefore, the necessary engineering approaches for final handling alternatives for irradiated graphite from reactor stacks must be taken into account and regulated when NPP units with RBMK reactors are decommissioned:

- long-term storage of graphite in the reactor core (after spent nuclear fuel has been discharged from the core) 
Table 4.3. Weights and Sizes of Major Systems in the Reactor Section of Unit \#1

\begin{tabular}{|c|c|c|c|}
\hline & Item & Dimensions, $\mathrm{m}$ & $\begin{array}{l}\text { Weight, } \\
\text { tonnes }\end{array}$ \\
\hline 1. & MFC circuit & & $4,120.0$ \\
\hline 1.1. & Steam separator (4) & $\varnothing 2300, \mathrm{~L}=30 \mathrm{~m}$ & 976 \\
\hline 1.2 . & TsVN-7 MCP (8) & & $1,263.7$ \\
\hline 1.3. & Steam separator water coffer-dams & $\varnothing 325 \times 15$ & 5.15 \\
\hline 1.4. & Steam separator steam coffer-dams & $\begin{array}{l}\varnothing 325 \times 15 \\
\text { and } 325 \times 18\end{array}$ & 20.7 \\
\hline 1.5 . & Downcomers & $\varnothing 325 \times 12$ & 147.3 \\
\hline 1.6. & MCP suction headers & $\varnothing 1020 \times 60$ & 80.6 \\
\hline 1.7. & MCP suction piping & $\varnothing 828 \times 38$ & 189.2 \\
\hline 1.8. & Pressure piping & $\begin{array}{c}\varnothing 836 \times 42 \\
\text { and } 858 \times 53\end{array}$ & 232.3 \\
\hline 1.9. & MCP pressure headers & $\varnothing 900$ & 113.0 \\
\hline 1.10. & GDH (44) & $\varnothing 300$ & 125.0 \\
\hline 1.11 . & Bottom water lines & $\varnothing 57$ & 322.0 \\
\hline 1.12. & Fuel channels & & 333.0 \\
\hline 1.13. & Steam-water lines & $\varnothing 70$ & 312.0 \\
\hline 2. & Main steam lines & $\begin{array}{c}\varnothing 426 \times 22 \\
\text { and } 325 \times 18\end{array}$ & 165.4 \\
\hline 3. & $\begin{array}{l}\text { Feedwater piping (inside reactor } \\
\text { rooms, unit filters and fittings) }\end{array}$ & $\begin{array}{l}\varnothing 426 \times 22 \\
\text { and } 159 \times 9\end{array}$ & 111.2 \\
\hline 4. & $\begin{array}{l}\text { Purging and cooling system (inside } \\
\text { reactor rooms) }\end{array}$ & $\begin{array}{c}\varnothing 325 \times 15 \text {, } \\
219 \times 11 \text {, } \\
\text { and } 159 \times 8\end{array}$ & 43.4 \\
\hline 5. & $\begin{array}{l}\text { Feedwater cooling system piping } \\
\text { (inside reactor block) }\end{array}$ & $\begin{array}{l}\varnothing 325 \times 15 \\
\text { and } 76 \times 4.5\end{array}$ & 30.5 \\
\hline 6. & Drains and vent valves for both loops & & 5.3 \\
\hline 7. & $\begin{array}{l}\text { Emergency steam dump condensation } \\
\text { system }\end{array}$ & & 193.0 \\
\hline 8. & $\begin{array}{l}\text { MCP seal supply systems (inside } \\
\text { reactor plant) }\end{array}$ & & 16.2 \\
\hline 9. & MCP auxiliary systems & & 12.9 \\
\hline 10. & MCP oil system & & 18.5 \\
\hline 11. & $\begin{array}{l}\text { Cooling system for CPS, FIC, ERS } \\
\text { and RC channels }\end{array}$ & & 202.5 \\
\hline 12. & $\begin{array}{l}\text { Pump-heat exchanger unit for fuel } \\
\text { cooling pond }\end{array}$ & & 9.3 \\
\hline
\end{tabular}


- dismantling the core's graphite stack, processing and placing removed dismantled graphite blocks into a special long-term storage facility

- dismantling the core's graphite stack, reprocessing, recycling, or burying the irradiated graphite.

Each of these approaches requires appropriate steps to ensure radiation safety in handling irradiated graphite.

Consequently, the handling of large amounts of radioactive graphite, which is an environmental hazard because it contains a large amount of long-lasting, genetically significant radionuclides, requires additional consideration and analysis in design materials or in regulations on the decommissioning of units with RBMK reactors.

Third, units with RBMK reactors have a single circuit reactor cooling system and a rather branched and cumbersome circuit for circulating steam-water coolant. Single-circuit heat removal permits radiation contamination of the steam-water circulating circuit as a result of corrosion or as a result of the transfer and deposition of products of fission in it if the fuel rods in the nuclear reactor core leak.

Thus, compared with units with VVER reactors, whose primary circuit equipment may be subject to radiation contamination, all circulation circuit equipment, including turbine hall equipment, may be subject to radiation contamination. This requires an increase in the amount of work done to deactivate and remove equipment and steam-water lines from units with RBMK reactors, additional regulation of how this work is done, and development of appropriate safety regulations. Furthermore, additional requirements may be imposed for exit radiation inspection of dismantled systems and equipment or their parts.

\subsection{Operational Features of LNPP Unit \#1 to be Considered at Decommissioning}

On September 30, 1975, an accident occurred during operation of LNNP Unit \#1. This accident led to a break in one of the fuel channels in the reactor core, which allowed nuclear fuel fission products to enter the reactor's graphite stack.

The accident was caused by the under-design of LNPP systems that monitored the energy release field, which led to an uncontrollable distortion in the energy release field and a non-design-basis increase in power in the fuel assemblies in the scram channel. (Current automated reactor control devices, in principle, prevent local power increases.)

During this accident, as a result of a local and rather protracted (about 20-25-minute) increase in power in the group of fuel channels surrounding the channel where the break occurred, several fuel elements leaked and some of the scram channel fuel elements were destroyed. Because the scram channel fuel elements and assemblies deformed, the fuel elements touched the channel tube, which caused it to break. Some of the fuel elements in the scram channel fuel assembly were destroyed, and nuclear fuel entered the graphite stack. It was impossible to determine the amount of nuclear fuel that entered the graphite stack, but it was estimated to be small. 
After the accident, while the damage was being repaired in the shutdown reactor, the fuel assembly was removed, the scram tube was restored, and the fuel assemblies in adjacent (surrounding) fuel channels were replaced.

When LNPP Unit \#1 is decommissioned, the following procedures should be carried out to ensure safety during dismantling and removal of the graphite stack blocks:

- The graphite stack should be inspected to determine radioactivity and the amount and local distribution of fission products.

- If the graphite stack is preserved and put into long-term storage on site, the required inspection and cleaning of gas blowdowns from the graphite must be performed (it may be necessary to continue operation of the gas circuit in this case).

- The gas circuit should be inspected to determine the need to decontaminate when Unit \#1 is decommissioned.

Furthermore, as long as Unit \#1 is operating, and up until final shutdown, the necessary studies should be performed of the nuclide composition of the gas blowdowns from the reactor space. 


\subsection{Actions Necessary to Organize and Carry Out NPP Unit Decommissioning}

\subsection{The Procedure For Licensing an NPP Unit Decommissioning}

On July 14,1997 , Russia approved and implemented a regulation on licensing activities related to the use of nuclear energy, including decommissioning NPP units. The regulation establishes general requirements for the procedures for submitting and reviewing applications and for preparing and issuing licenses for various kinds of activities related to the use of nuclear energy.

Under the federal law, "On the Use of Nuclear Energy," all activities related to the use of nuclear energy, including nuclear facility decommissioning (the activities are determined by the government of the Russian Federation) work must be licensed. A license is an official document permitting a specific activity for an established period provided certain conditions are met. The regulation states that the procedure for licensing the decommissioning of an NPP unit includes

- preliminary check of the operating organization's application to decommission the unit

- review by GAN of the set of documents submitted in support of the license application

- GAN's decision to issue or refuse to issue a license

- issuance of a license to the operating organization for decommissioning a unit and defining the conditions under which the work is permitted

- inspections, application of necessary penalties, and revision of the terms of the license if necessary

- issuance of licenses to legal entities performing work or rendering services to operating organizations.

In reviewing applications and making decisions to issue licenses for unit decommissioning, GAN coordinates its actions with federal authorities and authorities of Russian Federation constituents.

To obtain a license to decommission a NPP unit, an operating organization (applicant) submits an application to GAN. The application includes the decision of the Russian Federation Government to decommission the unit; a statement of the operating organization's legal form of organization with its legal address, the kind of activity and site where it will be carried out; the term of the requested license; a document confirming that the federal and local governments consent to this activity; the decision of the state environmental review board; and the set of documents supporting the application.

An application to GAN is accepted for review or rejected on the basis of the preliminary check, during which the adequacy of the documents submitted and compliance with the established rules for application are verified. The following factors are analyzed when the documents supporting the application are reviewed:

- the compliance of the proposed decommissioning practices with current safety regulations and codes 
- the adequacy of technical and organizational measures to ensure radiation safety during decommissioning

- the existence of a decommissioning quality assurance system

- the organization of radioactive substance control and accounting, including radwastes and reusable (restricted or unrestricted) materials

- procedures for safe storage and processing of radwastes

- organization of physical protection of radioactive substances

- required certification of operating organization (applicant) personnel

- the existence of the necessary engineering, technical, and informational support (database)

- readiness to carry out emergency management procedures and plans to eliminate the consequences of accidents during decommissioning

- the existence and adequacy of financial, material, and technical resources to decommission the unit, including funds to cover possible damage in case of a radiation accident.

When reviewing an application, GAN may inspect the NPP units to be decommissioned, examine materials supporting safety, and interact with the applicant to resolve comments and deficiencies identified when the supporting documentation is reviewed.

GAN makes the decision to issue a license based on inspections and the results of an expert review board's decision. The expert review board's decision, based on materials proving the safety of the unit decommissioning, must contain a description of the kind of activity and where it will be carried out; an analysis of the completeness and adequacy of documentation submitted for the review; and a description of the goals of the review and requirements and criteria used in analyzing the safety of the unit decommissioning. In addition, the review board's decisions must include analysis of the approaches selected for decommissioning the unit; sources of ionizing radiation and the reliability of the estimates of their effect on personnel, the public, and the environment; procedures, systems, and equipment required for decommissioning the unit; equipment for handling and monitoring radwastes, including reusable materials; and the adequacy of radiation monitoring devices.

On the basis of the board's decision, GAN may issue the operating organization (applicant) a license with the terms defining requirements for radiation safety when the unit is decommissioned. Russia has no process for obtaining a temporary permit for decommissioning.

\subsection{Features of the Procedure for Licensing NPP Unit Decommissioning}

Final shutdown requires no special permit from GAN if a decision is made to decommission a unit because its design service life has expired. However, if a decision on final shutdown and decommissioning is made, the operating organization must ask GAN to make the necessary corrections to the annual operating license and to authorize further work to decommission the unit. Otherwise, the unit will be considered to be operational and will be subject to mandatory operating requirements, including requirements for operational documentation and personnel. 
The legal and regulatory basis for decommissioning NPP units in Russia does not impose any restrictions on the operating organization in terms of 1) the choice of a decommissioning strategy or 2) the choice of individual stages in decommissioning. Nevertheless, when selecting a decommissioning strategy, the operating organization should take into account the following requirements of existing regulations:

- Problems with decommissioning NPP units must be kept in mind when units are operated, serviced, and repaired.

- At least 5 years before the expiration of the unit's design service life, the operating organization should ensure the development of a decommissioning program, including justification of the choice of its unit decommissioning approach.

- Unit decommissioning must be preceded by a comprehensive (radiation and engineering) inspection of the unit.

- On the basis of the results of the comprehensive inspection, the operating organization should ensure development of a unit decommissioning project, prepare a report substantiating the safety of the decommissioning work, and obtain a GAN license to decommission the unit.

- A unit that has been shut down for decommissioning is considered to be in operation until the spent nuclear fuel is removed.

Until a decommissioning license is obtained, any partial cutback in maintenance, shutdown of individual systems and components, or reduction in the number of operating personnel requires the consent of GAN with corresponding changes in the terms of the operating license.

\subsection{Documents Required for Application for an NPP Unit Decommissioning License}

To obtain a license to decommission an NPP unit, an operating organization must submit an application to GAN together with the following documents supporting the application:

1. a decommissioning program

2. a report on the results of the comprehensive (radiation and engineering) inspection of the unit

3. a report substantiating safety during unit decommissioning

4. a program and schedule for work to dismantle equipment, systems and civil structures

5. a decommissioning quality assurance program

6. instructions on emergency management

7. a plan of personnel protection procedures in case of an accident

8. operating manuals for equipment and systems that include the dismantling program for them

9. decommissioning planning materials according to the list approved by GAN

10. a schedule for removing radwastes from the plant site for burial

11. a plan for deactivation and restoration of the plant site. 
The report on safety validation when the unit is decommissioned must specifically include requirements for the condition of unit systems, equipment, instrumentation, and automation necessary for decommissioning; an estimate of the amount of radwaste and reusable materials formed when equipment and civil structures are dismantled; and an estimate of the annual effective collective dose for personnel and the population of the surrounding area when the unit is decommissioned.

As noted, Russia has not yet established compulsory requirements for the content of documents supporting an application for a license to decommission an NPP unit. It is assumed that these requirements will be developed and implemented in the future.

\subsection{Recommendations for LNPP Administration Actions During Unit \#1 Decommissioning}

When any industrial facility approaches the end of its design service life, the question arises whether it can or should continue to operate. Obviously the same problem will arise for any nuclear facility or NPP unit whose operation satisfies current safety requirements. Current practice shows that solving this problem for an NPP unit requires an analysis on operational alternatives: extend its service life or decommission it.

The alternative analysis is to analyze the technical feasibility and cost-effectiveness of extending the unit's service life. This analysis should be performed with regard to the current and future electricity needs of the region where the NPP is located. The analysis should be based on a customized comprehensive engineering inspection of the unit, the main goal of which is to determine the actual engineering and technical condition of the unit's reactor, equipment, systems, and civil structures. A comprehensive inspection to select an operational alternative may be performed in several stages, but the inspection must provide the information required to select and justify the chosen operational alternative.

It is now generally recognized that extending a unit's service life may have tremendous energy and economic potential. Nevertheless, the attempt to extend the service life of a first-generation NPP unit, particularly one with an RBMK-1000, must be based on sound arguments and will require serious, comprehensive justification. For this purpose an extensive set of theoretical and experimental studies are necessary to prove that the serviceability and reliability of reactor metal structures and graphite stack, fuel channels and their upper paths, the condition of the base metal and welds in equipment, steam-turbine equipment, civil structures, cable runs and other elements can be maintained and that their condition complies with modern safety requirements. This proof must be subjected to a comprehensive review.

Completing the necessary research is a complicated and costly task that requires a lot of time. According to estimates, it may take 7-8 years to analyze operational alternatives for a unit with a first generation RBMK-1000 reactor, including the comprehensive unit inspection program.

Regulatory requirements for the operational alternatives analysis and the comprehensive inspection program required have not been defined in Russia. This complicates the licensing of continued operation beyond the design service life of a first-generation NPP unit and, consequently, 
requires additional time. Analysis of the required procedures and actions to justify the possibility of extending the service life of an NPP unit is an independent task and requires separate studies.

This study has been devoted to analyzing only one operational alternative for decommissioning Unit \#1. Therefore, the starting point for this work has been the decision on final shutdown and decommissioning of Unit \#1, which is based on the results of the operational alternative analyses. In any case, when the design or extended service life of NPP units has expired; it is time to decommission them. Therefore it is worthwhile to attempt to generalize and systematize procedures and actions required to prepare a unit for decommissioning.

Domestic and foreign experience planning, preparing, and carrying out work to decommission nuclear facilities shows that right up until final shutdown of the unit a whole series of organization and technical procedures must be performed to prepare the unit for decommissioning and to ensure greater efficiency during work after final shutdown. Analysis of this experience shows that these procedures are usually carried out within the following two hypothetical stages:

- Preliminary stage - up to final unit shutdown, before which all required pre-shutdown procedures should be completed.

- Unit preparation stage for decommissioning - after final unit shutdown but before removal of the nuclear fuel from the reactor and receipt of the decommissioning license.

The following are recommendations on organizational and technical procedures and actions for the Administration of LNPP. Legal and regulatory requirements should be met within the two stages mentioned above in order to organize and carry out Unit \#1 decommissioning.

\subsubsection{Preliminary Stage}

After the decision to decommission Unit \#1 is made, the LNPP Administration, as the operating organization, should develop a concept for decommissioning Phase I units or all nuclear power plant units. The concept should take into account the provisions of the concept for decommissioning Russian NPP units, but it must also consider and analyze specific ways and means for implementing the provisions of the Russian concept in terms of the site and capabilities of the LNPP. The concept should define the end state of the unit and its site, preferred ways to achieve it, and requirements for the development of processes and equipment.

Then analysis of decommissioning alternatives for Unit \#1 should be completed with regard to the provisions of the concept for decommissioning Leningrad Unit \#1. The analysis may be the continuation of the operational alternatives analysis or may be performed independently. The goal is to consider possible ways to decommission the unit, analyze and compare the technical feasibility and cost-effectiveness of the alternatives, and select a preferred alternative.

The basic alternatives to decommissioning an NPP unit are unit burial (ENTOMB) or liquidation (with deferred (SAFESTOR) or immediate (DECON) dismantling of reactor structures). These alternatives differ in time frames, kinds of activities, technologies, and equipment, as well as the end state of the unit.

The decommissioning alternatives analysis should also consider the results of the comprehensive engineering and radiation inspection of the unit, but in this case the actual radiation condition of 
the reactor, equipment, systems, and civil structures of the unit and its site should be considered. To carry out a comprehensive engineering and radiation inspection of Unit \#1, the LNPP Administration should develop the corresponding program for comprehensive engineering and radiation inspection of the unit.

A comprehensive inspection for analyzing decommissioning approaches may be performed in several stages, but the scope and content of the inspection must provide the information necessary to justify the choice of a unit decommissioning approach and to develop the appropriate plan. Later, the results of the decommissioning alternatives analysis and comprehensive inspection should be used to optimize the selected alternative for decommissioning Unit \#1. The goal of this optimization is to analyze temporal, technical, economic, social and other factors and determine the optimum, most effective way to carry out the selected decommissioning approach while ensuring safety.

After optimizing the chosen decommissioning approach, the LNPP Administration should develop a Unit \#1 decommissioning program that should define all organizational and technical procedures required to achieve a specific end state and the method for carrying out the procedures and the responsibilities.

Russian regulations define the need to develop and submit to GAN a unit decommissioning program five years before the end of Unit \#l's design service life. The regulations provide no justification for this deadline but similar deadlines have been established by national regulatory bodies abroad (e.g., the U.S.).

Russia has not developed regulatory requirements for the alternatives or optimization analyses, or the program for comprehensive engineering and radiation inspection. However, programs have been developed for preparing and decommissioning prototype Units \#1 and \#2 at the NovoVoronezh and the Beloyarsk NPPs and were approved by Rosenergoatom in 1995 and 1996. These programs were developed only for the initial stages of the decommissioning of these units, i.e., they do not encompass the entire scope of required work.

Before final shutdown of the unit and by the deadlines set by the LNPP Unit \#1 decommissioning program, the LNPP Administration should prepare a specification for development of a Unit \#I decommissioning project.

With the current economic situation in Russia, planning and preparation for decommissioning is deferred until after shutdown. Additional unavailable funds are required to allow for earlier planning and preparation. Before final Unit \#1 shutdown the LNPP Administration should also

- create a database containing information necessary to prepare for and carry out unit decommissioning, including information on the history of the unit's operation

- develop a unit servicing procedure that would be implemented after spent nuclear fuel is removed from the unit.

This last item must be done to "soften" regulatory requirements on unit equipment and system operation and reduce the number of service personnel at the unit after the spent nuclear fuel is removed and until the decommissioning license is obtained. Furthermore, before final shutdown, 
work must be done to prepare the cooling ponds and spent nuclear fuel storage facilities for the complete removal of the spent nuclear fuel from the Unit \#1 reactor. Expert evaluations show that planning must begin about 10 years before the scheduled unit shutdown to satisfy all regulation requirements and prepare for and carry out all procedures. Table 5.1 summarizes the preliminary-phase planning activities, which the LNPP Administration should complete before final shutdown of Unit \#1 and estimates of the time needed to complete them.

\subsubsection{Unit Preparation Stage for Decommissioning Activities}

After final shutdown, steps must be taken to bring Unit \#1 to a nuclear-safe condition: remove SNF from the reactor core and cooling ponds and remove fuel and other nuclear materials from the unit. After the removing the SNF, the LNPP Administration should implement a procedure for servicing the unit. This procedure will be in effect until the decommissioning license is received from GAN. If the decommissioning license is received by the time the nuclear fuel is removed, it will no longer be necessary to implement this "temporary" procedure.

The LNPP Administration's main task in preparing the unit for decommissioning is to ensure the proper development, approval, and authorization of a Unit \#1 decommissioning project. Developing a decommissioning project will require a detailed, comprehensive engineering and radiation inspection of the unit and its site. Furthermore, certain basic research and experimental design work may be necessary to develop the decommissioning project.

Regulatory requirements for the unit decommissioning project still have not been developed. However, on the basis of experience developing planning materials, including those to erect nuclear facilities, and with regard to regulations being developed, one might assume that the decommissioning project should include:

- a description of the practices used to decontaminate reactor equipment, systems and areas

- proof of the effectiveness of existing protective barriers and/or a description of the construction of additional protective barriers if those existing at the unit do not provide the required safety during decommissioning

- a description of the sequence to be followed in opening the protective barriers to limit the escape of radioactive substances into the atmosphere

- a description of the sequence to be followed and the practices to be used to dismantle reactor equipment and systems

- a description of the methods and practices for processing and conditioning radwastes formed during decommissioning

- a description of how control of the removal of radwastes and radioactive materials will be organized, and the methods for separating them, including registration and accounting during transportation and storage

- a description and justification of the adequacy of radiation control equipment used in decommissioning. 
Table 5.1. List of Required Planning Activities in the Preliminary Stage

\begin{tabular}{|c|c|c|}
\hline \multirow[b]{2}{*}{ Stage and list of required procedures } & \multicolumn{2}{|c|}{ Work schedule, $\mathrm{yr}^{\mathrm{a}}$} \\
\hline & Start & Finish \\
\hline Preliminary stage (pre-shutdown procedures) & -10 & 0 \\
\hline $\begin{array}{l}\text { 1. Develop a program for comprehensive radiation and engineering } \\
\text { inspection of unit }\end{array}$ & -10 & -9 \\
\hline 2. Complete a comprehensive inspection for analyses & -9 & -6.5 \\
\hline $\begin{array}{l}\text { 3. Conduct feasibility studies to select an operational alternative and } \\
\text { the approach to decommissioning the Phase I units }\end{array}$ & -6.5 & -5.5 \\
\hline 4. Develop an overall concept for decommissioning Phase I units & -5.5 & -4.5 \\
\hline $\begin{array}{l}\text { 5. Conduct an optimizational analysis on the approach chosen for } \\
\text { decommissioning the unit }\end{array}$ & -5.5 & -4.5 \\
\hline 6. Develop organizational and technical documentation: & -5.5 & 0 \\
\hline $\begin{array}{l}\text { 6.1. Develop a procedure for servicing the unit after spent nuclear } \\
\text { fuel is removed from it }\end{array}$ & & \\
\hline $\begin{array}{l}\text { 6.2. Develop unit decommissioning plan, including the plan for } \\
\text { required investments }\end{array}$ & & \\
\hline $\begin{array}{l}\text { 6.3. Develop specification for development of a unit } \\
\text { decommissioning project }\end{array}$ & & \\
\hline 6.4. Create a data base of information for unit decommissioning & & \\
\hline 7. Start preparing cooling pond \& spent nuclear fuel storage facilities & -1 & 0 \\
\hline
\end{tabular}

A decommissioning safety validation report must be developed and submitted as part of the project materials. This report should include a list and analysis of possible hazardous/radiation accidents during decommissioning work; a list of procedures required to prevent them and diminish their consequences; proof of radiation safety assurance for personnel and the population; an evaluation of the environmental impact of the decommissioning, including a description of planned environmental protection measures and proof of their adequacy.

The evaluation of the environmental impact of the decommissioning should contain the following items:

- calculations on the escape of radionuclides and harmful chemicals and their emissions and discharges into the environment 
- a forecast of the environmental impact of the change in the unit's status

- a list of organizational and technical procedures to diminish the environmental impact

- a description of the ways and means to observe the site and environmental parameters and prove their adequacy.

The required project materials, including the decommissioning safety validation report, along with other documents supporting the license application (Section 5.3), must be submitted for proper review and approval by GAN. As part of the review process, the decommissioning project undergoes environmental (state and public) review. If the decommissioning project is approved and authorized after the review, GAN will issue a decommissioning license for LNPP Unit \#1. Decommissioning must then be done in strict compliance with the authorized project.

The LNPP Administration must develop, obtain approval for, and, after receiving the license, implement the procedure for Unit \#1 decommissioning work. When the project is being developed, the design organization may develop initial requirements for technology and special custom equipment required during decommissioning. After the project is approved, the LNPP Administration places the order for developing and producing the technologies and equipment at specialized enterprises. Table 5.2 shows activities to be performed by the LNPP Administration during preparation stage for Unit \#1 decommissioning and estimates the time needed to complete them. 
Table 5.2. List of Activities During the Preparation Stage for Unit Decommissioning

\begin{tabular}{|c|c|c|}
\hline \multirow{2}{*}{ Stage and list of required procedures } & \multicolumn{2}{|c|}{ Work schedule, yr(a) } \\
\hline & Start & Complete \\
\hline Preparation stage for unit decommissioning & 0 & 5 \\
\hline 1. Standard unit shutdown and cooldown & 0 & 1 \\
\hline 2. Handling of spent nuclear fuel & 2 & 5 \\
\hline 2.1. Nuclear fuel storage in the reactor core & & \\
\hline 2.2. Standard removal of nuclear fuel from the reactor to the cooling ponds & & \\
\hline 2.3. Removal of nuclear fuel from unit to spent nuclear fuel store & & \\
\hline 3. Removal of other nuclear materials from unit equipment and areas (if necessary) & 0 & 5 \\
\hline 4. Drainage of multiple forced circulation circuit and other process circuits & 4 & 5 \\
\hline 5. Decontamination work: & 4 & 5 \\
\hline $\begin{array}{l}\text { 5.1. Inspection and required reconstruction of equipment and systems during } \\
\text { decontamination }\end{array}$ & & \\
\hline 5.2. Standard decontamination of MFC circuit & & \\
\hline 5.3. Decontaminate process circuits and nuclear fuel cooling ponds & & \\
\hline $\begin{array}{l}\text { 6. Comprehensive inspection of unit and experimental design work to the extent } \\
\text { necessary to develop a unit decommissioning project }\end{array}$ & 1 & 3 \\
\hline $\begin{array}{l}\text { 7. Development and approval of required organizational, technical, and design } \\
\text { documentation: }\end{array}$ & 1 & 5 \\
\hline 7.1. Approval of a procedure for servicing the unit after removal of nuclear fuel & & \\
\hline 7.2. Development and approval of the unit decommissioning project & & \\
\hline 7.3. Receipt of decommissioning license & & \\
\hline 7.4. Development of specification for required dismantling practices and equipment & & \\
\hline 7.5. Development of other documentation & & \\
\hline 8. Handling of operational radwastes & 2 & 5 \\
\hline 8.1. Erection of units to process radwastes (if necessary) & & \\
\hline 8.2. Start of operational radwaste processing & & \\
\hline 9. Operation and maintenance & 0 & 5 \\
\hline 9.1. Operation of systems and equipment in final unit shutdown mode & & \\
\hline 9.2. Operation of the spent nuclear fuel store & & \\
\hline 9.3. Operation of radwaste stores & & \\
\hline 10. Preparations for the next phase & 4.5 & 5 \\
\hline
\end{tabular}




\subsection{Estimation of Radioactivity Accumulated at the LNPP Unit \#1 and NPP Site}

\subsection{Classification of Radioactivity Sources at Leningrad Unit \#1}

Work to decommission Unit \#1 at LNPP should be planned considering the following three sources of radioactivity: radioactive wastes accumulated in nuclear reactor structures and in the multiple forced circulation (MFC) circuit; spent nuclear fuel (SNF) stored in cooling ponds near the reactors and in SNF storage facilities at the NPP site; and liquid (LRW) and solid (SRW) radwastes in NPP storage facilities. Russian regulations divide solid radwastes into three categories depending on their radioactivity: low-activity, moderate-activity, and high-activity wastes (Table 9.5).

\subsection{Estimation of the Radioactivity of Reactor Structures}

After spent fuel assemblies have been removed from the core, the radioactivity of the reactor will be defined by the radioactivity accumulated in its metal structures and graphite stack. The radioactivity of the graphite stack will, in turn, depend on the radioactivity of the graphite and the fuel channel tubes. Section 4.0 provides a description of these structural elements of the RBMK1000 reactor. Table 6.1 describes the radionuclides which are sources of radioactivity in the structural elements of the RBMK-1000 reactor.

\subsubsection{Methodology}

The following methodology was used to estimate the activation of reactor metal structures. The neutron flow is assumed to travel through side (radially), bottom, and top end shield reflectors.

When a neutron flow passes through a layer of water or serpentine, it is reduced to a negligible level. For this reason the radioactivity of the metal structures at the end of the reactor's service life (30 years) was estimated only for the protective elements most highly irradiated during reactor operation, which included 1) side shell, 2) inner wall of the water shield tank, 3) top protective plates, 4) the bottom protective plate of the top metal structure, 5) bottom protective plates, and 6) the top protective plate of the bottom metal structure. It was assumed that all steel structures are made of steel 10XN1M and have the same composition, which is shown in Table 6.2.

Neutron flux on the boundary of the reflectors was estimated using the MCNP computer code Monte Carlo method by approximating steady state overloads for calculating three-dimensional poly-cells of $12 \times 12$ channels and a full-scale reactor. It was assumed that the reactor operates at rated output for 30 years and has a load corresponding to the modern load of RBMK-1000 reactors, i.e., fuel with a $2.4 \%$ enrichment in the core with 81 additional absorbers (AA) and an operating supply of 45 manual control rods (MC rods). The effect of reactor operation at the start of its service live with fuel at $1.8 \%$ and $2.0 \%$ in the core, with a smaller operating supply, and with a different number of additional absorbers was not considered. 
Table 6.1. Sources of Radioactivity in RBMK-1000 Reactor Structure Elements

\begin{tabular}{|c|c|c|c|c|}
\hline Element & $\begin{array}{l}\text { Radio- } \\
\text { nuclide }\end{array}$ & $\begin{array}{c}\text { Half life, } \\
\mathrm{yr}\end{array}$ & $\begin{array}{l}\text { Isotopes it is } \\
\text { formed from }\end{array}$ & Comments \\
\hline Hydrogen & ${ }^{3} \mathrm{H}$ & 12.33 & $\begin{array}{l}{ }^{1} \mathrm{H},{ }^{2} \mathrm{H} \\
{ }^{6} \mathrm{Li}\end{array}$ & $\begin{array}{l}\text { Impurity in graphite } 1.1 \times 10^{-3} \mathrm{wt} \% \text { (natural } \\
\text { mixture of isotopes). } \\
\text { Impurity in graphite } 1.0 \times 10^{-3} \mathrm{wt} \% \text { (natural } \\
\text { mixture of isotopes of lithium with an }{ }^{6} \mathrm{Li} \\
\text { content in the mixture of } 7.5 \mathrm{wt} \% \text { ) }\end{array}$ \\
\hline Carbon & ${ }^{14} \mathrm{C}$ & 5730 & ${ }^{13} \mathrm{C}$ & $\begin{array}{l}\text { Natural carbon mixture. } \\
\text { Impurity in graphite } 0.4 \times 10^{-3} \mathrm{wt} \% \text { (natural } \\
\text { nitrogen mixture with } \mathrm{a}{ }^{14} \mathrm{~N} \text { content of } \\
99.63 \mathrm{wt} \% \text { ). }\end{array}$ \\
\hline Cobalt & ${ }^{60} \mathrm{Co}$ & 5.27 & ${ }^{59} \mathrm{Co}$ & $\begin{array}{l}\text { 1. Impurity in graphite } 1.2 \times 10^{-6} \mathrm{wt} \% \text { (natural } \\
\text { mixture of cobalt isotopes). } \\
\text { 2. Impurity in steel grade } 10 \mathrm{KhN} 1 \mathrm{I} \\
\text { (Table 6.2). }\end{array}$ \\
\hline Nickel & ${ }^{59} \mathrm{Ni}$ & $\begin{array}{l}75000 \\
100.1\end{array}$ & $\begin{array}{l}{ }^{38} \mathrm{Ni} \\
{ }^{58,60,61,66} \mathrm{Ni}\end{array}$ & $\begin{array}{l}\text { 1. Impurity in graphite } 0.03 \times 10^{-3} \mathrm{wt} \% \\
\text { (natural mixture of nickel isotopes). } \\
\text { 2. Impurity in steel grade 10KhN1İ } \\
\text { (Table 6.2). } \\
\text { 3. Impurity in alloy } 125 \text { (Table 6.6). }\end{array}$ \\
\hline Iron & $\begin{array}{l}{ }^{55} \mathrm{Fe} \\
{ }^{59} \mathrm{Fe}\end{array}$ & $\begin{array}{l}2.73 \\
44.5 \\
\text { days }\end{array}$ & $\begin{array}{l}{ }^{54} \mathrm{Fe} \\
{ }^{54,56,57,58} \mathrm{Fe}\end{array}$ & $\begin{array}{l}\text { 1. Impurity in graphite } 1.0 \times 10^{-3} \mathrm{wt} \% \text { (natural } \\
\text { mixture of iron isotopes). } \\
\text { 2. Impurity in alloy } 125 \text { (Table } 6.6 \text { ). } \\
\text { 3. Impurity in steel grade } 10 \mathrm{KhN} 1 \mathrm{I} \\
\text { (Table 6.2). }\end{array}$ \\
\hline Niobium & ${ }^{94} \mathrm{Nb}$ & $2.03 \times 10^{4}$ & ${ }^{93} \mathrm{Nb}$ & $\begin{array}{l}\text { 1. Impurity in steel grade } 10 \mathrm{KhN1I} \\
\text { (Table 6.2), (natural mixture of niobium } \\
\text { isotopes). } \\
\text { 2. Impurity in alloy } 125 \text { (Table } 6.6 \text { ). }\end{array}$ \\
\hline Zirconium & $\begin{array}{ll}{ }^{93} \mathrm{Zr} \\
{ }^{95} \mathrm{Zr}\end{array}$ & $\begin{array}{l}1.53 \times 10^{6} \\
64 \text { days }\end{array}$ & ${ }^{92} \mathrm{Zr}$ & $\begin{array}{l}\text { 1. Impurity in alloy } 125 \text { (Table } 6.6) \text {. } \\
\text { 2. Natural mixture of zirconium isotopes. }\end{array}$ \\
\hline
\end{tabular}

Table 6.2. Composition of Steel 10XN1M

\begin{tabular}{|l|c|c|c|c|c|c|c|c|c|c|c|c|}
\hline Element & $\mathrm{C}$ & $\mathrm{Ni}$ & $\mathrm{Mo}$ & $\mathrm{Cr}$ & $\mathrm{Mn}$ & $\mathrm{Si}$ & $\mathrm{P}$ & $\mathrm{S}$ & $\mathrm{Cu}$ & $\mathrm{Co}$ & $\mathrm{Nb}$ & $\mathrm{Fe}$ \\
\hline $\mathrm{wt} \%$ & 0.1 & 1.0 & 1.0 & 0.6 & 0.6 & 0.3 & 0.035 & 0.035 & 0.03 & 0.04 & 0.002 & remainder \\
\hline
\end{tabular}


The following parameters were used in the MCNP computer code to estimate levels of radioactivity:

Radially: graphite reflector columns ( $75 \mathrm{~cm}$ thick); cooling channels $(25 \mathrm{~cm})$; the space filled with nitrogen-helium mixture between the graphite stack and the shell $(26 \mathrm{~cm})$; the steel reactor shell $(1.6 \mathrm{~cm})$; the space between the shell and the water shield tank $(102.4 \mathrm{~cm})$; the steel inside wall of the water shield tank $(3 \mathrm{~cm})$; the water in the tank $(114 \mathrm{~cm})$; and the outside steel wall of the water shield tank $(3 \mathrm{~cm})$.

Toward the top end reflector: graphite reflector, including channel tube (50 cm thick); steel protective blocks $(25 \mathrm{~cm})$; the space between the protective blocks and the top metal structure $(150 \mathrm{~cm})$; the steel bottom metal structure plate $(4 \mathrm{~cm})$; serpentine fill with a density of $1.7 \mathrm{~g} / \mathrm{cm}^{3}$ $(280 \mathrm{~cm})$; the steel top metal structure plate $(4 \mathrm{~cm})$; the space between the top metal works and the slab floor $\left(1000 \mathrm{~cm}\right.$ ); the concrete (grade ZhBSTsK) slab floor with a density of $4 \mathrm{~g} / \mathrm{cm}^{3}$ $(82 \mathrm{~cm})$.

Toward the bottom end reflector: graphite reflector, including channel tube, $50 \mathrm{~cm}$ thick; steel support blocks $(20 \mathrm{~cm})$; the top plate of the steel bottom metal structure $(4 \mathrm{~cm})$; serpentine fill with a density of $1.7 \mathrm{~g} / \mathrm{cm}^{3}(190 \mathrm{~cm})$; the bottom plate of the steel metal structure $(4 \mathrm{~cm})$.

Given an average thermal flux $\mathrm{f}_{\mathrm{b}}$ for working channels of $7 \times 10^{13} \mathrm{n} / \mathrm{cm}^{2} \times \mathrm{sec}$, the following estimated averages of flux on the outer boundaries of the reflectors were obtained:

- top reflector $-3.3 \times 10^{12} \mathrm{n} / \mathrm{cm}^{2} \times \mathrm{sec}$

- bottom reflector $-8.8 \times 10^{12} \mathrm{n} / \mathrm{cm}^{2} \times \mathrm{sec}$

- side reflector $-6.6 \times 10^{11} \mathrm{n} / \mathrm{cm}^{2} \times \mathrm{sec}$.

These estimates are averages for the entire surface of the graphite stack in the appropriate directions and account for the spatial irregularity of the distribution of the neutron flux in the reactor core. These flux estimates on the boundaries of reflectors were used as raw data to calculate the attenuation of the neutron flux when it passes through the material of the protective structures.

\subsubsection{Radioactivity of Reactor Metal Structures}

The calculated total specific radioactivity of RBMK-1000 reactor metal structures, assuming a thermal neutron flux, averaged across the thickness of the material and constituting the specific radioactivity for basic radionuclides (cobalt ${ }^{60} \mathrm{Co}$, nickel- ${ }^{59} \mathrm{Ni}$ and ${ }^{63} \mathrm{Ni}$, iron- ${ }^{55} \mathrm{Fe}$ and ${ }^{59} \mathrm{Fe}$ ) appears in Tables 6.3, 6.4, and 6.5. The results show that the greatest influences on the total specific radioactivity are, for long-term storage up to 10 years, ${ }^{55} \mathrm{Fe}$; for long-term storage of 20 years, ${ }^{60} \mathrm{Co}$; for a longer long-term storage period, ${ }^{63} \mathrm{Ni}$.

The plate in the bottom metal structure turned toward the core is exposed to more radioactivity than the corresponding plate in the top metal structure. This is because the leakage of neutrons into the bottom reflector is greater and the bottom protective blocks are thinner.

Analysis of the results shows that, according to the solid radwaste classification (see Table 9.5), protective blocks, the reactor shell, and the inner wall of the water biological shield tank belong to the high-radioactivity category for long-term storage up to 30 years; i.e., the solid radwaste is still highly radioactive after a storage period of up to 30 years. 
Table 6.3a. Radioactivity of the Reactor Shell as a Function of Long-Term Storage

\begin{tabular}{|c|c|c|c|c|}
\hline \multirow{2}{*}{$\begin{array}{c}\text { Storage } \\
\text { period }\end{array}$} & \multicolumn{3}{|c|}{ Radionuclide radioactivity, $\mathrm{Bq} / \mathrm{g}$} & $\begin{array}{c}\text { Total } \\
\text { activity, Bq/g }\end{array}$ \\
\cline { 2 - 4 } & $\mathrm{Co}$ & $\mathrm{Ni}$ & $\mathrm{Fe}$ & $7.284+08$ \\
$1 \mathrm{sec}$ & $7.057+07^{(\mathrm{a})}$ & $4.833+06$ & $6.530+08$ & $5.688+08$ \\
$1 \mathrm{yr}$ & $6.188+07$ & $4.800+06$ & $5.021+08$ & $4.474+08$ \\
$\mathrm{yr}$ & $5.426+07$ & $4.768+06$ & $3.884+08$ & $3.528+08$ \\
$3 \mathrm{yr}$ & $4.758+07$ & $4.735+06$ & $3.005+08$ & $2.210+08$ \\
$5 \mathrm{yr}$ & $3.658+07$ & $4.670+06$ & $1.798+08$ & $7.328+07$ \\
$10 \mathrm{yr}$ & $1.896+07$ & $4.513+06$ & $4.981+07$ & $1.313+07$ \\
$20 \mathrm{yr}$ & $5.096+06$ & $4.214+06$ & $3.823+06$ & $5.597+06$ \\
$30 \mathrm{yr}$ & $1.369+06$ & $3.935+06$ & $2.934+05$ & $3.532+06$ \\
$50 \mathrm{yr}$ & $9.886+04$ & $3.432+06$ & $1.728+03$ & \\
$100 \mathrm{yr}$ & $1.385+02$ & $2.441+06$ & $4.602-03$ & $2.441+06$ \\
\hline (a) $7.057 \times 10^{+07}$ & & & \\
\hline
\end{tabular}

Table 6.3b. Radioactivity of the Inner Wall of Water Biological Shield Tank as a Function of Long-Term Storage

\begin{tabular}{|c|c|c|c|c|}
\hline \multirow{2}{*}{$\begin{array}{c}\text { Storage } \\
\text { period }\end{array}$} & \multicolumn{3}{|c|}{ Radionuclide radioactivity, Bq/g } & Total \\
\cline { 2 - 4 } & $\mathrm{Co}$ & $\mathrm{Ni}$ & $\mathrm{Fe}$ & activity, Bq/g \\
\hline $1 \mathrm{sec}$ & $2.876+07$ & $1.958+06$ & $2.642+08$ & $2.949+08$ \\
$1 \mathrm{yr}$ & $2.522+07$ & $1.945+06$ & $2.031+08$ & $2.303+08$ \\
$2 \mathrm{yr}$ & $2.211+07$ & $1.932+06$ & $1.571+08$ & $1.811+08$ \\
$3 \mathrm{yr}$ & $1.939+07$ & $1.918+06$ & $1.216+08$ & $1.429+08$ \\
$5 \mathrm{yr}$ & $1.491+07$ & $1.892+06$ & $7.274+07$ & $8.954+07$ \\
$10 \mathrm{yr}$ & $7.728+06$ & $1.828+06$ & $2.015+07$ & $2.971+07$ \\
$20 \mathrm{yr}$ & $2.076+06$ & $1.707+06$ & $1.547+06$ & $5.330+06$ \\
$30 \mathrm{yr}$ & $5.580+05$ & $1.594+06$ & $1.187+05$ & $2.271+06$ \\
$50 \mathrm{yr}$ & $4.029+04$ & $1.390+06$ & $6.992+02$ & $1.431+06$ \\
$100 \mathrm{yr}$ & $5.644+01$ & $9.889+05$ & $1.862-03$ & $9.889+05$ \\
\hline
\end{tabular}

\subsubsection{Radioactivity of Fuel Channel Tubes}

The graphite stack of an RBMK-1000 reactor contains vertical tubes of zirconium alloy 125 that form a fuel channel lattice. The reactor core includes 1,661 working channels with an inside diameter of $4.0 \mathrm{~cm}$ and 277 CPS system channels with an inside diameter of $4.1 \mathrm{~cm}$. The outside diameter of all the channel tubes is $4.4 \mathrm{~cm}$. Channel tubes run the entire height of the reactor core and end reflectors. For a graphite stack $800 \mathrm{~cm}$ high, the total weight of the zirconium alloy is $101,402.5 \mathrm{~kg} ; 91,873.5 \mathrm{~kg}$ of this is from working channel tubes, and $9,529.0 \mathrm{~kg}$ is from CPS channel tubes. 
Table 6.4a. Radioactivity of Steel Top Protection Blocks as a Function of Long-Term Storage

\begin{tabular}{|c|c|c|c|c|}
\hline \multirow{2}{*}{$\begin{array}{c}\text { Storage } \\
\text { period }\end{array}$} & \multicolumn{3}{|c|}{ Radionuclide radioactivity, Bq/g } & $\begin{array}{c}\text { Total } \\
\text { activity, Bq/g }\end{array}$ \\
\cline { 2 - 4 } & $\mathrm{Co}$ & $\mathrm{Ni}$ & $\mathrm{Fe}$ & $4.847+08$ \\
$1 \mathrm{sec}$ & $4.727+07$ & $3.227+06$ & $4.342+08$ & $3.796+08$ \\
$1 \mathrm{yr}$ & $4.145+07$ & $3.205+06$ & $3.350+08$ & $2.986+08$ \\
$2 \mathrm{yr}$ & $3.635+07$ & $3.183+06$ & $2.591+08$ & $2.354+08$ \\
$3 \mathrm{yr}$ & $3.187+07$ & $3.161+06$ & $2.004+08$ & $1.476+08$ \\
$5 \mathrm{yr}$ & $2.450+07$ & $3.118+06$ & $1.200+08$ & $4.894+07$ \\
$10 \mathrm{yr}$ & $1.270+07$ & $3.013+06$ & $3.323+07$ & $8.777+06$ \\
$20 \mathrm{yr}$ & $3.413+06$ & $2.814+06$ & $2.550+06$ & $3.741+06$ \\
$30 \mathrm{yr}$ & $9.172+05$ & $2.628+06$ & $1.958+05$ & $2.359+06$ \\
$50 \mathrm{yr}$ & $6.623+04$ & $2.292+06$ & $1.153+03$ & $1.630+06$ \\
$100 \mathrm{yr}$ & $9.278+01$ & $1.630+06$ & $3.070-03$ & \\
\hline
\end{tabular}

Table 6.4b. Radioactivity of the Bottom Plate of the Top Load-Bearing Structure as a Function of Long-Term Storage

\begin{tabular}{|c|c|c|c|c|}
\hline \multirow{2}{*}{$\begin{array}{c}\text { Storage } \\
\text { period }\end{array}$} & \multicolumn{2}{|c|}{ Radionuclide radioactivity, Bq/g } & $\begin{array}{c}\text { Total } \\
\text { activity, Bq/g }\end{array}$ \\
\cline { 2 - 5 } & $\mathrm{Co}$ & $\mathrm{Ni}$ & $\mathrm{Fe}$ & $8.084+04$ \\
$1 \mathrm{sec}$ & $7.943+03$ & $5.387+02$ & $7.236+04$ & $6.333+04$ \\
$1 \mathrm{yr}$ & $6.965+03$ & $5.351+02$ & $5.583+04$ & $4.983+04$ \\
$2 \mathrm{yr}$ & $6.107+03$ & $5.314+02$ & $4.319+04$ & $3.929+04$ \\
$3 \mathrm{yr}$ & $5.355+03$ & $5.278+02$ & $3.341+04$ & $2.463+04$ \\
$5 \mathrm{yr}$ & $4.118+03$ & $5.206+02$ & $1.999+04$ & $8.176+03$ \\
$10 \mathrm{yr}$ & $2.134+03$ & $5.030+02$ & $5.539+03$ & $1.468+03$ \\
$20 \mathrm{yr}$ & $5.735+02$ & $4.697+02$ & $4.251+02$ & $6.253+02$ \\
$30 \mathrm{yr}$ & $1.541+02$ & $4.386+02$ & $3.262+02$ & $3.939+02$ \\
$50 \mathrm{yr}$ & $1.113+01$ & $3.826+02$ & $1.923-01$ & $2.720+02$ \\
$100 \mathrm{yr}$ & $1.559-02$ & $2.720+02$ & $5.110-07$ & \\
\hline
\end{tabular}

The design service life of channel tubes is 15 years, after which they should be replaced. It was assumed that the power utility factor equals 0.77 , which is 280 effective days per year of operation at rated power. The radioactivity of fuel channel tubes was estimated for an average core thermal neutron flux in tubes $\mathrm{f}_{\text {th }}$ of $4.6 \times 10^{13}$ neutrons $/ \mathrm{cm}^{2} \times \mathrm{sec}$.

Similar to the procedure used to estimate the radioactivity of the reactor metal structures, the average neutron flux in channel tubes was calculated by Monte Carlo method using a computer code for three-dimensional polycell models and a full-scale reactor. Calculations were performed for fuel enrichment in the core of $2.4 \%, 81$ additional absorbers, and an operating supply of 45 manual control rods. The thermal neutron flux averaged for the entire weight of zirconium tubes was determined with regard for radial and vertical irregularity and for the change in flux in tubes of non-fertile channels. Table 6.6 shows the chemical composition of the zirconium alloy used in the calculations. 
Table 6.5a. Radioactivity of Bottom Plate Steel Support Blocks as a Function of Long-Term Storage

\begin{tabular}{|c|c|c|c|c|}
\hline \multirow{2}{*}{$\begin{array}{c}\text { Storage } \\
\text { period }\end{array}$} & \multicolumn{2}{|c|}{ Radionuclide radioactivity, Bq/g } & \multirow{2}{*}{$\begin{array}{c}\text { Total } \\
\text { activity, Bq/g }\end{array}$} \\
\cline { 2 - 4 } & $\mathrm{Co}$ & $\mathrm{Ni}$ & $\mathrm{Fe}$ & $1.660+09$ \\
$1 \mathrm{sec}$ & $1.591+08$ & $1.103+07$ & $1.490+09$ & $1.300+09$ \\
$1 \mathrm{yr}$ & $1.395+08$ & $1.096+07$ & $1.150+09$ & 1.309 \\
$2 \mathrm{yr}$ & $1.223+08$ & $1.088+07$ & $8.894+08$ & $1.023+09$ \\
$3 \mathrm{yr}$ & $1.072+08$ & $1.081+07$ & $6.881+08$ & $8.061+08$ \\
$5 \mathrm{yr}$ & $8.246+07$ & $1.066+07$ & $4.118+08$ & $5.049+08$ \\
$10 \mathrm{yr}$ & $4.274+07$ & $1.030+07$ & $1.141+08$ & $1.671+08$ \\
$20 \mathrm{yr}$ & $1.148+07$ & $9.619+06$ & $8.755+06$ & $7.410+07$ \\
$30 \mathrm{yr}$ & $3.086+06$ & $8.983+06$ & $6.719+05$ & $1.274+07$ \\
$50 \mathrm{yr}$ & $2.228+05$ & $7.834+06$ & $3.958+03$ & $8.061+06$ \\
$100 \mathrm{yr}$ & $3.122+02$ & $5.572+06$ & $1.054-02$ & $5.572+06$ \\
\hline
\end{tabular}

Table 6.5b. Radioactivity of the Top Plate of the Bottom Load-Bearing Structure as a Function of Long-Term Storage

\begin{tabular}{|c|c|c|c|c|}
\hline \multirow{2}{*}{$\begin{array}{c}\text { Storage } \\
\text { period }\end{array}$} & \multicolumn{2}{|c|}{ Radionuclide radioactivity, $\mathrm{Bq} / \mathrm{g}$} & \multirow{2}{*}{$\begin{array}{c}\text { Total } \\
\text { activity, Bq/g }\end{array}$} \\
\cline { 2 - 4 } & $\mathrm{Co}$ & $\mathrm{Ni}$ & $\mathrm{Fe}$ & $1.668+06$ \\
$1 \mathrm{sec}$ & $1.639+05$ & $1.112+04$ & $1.493+06$ & $1.307+06$ \\
$1 \mathrm{yr}$ & $1.437+05$ & $1.104+04$ & $1.152+06$ & 1.306 \\
$2 \mathrm{yr}$ & $1.107+05$ & $1.097+04$ & $8.913+05$ & $1.028+06$ \\
$3 \mathrm{yr}$ & $1.260+05$ & $1.089+04$ & $6.895+05$ & $8.109+05$ \\
$5 \mathrm{yr}$ & $8.497+04$ & $1.074+04$ & $4.126+05$ & $5.083+05$ \\
$10 \mathrm{yr}$ & $4.405+04$ & $1.038+04$ & $1.143+05$ & $1.687+05$ \\
$20 \mathrm{yr}$ & $1.184+04$ & $9.694+03$ & $8.773+03$ & $3.031+04$ \\
$30 \mathrm{yr}$ & $3.180+03$ & $9.052+03$ & $6.733+02$ & $1.290+04$ \\
$50 \mathrm{yr}$ & $2.296+02$ & $7.895+03$ & $3.966+00$ & $8.128+03$ \\
$100 \mathrm{yr}$ & $3.217-01$ & $5.614+03$ & $1.056-05$ & $5.614+03$ \\
\hline
\end{tabular}

Table 6.6. Chemical Composition of Zirconium Alloy 125

\begin{tabular}{|c|c|c|c|c|c|c|}
\hline Element & $\mathrm{Hf}$ & $\mathrm{Nb}$ & $\mathrm{Fe}$ & $\mathrm{Ni}$ & $\mathrm{Al}$ & $\mathrm{Zr}$ \\
\hline wt\% & $<0.04$ & 2.5 & 0.018 & 0.011 & 0.0046 & $>97.4264$ \\
\hline
\end{tabular}

Table 6.7 shows the total specific radioactivity for each radionuclide and the total specific radioactivity of the tube material as a function of long-term storage. 
Table 6.7. Radioactivity of Fuel Channel Material, $\mathrm{Ci} / \mathrm{kg}^{(\mathrm{a})}$

\begin{tabular}{|c|c|c|c|c|c|}
\hline \multirow{2}{*}{$\begin{array}{c}\text { Storage } \\
\text { period }\end{array}$} & $\mathrm{Zr}$ & \multicolumn{2}{|c|}{ Nuclide activity } & \multirow{2}{*}{$\begin{array}{c}\text { Total } \\
\text { activity }\end{array}$} \\
\cline { 3 - 4 } $1 \mathrm{sec}$ & 67.5202 & $7.9119-02$ & 0.29467 & $5.0744-02$ & 67.9447 \\
$1 \mathrm{yr}$ & 1.2993 & $7.9116-02$ & 0.22694 & $5.0397-02$ & 1.6558 \\
$2 \mathrm{yr}$ & $2.6485-02$ & $7.9114-02$ & 0.17555 & $5.0052-02$ & 0.3312 \\
$3 \mathrm{yr}$ & $2.0211-03$ & $7.9111-02$ & 0.13580 & $4.9710-02$ & 0.2666 \\
$5 \mathrm{yr}$ & $1.5419-03$ & $7.9106-02$ & $8.1269-02$ & $4.9033-02$ & 0.2109 \\
$10 \mathrm{yr}$ & $1.5417-03$ & $7.9092-02$ & $2.2514-02$ & $4.7381-02$ & 0.1505 \\
$20 \mathrm{yr}$ & $1.5417-03$ & $7.9065-02$ & $1.7280-03$ & $4.4243-02$ & 0.1266 \\
$30 \mathrm{yr}$ & $1.5417-03$ & $7.9038-02$ & $1.3262-04$ & $4.1314-02$ & 0.1220 \\
$50 \mathrm{yr}$ & $1.5417-03$ & $7.8984-02$ & $7.8117-07$ & $3.6032-02$ & 0.1166 \\
$100 \mathrm{yr}$ & $1.5416-03$ & $7.8850-02$ & $2.0802-12$ & $2.5624-02$ & 0.1060 \\
\hline (a) $1 \mathrm{Ci}=3.7 \times 10^{10} \mathrm{~Bq}$
\end{tabular}

The results show that immediately after the reactor has been shut down the main source of radioactivity is ${ }^{95} \mathrm{Zr}$. After a year storage, ${ }^{95} \mathrm{Zr}$ accounts for about $60 \%$ of total radioactivity; after two years, only $8 \%$. Upon further storage (three years or more) zirconium accounts for little of the total radioactivity from $0.8 \%$ after three years to $1.5 \%$ after 100 years. The radioactivity of ${ }^{94} \mathrm{Nb}$ is almost constant over time, but its contribution to total radioactivity increases: up to $5 \%$ for a storage period of about one year, but about $50 \%$ after 10 years and $75 \%$ after 100 years.

The radioactivity of iron isotopes (primarily ${ }^{55} \mathrm{Fe}$ after the decay of short-lived ${ }^{59} \mathrm{Fe}$ ) over a storage period up to 5 years exceeds that of ${ }^{94} \mathrm{Nb}$, but diminishes sharply thereafter. After one year's storage iron isotopes account for about $14 \%$ of total radioactivity. Iron's radioactivity reaches its maximum in terms of total radioactivity - more than 50\%—after two years' storage. After 10 years, iron isotopes contribute about $15 \%$, and after 20-30 years they have almost no effect on the total radioactivity of the material.

The radioactivity of nickel isotopes after 100 years of storage decreases by half (basically from the decay of ${ }^{63} \mathrm{Ni}$ ), but it accounts for about $3 \%$ of radioactivity after one year, $15 \%$ after two years, and more than $30 \%$ after 10 years. The effect of nickel on total radioactivity diminishes after about 50 years and after 100 years it accounts for $24 \%$. Reducing the content of nickel additions in an alloy by half lowers total radioactivity by about $12 \%$ after 100 years.

Immediately after irradiation stops, fuel channel tube radioactivity is caused by the beta-decay of ${ }^{95} \mathrm{Zr}$. Then as time passes, total radioactivity becomes primarily related to the beta-decay of ${ }^{94} \mathrm{Nb}$ and ${ }^{63} \mathrm{Ni}$. The accumulation of long-lived radionuclides $\left({ }^{63} \mathrm{Ni}\right.$ and $\left.{ }^{94} \mathrm{Nb}\right)$ is basically governed by thermal neutron fluence and is weakly dependent on the specific schedule for changing reactor output while preserving integral energy production. The equilibrium concentration of ${ }^{95} \mathrm{Zr}$, which determines the total radioactivity of the material immediately after reactor shutdown, is not dependent on the history of irradiation but is a function of the output (i.e., the level of neutron flux) at which the reactor operated for the last few months. According to the estimates, 
the radioactivity of fuel channel tubes even after 100 years will exceed $3.7 \times 10^{9} \mathrm{~Bq} / \mathrm{kg}$; i.e., it would be classified highly radioactive solid radwaste.

As noted previously, all calculations were performed for a thermal neutron flux density averaged for all core tubes. Preliminary calculations show that the error from using an approximation of average neutron flux may exceed $20 \%$. To achieve a more accurate analysis, one should take into account both the spatial irregularity of the neutron field and the spectral effects related to the heterogeneity of the composition of the core, since the absorption cross-section of emitters such as zirconium, niobium, iron, and nickel displays resonance characteristics.

\subsubsection{Radioactivity of the Reactor Block Stack Graphite}

The radioactivity of the reactor block stack graphite is governed by the presence of radioactive isotopes, which accumulate when the graphite is irradiated. Preliminary investigations have shown that most of the graphite's radioactivity results primarily from the presence of impurities in the graphite such as hydrogen, nitrogen, cobalt, nickel, iron, and lithium. Additional radioactivity may also result if steam and fission products enter the graphite stack during accidents or if activation products of the nitrogen-helium mixture filling the stack of the RBMK- 1000 reactor are absorbed.

Estimates of the radioactivity of the graphite stack were developed with consideration for only the component which is governed by graphite radioactivity. Possible contamination of the reactor's graphite stack by external sources was not considered.

Estimates of the graphite's radioactivity for such basic long-lived radionuclides as ${ }^{14} \mathrm{C},{ }^{59} \mathrm{Ni},{ }^{63} \mathrm{Ni}$, and ${ }^{94} \mathrm{Nb}$, which define the radiation parameters of the unit when it is decommissioned, may be derived by calculation with sufficient accuracy to plan decommissioning.

As described in Section 4 of this report, the graphite stack of an RBMK-1000 reactor consists of 2,488 square section $(25 \times 25 \mathrm{~cm})$ graphite columns $800 \mathrm{~cm}$ high. Each column has a cylindrical axial opening $11.4 \mathrm{~cm}$ in diameter for fuel channels. Fuel channels with an outside diameter of $8.8 \mathrm{~cm}$ are located in the stack holes in the core, which comprises 1,884 graphite columns. Graphite sleeves for contact heat exchange are set between the channel tubes and the graphite stack.

The 444 graphite columns whose openings are filled with graphite inserts are placed around the core to form a side reflector. The 156 columns surrounding the reflector enclose the graphite stack and are designed to hold the graphite cooling channels.

The composition and density of the graphite in RBMK-1000 reactors varies widely. A graphite block density of $1.72 \mathrm{~g} / \mathrm{cm}^{3}$ was used to estimate the radioactivity of the graphite. With regard to the spaces between the blocks, this figure corresponds to an effective density of $1.7 \mathrm{~g} / \mathrm{cm}^{3}$; the density of the graphite contact heat exchange sleeves is $1.82 \mathrm{~g} / \mathrm{cm}^{3}$. Table 6.8 shows the distribution of the weight of the graphite throughout the reactor that was used in the estimates. 
Table 6.8. Weight Distribution of Graphite in an RBMK-1000 Reactor

\begin{tabular}{|l|c|}
\hline \multicolumn{1}{|c|}{ Structure } & Weight, tonnes \\
\hline Core columns & 1339.9 \\
Core sleeves & 92.5 \\
Reflector columns & 377.4 \\
Cooling channels & 110.9 \\
\hline Total weight of graphite & 1920.7 \\
\hline
\end{tabular}

Radioactivity was estimated for the following isotopes: ${ }^{3} \mathrm{H},{ }^{14} \mathrm{C},{ }^{59} \mathrm{Co},{ }^{59} \mathrm{Ni},{ }^{63} \mathrm{Ni},{ }^{55} \mathrm{Fe}$, and ${ }^{59} \mathrm{Fe}$. Table 6.1 presents the principle characteristics of these radionuclides and the sources of their formation. An average thermal neutron flux of $5.245 \times 10^{13} \mathrm{n} / \mathrm{sec} \mathrm{x} \mathrm{cm}$ was used to calculate the buildup of these radionuclides. The buildup of radionuclides in the graphite sleeves was determined separately at the time when the channel tubes were removed from the reactor with an average thermal neutron flux of $5.82 \times 10^{13} \mathrm{n} / \mathrm{sec} \times \mathrm{cm}^{2}$. Flux values were determined from calculations for the RBMK-1000 reactor by Monte Carlo method using the MCNP computer code. This procedure was similar to that described for estimating the radioactivity of metal structures and fuel channel tubes.

Table 6.9 shows the specific graphite radioactivity averaged for the entire stack as a function of long-term storage. Table 6.10 shows the specific radioactivity of the graphite sleeves. These tables present estimates of radioactivity for each of the basic radionuclides and of total radioactivity.

The results show that ${ }^{14} \mathrm{C}$ is almost unchanged even after a long-term storage of 100 years, while tritium accounts for the largest portion of radioactivity during the first 10-20 years after reactor shutdown. Total radioactivity drops by more than half after 10 years.

The specific radioactivity of the graphite sleeves is higher because the density of neutron flux in the core channels is higher than the average for the reactor.

In general, the relationship between radioactivity and neutron flux density is highly nonlinear, which results in a considerable number of errors in determining total radioactivity using the average flux density model. Using a more detailed description of the distribution of the neutron flux through the graphite reactor stack increases the overall estimate of radioactivity for the first 10 years by $10-15 \%$. As time passes, the estimate based on average neutron flux exaggerates radioactivity. For greater accuracy in estimating the radioactivity of the graphite stack, calculations should be performed channel-by-channel for specific conditions in a particular reactor. Estimates must take into account the accumulation of radionuclides throughout the entire reactor zone according to the microstructure of the neutron flux inside the graphite blocks and any coolant leaks into the graphite stack space that may have occurred. 
Table 6.9. Estimate of the Specific Radioactivity of a Graphite Stack as a Function of Long-Term Storage

\begin{tabular}{|c|c|c|c|c|c|c|}
\hline \multirow{2}{*}{$\begin{array}{c}\text { Storage } \\
\text { period }\end{array}$} & ${ }^{3} \mathrm{H}$ & ${ }^{14} \mathrm{C}$ & ${ }^{60} \mathrm{Co}$ & $\mathrm{Ni}$ & $\mathrm{Fe}$ & $\begin{array}{c}\text { Total } \\
\text { radioactivity, } \\
\mathrm{Bq} / \mathrm{kg}\end{array}$ \\
\hline $1 \mathrm{sec}$ & $1.758+09$ & $2.028+08$ & $6.224+07$ & $7.664+06$ & $8.193+08$ & $2.850+09$ \\
$1 \mathrm{yr}$ & $1.662+09$ & $2.028+08$ & $5.457+07$ & $7.612+06$ & $6.304+08$ & $2.557+09$ \\
$2 \mathrm{yr}$ & $1.571+09$ & $2.023+08$ & $4.785+07$ & $7.560+06$ & $4.877+08$ & $2.316+09$ \\
$3 \mathrm{yr}$ & $1.485+09$ & $2.027+08$ & $4.196+07$ & $7.508+06$ & $3.773+08$ & $2.114+09$ \\
$5 \mathrm{yr}$ & $1.327+09$ & $2.026+08$ & $3.226+07$ & $7.406+06$ & $2.258+08$ & $1.795+09$ \\
$10 \mathrm{yr}$ & $1.002+09$ & $2.025+08$ & $1.672+07$ & $7.157+06$ & $6.254+07$ & $1.291+09$ \\
$20 \mathrm{yr}$ & $5.709+08$ & $2.023+08$ & $4.494+06$ & $6.684+06$ & $4.800+06$ & $7.892+08$ \\
$30 \mathrm{yr}$ & $3.254+08$ & $2.020+08$ & $1.208+06$ & $6.243+06$ & $3.684+05$ & $5.352+08$ \\
$50 \mathrm{yr}$ & $1.057+08$ & $2.016+08$ & $8.719+04$ & $5.447+06$ & $2.170+03$ & $3.128+08$ \\
$100 \mathrm{yr}$ & $6.350+06$ & $2.003+08$ & $1.222+02$ & $3.880+06$ & $5.779-03$ & $2.105+08$ \\
\hline
\end{tabular}

Table 6.10. Estimate of the Specific Radioactivity of Graphite Sleeves as a Function of Long-Term Storage

\begin{tabular}{|c|c|c|c|c|c|c|}
\hline \multirow{2}{*}{$\begin{array}{l}\text { Storage } \\
\text { period }\end{array}$} & \multicolumn{5}{|c|}{ Partial radioactivity by radionuclide, $\mathrm{Bq} / \mathrm{kg}$} & \multirow{2}{*}{$\begin{array}{c}\text { Total } \\
\text { radioactivity, } \\
\mathrm{Bq} / \mathrm{kg}\end{array}$} \\
\hline & ${ }^{3} \mathrm{H}$ & ${ }^{14} \mathrm{C}$ & ${ }^{60} \mathrm{Co}$ & $\mathrm{Ni}$ & $\mathrm{Fe}$ & \\
\hline $1 \mathrm{sec}$ & $2.106+09$ & $2.246+08$ & $5.815+07$ & $8.206+06$ & $8.996+08$ & $3.296+09$ \\
\hline $1 \mathrm{yr}$ & $1.990+09$ & $2.246+08$ & $5.099+07$ & $8.150+06$ & $6.920+08$ & $2.966+09$ \\
\hline 2 yr & $1: 882+09$ & $2.246+08$ & $4.471+07$ & $8.094+06$ & $5.353+08$ & $2.695+09$ \\
\hline $3 \mathrm{yr}$ & $1.779+09$ & $2.246+08$ & $3.920+07$ & $8.039+06$ & $4.141+08$ & $2.465+09$ \\
\hline 5 yr & $1.590+09$ & $2.245+08$ & $3.014+07$ & $7.930+06$ & $2.478+08$ & $2.100+09$ \\
\hline $10 \mathrm{yr}$ & $1.200+09$ & $2.244+08$ & $1.562+07$ & $7.663+06$ & $6.865+07$ & $1.516+09$ \\
\hline $20 \mathrm{yr}$ & $6.839+08$ & $2.241+08$ & $4.198+06$ & $7.157+06$ & $5.269+06$ & $9.246+08$ \\
\hline $30 \mathrm{yr}$ & $3.898+08$ & $2.238+08$ & $1.128+06$ & $6.685+06$ & $4.044+05$ & $6.218+08$ \\
\hline $50 \mathrm{yr}$ & $1.266+08$ & $2.233+08$ & $8.146+04$ & $5.833+06$ & $2.382+03$ & $3.558+08$ \\
\hline $100 \mathrm{yr}$ & $7.610+06$ & $2.219+08$ & $1.141+02$ & $4.154+06$ & $6.343-03$ & $2.337+08$ \\
\hline
\end{tabular}

According to the estimates, after 10 years of storage, if there is no evidence that activated water from channel tubes has entered the graphite stack for a given reactor, the reactor graphite may be classified as a moderately radioactive solid radwaste.

Operating experience shows that determining the radioactivity of graphite with regard to past accidents at a specific RBMK-1000 unit is a rather complicated task. It seems most sensible to measure this parameter during a comprehensive radiation inspection after final shutdown of the reactor. The results of these measurements of graphite radioactivity should be used in developing the unit decommissioning plan. 
Graphite radioactivity calculations averaged over the entire graphite stack are sufficient to plan the preparation stage of unit decommissioning and developing the appropriate decommissioning program. Table 6.11 shows the total graphite radioactivity as a function of long-term storage that was used in subsequent analyses.

Table 6.11 shows that the radioactivity of the reactor cavity concrete is insignificant. For example, the maximum specific radioactivity of the inside surface of the concrete in the radial direction after final reactor shutdown does not exceed $1 \mathrm{~Bq} / \mathrm{cm}^{3}$. This is a result of the thickness of the material between the graphite stack and the inside surface of the concrete. Therefore, the radioactivity of the reactor cavity concrete was not considered in later estimates of the radioactivity of RBMK-1000 reactor structures.

\subsubsection{Total Reactor Radioactivity}

The total radioactivity of the RBMK-1000 reactor at the decommissioning stage was estimated using the following weight parameters for the main elements of the reactor structures:

1. Stack housing

2. Inner wall of radial shield

3. Bottom metal structure of the top load-bearing structure

4. Top metal structure of the bottom load-bearing structure

5. Steel support plates

6. Steel protective plates

7. Fuel channel tubes

8. Total weight of radioactive reactor metal structures

9. Reactor graphite stack weight

10. Total weight of radioactive reactor structures
46 tonnes

100 tonnes

47 tonnes

47 tonnes

250 tonnes

254 tonnes

101 tonnes

845 tonnes

1920 tonnes

2770 tonnes

Table 6.11 gives the resulting estimates of the total radioactivity of structural elements in the RBMK-1000 reactor as a function of long-term storage.

\subsection{Radioactivity of the Multiple Forced Circulation Circuit}

During the decommissioning of NPP units with RBMK-1000 reactors, work in areas where multiple forced circulation (MFC) circuit equipment is located after reactor dismantling represents the greatest radiation hazard. 
Table 6.11. Estimated Total Radioactivity of Structural Elements of an RBMK-1000 Reactor and MFC Circuit as a Function of Long-Term Storage, Ci

\begin{tabular}{|c|c|c|c|c|c|c|c|c|c|}
\hline \multirow{2}{*}{$\begin{array}{l}\text { Structural elements of } \\
\text { reactor and circuit }\end{array}$} & \multicolumn{9}{|c|}{ Storage period, $\mathrm{yr}$} \\
\hline & 0 & 1 & 3 & 5 & 10 & 20 & 30 & 50 & 100 \\
\hline 1. Stack liner & $9.0+05^{(a)}$ & $7.0+05$ & $4.4+05$ & $2.7+05$ & $9.1+04$ & $1.6+04$ & $7.0+03$ & $4.4+03$ & $3.0+03$ \\
\hline $\begin{array}{l}\text { 2. Inside wall of side } \\
\text { protection }\end{array}$ & $8.0+05$ & $6.0+05$ & $3.8+05$ & $2.4+05$ & $8.1+04$ & $1.5+04$ & $6.1+03$ & $3.9+03$ & $2.7+03$ \\
\hline $\begin{array}{l}\text { 3. Bottom structure of } \\
\text { top load-bearing } \\
\text { structure }\end{array}$ & $1.0+02$ & $8.0+01$ & $5.0+01$ & $3.1+01$ & $1.0+01$ & $1.9+00$ & $0.8+00$ & $0.5+00$ & $0.3+00$ \\
\hline $\begin{array}{l}\text { 4. Top structure of } \\
\text { bottom load-bearing } \\
\text { structure }\end{array}$ & $2.1+03$ & $1.7+03$ & $1.0+03$ & $6.5+02$ & $2.1+02$ & $3.8+01$ & $1.6+01$ & $1.0+01$ & $7.1+00$ \\
\hline $\begin{array}{l}\text { 5. Steel protective } \\
\text { plates }\end{array}$ & $3.3+06$ & $2.5+06$ & $1.6+06$ & $1.0+06$ & $3.4+05$ & $1.5+05$ & $2.5+04$ & $1.6+04$ & $1.1+04$ \\
\hline 6. Steel support plates & $1.1+07$ & $8.8+06$ & $5.4+06$ & $3.4+06$ & $1.1+06$ & $5.0+05$ & $8.6+04$ & $5.4+04$ & $3.8+04$ \\
\hline 7. Total $1+6$ & $1.5+07$ & $1.3+07$ & $7.8+06$ & $4.9+06$ & $1.6+06$ & $6.8+05$ & $1.2+05$ & $7.8+04$ & $5.5+04$ \\
\hline 8. Fuel channel tubes & $6.9+07$ & $1.7+06$ & $2.7+05$ & $2.1+05$ & $1.5+05$ & $1.3+05$ & $1.24+05$ & $1.2+05$ & $1.1+05$ \\
\hline 9. Total $7+8$ & $8.4+07$ & $1.4+07$ & $8.1+06$ & $5.1+06$ & $1.8+06$ & $8.1+05$ & $2.5+05$ & $2.0+05$ & $1.7+05$ \\
\hline 10. Graphite stack & $1.5+05$ & $1.3+05$ & $1.1+05$ & $9.3+04$ & $6.7+04$ & $4.1+04$ & $2.8+04$ & $1.6+04$ & $1.1+04$ \\
\hline 11. Total for reactor & $8.4+07$ & $1.4+07$ & $8.2+06$ & $5.2+06$ & $1.9+06$ & $7.6+05$ & $2.8+05$ & $2.2+05$ & $1.8+05$ \\
\hline 12. MFC Circuit & $4.6+03$ & $3.2+03$ & - & $1.4+03$. & $5.1+02$ & - & - & $6.2+01$ & $3.2+01$ \\
\hline
\end{tabular}

Experience shows that radioactive corrosion products, which form as a result of neutron activation of corroded structure materials in the main fuel circuit, determine the radiation environment in MFP circuit areas. Experience monitoring the radiation environment at an NPP with RBMK1000 also shows that, if the units operate trouble-free, gamma rays from emitters such as ${ }^{51} \mathrm{Cr}$, ${ }^{58} \mathrm{Co},{ }^{54} \mathrm{Mn},{ }^{59} \mathrm{Fe}$, and ${ }^{60} \mathrm{Co}$ constitute about $80 \%$ of the gamma ray dose rate in MFC circuit areas and next to MFC circuit equipment.

If there is a large-scale depressurization of MFC circuit equipment during decommissioning, the beta-active long-lived radionuclides ${ }^{55} \mathrm{Fe},{ }^{59} \mathrm{Ni}$, and ${ }^{63} \mathrm{Ni}$ may contribute to the radiation situation. Table 6.12 presents estimates of the radioactivity of these radionuclides made with the TRAKT-1 computer code as a function of the long-term storage after reactor shutdown. The TRAKT-1 code is an RBMK specific Russian code for evaluating corrosion products inside MFC circuits.

When an NPP unit with RBMK-1000 reactors is decommissioned, radwastes will be formed both when the reactor and fuel circuits are dismantled and when civil structures (concrete), where the equipment and piping for the circuits are located, are demolished. Radioactive contamination of 
Table 6.12. Estimated Radioactivity of Corrosion Products on MFC Circuit Equipment Surfaces (outside the core) as a Function of Long-Term Storage, Bq

\begin{tabular}{|c|c|c|c|c|c|c|}
\hline \multirow{2}{*}{ Radionuclide } & \multicolumn{7}{|c|}{ Storage period after reactor shutdown, yr } \\
\cline { 2 - 7 } & 0 & 1 & 5 & 10 & 50 & 100 \\
\hline${ }^{51} \mathrm{Cr}$ & $9.6+12$ & $8.3+01$ & - & - & - & - \\
\hline${ }^{58} \mathrm{Co}$ & $3.0+12$ & $8.3+10$ & $5.0+04$ & - & - & - \\
\hline${ }^{54} \mathrm{Mn}$ & $1.8+12$ & $7.9+11$ & $3.0+10$ & $5.0+04$ & - & - \\
\hline${ }^{59} \mathrm{Fe}$ & $4.1+12$ & $1.0+10$ & $8.7+00$ & - & - & - \\
\hline${ }^{60} \mathrm{Co}$ & $8.4+12$ & $6.5+12$ & $3.9+12$ & $2.0+12$ & $1.2+10$ & $1.8+07$ \\
\hline${ }^{55} \mathrm{Fe}$ & $1.4+14$ & $1.1+14$ & $4.3+13$ & $1.4+13$ & $1.4+09$ & $1.0+04$ \\
\hline${ }^{59} \mathrm{Ni}$ & $9.2+09$ & $9.2+09$ & $9.2+09$ & $9.2+09$ & $9.2+09$ & $9.2+09$ \\
\hline${ }^{63} \mathrm{Ni}$ & $3.6+12$ & $3.6+12$ & $3.6+12$ & $3.2+12$ & $2.1+12$ & $1.2+12$ \\
\hline Total, $\mathrm{Bq}$ & $1.7+14$ & $1.2+14$ & $5.0+13$ & $1.9+13$ & $2.3+12$ & $1.2+12$ \\
\hline Total, $\mathrm{Ci}$ & $4.6+03$ & $3.2+03$ & $1.4+03$ & $5.1+02$ & $6.2+01$ & $3.2+01$ \\
\hline
\end{tabular}

concrete will occur because MFC circuit leaks, e.g., through valve stems packing, have occurred during operation or deactivation work. During leaks, the highly radioactive decontamination solution (with a specific radioactivity in terms of ${ }^{60} \mathrm{Co}$ of about $10^{7} \mathrm{~Bq} / \mathrm{kg}$ ) may spill on the floor and then leak through the metal facing into the concrete ceilings to a depth of several centimeters. Radionuclide penetration and radioactive contamination of concrete may occur when the unit is working at capacity.

Spills of decontamination solutions and coolants contain such long-lived radionuclides as ${ }^{59} \mathrm{Ni}$ and ${ }^{63} \mathrm{Ni}$. Estimates indicate that individual areas may be contaminated to a radioactivity level of $10 \mathrm{~Bq} / \mathrm{g}$ by ${ }^{59} \mathrm{Ni}$ and up to $10^{4} \mathrm{~Bq} / \mathrm{g}$ by ${ }^{63} \mathrm{Ni}$. In other words, radwaste from building materials formed during unit dismantling may contain long-lived isotopes. Consequently, the appropriate methods and equipment should be developed for detecting and recording these radionuclides.

\subsection{Radioactivity of LNPP Unit \#1 as a Function of Long-Term Storage}

Table 6.11 shows the estimates of radioactivity for reactor and MFC circuit structural elements. One may make the following conclusions on the basis of the estimates:

1. The radioactivity of the surfaces of MFC circuit equipment outside the core is no more than $1 \%$ of the reactor's total radioactivity. The error in estimating sources of radioactivity resulting from radioactivity is no more than $10 \%$, that in estimating sources of radioactivity resulting from corrosion in the MFC circuit about $50 \%$. Experience shows that circuit decontamination after final unit shutdown may lower the total radioactivity of the MFC circuit by about a factor of 10 .

The MFC circuit makes a minor contribution to determining and analyzing the balance of total unit radioactivity when planning for decommissioning. However, the radioactivity of this circuit must be taken into account when its equipment is dismantled. 
2. Fuel channel tubes are the most radioactive structural element of an RBMK-1000 reactor during the first 1-1.5 years after its shutdown because of the activation of zirconium and the decay of the radionuclide ${ }^{95} \mathrm{Zr}$ with a half-life of 64 days. As time passes, the radioactivity of the channel tubes is governed by the radionuclides ${ }^{94} \mathrm{Nb},{ }^{59} \mathrm{Ni}$, and ${ }^{63} \mathrm{Ni}$. After a storage period of 30 years or more, the radioactivity of fuel channel tubes exceeds that of all the reactor's metal structures (top and bottom load-bearing structures, side biological shield, graphite stack shell).

Since ${ }^{94} \mathrm{Nb}$ is a gamma-ray emitting radionuclide, the fuel channel tubes should be removed to lower the levels of ionizing radiation during reactor metal structure and graphite stack disassembly for long-term storage. The time for extracting channel tubes from the reactor must be optimized and specified when developing the unit decommissioning plan. The reconstruction of Phase I units at LNPP provided sufficient experience extracting and handling channel tubes.

3. Thirty years after final unit shutdown, the radioactivity of the metal structures of the RBMK-1000 reactor declines by a factor of about 100; the radioactivity of fuel channel tubes by a factor of 500; total reactor radioactivity by a factor of 300 . For long-term storage from 30 to 100 years, the radioactivity drops by a factor of $2.2,1.1$, and 1.6; over 50 to 100 years, by a factor of $1.4,1.09$ and 1.2 , respectively. Consequently, from the standpoint of the level of total unit radioactivity, long-term storage beyond 40-50 years cannot be regarded as worthwhile.

4. Total unit radioactivity may be considered as the parameter defining the choice of a lower limit for long-term storage. The upper limit for long-term storage could be the time at which the gamma ray dose rate near the main reactor structures, if they are dismantled, will not exceed 1-5 mrem $/ \mathrm{hr}$. At this gamma ray dose rate, structures may be dismantled without using special remote-controlled equipment.

The main dose-producing gamma ray emitter over a 30- to 100-year long-term storage is cobalt-60 (it is the only one if fuel channel tubes are removed). For ${ }^{60} \mathrm{Co}$ the specific radioactivity of the reactor metal structures for a 100 year longterm storage drops to no more than $300 \mathrm{~Bq} / \mathrm{g}$ (Table 6.13). In this case the dose rate near the surface of the bottom support plates (which are the most activated elements in the reactor structure) will be $10 \mathrm{mrem} / \mathrm{hr}$. The "upper limit" for longterm storage determined by the dose rate for exterior gamma radiation near its structures may be set at about 100 years. A further increase in storage period of over 100 years is not effective from the standpoint of reducing the dose rate. Consequently, from the standpoint of a unit's radiation parameters (total reactor radioactivity and gamma radiation dose rate), the long-term storage until reactor dismantling begins should be from 50 to 100 years.

The long-term storage period may be chosen and finally set when the unit decommissioning plan is developed. Other factors (economic, social, the existence of storage facilities for burying radwaste, and others) must be considered before choosing the optimal storage time. 


\subsection{Estimation of Radioactivity at Leningrad NPP}

\subsubsection{Radioactivity of Spent Nuclear Fuel}

Spent nuclear fuel removed from the core of an RBMK-1000 reactor is stored in cooling ponds near the reactor and at an SNF storage facility (SNFS) at the plant site. The estimates in Table 6.13 for the total radioactivity of fuel assemblies placed in cooling ponds and the SNFS are for early 1995. The total radioactivity of SNF transported to the SNFS from the 4 units at LNPP is about $2.1 \times 10^{19} \mathrm{~Bq}$.

The total radioactivity of SNF stored in the cooling ponds of the four units at LNPP is estimated to be about $2.1 \times 10^{19} \mathrm{~Bq}$, including

$$
\begin{aligned}
& \text { Unit \#1 - } 0.38 \times 10^{19} \mathrm{~Bq} \\
& \text { Unit \#2 - } 0.36 \times 10^{19} \mathrm{~Bq} \\
& \text { Unit \#3 - } 0.76 \times 10^{19} \mathrm{~Bq} \\
& \text { Unit \#4 - } 0.62 \times 10^{19} \mathrm{~Bq} \text {. }
\end{aligned}
$$

Table 6.13. Specific Radioactivity (Bq/g) of Cobalt-60 in Structural Elements of an RBMK-1000 Reactor and the Dose Rate $(\mathrm{mrem} / \mathrm{hr})$ Near the Structural Elements

\begin{tabular}{|l|c|c|}
\hline \multirow{2}{*}{ Reactor structural element } & \multicolumn{2}{c|}{ Storage period, yr } \\
\cline { 2 - 3 } & 50 & 100 \\
\hline 1. Reactor stack shell & $1.0+05(3.8+03)^{(\mathrm{a})}$ & $1.4+02(5.3+00)$ \\
\hline 2. Inside wall of side protection & $4.0+04(1.5+03)$ & $5.6+01(2.2+00)$ \\
\hline $\begin{array}{l}\text { 3. Bottom metal structure of the top load- } \\
\text { bearing structure }\end{array}$ & $1.1+01(0.4+00)$ & $1.6-02(-)$ \\
\hline $\begin{array}{l}\text { 4. Top metal structure of the bottom load- } \\
\text { bearing structure }\end{array}$ & $2.3+02(9.0+00)$ & $3.2-01(-)$ \\
\hline 5. Steel protective plates & $6.6+04(2.5+03)$ & $9.3+01(3.5+00)$ \\
\hline 6. Steel support plates & $2.2+05(8.4+03)$ & $3.1+02(12+00)$ \\
\hline 7. Reactor graphite stack & $8.7+01(3.3+00)$ & $1.2-01(-)$ \\
\hline (a)1.0+05 = 1.0×10 & & \\
\hline
\end{tabular}

The total radioactivity of SNF at the site of the LNPP is estimated to be about $4.2 \times 10^{19} \mathrm{~Bq}$. The total radioactivity of fission products in the SNF stored at the NPP site is estimated to be $3.7 \times 10^{19} \mathrm{~Bq}$; total actinide radioactivity, $3.0 \times 10^{18} \mathrm{~Bq}$. The radioactivity of the long-lived radionuclides in the SNF representing a radiation hazard is the following: 


$$
\begin{aligned}
& { }^{137} \mathrm{Cs}-4.3 \times 10^{18} \mathrm{~Bq} \\
& { }^{85} \mathrm{Kr}-2.6 \times 10^{18} \mathrm{~Bq} \\
& { }^{90} \mathrm{Sr}-2.0 \times 10^{18} \mathrm{~Bq} \\
& { }^{106} \mathrm{Ru}-1.8 \times 10^{18} \mathrm{~Bq} \\
& { }^{129} \mathrm{I}-1.0 \times 10^{12} \mathrm{~Bq} .
\end{aligned}
$$

\subsubsection{Radioactivity of Operational Radwaste}

This section presents information on estimates of the radioactivity of operational radwaste (solid and liquid) now stored at the plant site. Liquid radwaste is basically low radioactivity; solid radwastes are low-level to moderately radioactive. The radionuclide composition of radwaste is rather varied but is mostly attributable to radionuclides present in the fuel channels of NPP units. According to estimates, the total radioactivity of operational liquid and solid radwaste stored at the NPP site is

$$
\text { Liquid radwaste }-1.5 \times 10^{14} \mathrm{~Bq}
$$

Solid radwaste $-3.0 \times 10^{13} \mathrm{~Bq}$.

At present the total radioactivity of radwaste at LNPP is estimated at (2-3) $\times 10^{14} \mathrm{~Bq}$.

From the standpoint of planning the decommissioning of Unit \#1 at LNPP, the order of magnitude of the main sources of radioactivity at the plant site is

Unit \#1 reactor radioactivity (after 1 year of storage)

$$
\begin{aligned}
& 3 \times 10^{17} \mathrm{~Bq} \\
& 2 \times 10^{19} \mathrm{~Bq} \\
& 3 \times 10^{14} \mathrm{~Bq} .
\end{aligned}
$$

Radioactivity of the SNF at the plant site

Radioactivity of operational radwaste

These data, including the nuclide composition of existing radioactivity sources, show that if Unit \#1 at LNPP is decommissioned and there is an SNF storage facility at the plant site, the primary radiation hazard will come not from the unit's radioactivity but from the radioactivity accumulated in the SNF storage facility. 


\subsection{Spent Nuclear Fuel Handling}

\subsection{Spent Nuclear Fuel Handling Facilities}

The LNPP was designed and built in the 1960s and 1970s. The design calls for discharging spent fuel assemblies from the reactor to the cooling ponds, followed by a short-term (up to 2-3 years) storage in the ponds. The fuel assemblies would be discharged from the fuel pond after cooling and transported from the NPP site for processing.

However, after the units were commissioned, it was discovered that it was not cost-effective to process RBMK-1000 spent fuel. Transport of spent nuclear fuel could not be supported technically, and the problem of long-term storage or burial of highly radioactive wastes had not been studied. Therefore discharging the spent nuclear fuel from NPPs with RBMK-1000 reactors was deferred for an indefinite period, and spent fuel stores-separate buildings-were constructed at NPPs with RBMK reactors for storage purposes. The spent fuel storage facility at the LNPP was built in 1981 (Figure 3.1, Building 428).

To date the operation of the units at LNPP has resulted in the accumulation of more than 3000 tonnes of spent nuclear fuel, which equals about 26,000 spent fuel assemblies. Spent fuel assemblies are stored in the spent fuel storage facility or in the cooling ponds of Units \#1, \#2, \#3, and \#4.

More than 8,200 spent fuel assemblies have been discharged from Unit \#1 at LNPP. Of these, 870 are now stored in the unit's two cooling ponds, while the rest have been taken to the spent fuel storage facility. The LNPP spent fuel storage facility was designed for 17,520 spent fuel assemblies, but this capacity does not meet the power plant's total need to contain spent fuel assemblies. Work to increase the capacity of the cooling ponds and the spent nuclear fuel at LNPP by upgrading them to provide for dense storage of spent fuel assemblies began in 1995 .

The work to increase the capacity of the cooling ponds and spent nuclear fuel storage is being done in strict compliance with the requirements of current Russian nuclear power engineering regulations and with unconditional adherence to the required nuclear and radiation safety for storage of spent fuel assemblies. Work has begun to develop special containers to ensure the possibility of long-term "dry" storage of spent fuel assemblies.

\subsubsection{Spent Nuclear Fuel Cooling Ponds}

Each unit at LNPP has two cooling ponds to hold fuel. The design capacity of each pond is about 850 fuel assemblies. Upgrading the cooling ponds will allow for storing spent fuel assemblies more densely without containers, increasing a cooling pond's capacity to 1491 fuel assemblies.

Intact spent fuel assemblies are stored in cooling ponds without containers, while failed spent fuel assemblies are stored in cooling ponds in special containers. The design of the cooling ponds permits mixed storage of spent fuel assemblies-in containers and without them. 
About 400 spent fuel assemblies a year are discharged from the reactor to the cooling pond. The maximum design rate of spent fuel assembly emergency discharge from a reactor is 20 fuel assemblies a day. Before shipment to the spent nuclear fuel storage facility, all spent fuel assemblies must be held in cooling ponds for at least one year. The fuel assemblies are transported in the plant's TK-8 container cars, which accommodate fuel assembly transport cans holding 9 and 16 assemblies each. The maximum design rate for transporting spent fuel assemblies from the cooling pond to the spent nuclear fuel storage facility is 32 assemblies a day, or two container car trips a day.

\subsubsection{The Spent Nuclear Fuel Storage Facility}

As noted above, the spent nuclear fuel storage facility at LNPP was built in 1981 . The design capacity of the spent nuclear fuel storage facility was 17,520 fuel assemblies; its design life is 30 years. Spent fuel assemblies are kept in spent nuclear fuel storage ponds which are filled with water, i.e., they are stored "wet." Before placement in the spent nuclear fuel storage ponds, the spent fuel assemblies are put into special containers.

Work began in 1995 to increase the capacity of the spent nuclear fuel storage facility by decreasing the spacing between assemblies. This work should increase the capacity of the spent nuclear fuel storage to 35,556 fuel assemblies. The building and equipment necessary to ensure the possibility of increasing the capacity of spent nuclear fuel storage ponds are also being upgraded. The work to upgrade equipment for dense storage in the spent nuclear fuel storage ponds and increasing the capacity of the ponds was supposed to be completed in 1996. The equipment upgrade and the installation of necessary equipment are now to be completed in 1998-2001. The main goal of increasing the capacity of the spent nuclear fuel storage facility is to provide for continued operation of the power plant's units.

\subsection{Development of Dry Storage Casks for Spent Nuclear Fuel}

With all four LNPP units operating normally and the cooling ponds and spent nuclear fuel storage facility upgrades, planned capacity will only meet operating needs for the next 13-15 years. To ensure reliable and safe long-term operation of the LNPP units and in view of the inevitable decommissioning of the plant's units, there must be a sufficient reserve capacity for placement and long-term storage of spent fuel assemblies at LNPP.

At present Russia does not have a licensed design for building new-generation spent nuclear fuel storage facilities that would meet current regulatory requirements for storing spent nuclear fuel from RBMK-1000 reactors. Therefore, in 1995, in compliance with order No. 142 of the Minister for Atomic Power Engineering of Russia dated 24 April 1995, LNPP began to design metalconcrete casks (MCC) for both long-term (at least 50 years) "dry" storage and transportation of spent fuel assemblies from RBMK-1000 reactors. Work is to be completed in 1996-1998 to set up dry storage of spent fuel assemblies broken down into fuel assemblies in MCC at LNPP.

The following basic research and experimental design work is planned: design of a cask to store and transport spent fuel from RBMK-1000 reactors; production of two test casks; programmed tests on casks; receipt of a certificate permitting transport and storage of spent fuel assemblies 
from RBMK-1000 reactors in the casks; design of equipment to break fuel assemblies down into fuel assembly parts and load them for storage into casks; basic research to justify the maximum dry storage period for spent fuel assemblies in casks; construction of a building for fuel assembly breakdown, cask loading, and long-term storage of casks at LNPP.

The design capacity of one cask is about 60 fuel assemblies. Before loading into casks, the spent fuel assemblies must be held in cooling ponds for at least 10 years. The planned maximum spent fuel assembly breakdown and loading rate is $\mathbf{3 5 0 0}$ fuel assemblies a year. It is assumed that a storage facility for $200 \mathrm{MCCs}$ will be set up at LNPP in the first stage of transferring spent fuel assemblies to "dry" cask storage. This facility will hold about 12,000 fuel assemblies.

The cost of MCC development is about 5 billion rubles; the total cost to create an MCC storage facility, including construction and purchase of the necessary equipment, is estimated at 100 billion rubles (in 1995 prices). According to estimates, the cost of assembly-line production of one cask will be about $\$ 250,000$. The MCC design is complete, and MCC prototypes have been built and are undergoing planned tests to prepare the prototypes for commercial production and licensing. After completion of the work to develop and certify commercially produced MCCs at LNPP, spent fuel assemblies requiring storage for more than 10 years will be transferred from cooling ponds to MCC.

Operating LNPP units requires about 35 MCCs per year, i.e., from 1800 to 2100 spent fuel assemblies will be transferred to "dry' storage. One may assume that, if the plan to develop MCCs is successful, the operating requirements of the LNPP units will be met, and problems of storing and handling spent fuel assemblies when the plant's Unit \#1 is decommissioned will be solved.

\subsection{Spent Nuclear Fuel Handling During Decommissioning of LNPP Unit \#1}

The requirements of current Russian regulations state that an NPP unit shut down for decommissioning is considered to be in operation until the spent nuclear fuel is discharged. The license to begin decommissioning an NPP unit takes effect as soon as SNF is discharged from the unit.

After final shutdown of Unit \#1 at LNPP, 1600 partially spent fuel assemblies will remain in the core; up to 2900 spent fuel assemblies in the cooling ponds. Consequently, steps must be taken to ensure safe discharge of spent fuel assemblies from the reactor core and cooling ponds and their removal from the unit.

\subsubsection{Sequence for Handling Spent Nuclear Fuel During Decommissioning}

When Unit \#1 is decommissioned, handling operations must be performed to discharge fuel assemblies from the core, hold them in the cooling ponds, remove them from the cooling ponds, and transport them for storage at the spent nuclear fuel storage facility. To do this, the existing spent fuel handling and transportation systems in the reactor buildings and the spent nuclear fuel storage facility must be used within the limits of the operating conditions stipulated in the design. The sequence for handling spent fuel assemblies from Unit \#1 will not differ from that now in effect at LNPP; which includes the following steps. 
Step 1. Preliminary storage of spent fuel assemblies. Preliminary storage of spent fuel assemblies in the reactor core and in the cooling ponds before they are transported to the spent nuclear fuel storage facility lasts for at least one year. Preliminary storage of fuel assemblies in the core itself after Unit \#1 shutdown is advisable because it ensures the optimum conditions for fuel assembly storage.

Step 2. Discharge and transfer of spent fuel assemblies stored at Unit \#1 to other LNPP units and to the spent nuclear fuel storage facility. After storage in the core for one year, nearly-spent fuel assemblies may be sent for complete burnup at other LNPP units, while spent fuel assemblies are transferred for storage to the spent nuclear fuel storage facility. At a transfer rate of 32 fuel assemblies (two container car trips) per day, this operation will take at least 140 days. It could take a year to transport the fuel assemblies from Unit \#1 given time lost for required preventive equipment maintenance and the necessity of discharging spent fuel assemblies from other operating units and placing them in the spent nuclear fuel storage facility.

Step 3. Storage of spent fuel assemblies at the plant's spent nuclear fuel storage facility. Spent fuel assemblies are temporarily stored "wet" in spent nuclear fuel storage ponds for at least 10 years.

Step 4. Transfer of spent fuel assemblies to metal-concrete casks and storage of the MCCs at LNPP. The minimum requirement for containers for holding and for "dry" storage of spent fuel assemblies left at the unit when it is shutdown is 50$60 \mathrm{MCCs}$. The cost of these casks is approximately $\$ 15$ million.

Step 5. Removal of MCCs with spent fuel assemblies from LNPP for processing or burial.

\subsubsection{Problems Handling Spent Nuclear Fuel To Be Solved at LNPP Unit \#1}

The spent nuclear fuel handling problems that must be solved in the decommissioning of Unit \#1 at LNPP include

1) Problems related to the procedure for removing failed fuel assemblies from the cooling pond and transporting them from the unit have not been solved. Failed fuel assemblies are stored in the cooling ponds in special sealed containers about 17 meters long.

2) The time needed to discharge spent fuel assemblies from units must be further optimized to lower the dose rates to personnel during fuel assembly transport.

3) The problem of prolonging the spent nuclear fuel storage facility's operating life beyond the design limit has not been solved. The decision to use the spent nuclear fuel storage facility for intermediate storage after its design service life has ended depends on the outcome of an analysis of its condition and any required reconstruction. It seems necessary to justify prolonging the working life of the spent nuclear fuel storage facility for at least 15 years, since the spent nuclear fuel 
storage facility is supposed to be used for intermediate storage of spent fuel assemblies from all units at the power plant.

4) The presence of a rather large number of fuel assemblies with low burnup fraction in the core after reactor shutdown makes it necessary to analyze both the economic optimization of the final handling of the assemblies and nuclear safety assurance when they are subsequently stored in water (the latter requires attention to the current tendency to increase the enrichment of fresh RBMK fuel).

5) There are no reliable economic estimates of the costs related to long-term storage of spent fuel assemblies in the spent nuclear fuel storage facility or in MCCs.

6) State issues related to removing spent nuclear fuel from the plant site have not been solved. Solving the state issues will require development of a nationwide plan for processing or burying spent nuclear fuel from RBMK-1000 reactors. A more precise description and accurate economic estimates in the future will require a detailed design study taking into account problems of extending the life of or the decommissioning of the spent fuel storage facility, recycling the resulting radwaste, and others. 


\subsection{Decontamination Activities During Decommissioning of Leningrad Unit \#1}

The main decontamination objectives for RBMK-1000 reactor units are to reduce the gamma radiation dose rate when the equipment in the multiple forced-circulation (MFC) and gas circuit is dismantled and/or to ensure an acceptable level of reactor unit radiation safety when the reactor is readied for long-term storage. In addition, a large portion of the metal structures in an RBMK- 1000 has only surface contamination (or is not radioactive at all). The metal can be decontaminated to a level permitting its restricted or unrestricted use, so that it may be re-used at least for nuclear power engineering needs.

Decontaminating the metal significantly reduces the amount of solid radwastes, but, at the same time, secondary, primarily liquid, radwastes are formed. Therefore, choosing or developing high-efficiency metal decontamination technologies (including "rigorous" methods), which produce the minimum amount of wastes (e.g., through the use of foam or vapor mixtures, gel, or pastes containing different chemical reagents) is an important task. The level and locale of radioactive contaminants, the future disposition of the decontaminated materials, and the required degree of decontamination must be determined before materials/equipment are decontaminated in order to improve efficiency and reduce the amounts of secondary radwastes.

\subsection{RBMK-1000 Decontamination Experience}

Russia has no experience decontaminating equipment and systems during decommissioning of NPPs with RBMK- 1000 reactors. But Russia does have experience decontaminating graphiteuranium reactors. This experience was gained primarily during the decommissioning of the Phase I units at the Beloyarsk NPP with commercial graphite-uranium reactors. Decontamination has also been carried out on MFC circuits of units with RBMK-1000 reactors prior to preventive maintenance and major overhauls. Several chemical, reagent-free, or low-reagent decontamination methods have been developed for this purpose.

Single-bath formulas have been used for chemical decontamination of the RBMK-1000 MFC circuit. The first such formula involved chemical decontamination based on a solution of oxalic acid $(10-20 \mathrm{~g} / \mathrm{L})$. To bring the $\mathrm{pH}$ to $2.0-2.5$, an ammonium solution was used initially, then caustic soda, because there were problems processing the resulting liquid radwastes and removing the ammonium ions from the condensate. The MFC circuit must be treated with this solution at a temperature of $90^{\circ} \mathrm{C}$ for $9-15 \mathrm{hrs}$. Then a solution of hydrogen peroxide in a concentration to $2-5 \mathrm{~g} / \mathrm{L}$ is introduced into the MFC circuit, and processing is continued at $70-90^{\circ} \mathrm{C}$ for $5-$ $8 \mathrm{hrs}$. The solution is then drained or treated to remove the radioactive corrosion products in the bypass purification system. After the solution is drained, the MFC circuit is washed with water. Two chemical decontamination cycles are recommended to achieve the highest efficiency in treating the surfaces of the MFC circuit.

The main drawback of this process is the significant amount of radioactive iodine released into the production areas and the environment when $\mathrm{H}_{2} \mathrm{O}_{2}$ is introduced. Radioactive iodine forms because the hydrogen peroxide oxidizes the iodine ion to molecular iodine in an acid 
environment. Up to $30 \%$ of the iodine is converted to a vapor-gas phase together with the gaseous products of the oxidation of oxalic acid and the breakdown of hydrogen peroxide.

Two charcoal adsorbers are installed to trap the radioactive iodine in the circulation circuit vacuum system. The release of gases $\left(\mathrm{CO}_{2}, \mathrm{O}_{2}, \mathrm{H}_{2}\right)$ when this decontamination technology is used may reach $3,000 \mathrm{~m}^{3}$. To prevent hydrogen buildup, the steam separators are continuously purged with compressed air at a rate of $5,000 \mathrm{~m}^{3} / \mathrm{hr}$.

An improved method for decontaminating the MFC circuit in RBMK-1000 reactors, using a solution of oxalic acid $(5-10 \mathrm{~g} / \mathrm{L})$ with a small concentration of $\mathrm{KNO}_{3}$, was developed to reduce the release of radioactive iodine and gases. After the circuit is treated with this solution for 25$50 \mathrm{hrs}$ at $90-100^{\circ} \mathrm{C}$, the solution is partially drained by displacement and $\mathrm{H}_{2} \mathrm{O}_{2}$ added to the circuit. The concentration of $\mathrm{H}_{2} \mathrm{C}_{2} \mathrm{O}_{4}$ and $\mathrm{KNO}_{3}$ drops by a factor of about 10 . Processing with this solution continues for another $3-8 \mathrm{hrs}$ at $70-75^{\circ} \mathrm{C}$. Later the solution is purified in bypass purification filters and drained. Using this technology reduces the amount of gas released to $200 \mathrm{~m}^{3}$ and the compressed air flow rate to purge the steam separators to $500 \mathrm{~m}^{3} / \mathrm{hr}$.

Both of these MFC decontamination methods were used as the standard pre-repair decontamination method at Leningrad, Chornobyl, and Kursk NPPs. The.MFC circuits have been repeatedly decontaminated by these methods since 1976, and the practice continues. The data in Table 8.1 demonstrate that these methods are about equally efficient.

Table 8.1. Parameters For and Efficiency Of Chemical Decontamination of the MFC Circuits at LNPP

\begin{tabular}{|c|c|c|c|c|c|c|c|}
\hline \multirow[b]{2}{*}{ Unit } & \multirow[b]{2}{*}{ Year } & \multirow[b]{2}{*}{$\begin{array}{c}\text { Solution } \\
\text { composition }\end{array}$} & \multirow[b]{2}{*}{ Area } & \multirow{2}{*}{$\begin{array}{c}\text { Decontamin- } \\
\text { ation factor } \\
\text { in terms of } \\
\text { dose rate }\end{array}$} & \multicolumn{2}{|c|}{ Removed } & \multirow[b]{2}{*}{$\begin{array}{c}\text { Duration, } \\
\mathrm{hr}\end{array}$} \\
\hline & & & & & $\begin{array}{c}\text { Activity, } \\
\mathrm{Ci}\end{array}$ & $\begin{array}{l}\mathrm{Fe} \\
\mathrm{kg}\end{array}$ & \\
\hline$\# 1$ & 1976 & $\begin{array}{c}\mathrm{H}_{2} \mathrm{C}_{2} \mathrm{O}_{4}+ \\
\mathrm{NH}_{4} \mathrm{OH}+\mathrm{H}_{2} \mathrm{O}_{2}\end{array}$ & $\begin{array}{l}\text { Control rooms } \\
\text { RCP enclosures }\end{array}$ & $\begin{array}{c}2.1 \\
2.7-32 \\
\end{array}$ & 10000 & 936 & $\sim 100$ \\
\hline$\# 2$ & 1977 & Same & $\begin{array}{l}\text { Control rooms } \\
\text { RCP enclosures } \\
\text { Drum-type } \\
\text { separators }\end{array}$ & $\begin{array}{c}2-3.6 \\
2.2-9.5 \\
5.7-4.4 \\
\text { average } 4.6\end{array}$ & $\begin{array}{c}6000- \\
7000 \\
\text { LRW - } \\
4300 \mathrm{~m}^{3}\end{array}$ & 1300 & 95 \\
\hline$\# 1$ & 1989 & $\begin{array}{c}\mathrm{H}_{2} \mathrm{C}_{2} \mathrm{O}_{4}+ \\
\mathrm{KHO}_{3}+\mathrm{H}_{2} \mathrm{O}_{2} \\
2 \text { cycles }\end{array}$ & $\begin{array}{c}\text { Control rooms } \\
\text { RCP enclosures } \\
\text { Bottom water lines } \\
\text { Drum-type } \\
\text { separators }\end{array}$ & $\begin{array}{c}18-32 \\
2.9 \\
2.1 \\
10.1 \\
\text { average } 6.3\end{array}$ & 5000 & 1000 & 118 \\
\hline
\end{tabular}


If the core is cut off, the solutions might be circulated through the MFC circuit in different sequences. For example:

- MCP delivery line - surge lines - cooling pumps - surge aftercooler - cofferdam between surge supply and return on SVO-1 (active water treatment plant) - surge return line - surge recyclers - feed unit mixer - drum-type separator - down pipes - cofferdam between MCP suction and delivery lines - MCP delivery line.

- MCP delivery line - surge lines - cooling pumps - surge aftercooler - cofferdam between surge supply and return to SVO-1 (active water treatment plant) - surge return line - surge recyclers - feed unit mixer - drum-type separator - steam-water lines - fuel channels - bottom water lines - MCP distribution line - MCP delivery line.

- MCP - delivery line - bottom water lines - fuel channels - steam-water lines - drum-type separator - down pipes - MCP suction line - MCP.

The savings from performing chemical decontamination of the Leningrad units before preventive maintenance is estimated at 1.4 million rubles (in 1977 prices).

Low-reagent decontamination involves activating the process of degassing particles of corrosive deposits when water is saturated with carbon dioxide gas. The result is a two-to fourfold increase in the content of suspended corrosion products in the water. Then the suspended products are removed from the coolant in the MFC circuit bypass water purification system. The reagent-free method of decontaminating the MFC circuit is based on changing the charge on the corrosion products when $5-7 \mathrm{mg} / \mathrm{L}$ of ambient air is introduced into the circuit water.

Specifically, reagent-free oxygen decontamination consists of replacing MFC water which has been cooled to $40-50^{\circ} \mathrm{C}$ with chemically demineralized water saturated with atmospheric oxygen (to $8 \mathrm{mg} / \mathrm{L} \mathrm{O}_{2}$ ). The water may be replaced by displacing the circuit water with mixing the coolant and circulating (for about $2 \mathrm{hrs}$ ). Then there is a 10-hr hold with natural circulation, after which the corrosion products are extracted by bypass purification (for $50 \mathrm{hrs}$ ). The replacement water follows the sequence: ERCS (Emergency Reactor Cooling System) lines - fuel channels core - drum-type separator - down pipes - MCP drains. Reagent-free decontamination was used in 1984 on Leningrad Units \#2 and \#3 and Chornobyl Units \#1 and \#2 and in 1987 at Chornobyl Unit \#2.

Carbon dioxide decontamination includes cooling the coolant to $60-100^{\circ} \mathrm{C}$, saturating it with $\mathrm{CO}_{2}$ to a content of $100-400 \mathrm{mg} / \mathrm{L}$, circulating, holding and treating it to remove corrosion products. Carbon dioxide decontamination takes a total of 75-92 hours. Carbon dioxide decontamination was done in 1984 at three units at Chornobyl.

Table 8.2 gives the results of reagent-free decontamination on the Leningrad MFC circuits. The use of reagent-free or low-reagent decontamination resulted, on average, in a two- to fourfold drop in dose rate in MFC circuit areas. About 150-670 Ci were removed from the circuit. In terms of efficiency, the reagent-free decontamination method is comparable with chemical decontamination. 
Table 8.2. Effectiveness of Reagent-Free Decontamination on the Leningrad MFC Circuits

\begin{tabular}{|c|c|c|c|c|c|c|c|c|}
\hline \multirow[b]{2}{*}{ Unit } & \multirow[b]{2}{*}{ Date } & \multicolumn{3}{|c|}{ Dose rate, $\mathrm{mcR} / \mathrm{sec}$} & \multirow{2}{*}{$\begin{array}{l}\text { Decontam- } \\
\text { ination factor } \\
\text { in terms of } \\
\text { dose rate }\end{array}$} & \multicolumn{2}{|c|}{ Removed } & \multirow[b]{2}{*}{$\begin{array}{c}\text { Time, } \\
\mathrm{hr}\end{array}$} \\
\hline & & Area & $\begin{array}{c}\text { Before } \\
\text { decontamination }\end{array}$ & $\begin{array}{c}\text { After } \\
\text { decontam- } \\
\text { ination }\end{array}$ & & $\begin{array}{c}\text { Radio- } \\
\text { activity, } \\
\mathrm{Ci}\end{array}$ & $\begin{array}{l}\mathrm{Fe}, \\
\mathrm{kg}\end{array}$ & \\
\hline \multirow[t]{6}{*}{$\# 2$} & \multirow[t]{6}{*}{04.84} & Reactor bottom room & $\begin{array}{c}350 ; 420 ; 350 \\
650\end{array}$ & $\begin{array}{c}180 ; 230 ; 160 \\
180\end{array}$ & 2.4 & \multirow[t]{6}{*}{670} & \multirow[t]{6}{*}{ - } & \multirow[t]{6}{*}{69} \\
\hline & & Bottom water lines & $88 ; 146 ; 56 ; 186$ & $70 ; 140 ; 30 ; 48$ & 2.0 & & & \\
\hline & & MCP enclosures & $\begin{array}{c}53 ; 30 ; 146 ; \\
127 ; 47 ; 29 ; 103\end{array}$ & $\begin{array}{c}43 ; 47 ; 42 ; 28 \\
20 ; 23 ; 28\end{array}$ & 2.46 & & & \\
\hline & & Drum-type separators & $24 ; 18$ & $18 ; 19$ & 1.14 & & & \\
\hline & & Down pipes & \multirow[t]{2}{*}{$7.3 ; 6.3$} & \multirow[t]{2}{*}{$6.0 ; 2.6$} & 1.82 & & & \\
\hline & & & & & average 20 & & & \\
\hline$\# 3$ & 05.84 & Reactor bottom room & $\begin{array}{c}405 ; 335 ; 337 \\
387\end{array}$ & $100 ; 80 ; 84 ; 83$ & 4.2 & 227 & 2.33 & 63 \\
\hline & & MCP enclosures & $\begin{array}{c}85 ; 127 ; 121 ; \\
83 ; 124 ; 138 \\
271 ; 66\end{array}$ & $\begin{array}{c}66 ; 159 ; 83 ; 78 \\
181 ; 130 ; 261 \\
47\end{array}$ & 1.1 & & & \\
\hline & & Bottom water lines & $\begin{array}{c}119 ; 188 ; 148 \\
225\end{array}$ & $\begin{array}{c}78 ; 128 ; 102 \\
130\end{array}$ & 1.55 & & & \\
\hline & & Drum-type separators & $25 ; 22$ & $19 ; 18$ & 1.28 & & & \\
\hline & & Down pipes & $8 ; 7$ & $4 ; 4$ & 1.28 & & & \\
\hline & & & & & average 1.9 & & & \\
\hline
\end{tabular}

The advantages of the reagent-free process include short time, minimum material corrosion, and three to six times less liquid radwastes than with chemical decontamination. All the necessary operations are included in the standard regulations for units with RBMK-1000 reactors.

Compared with the reagent-free process, carbon dioxide decontamination is more efficient to carry out, and there is almost no liquid radwaste. The savings from reagent-free or carbon dioxide decontamination, over previous methods, are about 200,000 rubles a year for one unit (in 1990 prices). Operating costs for decontamination prior to preventive maintenance and major overhauls were 6,700 rubles (in 1990 prices), and savings from an 87.5-man-rem reduction in the collective personnel radiation dose during major overhauls are 201,000 rubles (at a cost of 2,310 rubles per man-rem). The operating costs for chemical decontamination were 97,000 rubles (in 1990 prices).

Equipment for units with RBMK-1000 reactors (repair and preventive maintenance of pumps and fittings) is decontaminated once every 1-2 years. Two-bath methods, which have been thoroughly described in scientific and technical literature, are used.

The decontamination area in units with RBMK-1000 usually includes trays for steam-emulsion decontamination; a bath for decontamination of large equipment, fittings, and parts by immersion; a bath for ultrasonic decontamination of small parts, instrumentation sensors, and tools; water and solution pumps; disassembly tables; and racks for steam-emulsion washing. In addition, there should be portable decontamination equipment: steam-emulsion sprayers and guns; an electrochemical decontamination unit; portable tanks; and decontaminating solutions. 
The internal surfaces of the MCP are decontaminated by circulating decontamination solutions; the outside surfaces, by steam-emulsion method. After rinsing with water, the MCP is disassembled into assemblies and parts and, if necessary, it undergoes further immersion decontamination.

In addition to this decontamination equipment, the central hall of the RBMK-1000 has a 100-L bath for electrochemical anodic decontamination of long pieces (reactor mounts). A $2-4 \%$ solution of oxalic acid was used at first, but the surfaces of the bath oxalated and current strength diminished. A solution of nitric acid (4-6 wt\%) at a current density of $50 \mathrm{~mA} / \mathrm{cm}^{2}$ is now used. The electrochemical deactivation coefficient in the bath is 400-600. The bath may also be used to decontaminate other long items (e.g., those made of stainless steel) measuring from 3-4 to 8-9 meters long and up to $80-85 \mathrm{~mm}$ in diameter.

\subsection{Problems Decontaminating RBMK-1000 Units}

The problems encountered in decontaminating the MFC circuit in units with RBMK-1000 reactors result from the features of their design and operation. The RBMK-1000 MFC circuit differs from other types of reactor coolant circulation circuits in its larger volume $\left(1,200 \mathrm{~m}^{3}\right)$, the greater branching of its lines, and the presence of wake areas in it. These design features prevent the MFC circuit from being broken down into individual segments for decontamination, which considerably limits the use of most of the decontamination methods used for NPP circulating circuits.

A single-bath or reformulated decontamination solution formula is recommended for solvent washing of the MFC circuit. The use of single-bath decontamination methods makes it possible to reduce the volume of liquid radwaste products, which often reaches $5,000-10,000 \mathrm{~m}^{3}$. The choice of decontamination solution formula is highly dependent on the kinds of structural materials, the amount and chemical composition of corrosion deposits, the level of radioactive contamination in various segments of the MFC circuit, and the radiochemical composition of the contamination.

The primary structural materials used in the MFC circuit for units with RBMK-1000 reactors are stainless steel $0 \mathrm{Kh} 18 \mathrm{~N} 10 \mathrm{~T}$ (similar to 321 stainless steel), zirconium alloys (110 and 125) and carbon steel, whose surfaces are $38,000,13,600$, and $330 \mathrm{~m}^{2}$, respectively.

A neutral, uncorrected aqueous chemical regime is used in the MFC circuit for RBMK-1000 reactors. The oxygen content in the coolant in individual segments of the circuit reaches 100 $200 \mu \mathrm{g} / \mathrm{kg}$. The water-chemical regime for the RBMK-1000 circulation circuit is oxidizing. Therefore, the distinguishing feature of the composition of corrosive deposits in the MFC circuit is the lower chromium content in loose deposits.

As the chemical composition of the corrosion deposits in the MFC circuit given in Table 8.3 shows, iron oxides with impurities of nickel, chromium, and manganese predominate in the deposits. The deposits may also contain up to $5 \%$ silicon, which results from the sea water soak (penetration) in the main condenser. The concentration of silicic acid in the MFC circuit water ranges from $70-400 \mu \mathrm{g} / \mathrm{L}$. The formation of silicon-containing deposits in the circuit severely complicates decontamination. 
Table 8.3. Chemical Composition of Corrosion Deposits in the MFC Circuit for Units with RBMK-1000 Reactors

\begin{tabular}{|l|c|c|c|c|c|c|c|}
\hline \multirow{2}{*}{ Sample taken from } & \multicolumn{6}{|c|}{ Chemical composition in conversion to oxides, \% } \\
\cline { 2 - 8 } & $\mathrm{Fe}_{2} \mathrm{O}_{3}$ & $\mathrm{Cr}_{2} \mathrm{O}_{3}$ & $\mathrm{NiO}$ & $\mathrm{MnO}$ & $\mathrm{CuO}$ & $\mathrm{ZrO}_{2}$ & Notes \\
\hline $\begin{array}{l}\text { Drum-type separator, stainless steel, } \\
\text { loose layer (13,000 hr) }\end{array}$ & 89.9 & 2.4 & 5.3 & 2.0 & 0.4 & - & \\
\hline Same, grade 20 steel & 95.3 & 1.1 & 1.8 & 1.0 & 0.7 & - & \\
\hline $\begin{array}{l}\text { Fuel channel, zirconium alloy 125, } \\
\text { loose layer (13,000 hr) }\end{array}$ & 92.0 & 1.8 & 3.3 & 0.7 & 0.7 & 2.0 & \\
\hline Deposits on the drum-type separator & 63.7 & 2.4 & 0.7 & 0.6 & 0.5 & 0.2 & $\begin{array}{c}18.9 \\
\text { insoluble } \\
\text { portion }\end{array}$ \\
\hline Deposits on fuel elements & 88.6 & 5.1 & 2.7 & 2.7 & 0.9 & 0.3 & \\
\hline
\end{tabular}

Research conducted at LNPP has demonstrated that the total amount of deposits in the MFC circuit in terms of $\mathrm{Fe}\left({ }^{59} \mathrm{Fe}\right.$ predominates in the deposits) is $100-200 \mathrm{~kg}$; about $300 \mathrm{~kg}$ in the core. For stainless steel the surface density of the deposits reaches $20-25 \mathrm{~g} / \mathrm{m}^{2}$; for zirconium alloy, $2.5-3 \mathrm{mg} / \mathrm{m}^{2}$.

The specific radioactivity of the loose deposits in the MFC circuit is $3 \times 10^{-8}-4 \times 10^{-3} \mathrm{Ci} / \mathrm{g}$ $\left(1.1 \mathrm{~Bq} / \mathrm{g}-150 \mathrm{MBq} / \mathrm{g}\right.$ ) or $1-7.5 \mu \mathrm{Ci} / \mathrm{cm}^{2}$. The total radioactivity of the deposits on the surfaces of the MFC circuit reaches $630-1,000 \mathrm{Ci}(23 \mathrm{GBq}-37 \mathrm{TBq})$, which , together with the radioactivity of the core deposits, exceeds $2 \times 10^{5} \mathrm{Ci}$ (up to 7,400 TBq). The results show that up to $90-95 \%$ of the total radioactivity of all deposits is concentrated in the loose deposits. The MFC circuit surfaces account for no more than $0.5-1 \%$ of the total radioactivity of the corrosion products. The typical radionuclide composition of deposits and the radioactivity of samples in the MFC circuit of LNPP is ${ }^{60} \mathrm{Co}-36 \times 10^{-8} ;{ }^{58} \mathrm{Co}-1.7 \times 10^{-8} ;{ }^{54} \mathrm{Mn}-18 \times 10^{-8} ;{ }^{95} \mathrm{Zr}-0.4 \times 10^{-8}$; ${ }^{94} \mathrm{Nb}-1.2 \times 10^{-8} ;{ }^{144} \mathrm{Ce}-0.3-80 \times 10^{-8}$; total $-57.6-137.6 \times 10^{-8} \mathrm{Ci} / \mathrm{cm}^{2}$.

This radiochemical composition indicates that the radioactivity of corrosion product deposits is basically attributable to ${ }^{51} \mathrm{Cr},{ }^{60} \mathrm{Co},{ }^{95} \mathrm{Zr}$, and ${ }^{94} \mathrm{Nb}$. The contribution made by individual radionuclides to dosimetry conditions varies depending on the period over which the deposits built up; the longer the buildup period, the greater the contribution of ${ }^{60} \mathrm{Co}$ and the smaller the contribution of ${ }^{51} \mathrm{Cr}$ and ${ }^{58} \mathrm{Co}$. The buildup of deposits increases the irradiation dose rate, particularly in reactor bottom rooms, to 3,600-14,000 $\mathrm{mR} / \mathrm{hr}$ (after reactor shutdown); in MCP areas, from 50$2,500 \mathrm{mR} / \mathrm{hr}$.

The MFC circuit at LNPP was usually decontaminated during routine major overhauls. For example, in 1995, before Unit \#3 was repaired and rebuilt, the decontamination procedure included the following operations: introduction of a solution of $\mathrm{KNO}_{3}$ and oxalic acid into the MFC circuit and circulation of this solution through the circuit; partial drainage of the solution; 
reduction in temperature and introduction of a hydrogen peroxide solution; reintroduction of $\mathrm{KNO}_{3}, \mathrm{H}_{2} \mathrm{C}_{2} \mathrm{O}_{4}$ and then $\mathrm{H}_{2} \mathrm{O}_{2}$; displacement of the spent solutions from the MFC circuit; circuit water wash.

Radioactivity is removed from the MFC circuit by the bypass purification line (perlite filters) and by partial drainage of the solutions. The total specific gamma radioactivity of the solution reaches $1.5 \times 10^{-3} \mathrm{Ci} / \mathrm{L}$. If the solution is drained twice, $1,192(534+658) \mathrm{Ci}$ are removed; if the solution is displaced, $190 \mathrm{Ci}$; if by bypass purification, $48 \mathrm{Ci}$. A total of $900 \mathrm{~kg}$ of iron is extracted as a result of decontamination. The average decontamination coefficient is about 6 .

A local buildup of radioactive suspensions was detected in dead areas (particularly in the spaces between the water flow meters and the bottom water line housing, in plugged branch pipes of the steam-water lines at the drum-type separators and the interior cofferdams of the drum-type separators, in the pipe of the MCP suction line, and on the inside surfaces of the multi-gyro cyclones). The water return path past the MCP multi-gyro cyclones may be changed to improve removal of suspensions by directing the water to the bypass purification line or by changing the circulation pattern.

The problem of decontaminating the gas circuit merits special attention-especially where there have been fuel channel leaks during operation, which have happened at Leningrad Unit \#1. The rather technically complicated problems of handling graphite blocks in the reactor stack and the fuel channels also require attention. Removing and decontaminating the fuel channels and decontaminating the reactor zone drains should be considered before handling the graphite.

The technologies used to decontaminate equipment and systems in units with RBMK-1000 reactors must meet the following requirements:

- highly efficient removal of radioactive contaminants and decontamination of equipment ("deep decontamination")

- minimum amounts of liquid and solid radwastes

- minimum formation of radioactive gases and aerosols during decontamination

- the possibility of automation or remote control of the decontamination process

- the possibility of maximum use of existing standard systems

- high decontamination productivity, efficiency, and economy for different materials and types of contamination

- minimum dose loads for personnel and radioactive effects on the environment

- provision of the required reduction in the radioactivity of materials to be decontaminated to a level that permits their further limited or unlimited use.

There is no requirement for a decontamination solution with a low corrosive action on structural materials when unit equipment and structures are to be dismantled during decommissioning. As a result, rigorous decontamination methods and procedures may be used during decommissioning. Their choice, however, requires certain caution and optimization, since rapid dissolution of the metal which is being treated may increase the content of iron and other structural material 
components in the secondary liquid radwastes. This increase may then make subsequent processing of the liquid waste much more complicated.

In conclusion, the problems of decontaminating the MFC circuit, equipment, and areas described above may be solved on the basis of experience decontaminating the MFC circuit and equipment in units with RBMK-1000 reactors using existing decontamination methods and technologies. This experience and these technologies may be successfully used in decommissioning Leningrad Unit \#1. If equipment dismantling is undertaken on a large scale, however, the decontamination facilities now on hand may be inadequate to handle the required scope of various kinds of decontamination work. For this reason the plan for decommissioning Leningrad Unit \#1 should define the requirements for the decontamination facilities, the variety of equipment needed, and the scope of the necessary research and design work, particularly in terms of the technologies that do not require human involvement for decontamination.

\subsection{Recommendations On Decontaminating Equipment, Systems, and Process Circuits}

The following sections contain recommendations on decontamination during the preparation stages for decommissioning and long-term storage at Leningrad Unit \#1.

\subsubsection{Decontamination for Decommissioning of Leningrad Unit \#1}

The levels of radioactive contamination of equipment, systems, and process circuits and the irradiation dose rate in the reactor bottom rooms and areas where equipment will be dismantled must be determined during engineering and radiation inspections after the unit is shut down. The following items should be studied and resolved based on the results of the inspection and the levels of radioactive contamination at this stage:

- Determine the merit of decontaminating the MFC circuit chemically or without reagents.

- Determine the need to decontaminate the gas circuit and fuel channels.

- Select the method for decontaminating the equipment to be dismantled.

- Develop and produce the required decontamination equipment, tooling, and robotics for remote control of the decontamination process.

- Prepare areas where primary and secondary radwastes will be processed and localized.

- Determine the required material outlays for decontamination.

- Prepare the necessary logistical support.

After the standard operations to remove the fuel assemblies from the reactor core are completed, spent fuel assemblies should be removed from the reactor cooling ponds and taken to the spent nuclear fuel storage facility; fuel assemblies that can still be used should be taken to the cooling ponds of the operating units.

If necessary, fuel assemblies suitable for reuse must be treated to remove radioactive corrosion deposits. This is done in a special unit with decontaminating solutions. 
After the fuel assemblies have been removed, the cooling ponds must undergo decontamination. If necessary, they may be reused after they have been repaired (including elimination of possible leaks) and returned to operating readiness.

Cooling pond decontamination operations consist of removal of damaged fuel element pieces from the bottom of the cooling pond, removal of other extraneous objects and sludge, and decontamination of the pond walls and bottom. The pond may be decontaminated, for example, with a jet treatment with a chemical solution and jet monitor, or electrochemically with a remotecontrolled removable electrode that is programmed to move along the walls of the pond. If the chemical jet decontamination is chosen as the basic method for decontaminating cooling pond walls, electrochemical decontamination may be used later for final decontamination of welded joints in the stainless steel facing of the cooling ponds.

As GAN regulations regarding waste management of chemicals become more restrictive, other methods of decontamination should be considered, such as high-pressure water jets and the water lance. After the fuel assemblies have been removed from the cooling ponds and the pond walls have been washed, the cooling ponds may be considered to be in a nuclear-safe state.

\subsubsection{Decontamination for Long-Term Storage}

The basic problem in preparing the unit for long-term storage is to determine the merit and need for decontaminating the MFC circuit. The solution to this problem depends considerably on the need to work in the MFC spaces and the dose rate in these spaces.

The experience of units with RBMK-1000 reactors shows that when the reactor is operating, the dose rate in the MFC circuit reactor bottom rooms is $100-200 \mu \mathrm{R} / \mathrm{sec}$. As the thermal output of the reactor declines and/or the reactor is shut down, the dose rate rises to $2,000-4,000 \mu \mathrm{R} / \mathrm{sec}$. The gamma ray background in other MFC circuit spaces also increases as radioactive corrosion products are deposited. However, when the unit is being prepared for long-term storage and the fuel has been removed from the reactor, total radioactivity will have decreased by a factor of 100 one year after reactor shutdown. After 5 years, the radioactivity of the corrosion deposits will further decline by a factor of at least 4 to 5 , and the major contributor will be ${ }^{60} \mathrm{Co}$.

The gamma radiation dose rate in reactor bottom rooms and other areas also drops because of the radioactive decay of most of the corrosion-related radionuclides (except ${ }^{60} \mathrm{Co}$ ) and because radioactive deposits are not transferred from the reactor core. Therefore, the need to decontaminate the MFC circuit may be assessed from the standpoint of the permissible dose rate for personnel in circuit areas when the work begins. Experience with scheduled maintenance and major overhauls at units with RBMK- 1000 reactors indicates that decontaminating the MFC while the unit is being prepared for long-term storage has merit. First, a large portion of loose corrosion deposits will be removed from the MFC circuit. Second, radiation safety conditions for longterm storage of the unit will be improved.

Either reagent-free or low-reagent methods or chemical decontamination may be chosen as the technology for decontaminating the MFC circuit at this stage. Reagent-free decontamination can be accomplished by replacing the MFC circuit coolant, which has been cooled to $40-50^{\circ} \mathrm{C}$, with a chemically demineralized water saturated with atmospheric oxygen $\left(6-8 \mathrm{mg} / \mathrm{L}\right.$ in terms of $\left.\mathrm{O}_{2}\right)$. 
The demineralized water is circulated and allowed to settle; then the radioactive corrosion products are extracted through bypass purification. Replacement with demineralized water may be done by displacement along the following route: ERCS main - grouped distribution mains - core fuel channels - drum-type separator - MCP suction line - MCP drains.

The advantage of reagent-free technology lies in the minimum amount of liquid radwastes that form and the use of only standard MFC circuit equipment in the process so that all operations are part of the plant's standard operations. Using reagent-free decontamination saves 430,000 rubles a year in 1990 prices (assuming two scheduled overhauls per year) compared with chemical decontamination. Table 8.4 compares data on the efficiency of reagent-free and chemical decontamination methods. Note that the data in this table pertain to two processing cycles for chemical decontamination.

If the MFC circuit is chemically decontaminated, the procedure operations will include

- introduction of a $\mathrm{KNO}_{3}$ solution, followed by oxalic acid, into the MFC circuit water to achieve concentrations of $3.0-3.5$ and $9-10 \mathrm{~g} / \mathrm{L}$, respectively

- circulation of the solution for 20 hours at $90-100^{\circ} \mathrm{C}$

Table 8.4. Comparison of Efficiency Parameters for Reagent-Free and Chemical Decontamination of the MFC Circuit in Units with RBMK-1000 Reactors

\begin{tabular}{|c|c|c|c|}
\hline \multirow[b]{2}{*}{ Area or equipment; parameter } & \multirow[b]{2}{*}{$\begin{array}{l}\text { Initial dose } \\
\text { rate } \mu R / \mathrm{sec}\end{array}$} & \multicolumn{2}{|c|}{ Decontamination coefficient (Cd) } \\
\hline & & $\begin{array}{c}\text { Reagent-free } \\
\text { decontamination }\end{array}$ & $\begin{array}{l}\text { Chemical Decon- } \\
\text { tamination }(\mathrm{cd})^{(\mathrm{a})}\end{array}$ \\
\hline Reactor bottom room $(016 / 1,2)$ & $335-970$ & 4.2 & $1.8-32$ \\
\hline Bottom water line area $(033 / 3,4)$ & $\begin{array}{c}36-119 \\
166-240\end{array}$ & 3.1 & 2.1 \\
\hline MCP enclosures (08/9-16) & $25-125$ & 3.9 & 2.9 \\
\hline Down pipes, suction line $(115 / 3,4)$ & $7-20$ & 1.5 & 10.1 \\
\hline Drum-type separators $(505 / 3,4)$ & $21-140$ & 1.3 & 6.5 \\
\hline Average Cd & - & $2.0-4.1$ & $\begin{array}{c}\text { 1st cycle }-2.6 \\
\text { 2nd cycle }-6.1\end{array}$ \\
\hline $\begin{array}{l}\text { Removed: } \\
\text { gamma radioactivity, } \mathrm{Ci} \\
\text { iron, } \mathrm{kg}\end{array}$ & - & $\begin{array}{c}142-670 \\
2.3-2.6\end{array}$ & $\begin{array}{c}5000 \\
580+390\end{array}$ \\
\hline Reduction in dose rate & - & 2.0-4.1 times & 5.2 times \\
\hline Liquid radwaste, $\mathrm{m}^{3}$ & - & $1200-1800$ & $4000-5000$ \\
\hline Process time, $\mathrm{hr}$ & - & $60-70$ & $\begin{array}{c}1 \text { st cycle }-62 \\
2 \text { nd cycle }-56\end{array}$ \\
\hline
\end{tabular}


- partial drainage of the solution and its replacement with water; introduction of $\mathrm{H}_{2} \mathrm{O}_{2}$ to a concentration of about $0.25 \mathrm{~g} / \mathrm{L}$

- circulation of the solution for $3-5 \mathrm{hr}$ at $70-75^{\circ} \mathrm{C}$

- drainage of the decontamination solution

- water wash.

The data in Table 8.4 show that chemical decontamination removes much more iron and gamma radioactivity than the reagent-free method. This indicates that more radioactive deposits are removed from the core. If reagent-free decontamination is used, the deposits removed are mostly from the surfaces of the MFC circuit. The reagent-free decontamination method is preferable in terms of the amount of liquid radwastes, and process efficiency. After decontamination, the water is drained from the MFC circuit and the circuit is dried. Equipment which is not to be used during long-term storage is dismantled.

The problem whether to decontaminate and dismantle the fuel channels requires special consideration when the unit is being prepared for long-term storage. Operating an RBMK-1000 reactor results in radioactive corrosion deposits on the surface of and induced radioactivity in the fuel channels.

If the MFC circuit is decontaminated when the unit is being prepared for long-term storage, the layer of loose corrosion deposits will be removed from the fuel channel. If the MFC circuit is not decontaminated, the fuel channels must be decontaminated after they are removed, but the problem of dismantling the fuel channels is better considered after MFC circuit decontamination. This is related to the fact that, as was the case at plutonium-production reactors, the graphite stack may be partially destroyed because of radiation-induced changes that took place during operation, disturbances to fuel channel integrity, and water and steam leaks into the graphite stack.

Therefore, depending on the condition of the graphite stack resulting from the duration and intensity of neutron radiation, disturbances to channel integrity, and the possibility of graphite oxidation and radiation ballooning, the following alternatives should be assessed:

- If the mechanical properties of the graphite are not adequate, the fuel channels should be left in place for long-term storage.

- If the mechanical properties of the graphite stack are adequate, the removal of the fuel channels should be assessed.

The decision to dismantle and decontaminate fuel channels may be made if it has been established that dismantling them will not cause serious damage to the graphite stack blocks.

The next item for decontamination at this stage in decommissioning should be the gas circuit, but the gas circuit cannot be chemically decontaminated. Either the gas circuit equipment should be dismantled and then decontaminated or the gas circuit should be decontaminated while the circuit is being purged with gas or vapor mixtures or thermally. 
Non-circuit equipment should be inspected to determine its level of radioactive contamination and to decide whether to decontaminate for re-use. After the circuits are decontaminated, their individual segments, e.g., the condensate-feed track, may be put into safe storage after "mild" chemical decontamination.

Various polymer coatings may be used extensively in equipment decontamination and dismantling. Several classes of these coatings have now been developed: protective, to protect metal against corrosion; decontaminating, to remove radioactive contaminants from the surface; isolating, to protect surfaces from radioactive contamination or isolate contaminated surfaces; localizing, to isolate local contaminants, seepage. The polymer coatings may be removable or permanent. In terms of fire safety, it is better to use water-soluble formulas, i.e., those based on polyvinyl alcohol.

When unit equipment is dismantled, the polymer coatings may be used to isolate contaminated surfaces as they are cut and broken up or to protect clean surfaces and to prevent the propagation of radioactive contaminants into the atmosphere when contaminated equipment is transported to the burial or temporary storage site. The thickness of such a coating is $100-250 \mu \mathrm{m}$, and the coating retains its mechanical strength for 1 to 1.5 years. These polymer coatings may also be applied to the surface of silicate materials, such as concrete and brick. If necessary, the polymer coating may be removed after it has been processed with water or a steam-water mixture. To make it easier to remove the polymer film, the coating surface of the equipment should be first treated with an alkaline solution.

Polyvinyl alcohol-based decontaminating coatings may also include decontaminating agents such as organic or mineral acids. Several such formulas have been developed for use on various surfaces, including those with complicated contours.

Decontamination coefficients for polymer coatings may reach 8-130, depending on the radionuclide composition of the surface contaminants. The use of these coating almost eliminates the formation of secondary liquid radwastes. The detached polymer films may be collected into bags and crushed or compacted by bituminization or hot compacting. 


\subsection{Radwaste Handling at LNPP}

\subsection{Concept of Radwaste Handling at Russian NPPs}

The evolution of atomic power engineering requires a definite technical policy toward radwaste handling at atomic power facilities. This policy should be developed and carried out with regard to the accepted state waste handling concept. The technical policy on handling radwaste at NPPs in Russia presumes the following five waste handling stages and a burial stage (Figure 9.1).

Stage One: Collection and separation of radwaste according to radioactivity level.

Liquid radwastes at an NPP are collected and separated by both their radioactivity level, their salt content, and the presence of surfactants. Solid radwaste is sorted by radioactivity level and is further separated into combustible, noncombustible, metal, and "others," according to subsequent planned processing or storage.

Stage Two: Temporary storage of untreated wastes at the NPP.

Temporary storage reflects the current lack of solid radwaste processing units at NPPs. It may also be used to lower the waste's radioactivity through the decay of short-lived radioisotopes.

Stage Three: Processing (treatment) of radwaste.

The objective of this stage is to process liquid and solid radwaste into forms suitable for longterm storage, transport, and burial. The criteria for selecting radwaste processing methods should be chemical, thermal, and radiation stability, explosion safety, mechanical strength, the lack of gas release, and economic indicators.

Liquid radwastes are treated and solidified, and the product is placed in containers (drums, casks, or others). Solid radwastes are burned, compacted, deactivated, coated with protective coatings, and/or placed in containers (drums, casks, or other containers).

Stage Four: Long-term storage of treated radwaste at the NPP.

This stage is needed because there is a lack of regional repositories in Russia. It may also be carried out to lower the radioactivity of wastes before they are transported and finally buried.

Stage Five: Transport of wastes both at the NPP and off site to repositories.

Stage Six: Burial of radwaste in repositories.

The purpose of this stage is the final removal of radwaste from areas of human activity. Wastes may be buried either in near-surface (shallow) repositories or in deep geological formations depending on the isotope content and other characteristics of the wastes.

At present no Russian NPP has the required facilities for processing solid radwaste to reduce its volume or facilities to convert solid radwaste into forms suitable for transport and burial in compliance with current regulatory requirements. Moreover, waste treatment facilities at Russian NPPs are basically Russian-made, and some of them must be upgraded. 
TEMPORARY STORAGE:

IN CONTAINERS, HOPPERS

TREATMENT:

CONCENTRATION, SOLIDIFICATION, COMBUSTION, COMPACTION,

DEACTIVATION, PACKAGING OR CONTAINERIZATION

\begin{tabular}{|c|}
\hline LONG-TERM TEMPORARY STORAGE ON-SITE: \\
IN ABOVE-GROUND STRUCTURES, \\
IN NEAR-SURFACE STRUCTURES
\end{tabular}

TRANSPORTATION:

CONSTRUCTION OF TRANSPORT CONTAINERS, TRANSPORT, UNLOADING OF TRANSPORT CONTAINERS

BURIAL:

IN GEOLOGICAL FORMATIONS, IN NEAR-SURFACE STRUCTURES

Figure 9.1. Main Stages in NPP Radwaste Handling

Table 9.1 presents the current requirements of Russian NPPs with water-cooled graphitemoderated reactors for radwaste processing technologies and equipment (" + " signifies a future need, "-" signifies no need). Tables 9.2 and 9.3 show the amounts of operational liquid and solid radwaste that have accumulated at Russian NPPs with water-cooled, graphite-moderated reactors.

\subsection{Operational Radwaste at the LNPP}

The operation of LNPP units creates a large amount of operational liquid and solid radwaste of varying radioactivity (low, moderate, high) that is sent to the power plant's storage facility.

Tables 9.4 and 9.5 show the classification of radwaste by the categories used in Russia for liquid and solid radwaste. Table 9.6 describes the basic components of the operational radwaste created annually at one LNPP unit. The storage facilities at LNPP now contain a large amount of liquid radwaste that is stored in tanks from 500 to $3200 \mathrm{~m}^{3}$ in capacity. Sediment has formed at the 
Table 9.1. Radwaste Handling Technology Needs

\begin{tabular}{|l|c|c|c|c|}
\hline \multirow{2}{*}{ Technology } & \multicolumn{4}{c|}{ NPP } \\
\cline { 2 - 5 } & Beloyarsk & Kursk & Smolensk & Leningrad \\
\hline Solid radwaste compaction & Exists & + & + & + \\
\hline Burning of combustible solid radwaste & Exists & + & + & + \\
\hline Remelting of metal solid radwaste & Exists & - & - & + \\
\hline Cementation of liquid radwaste & + & + & + & + \\
\hline Bitumization of liquid radwaste & - & - & - & Exists \\
\hline Vitrification of molten salt & - & - & - & $+^{(a)}$ \\
\hline (a)LNPP is supposed to develop a low-waste technology with vitrification of a non-radioactive salt solution. \\
\hline
\end{tabular}

Table 9.2. Liquid Radwaste Volumes at Russian NPPs with Water-Cooled GraphiteModerated Reactors (as of December 31, 1995)

\begin{tabular}{|l|c|c|c|c|}
\hline \multicolumn{1}{|c|}{$\mathrm{NPP}$} & $\begin{array}{c}\text { Liquid radwaste } \\
\text { storage } \\
\text { capacity, } \mathrm{m}^{3}\end{array}$ & $\begin{array}{c}\text { Amount of } \\
\text { liquid } \\
\text { radwaste, } \mathrm{m}^{3}\end{array}$ & $\begin{array}{c}\text { Liquid radwaste } \\
\text { storage capacity } \\
\text { used, \% }\end{array}$ & $\begin{array}{c}\text { Radioactivity of } \\
\text { liquid radwaste, } \\
\mathrm{Ci} \times 10^{4}\end{array}$ \\
\hline Beloyarsk & 6400 & 5449 & 85.1 & 0.14 \\
\hline Bilibinsk & 1000 & 686.9 & 68.7 & 0.02 \\
\hline Kursk & 63000 & 35238 & 55.9 & 1.35 \\
\hline Leningrad & 17020 & 11923 & 70.1 & 0.42 \\
\hline Smolensk & 19400 & 11725 & 57.6 & 0.41 \\
\hline
\end{tabular}

bottom of some of these tanks, and others contain a large amount of ion-exchange resins and perlite. Table 9.7 shows the dynamics of LNPP liquid radwaste delivery to storage facilities.

In accordance with recommendations by the International Atomic Energy Agency and current Russian regulations, all liquid radwaste must be solidified and then stored at the NPP until it is removed to regional repositories. For this purpose the LNPP has built a liquid radwaste bitumization facility that processes some of the operational radwaste at the plant. After bitumization the wastes are sent for storage at specialized canyons in building 667 at the power plant (there are 12 canyons, each with a capacity of $2000 \mathrm{~m}^{3}$ ).

At present, all bitumized liquid radwastes at LNPP are stored in a storage compound on site; perlite, ion-exchange resins, sediments, and other newly accumulated wastes are still stored in tanks. 
Table 9.3. Solid Radwaste Volumes at Russian NPPs with Water-Cooled GraphiteModerated Reactors (as of December 31, 1995)

\begin{tabular}{|l|c|c|c|c|}
\hline \multicolumn{1}{|c|}{ NPP } & $\begin{array}{c}\text { Solid radwaste } \\
\text { storage capacity, } \mathrm{m}^{3}\end{array}$ & $\begin{array}{c}\text { Amount of solid } \\
\text { radwaste, } \mathrm{m}^{3}\end{array}$ & $\begin{array}{c}\text { Solid radwaste } \\
\text { storage capacity } \\
\text { used, \% }\end{array}$ & $\begin{array}{c}\text { Solid radwaste } \\
\text { radioactivity, Ci }\end{array}$ \\
\hline Beloyarsk & 23760 & 14299 & 60.2 & 2.5 \\
\hline Bilibinsk & 3150 & 2152 & 68.3 & 70 \\
\hline Kursk & 21760 & 21643 & 99.5 & 1880 \\
\hline Leningrad & 24000 & $15724^{(a)}$ & 65.6 & 800 \\
\hline Smolensk & 15150 & 10630 & 70.2 & 90 \\
\hline
\end{tabular}

Table 9.4. Classification of Liquid Radwaste

\begin{tabular}{|l|c|}
\hline \multicolumn{1}{|c|}{ Liquid radwaste category } & $\begin{array}{c}\text { Volumetric radioactivity of } \\
\text { liquid radwaste, } \mathrm{Bq} / \mathrm{L}\end{array}$ \\
\hline 1. Low radioactivity & less than $3.7 \times 10^{5}$ \\
\hline 2. Moderate radioactivity & from $3.7 \times 10^{5}$ to $3.7 \times 10^{10}$ \\
\hline 3. High radioactivity & more than $3.7 \times 10^{10}$ \\
\hline
\end{tabular}

Table 9.5. Classification of Solid Radwaste

\begin{tabular}{|c|c|c|c|}
\hline $\begin{array}{l}\text { Solid radwaste } \\
\text { category }\end{array}$ & $\begin{array}{l}\text { Gamma-ray dose rate } \\
\text { at a distance of } 10 \mathrm{~cm} \\
\text { from the surface, } \\
\mathrm{mrem} / \mathrm{hr}(\mathrm{mSv} / \mathrm{hr})\end{array}$ & $\begin{array}{l}\text { Specific beta- } \\
\text { activity, } \\
\mathrm{Bq} / \mathrm{g}(\mathrm{Ci} / \mathrm{kg})\end{array}$ & $\begin{array}{l}\text { Specific alpha- } \\
\text { activity, } \\
\text { Bq/g }(\mathrm{Ci} / \mathrm{kg})\end{array}$ \\
\hline 1. Low radioactivity & $\begin{array}{c}0.3-30 \\
(3-300)\end{array}$ & $\begin{array}{l}7.4 \times 10^{1}-3.7 \times 10^{3} \\
\left(2 \times 10^{-6}-1 \times 10^{-4}\right)\end{array}$ & $\begin{array}{l}7.4 \times 10^{0}-3.7 \times 10^{2} \\
\left(2 \times 10^{-7}-1 \times 10^{-5}\right)\end{array}$ \\
\hline $\begin{array}{l}\text { 2. Moderate } \\
\text { radioactivity }\end{array}$ & $\begin{array}{c}30-1000 \\
(300-10000)\end{array}$ & $\begin{array}{c}3.7 \times 10^{3}-3.7 \times 10^{6} \\
\left(1 \times 10^{-4}-1 \times 10^{-1}\right)\end{array}$ & $\begin{array}{c}3.7 \times 10^{2}-3.7 \times 10^{5} \\
\left(1 \times 10^{-5}-1 \times 10^{-2}\right)\end{array}$ \\
\hline 3. High radioactivity & $\begin{array}{l}\text { more than } 1000 \\
(10000)\end{array}$ & $\begin{array}{l}\text { more than } 3.7 \times 10^{6} \\
\left(1 \times 10^{-1}\right)\end{array}$ & $\begin{array}{l}\text { more than } 3.7 \times 10^{5} \\
\qquad\left(1 \times 10^{-2}\right)\end{array}$ \\
\hline \multicolumn{2}{|c|}{ Unrestricted use } & \multicolumn{2}{|c|}{$\begin{array}{l}\text { In Russia there are no corresponding } \\
\text { requirements accepted at the State level } \mathrm{I}^{(\mathrm{a})}\end{array}$} \\
\hline
\end{tabular}


Table 9.6. Characteristics of Operational Radwaste Deliveries from One NPP Unit with an RBMK-1000 Reactor

\begin{tabular}{|c|c|}
\hline Radwaste characteristic & Amount \\
\hline $\begin{array}{l}\text { 1. Evaporator bottoms: } \\
\text { - delivery, } \mathrm{m}^{3} / \mathrm{yr} \\
\text { - } \text { average salt content of evaporator bottoms, } \mathrm{g} / \mathrm{L} \\
\text { - total amount of salts, tonnes/yr } \\
\text { - } \text { specific radioactivity of evaporator bottoms, } \mathrm{Ci} / \mathrm{L}\end{array}$ & $\begin{array}{c}300-500 \\
300-350 \\
90-175 \\
5 \times 10^{-5}\end{array}$ \\
\hline $\begin{array}{l}\text { 2. Low-radioactivity sorbents: } \\
\text { - delivery, } \mathrm{m}^{3} / \mathrm{yr} \\
\text { - } \quad \text { specific radioactivity, } \mathrm{Ci} / \mathrm{L}\end{array}$ & $\begin{array}{c}16 \\
3 \times 10^{-3}\end{array}$ \\
\hline $\begin{array}{l}\text { 3. High-radioactivity sorbents: } \\
\text { - delivery, } \mathrm{m}^{3} / \mathrm{yr} \\
\text { - } \quad \text { specific radioactivity, } \mathrm{Ci} / \mathrm{L}\end{array}$ & $\begin{array}{c}22.0 \\
5 \times 10^{-2}\end{array}$ \\
\hline $\begin{array}{l}\text { 4. Perlite: } \\
\text { - delivery, } \mathrm{m}^{3} / \mathrm{yr} \\
\text { - } \text { specific radioactivity, } \mathrm{Ci} / \mathrm{L}\end{array}$ & $\begin{array}{c}25 \\
2 \times 10^{-3}\end{array}$ \\
\hline $\begin{array}{l}\text { 5. Solid radwaste } \\
\text { - delivery, } \mathrm{m}^{3} / \mathrm{yr} \\
\text { - } \text { solid radwaste group } 1 / 2 / 3, \%\end{array}$ & $\begin{array}{c}400 \\
\text { to } 65 / \text { to } 30 / \text { to } 5\end{array}$ \\
\hline $\begin{array}{l}\text { 6. Sanitary waste water: } \\
\text { - delivery, } \mathrm{m}^{3} / \mathrm{yr} \\
\text { - } \text { salt content, } \mathrm{kg} / \mathrm{m}^{3} \\
\text { - } \text { specific radioactivity, } \mathrm{Ci} / \mathrm{m}^{3}\end{array}$ & $\begin{array}{c}100,000-130,000 \\
0.2 \\
2 \times 10^{-6}\end{array}$ \\
\hline $\begin{array}{l}\text { 7. Ion-exchange resins: } \\
\text { - delivery, } \mathrm{m}^{3} / \mathrm{yr} \\
\text { - specific radioactivity, } \mathrm{Ci} / \mathrm{L}\end{array}$ & $\begin{array}{c}84 \\
3 \times 10^{-3}\end{array}$ \\
\hline
\end{tabular}


Table 9.7. Liquid Radwaste Deliveries from LNPP Units

\begin{tabular}{|c|c|c|c|c|c|}
\hline \multirow{2}{*}{ Years } & \multicolumn{2}{|c|}{\begin{tabular}{c} 
Delivery of liquid radwaste from LNPP Units, $\mathrm{m}^{3}$ \\
\cline { 2 - 4 }
\end{tabular}} & $\begin{array}{c}\text { Evaporator } \\
\text { bottoms } \\
\text { botoms } \\
\mathrm{m}^{3}\end{array}$ & $\begin{array}{c}\text { Ion-exchange } \\
\text { resins }\end{array}$ & $\begin{array}{c}\text { Bitumen } \\
\text { compound } \\
\text { produced, } \\
\mathrm{m}^{3}\end{array}$ \\
\hline 1984 & 1900 & 95 & 920 & 1007 & 615 \\
\hline 1986 & 1663 & 72 & 724 & 1846 & 1108 \\
\hline 1987 & 1513 & 132 & 586 & 2012 & 1481 \\
\hline 1988 & 1321 & 131 & 725 & 2255 & 1096 \\
\hline 1989 & 1229 & 82 & 582 & 2144 & 1070 \\
\hline 1990 & 1740 & 111 & 730 & 2280 & 1347 \\
\hline 1991 & 1793 & 69.7 & 916 & 2033 & 1566 \\
\hline 1992 & 1419 & 145 & 661 & 3602 & 2267 \\
\hline 1993 & 1335 & 42 & 592 & 2388 & 1677 \\
\hline 1994 & 1359 & 51 & 596 & 619 & 463 \\
\hline 1995 & 1695 & 45.2 & 733 & 1100 & 1087 \\
\hline (a)With a solid/liquid radwaste ratio of $1: 10$. & & & \\
\hline
\end{tabular}

The solid radwastes formed at LNPP were originally sent to Lenspetskombinat for burial. Lenspetskombinat is a specialized enterprise that collects, processes, and buries all the radioactive waste for the city of St. Petersburg, Leningrad Oblast, and several other adjacent oblasts. Combustible solid radwaste from LNPP was processed at Lenspetskombinat's incinerator, and all other unprocessed solid radwaste were containerized and buried.

The solid radwaste created at LNPP and sent to Lenspetskombinat had the following composition:

- concrete and construction debris - $60 \%$

- combustible wastes (boards and litter) $-10 \%$

- metal wastes $-30 \%$.

Table 9.8 shows the volume and radioactivity of LNPP solid radwaste deliveries to Lenspetskombinat.

In 1996, however, for reasons beyond the control of LNPP, its solid radwaste was no longer accepted at Lenspetskombinat. The emergency (free) capacity assigned to LNPP at Lenspetskombinat solid radwaste storage facilities is only $330 \mathrm{~m}^{3}$, which does not satisfy its requirements. 
Table 9.8. Solid Radwaste Deliveries from LNPP to Lenspetskombinat

\begin{tabular}{|c|c|c|}
\hline Years & Waste volume, $\mathrm{m}^{3}$ & Radioactivity, $\mathrm{Ci}$ \\
\hline 1989 & 2162 & 30.0 \\
\hline 1990 & 3001 & 24.0 \\
\hline 1991 & 3352 & 24.7 \\
\hline 1992 & 4277 & 26.7 \\
\hline 1993 & 2907 & 11.4 \\
\hline 1994 & 2791 & 5.1 \\
\hline 1995 & 1798 & 4.4 \\
\hline 1996 & 234 & $\begin{array}{c}\text { low-level } \\
\text { moderate-level }\end{array}$ \\
\hline 1997 & 63 & $\begin{array}{c}\text { low-level } \\
\text { moderate-level }\end{array}$ \\
\hline
\end{tabular}

LNPP therefore is building its own solid radwaste storage facility. The design capacity of the storage facility LNPP (Building $674 \mathrm{R}$ ) is about $18,000 \mathrm{~m}^{3}$. At present metal radwaste is in an organized storage facility at LNPP.

\subsection{Radwaste Handling Program}

\subsubsection{Liquid Radwaste Handling}

The liquid radwaste handling program at LNPP is based on experience operating the waste processing equipment at the plant's chemical department. The provisions of the program define the basic directions in the development of liquid radwaste processing technology and the upgrading of radwaste treatment equipment at LNPP.

It is assumed that the existing equipment will be upgraded if required and its capacities increased to meet the needs of the decommissioning of LNPP units.

Reduction in liquid radwaste volume. The basic volume reduction process for liquid radwaste (sanitary waste water, water from equipment decontamination, and other liquid wastes) will be evaporation to a salt content of $300-350 \mathrm{~g} / \mathrm{L}$; further treatment to the condensate standard on precoat, charcoal, and ion-exchange filters; and condensate return to the plant's working circuit.

To increase the reliability of liquid radwaste processing systems and the operating life of evaporation equipment, which is used on high-chlorine ion-content solutions (up to $18 \%$ sodium chloride in the evaporator bottoms), design work is being done to develop molybdenum steel evaporation units, which are more resistant to corrosion by chloride-containing ions. 
Treatment of heterogeneous liquid radwaste. In 1994, under the TACIS program, LNPP began a collaboration with Magnox Electric Company to solve the problem of processing filtering material pulps and slurries. The most expedient solution to this problem is to extract the materials from temporary storage tanks, concentrate them, and then incorporate them into a slag-cement matrix in a reinforced concrete container. In 1997, a supplier will be chosen. It is assumed that in 1998 the supplier will submit designs approved by inspection agencies and that areas at LNPP will be readied for installation of the new process equipment. According to the schedule prepared by Magnox Electric, installation of pulp and slurry extraction equipment should be completed in 1998; installation of startup and adjustment equipment and the commissioning of the cementation plant equipment should take place in 1999.

Treatment of homogeneous liquid radwastes. Because of the fire hazard of the bitumen compound, a contract was signed in 1994 to build two low-waste evaporator bottoms processing plants in free space at the NPP chemical department's waste processing complex. The process involves the following procedures:

- deep removal of ${ }^{134,137} \mathrm{Cs}$ on cartridge filters with an ion-selective sorbent, followed by cementation of the spent filter cartridges in 200-liter barrels or reinforced concrete containers (with an annual usage of 150-200 barrels or containers)

- removal of radionuclides ${ }^{60} \mathrm{Co},{ }^{51} \mathrm{Cr}$, and ${ }^{90} \mathrm{Sr}$ from the solution resulting after the first procedure; production of a permeate with a specific radioactivity of less than $1.0 \times 10^{-7} \mathrm{Ci} / \mathrm{L}$; and return of the slurry-containing solution to the liquid radwaste temporary storage tank

- drying of the permeate with sand and fluxing additives in a vacuum rotary dryer, followed by vitrification of the salts in a glassmaking furnace to produce about $2-4$ tonnes a day of glass granulate with a specific radioactivity below $1.0 \times 10^{-7} \mathrm{gram}$-eq. Ra/g

- collection of nitrous oxides in the glassmaking furnace's gas treatment system to produce nitric acid and bring its parameters to within the norms.

Treatment of liquid radwaste containing surfactants. Liquid radwaste containing surfactants is formed primarily during the decontamination of work clothing, work areas, and heavily lubricated equipment. The processing of the liquid radwastes containing surfactants is complicated because they tend to foam and produce a low-quality condensate that must be sent for repeat evaporation. Moreover, if the surfactant content in the evaporator bottoms is high, there may be problems processing the liquid radwaste with low-waste technology, because the ion-selective sorbents and semipermeable membranes are poisoned, and the drying process and the increasing of the amount of impurities in the nitric acid are complicated.

LNPP has designed a unit to treat spent water from special laundries. The design is based on foam floatation and biofiltration methods with subsequent destruction of the surfactants in an ionizer in a foam concentrate in recirculation mode. The water from which the surfactants has been removed is returned to the general flow of sanitary waste water for processing.

One may state that these procedures, as a complement to the LNPP's current liquid radwaste processing infrastructure, will make it possible to process (concentrate) all liquid wastes formed during operation of the power plant's units until 2005. 


\subsubsection{Solid Radwaste Handling}

Low- and moderate-radioactivity (low- and moderate-level) solid radwaste (Table 9.5) at LNPP is created when equipment, piping, fittings, and thermal insulation are repaired, and when water and air treatment filters are replaced.

High-radioactivity (also referred to as "high-level") solid radwaste results from replacing spent absorption rods, energy release sensors, and other components in the reactor core and during reconstruction of NPP units to replace fuel channels. At present about $100 \mathrm{~m}^{3}$ of highradioactivity solid radwaste are in temporary storage at LNPP.

LNPP does not have its own solid radwaste repositories or facilities to burn, compact, or package low- and moderate-level solid radwaste. All low- and moderate-level solid radwaste was removed previously to repositories at Lenspetskombinat. High-radioactivity solid radwaste (spent absorbers and fuel channels, energy release sensors, etc.) is crushed and warehoused for temporary storage on site.

The solid radwaste handling program at LNPP calls for upgrading existing equipment and constructing a solid radwaste processing facility. The basic points of the program are

1. LNPP and Lenspetskombinat have agreed to provide the NPP with a $500 \mathrm{~m}^{3}$ solid radwaste storage facility at building No. 49 at Lenspetskombinat.

2. A procedure for organizing the opening and further filling of compartments in building No. 668V at Lenspetskombinat, which is reserved for LNPP, has been worked out and approved. The approximate free space in the compartments is $400 \mathrm{~m}^{3}$. Another two compartments with a capacity of $600 \mathrm{~m}^{3}$ in building $668 \mathrm{~V}$ are also to be made available.

3. Technical documentation for construction of a solid radwaste storage facility at LNPP (building 674R) has been developed. This building is intended to store low- and moderate-level $\left(180,000 \mathrm{~m}^{3}\right)$ and high-level solid radwaste $\left(720 \mathrm{~m}^{3}\right)$. Partial commissioning of the storage facilities was scheduled as early as 1996. The total capacity of the storage facilities for low-, moderate-, and high-level solid radwaste should reach $160,000 \mathrm{~m}^{3}$, and the facilities should be commissioned by the end of 1997.

4. Technical documentation for development of a $1-\mathrm{m}^{3}$ reinforced concrete cask for storing low- and moderate-level solid radwaste has been developed. Five test casks were produced, tested, and certified in 1997. Work is being done to develop a solid radwaste storage facility based on these casks.

5. The design is being developed for a solid radwaste processing facility including the following equipment: waste receiving and sorting, cold compacting, hot compacting (for plasticate waste), waste incineration with gas treatment, and decontamination and floatation of metal wastes. 


\subsection{Radwaste Handling Strategy During the Decommissioning of LNPP Unit \#1}

When LNPP Unit \#1 is decommissioned, the total radwaste to be handled will consist of

- 30 years worth of operational liquid (solidified) and solid wastes

- liquid and solid wastes created during unit decommissioning and during the operation of radwaste processing facilities (according to estimates, these wastes may equal 10-15\% of the volume of accumulated operational wastes)

- solid wastes from disassembly of equipment, buildings, and structures.

Tables 9.9 and 9.10 contain estimates of the volume, or weight, of wastes in each category.

Radwaste created during unit decommissioning must be processed: liquid radwaste is processed and solidified; solid radwaste is incinerated; non-combustible solid radwaste is compacted. High radioactivity solid radwaste must be placed in containers (drums, casks) and made monolithic with a cement solution, except for the graphite blocks in the reactor stack, whose handling requires a special process.

A large amount of metal wastes will be created when equipment is dismantled. These wastes must either be decontaminated and remelted to return the metal to the economy or compacted and sent for storage or burial. Remelting makes it possible to further purify metal and compact the wastes; however, metal waste with induced radioactivity cannot be purified during subsequent remelting. Therefore, it must be compacted and sent for storage until the ${ }^{60} \mathrm{Co}$ decays. After the ${ }^{60} \mathrm{Co}$ decays and the level of residual radioactivity has been estimated, further use of the metal can be analyzed.

The establishment of regional repositories in Russia has been deferred for an indefinite period. Therefore, the problem of burying radwaste from Russian NPPs cannot be solved in the near future. Since radioactive waste continues to accumulate at LNPP, specialized long-term storage sites must be built at the plant. The capacity of the storage facility at the plant must take into account the volume of waste accumulated over the entire NPP unit operating period and of the waste that will be created when the units are decommissioned.

Obviously the problem of radwaste handling at LNPP must be solved considering the state policy and radwaste handling program and the provisions of federal law on radioactive wastes, which state that the final stage of NPP radwaste handling is burial in regional repositories.

Table 9.9. Estimated Volume of Operational Radwaste Created Over 30 Years for an NPP Unit with an RBMK-1000

\begin{tabular}{|l|c|}
\hline \multicolumn{1}{|c|}{ Type of radwaste } & Volume, $\mathrm{m}^{3}$ \\
\hline Solidified (bitumized) liquid radioactive wastes & 6000 \\
\hline Solid radioactive wastes & 12000 \\
\hline
\end{tabular}


Table 9.10. Estimate of Solid Radwaste Created During the Dismantling of an NPP Unit with an RBMK-1000(a)

\begin{tabular}{|l|c|}
\hline \multicolumn{1}{|c|}{ Type of solid radwaste } & Weight, tonnes \\
\hline Fuel channel zirconium & 120 \\
\hline Reactor stack graphite & 1800 \\
\hline Metal structures & \\
\hline Equipment $^{(b)}$ & 15000 \\
\hline Concrete & $(\mathrm{b})$ \\
\hline $\begin{array}{l}\text { (a)The amount of solid radwaste depends on how decommissioning is done. It must } \\
\text { be specified when the decommissioning plan for a specific NPP unit is developed. }\end{array}$ & 3600 \\
\hline $\begin{array}{l}\text { (b)The maximum estimate of the amount of radioactively contaminated wastes that } \\
\text { may form during dismantling of various unit components (theoretically, if certain } \\
\text { conventions are observed, the quantity of these wastes may be reduced). }\end{array}$ \\
\hline
\end{tabular}

Consequently, if LNPP is to meet the requirements of the state radwaste handling policy, the waste must be treated and stored at the plant in an orderly fashion that will permit later removal for burial. Radwaste storage facilities at the plant must be built before decommissioning work begins and must be designed to store the total volume of radwaste in processed and containerized form, ready for removal for burial.

Naturally, the switch to organized long-term radwaste storage at LNPP will require a certain amount of time to complete organizational and technical procedures, both at the NPP and throughout the entire atomic power engineering sector. Meanwhile, radwastes must be stored at LNPP in compliance with accepted design and technological decisions.

\subsubsection{Problems Handling Radwaste Created During Unit \#1 Decommissioning}

LNPP does not have a full complement of facilities for processing solid radwaste to reduce its volume or for processing liquid radwaste into forms suitable for transport and burial in compliance with current regulatory requirements. The uncertainty in the construction of a regional repository for radwaste and the growing amount of waste at LNPP makes it necessary to set up long-term radwaste storage at the site.

If the operating life of Unit \#1 is extended (by approximately 10 years, or until 2014), the current radwaste handling program at LNPP will need to be revised, because additional liquid and solid radwaste storage will have to be built at the plant. The need to build solid radwaste storage will become acute when the decommissioning of Unit \#1 and the other units at LNPP begins. For LNPP to meet the requirements of the state radwaste handling policy, wastes must be processed and then stored on site in an orderly fashion to permit later removal for burial. The facilities required to process radwaste must be built and commissioned. 
Furthermore, a long-term radwaste storage facility should be built at LNPP. This facility may be a separate building at the plant or specially prepared areas within existing facilities at Unit \#1 may be used for this purpose.

The total amount of wastes created when LNPP Unit \#1 is decommissioned will depend on the unit's final condition and the planned dismantling work (dismantling only the equipment and protective structures, demolishing buildings and structures, etc.). The design parameters for construction of NPPs with RBMK-1000 reactors given in Table 9.11 provide the maximum estimated quantity of waste that may be created when an NPP unit with an RBMK-1000 reactor is decommissioned.

However, the actual volumes of radwaste that will form during the decommissioning will be much lower than the construction quantities indicated in Table 9.11 because standard and, if necessary, intense decontamination of unit equipment and systems may convert about $80 \%$ of the total construction materials suitable for reuse (restricted or unrestricted). Only the remaining $20 \%$ will be radwaste (irradiated graphite, fuel channels, reactor metal structures, etc.) and will need to be sent for long-term storage or burial.

Additional volumes of radwaste (up to hundreds of thousands of tonnes of wastes of different materials) may be created if the buildings and structures of a unit with an RBMK-1000 reactor are fully or partially demolished, e.g., reducing a unit site to "greenfield" condition. However, the choice of this final condition for commercial NPPs will be extremely expensive and can hardly be considered realistic. Nevertheless, from the standpoint of radwaste handling, the decommissioning of LNPP Unit \#1 will create

- a large amount of waste, perhaps hundreds of thousands of tonnes, depending on the choice of decommissioning method and final condition of the unit site

- a large amount of waste categorized as suitable for reuse (restricted or unrestricted).

Waste suitable for "restricted reuse" has radioactivity lower than the bottom threshold for lowradioactivity radwaste but too high to be suitable for unrestricted reuse. The total weight of wastes that may fall into the category of reusable materials may be more than $90 \%$ of the total amount created when the unit is decommissioned. The large amount of these wastes will be one of the critical problems in radiation inspection of materials when the unit is decommissioned. The radiation inspection of these wastes involves tremendous technical difficulties because

Table 9.11. Construction Quantities for an NPP Unit with an RBMK-1000

\begin{tabular}{|l|c|}
\hline \multicolumn{1}{|c|}{ Type of structure or equipment } & Amount \\
\hline Reinforced concrete structures, thousand $\mathrm{m}^{3}$ including: & $189-192$ \\
- monolithic & 140 \\
- composite & $49-52$ \\
\hline Steel structures, thousand tonnes & $90-95$ \\
\hline Equipment and piping, thousand tonnes & 49 \\
\hline $\begin{array}{l}\text { Metal for special facings for areas and vessels, } \\
\text { thousand tonnes }\end{array}$ & 5.25 \\
\hline
\end{tabular}


of their large quantity and their low radioactivity. In handling these wastes, it will be necessary to 1) conduct a preliminary radiation inspection (at the stage of equipment, structure, or building dismantling; during sorting, remelting, packaging processes, etc.) to store them separately at specially prepared sites and 2) conduct a final radiation inspection. The solution to this problem will involve both technical challenges and expense and the need to ensure environmental safety, since it is not entirely clear what to do with these wastes.

The amount of wastes suitable for reuse will be rather high, and they cannot be stored without a radiation inspection. Since atmospheric precipitation may cause radionuclides to leach out of them, they may accumulate locally and exceed the background level of specific radioactivity. Burying this category of waste cannot be an acceptable solution, since it is extremely expensive. Other solutions must be found.

At present there are no regulatory requirements for handling materials suitable for reuse (restricted or unrestricted) created during radwaste processing nor regulatory requirements for handling the potentially large quantities of non-radioactive wastes that will be generated when NPP units are decommissioned. Nor is there a Russian regulatory basis for designing and building long-term radwaste storage facilities at NPPs. 


\subsection{Safety Assurance During Decommissioning Leningrad Unit \#1}

\subsection{Safety Assurance for Spent Nuclear Fuel}

\subsubsection{Nuclear Safety Assurance in Handling Spent Nuclear Fuel}

The nuclear safety of transportation and process operations for handling spent nuclear fuel is ensured by a set of technical procedures in unit buildings and at the spent nuclear fuel storage facility. These systems have been approved by GAN.

The basic technical procedures ensuring nuclear safety during normal operation and in case of design-basis accidents are

- spacing steel containers containing spent fuel assemblies in ponds to ensure nuclear safety both under normal operating conditions and in case the pond's heat removal system malfunctions, which may cause the water to boil

- removing immediately from the pond a fuel assembly container that has fallen

- spacing spent fuel assemblies in a transport container to ensure nuclear safety.

Nuclear safety can be violated only in cases of non-design-basis accidents (e.g., accidents related to equipment, civil structures, or flying objects falling into a pond) that may result from dense packing of spent fuel assemblies in the pond with a burnup fraction of at least $8 \mathrm{MW} \mathrm{x}$ day $/ \mathrm{kg}$.

However, according to estimates, the power of the burst in a non-design-basis accident does not have serious consequences. Contamination of pond areas and adjacent territory (up to a 500-m radius) will result primarily from radioactivity escaping from failed fuel assemblies.

\subsubsection{Physical Protection of the Spent Nuclear Fuel Storage Facility}

The physical protection of the spent nuclear fuel storage facility at Unit \#1 will be ensured by the physical protection system (FPS) existing at LNPP. This system is an integral part of the plantwide system for process, nuclear, and radiation safety, which is a set of organizational, engineering, and process procedures aimed at preventing theft of fissible materials or diversionary actions.

The existing FPS at LNPP performs functions of detecting, detention, and response. The FPS was structured with regard to the nuclear and radiation safety of the nuclear reactors, the systems and equipment supporting them, and other plant-wide process systems.

To ensure prioritization of protection, a three-zone protection principle was used. According to this principle, the territory of an NPP is divided into protected, inner, and critical zones, and areas are categorized depending on the severity of the radiation consequences that may result from unauthorized actions toward the systems and equipment and devices in them.

Organizational FPS measures include organizing security, preparing security, organizing access and inspection of personnel and vehicles, organizing access of emergency crews, organizing the control system, and others. 
Organizational FPS measures include organizing security, preparing security, organizing access and inspection of personnel and vehicles, organizing access of emergency crews, organizing the control system, and others.

FPS engineering and technical measures include engineered protection facilities, protection equipment; an access control system; communications, signaling, TV surveillance, and security lighting systems; an information collection and processing system; power supply systems; and other auxiliary systems.

Three types of controlled access have been set up around the perimeter of the LNPP: for personnel with a ban on carrying fissile materials past the access; for vehicles with a ban on carrying fissile materials past the access; and for receipt (entry) of fissile materials. Vehicle accesses are outfitted with inspection areas, security signaling, TV surveillance cameras, remote-control gates; gate interlock devices; anti-ramming devices; and other equipment. Categorized areas of buildings in critical and inner zones are accessed with in-door terminals with readers and keypads. A TV surveillance system provides visual control. To increase the effectiveness of physical protection for areas in critical zones, which includes the spent nuclear fuel storage facility, a special security service should be set up that would be entitled to access these zones and would be located within the critical zone.

One might conclude that the existing physical protection system at LNPP meets current requirements for monitoring the movement of fissile materials and for storing spent nuclear fuel and wastes from the nuclear fuel cycle and other radioactive contaminants, both across and within the perimeter of the NPP site. The organization of the existing FPS system at LNPP complies technically and theoretically to national and international standards.

\subsection{Radiological Safety Assurance}

The individual effective dose rate for personnel during decommissioning of NPP units with RBMK-1000 reactors will depend on the sources of radiation and will consist of two components: the external radiation dose and the internal radiation dose. External personnel irradiation is the effect on an individual of ionizing radiation from outside; internal irradiation, the irradiation of the human body, its individual organs, and tissues by ionizing radiation when radionuclides enter them. Note that internal and external irradiation may account for different proportions of the equivalent dose at different stages of an NPP life cycle.

An internal irradiation dose is attributable to radionuclides that may enter the human body by inhalation (as a result of breathing radioactive aerosols), orally (together with food and drink) and through skin wounds. At a nuclear power plant, radionuclides enter the body primarily through inhalation.

External irradiation usually plays the primary role during NPP operation because the formation of aerosols is negligible during operations. Moreover, specific organizational and technical procedures are used to reduce radionuclide concentration in the air. These procedures include developing programs for performing hazardous work, setting up repair zones, using different methods for decontaminating equipment to be repaired, outfitting work sites with devices and 
units for local exhaust of contaminated air, using work methods that result in small amounts of aerosols (underwater cutting, wetting surfaces to be treated, etc.), and using efficient individual protection devices.

Most of the labor in unit decommissioning is related to dismantling and disassembling piping and equipment in technological circuits and systems and possible demolition of unit civil structures. Dismantling and demolition work may be done throughout buildings and units. During this work there may be heavy dust formation and a large amount of radioactive aerosols may enter the air.

The unit decommissioning concept used in Russia presumes that a unit will be in long-term safe storage prior to dismantling. Long-term storage will reduce the gamma radiation dose rate through radionuclide decay to levels that do not jeopardize radiation safety during the work. Since the main dose-forming radionuclide at final unit shutdown is ${ }^{60} \mathrm{Co}$, the unit hold time from shutdown to start of decommissioning will depend on its half-life. However, research shows that ${ }^{60} \mathrm{Co}$ is the primary, but not the only, dose-forming radionuclide among contaminants. After ${ }^{60} \mathrm{Co}$ decays other long-lived radionuclides remain, emitting beta radiation and mild X-rays as they decay. These radionuclides include ${ }^{59} \mathrm{Ni}$ and ${ }^{63} \mathrm{Ni}$. These and other radionuclides that resemble them in terms of radiation characteristics will define the radioactivity of the aerosols formed during decommissioning work.

When civil structures are dismantled and demolished, external irradiation may account for a minor portion of the effective dose rate, while internal irradiation is expected to be the major contributing factor.

The Russian Federation Law, "On the Radiation Safety of the Population," established a new standard for the annual maximum permissible dose (MPD) of irradiation for personnel. It is now $0.02 \mathrm{~Sv}$ ( $2 \mathrm{rem})$. The individual dose may be exceeded by up to $0.05 \mathrm{~Sv}$ ( $5 \mathrm{rem})$ once a year, but the individual dose for the next 5 years may not exceed $0.1 \mathrm{~Sv}(10 \mathrm{rem})$. Obviously, the technological processes at any stage in decommissioning must be organized so that these legal requirements are met unconditionally.

\subsubsection{Main Sources of Ionizing Radiation at NPPs}

The main sources of ionizing radiation are radionuclides from fuel fission products and from reactor structural material corrosion products in the main coolant circulating circuit when the reactor is running and from the reactor structural materials when they are made radioactive by neutrons.

Fission products. If there is no damage to fuel elements, the specific radioactivity of the coolant is $10^{4}-10^{6} \mathrm{~Bq} / \mathrm{L}$. If the fuel elements leak, radioactivity may rise to $5 \times 10^{8} \mathrm{~Bq} / \mathrm{L}$ or more. If fission products enter the coolant circulating circuit, the level of equipment radioactivity will rise significantly. This represents a serious hazard for service personnel, especially if there are leaks in the circuit.

According to measurements, the MFC circuit in RBMK-1000 units may have, for example, longlasting fission products such as ${ }^{90} \mathrm{Sr},{ }^{106} \mathrm{Ru},{ }^{137} \mathrm{Cs}$, and ${ }^{144} \mathrm{Ce}$. In addition, if emergency operational 
situations led to direct contact between the nuclear fuel and the coolant, ișotopes of uranium and transuranium elements may be found among the ionizing radiation sources.

Corrosion products in the MFC. When a unit is operating, corrosion occurs on equipment surfaces exposed to the coolant. The physicochemical composition and structure of the corrosion products depend on the structural materials and the water regime of the nuclear power plant. Corrosion products enter the coolant as a result of the erosion and dissolution of the metal. As they travel through the reactor core, they become radioactive in the neutron flux and then settle outside the core, forming sources of beta and gamma radiation. According to measurements, radioactive corrosion products deposition determines $96-98 \%$ of the radioactivity of coolant circulating circuit equipment outside the reactor. Despite the fact that primarily corrosionresistant steels and zirconium alloys are used as structural materials in RBMK-1000 unit MFC circuits, 60 to 90 grams of corrosion products enter the coolant daily while an RBMK-1000 unit is operating.

Activation of nuclear reactor structural materials. Once spent nuclear fuel has been removed from the core, the radioactivity of an RBMK-1000 reactor will depend on the activation of the structural materials in its metal structures and graphite stack. The radioactivity of the reactor's graphite stack depends in turn on the activation of the graphite and the fuel channel tubes in it. Section 4 contains a more detailed description of the structural elements of the RBMK-1000 reactor; Section 6 contains a description of the radionuclides that define the sources of radioactivity in these structures.

\subsubsection{Radiation Safety Assurance During Decommissioning}

During unit decommissioning the work must be organized to ensure that the annual individual effective equivalent dose of $2 \mathrm{rem}(0.02 \mathrm{~Sv})$ is not exceeded. This dose is expected to result primarily from internal irradiation. However, experience gained over the 40 years since the founding of nuclear power engineering makes it possible to point to certain important problems that must be solved in order to meet the $0.02 \mathrm{~Sv}$ requirement.

Choice of filtering materials to ensure efficient aerosol entrapment. It seems highly likely that current methods for suppressing aerosol activity that are effective for relatively small volumes of air will not protect personnel from ionizing radiation if a large amount of aerosols form rapidly in large volumes of air. Doubts about the reliability of existing aerosol radioactivity suppression systems that have demonstrated their high efficiency under NPP operating conditions in largescale decommissioning work include the following:

First, to improve labor productivity in dismantling equipment, piping, and civil structures, methods will be used that are not now used in technological processes or are in quite limited use. These methods include laser cutting, plasma cutting, explosive technologies, and others. Because of the large scale of the work, a large amount of radioactive aerosols will form.

It is extremely likely that the parameters for the distribution by size of the quantity and radioactivity of particles in radioactive aerosols formed during various decommissioning processes will differ from those formed during operational processes. It is also possible that the distribution parameters will depend on the conditions under which the processes are carried out. 
Consequently, the physicochemical properties of aerosols formed during unit decommissioning may differ considerably from the physicochemical properties of aerosols formed while it is in operation.

The efficiency with which filtering materials trap particles depends on particle size. Therefore it is possible that a certain portion of the aerosols may, because of their small size, pass unobstructed through the filtering materials now being used. Special attention should be given to the possibility that ultra-small solid particles suspended in the air (so-called floating dust) will form. Experience shows that trapping them is a rather complicated technical problem.

To date the parameters for the distribution by size of the quantity of particles for non-radioactive aerosols have been determined mostly overseas and only for certain specific metal cutting methods (particularly laser, plasma, and band saw). Russia still has not performed these studies. Moreover, despite many years of experience, the parameters of distribution of the quantity and radioactivity of particles by size in aerosols formed when traditional tools, e.g., abrasive wheels, are used during repair work at NPPs are unknown.

Second, the efficiency and running time of filtration units depend on the concentration of the aerosols in the air. It is quite likely that new conditions and requirements for the operation of filtering units will necessitate a major change in their design.

Ignorance of the basic principles of formation of aerosols during decommissioning and of the conditions for suppressing specific radioactive aerosols will most likely result in inefficient filtering and individual protection devices at the very start of equipment dismantling. The threat of personnel overexposure, environmental contamination, and exposure of the public to radiation in excess of established norms will inevitably cause the work to stop while necessary additional studies are performed. Because these studies must be done rapidly, the results will be typically of low quality. This leads to additional emergency situations, efforts to eliminate their consequences, and the need for further, more careful studies.

To avoid a major rise in the cost of the work and an increase in the time to decommission the unit, research should begin now to determine the physicochemical properties of aerosols formed as a result of the different methods for dismantling equipment and civil structures. Analyses should also be performed to determine the optimum design for the required filtration units.

Radiological inspection of equipment after long-term storage. More than $90 \%$ of the radiation in an NPP unit running at capacity and at final nuclear reactor shutdown is the gamma radiation of the radioactive corrosion products in the circuits and the induced radioactivity of the reactor structural materials and biological shield. Gamma radiation from ${ }^{60} \mathrm{Co},{ }^{59} \mathrm{Fe},{ }^{54} \mathrm{Mn}$ and ${ }^{58} \mathrm{Co}$ is the greatest contributor to the formation of dose fields. These radionuclides form when the neutron flux renders isotopes of iron, cobalt, and nickel, i.e., components of the corrosion-resistant steels and carbon steels, which are the basic materials of nuclear power engineering.

From the standpoint of a continuous medium, iron, nickel, and cobalt are evenly distributed throughout the volume of both corrosion-resistant and carbon steels. The basic steel corrosion in NPP technological circuits is uniform corrosion. These features provide grounds for viewing the film of corrosion products deposits as a continuous medium with uniformly distributed chemical 
elements and radioactive isotopes of these elements within a system. Analysis of the results of experimental research on the formation of a film of radioactive deposits confirms this hypothesis. As operating time increases, the deep layers of deposits are depleted of short-lived isotopes as a result of radioactive decay. The long-lived deposits remain uniformly distributed through the film of corrosion products.

With long-term storage, the external gamma radiation dose rate declines significantly because of the decay of ${ }^{60} \mathrm{Co}$. This decline will reduce the dose during decommissioning. On the other hand, the disappearance of high-energy, high-intensity gamma radiation fields will lead to a loss of radiation monitoring efficiency by traditional methods. Long-lived radioactive isotopes of nickel possess low-energy beta and gamma radiation that is not recorded by standard dosimetry and radiometry instruments. When NPP units are operating and during equipment repair, the distribution of metal radioisotopes in the deposits of corrosion products make it possible to ensure the reliability of radiation monitoring of the radionuclides in the iron group based on the results of measurements of high-energy gamma and beta radiation of ${ }^{59} \mathrm{Fe},{ }^{60} \mathrm{Co},{ }^{54} \mathrm{Mn}$, and ${ }^{58} \mathrm{Co}$.

The loss of a reliable ${ }^{60} \mathrm{Co}$ radionuclide benchmark as a result of radioactive decay while the equipment is in long-term storage inevitably requires developing a system to monitor low-energy beta and gamma radiation. The required equipment should be developed now for monitoring low-energy beta and gamma radiation, or immediate dismantling (DECON) should be the choice in the future.

Radiological inspection for decommissioning planning. The results of comprehensive engineering and radiation inspections of a unit can provide a full picture of the radiation situation in NPP unit areas at various stages of decommissioning. However, the assessment of the anticipated radiological situation while dismantling the reactor metal structures and stack can come from calculations or available measurements.

Table 10.1 shows the results of measuring the radiological situation in certain areas of the MFC circuit and central reactor hall of LNPP Unit \#1. These measurements were taken in 1989-1991 during fuel channel replacement in the reactor. The measurements in Table 10.1 were obtained over 11 months after reactor shutdown, which eliminates the need to account for the contribution of relative short-lived radionuclides that will have no effect on the radiological situation during decommissioning. The measurements can be used to forecast the radiological situation in unit spaces at final reactor shutdown, which, in turn, will make it possible to determine the merit and need to perform vital work such as, decontamination of the MFC circuit.

Recording and containing "hot particles." The phenomenon of uncontrolled propagation of socalled "hot particles" within high-security zones and in some cases even beyond them has been observed during the operation of NPPs in different countries.

"Hot particles" are microscopic particles measured in microns or submicrons that have a radioactivity several orders of magnitude higher than average particles of that size. When in contact with the human body for a long time, these particles may cause irradiation of adjacent biological tissue in doses measuring thousands of rads or more. Hot particle radioactivity is usually attributed to ${ }^{137} \mathrm{Cs}$, although in certain cases hot particles containing ${ }^{60} \mathrm{Co}$ have been detected. 
Table 10.1. Radiological Situation in MFC Circuit Areas During Major Overhaul of LNPP Unit \#1

\begin{tabular}{|c|c|c|c|c|c|c|c|c|}
\hline \multirow[b]{2}{*}{ No. } & \multirow[b]{2}{*}{ Equipment } & \multirow[b]{2}{*}{$\begin{array}{l}\text { Area. } \\
\text { No. }\end{array}$} & \multicolumn{3}{|c|}{$\begin{array}{c}\text { Gamma background in area, } \\
\mu \mathrm{R} / \mathrm{sec}\end{array}$} & \multicolumn{3}{|c|}{$\begin{array}{l}\text { Surface contamination, } \\
\text { part } / \mathrm{cm}^{2} \times \min \end{array}$} \\
\hline & & & Avg. & $\begin{array}{l}\text { Avg. } 1 \mathrm{~m} \\
\text { from equip- } \\
\text { ment }\end{array}$ & $\begin{array}{c}\text { Max. at } \\
\text { equip- } \\
\text { ment }\end{array}$ & $\begin{array}{l}\text { Inside } \\
\text { equip- } \\
\text { ment }\end{array}$ & $\begin{array}{l}\text { Max. in } \\
\text { area }\end{array}$ & $\begin{array}{c}\text { Area } \\
\text { partitions }\end{array}$ \\
\hline 1 & Drum-type separator & $\begin{array}{l}505 / 1 \\
505 / 2\end{array}$ & $\begin{array}{c}80-100 \\
40-60\end{array}$ & $\begin{array}{c}100-150 \\
80\end{array}$ & $\begin{array}{l}2 \times 10^{4} \\
1 \times 10^{4}\end{array}$ & $8 \times 10^{3}$ & $\begin{array}{l}2 \times 10^{3} \\
2.5 \times 10^{3}\end{array}$ & $\begin{array}{l}200-400 \\
200-300\end{array}$ \\
\hline 2 & Down pipes & $\begin{array}{l}115 / 1 \\
115 / 2\end{array}$ & $\begin{array}{l}3-5 \\
3-5\end{array}$ & $\begin{array}{l}2-3 \\
2-3\end{array}$ & $\begin{array}{l}10 \\
10\end{array}$ & - & $\begin{array}{l}900 \\
800\end{array}$ & $\begin{array}{l}150-200 \\
150-200\end{array}$ \\
\hline 3 & RCP enclosures & $\begin{array}{l}08 / 1-4 \\
08 / 5-8\end{array}$ & $\begin{array}{l}20 \\
20\end{array}$ & $\begin{array}{l}20 \\
20\end{array}$ & $\begin{array}{l}3 \times 10^{3} \\
1 \times 10^{3}\end{array}$ & $\begin{array}{l}1.5 \times 10^{4} \\
1.5 \times 10^{4}\end{array}$ & $\begin{array}{l}1.5 \times 10^{3} \\
1.0 \times 10^{3}\end{array}$ & $\begin{array}{l}300-350 \\
300-350\end{array}$ \\
\hline 4 & $\begin{array}{l}\text { RGK and bottom } \\
\text { water line areas }\end{array}$ & $\begin{array}{l}033 / 1 \\
033 / 2\end{array}$ & $\begin{array}{l}25 \\
25\end{array}$ & $\begin{array}{l}30 \\
30\end{array}$ & $\begin{array}{l}140 \\
500\end{array}$ & $\begin{array}{l}- \\
-\end{array}$ & $\begin{array}{l}(6-14) \times 10^{3} \\
(4-8) \times 10^{3}\end{array}$ & $\begin{array}{l}500 \\
300\end{array}$ \\
\hline 5 & Control rooms & $016 / 1$ & $12-50$ & $40-50$ & $20-100$ & - & $6 \times 10^{3}$ & 500 \\
\hline$\overline{6}$ & $\begin{array}{l}\text { Central hall } \\
\text { Cooling pond } \\
\text { Reactor plateau }\end{array}$ & $612 / 1$ & $\begin{array}{l}- \\
-\end{array}$ & $\begin{array}{c}- \\
40-50 \\
6-10\end{array}$ & $\begin{array}{c}- \\
100-200 \\
-\end{array}$ & & $2 \times 10^{3}$ & 150 \\
\hline
\end{tabular}

Hot particles are assumed to form from aerosols (dust) when the primary circuit is opened and its inner surfaces are dried. Radioactive dust settles on work clothing and is carried by employees through the high security zone. The radiation hazard of hot particles lies in their ability to become a source of internal irradiation. Since the particles are small and the absolute value of their radioactivity is low, a particle does not often register on standard radiometry instruments at the exit from the high security zone. They are detected only during careful manual dosimetry inspection of work clothing.

When equipment and civil structures are dismantled, intense dust formation may make it difficult to suppress dust, purify the air and detect individual hot particles on the body and clothing (both work and personal clothing). When RBMK-1000 unit equipment is dismantled, a large number of hot particles containing ${ }^{93} \mathrm{Zr}$ and ${ }^{94} \mathrm{Nb}$ are expected. These particles result from spread of stoichiometric zirconium peroxide from the inner surfaces of the segments of the fuel channels that are made of zirconium alloy. The possibility that dispersed particles of stoichiometric zirconium oxide may wash off or be carried away through MFC circuit piping and equipment and the drainage channel that also delivers decontaminating solution is a problem that merits special attention. After decontamination ${ }^{93} \mathrm{Zr}$ and ${ }^{94} \mathrm{Nb}$ will not be bound to ${ }^{137} \mathrm{Cs}$ and radionuclides of iron metal corrosion products.

Since the formation of hot particles is inevitable when a unit is decommissioned, equipment should be developed for immediate detection of these particles and processes designed for dismantling equipment, demolishing civil structures, and processing radwastes to minimize the escape of hot particles from work areas. 


\subsubsection{Main Conclusions and Recommendations on Radiation Safety Assurance}

Internal irradiation is expected to account for the greatest share of the effective equivalent dose during dismantling and demolition of civil structures when NPP units are being decommissioned. The work will need to be organized to ensure that the annual individual effective equivalent dose of 2 rem $(0.02 \mathrm{~Sv})$ will not be exceeded in order to meet Russian requirements. The main potential sources of internal irradiation during decommissioning will be radioactive aerosols that may form during dismantling and demolition of equipment and civil structures.

To avoid a significant increase in overall costs and a delay in completion of decommissioning it is worthwhile to begin to determine the physicochemical properties of aerosols formed as a result of different methods of dismantling and to initiate work to determine the optimum designs for filtration units for the working conditions inherent to NPP unit decommissioning.

If a unit is held in long-term safe storage for 50 years or more, ${ }^{60} \mathrm{Co}$ will decay before equipment and civil structure dismantling begins. This radionuclide is now the benchmark nuclide for detecting long-lived ${ }^{59} \mathrm{Ni}$ and ${ }^{63} \mathrm{Ni}$. These radionuclides possess low-energy beta and gamma radiation, which is almost invisible to standard radiation monitoring devices. The loss of a reliable ${ }^{60} \mathrm{Co}$ radionuclide benchmark as a result of radioactive decay requires the development of a system for day-to-day monitoring of low-energy beta and gamma radiation.

Work to decommission NPP units will inevitably be accompanied by the formation of hot particles. Therefore, equipment must be developed for efficient detection of these particles. Processes for dismantling equipment, demolishing civil structures, and processing radwastes should be designed to minimize the amount of hot particles escaping radiation work areas. When work to decommission NPP RBMK-1000 units is planned and organized, the propagation of dispersed

particles of zirconium dioxide containing ${ }^{93} \mathrm{Zr}$ and ${ }^{94} \mathrm{Nb}$ must be prevented outside work areas and into the environment.

\subsection{Environmental Safety Assurance}

\subsubsection{Problems of Environmental Safety Assurance}

Today only environmentally safe activities are permitted that produce no serious disturbances in the natural environment and do not create unacceptable conditions for human life. An activity may be considered environmentally safe if all reasonable steps are taken to maintain the natural surroundings as they were before or when the activity began. During the activity the parameters of the natural surroundings either should not change or change no more than is deemed tolerable for the region and type of activity.

The following considerations should be taken into account in planning the decommissioning of LNPP Unit \#1: first, this will be the first decommissioning at LNPP; second, the recommended decommissioning strategy, which calls for using Unit \#1 for radwaste processing and storage, requires caution to ensure conditions are not for environmentally safe waste storage; third, LNPP units are located in a mountainous region on the shore of a wide and deep body of water. This requires careful evaluation and analysis of the possible environmental impact of unit decommissioning on the environment and human habitat that are specially adapted for LNPP conditions. 
According to the requirements of current Russian laws ("On Environmental Preservation," "On Environmental Review"), the project developed for decommissioning LNPP Unit \#1 must undergo environmental review (state and public).

Practical work to decommission an NPP unit is not permitted, and the project will not be financed without a positive decision by the environmental review board. Consequently, the decommission plan for LNPP Unit \#1 must assess the impact of the decommissioning process on the environment. A concept for environmental protection as LNPP's units, particularly Unit \#1, are decommissioned must be developed on the basis of the results of the assessment and the conditions of the LNPP region. As part of the assessment, the critical ecosystems of the region will be identified, their initial (corresponding to the time preceding unit decommissioning) condition will be assessed, and the impact of the NPP decommissioning will be established.

It will be necessary to study the specific critical characteristics of the ecosystems to set up the initial environmental monitoring and to study the natural surroundings of the LNPP region. It usually takes several years (at least three) of observation to detect variations from one year to the next and to establish the chronological trend in the change.

A major factor is that the LNPP is located on the border between land and water and that the impact of the Unit \#1 decommissioning will be felt in conjunction with the impacts of other operating units at LNPP and other sources of environmental impact. LNPP is located in a rather complicated region with several independent sources of environmental impacts, one of which is Kaporsk Bay (an aqueous ecosystem connected to the Gulf of Finland). The project for organizing environmental monitoring should be developed and implemented soon.

\subsubsection{Recommendations for Preparing Environmental Impact Reports on the Decommissioning of Leningrad Unit \#1}

The following steps are recommended for both the environmental impact assessment (EIA) and the environmental safety substantiation (ESS) for the Unit \#1 decommissioning project:

1. Prepare a general description of the territory of the LNPP within a radius of 20$30 \mathrm{~km}$ around the power plant, including a general physical geography and natural climatic description of the region and a description of the location of industry and population. This description will cover land and water ecosystems separately.

The description will provide a general environmental and geographical outline of the region. It indicates the main characteristics of the region, the natural and climatic zone for the region, whether there are preserves or protected territories nearby, and how and for what economic purposes the individual territories of the region, its hydrographic network, and transportation arteries are used.

The description may be based on archival and published materials. Materials from the design of the NPP should also be used, including any EIA or ESS materials developed at that time. If these environmental materials were not developed (this was the case when the plan for building LNPP was developed), the decommissioning EIA and ESS materials for the NPP should be based on the 
results of special studies using archival and published materials and the results of exploratory work. The description also describes the natural and climatic characteristics of the region. All information necessary for calculating the transfer of pollutants to the atmosphere as a result of their presence in ventilated air should be provided.

2. Prepare a detailed description of the territory within a radius of $5-7 \mathrm{~km}$ around LNPP, with an environmental profile of each territory, a description of the landscape, a soil map, vegetation map, geochemical conjugations. The radius was selected based on experience. It is the territory (with some margin) within which one may observe the consequences of the operation of LNPP (e.g., the presence of "plant" radionuclides). Critical land ecosystems will be defined on the basis of these materials. This description is a very important part of the environmental and geographic description of the region, since it includes all the information on land ecosystems which makes it possible to select and substantiate the choice of geographical distributions for critical plants and animals (biogeocenoses).

There may be several critical biogeocenoses among the land ecosystems. Therefore, environmental, landscape, and geochemical barriers (landscape conjugations) information are used to select the critical biogeocenoses. Regardless of the environmental, landscape, and geochemical barriers, biogeocenoses preservesreserves of rare and endangered plant and animal species-are critical.

The choice of critical environmental areas is a choice not only of indicators of the condition of the region of LNPP where the unit is being decommissioned but also of parameters describing the condition of the biogeocenoses. These parameters, or more accurately, the set of parameters, may be different for different geographical distributions of plants and animals.

3. Prepare a detailed description of the water network for this territory. The description is written in such a way that one may select and substantiate critical water ecosystems. In the case of LNPP and other nuclear power plants that used bodies of water for cooling, the critical water ecosystem is that body of water.

4. Prepare a description of the critical biogenocenoses. It contains all information necessary both to evaluate the current status of the geographical distribution of critical plants and animals and to forecast their possible conditions after they are affected by LNPP. This description presents the observations on the status of the biogeocenoses and the conclusions on the limits of acceptable changes. It must contain the quantitative characteristics of critical (land and water) ecosystems which, together with data from later descriptions, should make it possible to develop a concept for the preservation of the LNPP environment, the environmental standard for preservation of the natural environment, and the human habitat where the NPP is located. 
The description must be presented dynamically to establish trends in parameters selected to describe the condition of the critical plants and animals and their geographical distribution. This means that this description should be developed on the basis of information obtained over at least three successive years of observations. If three years of data do not exist for the LNPP region, studies should begin as quickly as possible to obtain the information.

5. The materials of description 4 are supplemented by analysis of the pollutants in critical ecosystems (basically the pollutants that may later be released during decommissioning of LNPP Unit \#1) and the analysis of the movement of pollutants in ecosystems.

Since the other units at LNPP will continue to operate while Unit \#1 is being decommissioned, it is important to have data to establish, if necessary, whether it is the decommissioning process or the operation of the plant's other units that lead to a particular (permissible or not) change in the condition of critical biogeocenoses or whether there is another reason [i.e., the effect of another (not LNPP) source].

Therefore, when the Unit \#1 decommissioning process is being designed, assessments should be made on the reactions of critical ecosystems to all possible impacts. As noted above, this may take at least three years.

6. Describe the forecasted condition of critical biogeocenoses as a result of the forces attributable to the decommissioning of LNPP Unit \#1.

If an unacceptable response is forecasted for the critical biogeocenoses due to forces caused by Unit \#1 decommissioning, the project should be revised or protective measures introduced to prevent the forces from developing.

7. The data in steps 4,5 , and 6 in the ESS for decommissioning an NPP unit are used to formulate environmental standards and acceptable damage to the natural surroundings of the region; i.e., the concept for preservation of the natural environment (the concept for environmental safety assurance) during Unit \#1 decommissioning is defined.

8. Proof that the proposed project for the Unit \#1 decommissioning process will not result in a violation of environmental public health codes.

This task may be accomplished by generally accepted methods, i.e, comparing accepted public health standards with emissions outside LNPP permitted by the project and the ground concentrations created by them and by an estimate of the dose load on an individual member of the population (critical population group) caused by radioactive emissions when Unit \#1 is decommissioned. 
9. Data from step 7 in the ESS materials and step 6 in the EIA materials are used to make a decision on the environmental safety of the proposed project for decommissioning Unit \#1.

Evaluating the impact of the Unit \#1 decommissioning process and proving its environmental safety would be greatly simplified if both had been done while LNPP was being designed or operated.

In this case the earlier versions of 1-5 and 7 could have been clarified for the Unit \#1 decommissioning; and 6,8, and 9 would have been completed with consideration for the fact that while this unit is being decommissioned, other LNPP units continue to operate; consequently, the NPP itself continues to have an impact on its natural surroundings and human habitat.

In summary, one might conclude that from the standpoint of environmental safety for the natural surroundings and population, the process of decommissioning LNPP Unit \#1 should be no more dangerous than other industrial activities in the region. The concept for environmental preservation, the decommissioning project, and the supporting environmental materials, which should undergo public and state environmental review, should be developed to implement the decommissioning of Unit \#1.

Environmental monitoring should be organized according to the diagram in Figure 10.1: observation of the condition of the natural surroundings and human habitat - assessment of the observed condition - forecast of the anticipated condition - assessment of the anticipated condition - condition control and decommissioning process adjustment signal (if necessary).

On the whole, from the standpoint of environmental safety assurance, the Unit \#1 decommissioning process should be organized according to the diagram in Figure 10.2. 


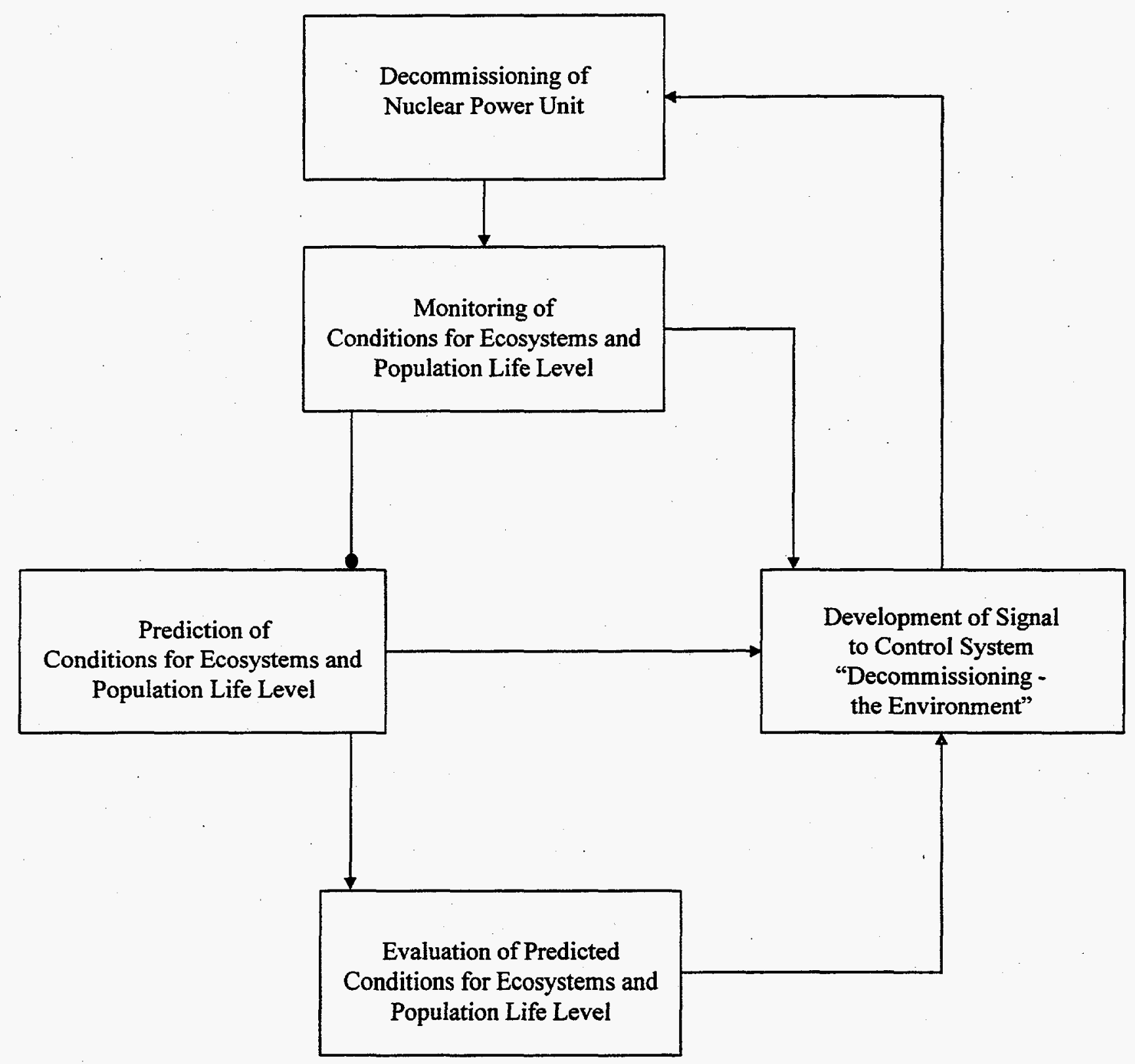

Figure 10.1. Diagram of Ecological Monitoring in NPP Region 


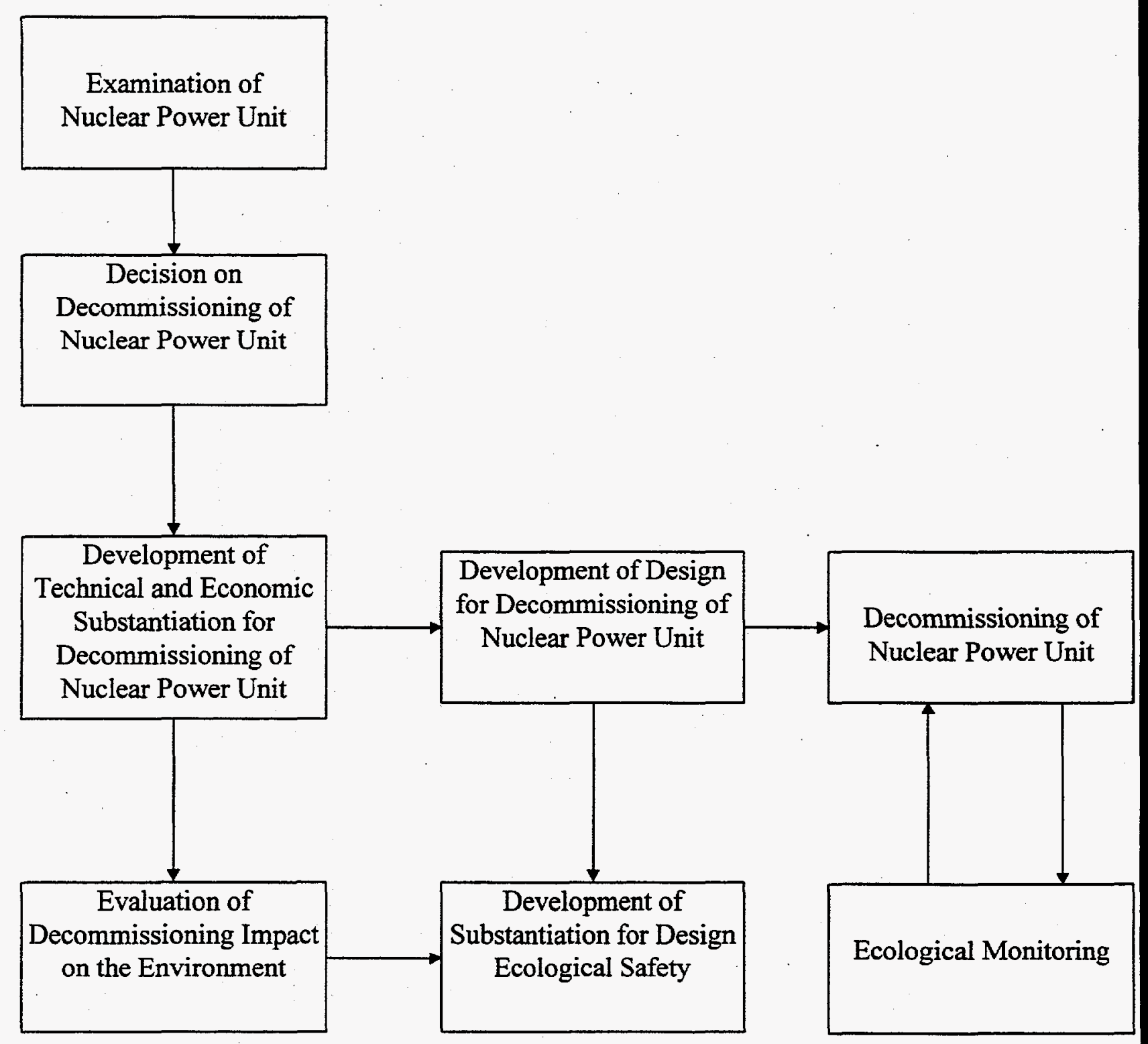

Figure 10.2. Diagram of Preparation for Decommissioning of Nuclear Power Unit 


\subsection{Decommissioning Alternative Proposed for Leningrad Unit \#1}

\subsection{Possible Decommissioning Alternatives}

Unlike the decommissioning of traditional industrial facilities, including power-generating plants, work at the final stage of the life cycle of a nuclear facility involves radiation-a consequence of the radioactivity that developed in the nuclear facility's basic equipment and structures while it was in operation. Radiation imposes limitations on the choice of technologies and on aspects of technical policy to be implemented when nuclear facilities are decommissioned.

When an NPP unit decommissioning is planned, the presence of radiation makes it necessary to find a decommissioning alternative advantageous in terms of complex criteria including economic acceptability, minimum personnel dose loads, and amounts of radwastes formed. The personnel dosage and the amount of radwastes formed may be reduced through the natural decay of radioactive elements when reactor equipment and structures are put in long-term storage after final shutdown, through decontamination, or through the use of remote technologies in the decommissioning.

Technical literature now recognizes the following basic decommissioning alternatives depending on the time required, the techniques used, and the expected final condition of the facility:

- unit entombment

- unit dismantling with immediate dismantling of the reactor

- unit dismantling with deferred dismantling of the reactor.

Western technical literature uses the terms ENTOMB, DECON, and SAFESTOR, respectively, to denote these decommissioning alternatives.

In practice, various combinations of these decommissioning alternatives may be used. This presumes different combinations of methods and work schedules and of the final condition of the units being decommissioned and of their sites. The combination of alternatives may be governed by the actual condition of the NPP unit, by other plans for subsequent use of the NPP site, or other factors. A brief description of the basic decommissioning alternatives follows with an analysis of their advantages for decommissioning RBMK-1000 units.

\subsubsection{ENTOMB}

The "entombment alternative" is one in which high-radioactivity equipment, systems, and the reactor are localized in place by erecting physical barriers to prevent access to them and make it impossible for radioactivity to escape into the environment. In Western literature, the ENTOMB alternative is in place until radioactivity within the entombed facility reaches background levels. In Russia, the ENTOMB alternative involves localizing equipment, systems, and reactors for 100 years or more, and the entombment zone and nearby environment are monitored. The 100-year limit is used because NPP land is expected to be reused for NPPs in Russia. 
The entombment alternative has the following basic stages: preparation for entombment; localization of high-radioactivity structures and the reactor; and entombment of high-radioactivity structures and the reactor.

Preparation for entombment: dismantling and removing clean, slightly contaminated, and lowradioactivity equipment and systems; recycling clean equipment; and decontaminating, processing, packaging, and storing equipment, structure elements, and radwastes in reactor rooms for localization and entombment.

Localization: reinforcement of the reactor's load-bearing metal structures; localization of highradioactivity equipment, systems, and the reactor in place; localization of conditioned radwastes in reactor rooms; full disassembly and demolition of unit equipment, systems, and civil structures that are not to be entombed or used further; and, if necessary, conservation of equipment and systems to be used in the next stage.

Entombment: erection of additional protective barriers around localized high-radioactivity systems, equipment, and the reactor to prevent unauthorized access and the spread of radioactivity into the environment, to ensure their physical protection, and to protect against natural disasters and the effects of atmospheric and other external forces; entombment of localized systems, equipment, and the reactor by filling and/or spreading buffer materials and monitoring of the entombment zone and the environment around it.

The required time and the criteria for completing each of these stages would be defined in the NPP unit decommissioning project. However, based on existing estimates, we may assume that the unit entombment alternative would take 3 to 5 years for preparation; 3 to 5 years for localization; and 100 years or more for the entombment itself in terms of maintaining the performance of the engineering structures.

Russian policy calls for clearing existing nuclear power plant sites and using them to build new (replacement) NPP units. In terms of the requirements of the main provisions of this concept, the entombment alternative must provide for possible subsequent elimination of entombment zones and for specific procedures to restore the NPP unit site. In this case, the main goal of the entombment alternative would be to lower the radioactivity of the reactor structure elements through natural decay to a level that allows their dismantling and the subsequent handling of the resulting wastes without specialized technologies or restrictions on workers. Highly radioactive reactor structure elements are localized by engineering structures (protective barriers) that isolate them from the environment and ensure safe entombment for the required period.

The service life and long-term reliability of the engineering structures will govern the length of the entombment stage. The entombment alternative may be suitable for nuclear facilities if the radioactivity can be lowered within the service life of the engineering structures used to isolate the highly radioactive reactor structures to a level permitting personnel to work without restriction.

When an RBMK-1000 reactor has operated for its design service life (30 years), a large amount of long-lived radionuclides (Section 6) such as ${ }^{59} \mathrm{Ni},{ }^{63} \mathrm{Ni},{ }^{93} \mathrm{Zr},{ }^{94} \mathrm{Nb}$, and ${ }^{14} \mathrm{C}$, most of which have half-lives in excess of 1000 years, form in the reactor's metal structures and graphite stack as a 
result of neutron activation. To bring reactor structures to a radiologically safe state, the reactor would need to be entombed for thousands of years, which is far longer than the period during which any engineering structures (primarily reinforced concrete) are capable of remaining free of leaks and of maintaining their strength. One might assume that the performance characteristics of reinforced concrete structures for RBMK- 1000 units will be maintained for a maximum of 100-150 years. This is clearly insufficient for the required decline in the level of reactor structure radioactivity if the entombment alternative is used.

\subsubsection{DECON}

Unit dismantling with immediate dismantling of the reactor is used when reactor structures, systems and equipment, unit civil structures, and radwastes are dismantled and removed almost immediately after final shutdown and the removal of spent nuclear fuel from the unit, after which specific steps are taken to restore the site. This alternative has two basic stages: preparation for dismantling of reactor structures and demolition of the reactor and other unit structures.

Preparation for dismantling of reactor structures includes decontamination (usually special "heavy" decontamination) of the unit's equipment, systems, and civil structures. In this stage, clean, slightly contaminated, and low-radioactivity equipment and systems are dismantled and removed, after which the clean equipment is recycled and the radwaste is processed, packaged, and stored at the unit site.

Demolition of the reactor and other unit structures includes complete dismantling, segmentation, and removal of moderate and highly radioactive reactor structures to sites specially prepared for their burial or long-term storage; demolition of unit civil structures, and specific procedures to restore the unit site. This alternative requires appropriate storage facilities for radwastes created during unit decommissioning.

The main advantages of this alternative are no need for long-term surveillance, technical and radiological inspection, or maintenance; the opportunity to recruit operational personnel to do the work; and rapid clearing of the site for constructing replacement capacities. The main disadvantages are rather high personnel dose outlays, large amounts of radwastes, and high one-time initial costs.

The duration of each stage would be defined in a unit's decommissioning project. On the basis of current estimates, it is assumed that it will take 5 to 7 years to prepare for and 5 to 7 years to complete dismantling. However, according to current expert estimates, it may be 8 to 10 years after final reactor shutdown before dismantling begins. Special remote equipment such as multifunctional remote-controlled systems would be required to dismantle the highly radioactive reactor structures and graphite stack of an RBMK-1000. Russia does not have this specialized equipment, but individual experimental design studies are being performed.

In addition, appropriate repositories or storage facilities would be needed to store large quantities of various categories of radwastes that would be formed when an RBMK-1000 is dismantled. Russia does not have radwaste repositories or storage facilities, nor are there plans to build them in the near future. Moreover, a method for environmentally safe handling of irradiated graphite from an RBMK-1000 still has not been developed. The graphite is a potential hazard because it 
contains long-lived, genetically significant ${ }^{14} \mathrm{C}$ and tritium radionuclides. We therefore conclude that preparations for decommissioning an RBMK-1000 unit by immediate dismantling of the reactor and unit civil structures are inadequate, and that DECON is not a near-term alternative.

\subsubsection{SAFESTOR}

Unit dismantling with deferred reactor dismantling involves staged dismantling and demolition of reactor structures, systems and equipment, unit civil structures, removal of radwastes, and use of certain procedures to restore the unit site. This alternative has three main stages: preparation for long-term storage, long-term storage, and dismantling of the reactor and other unit structures.

Preparation for long-term storage includes localization of high-radioactivity equipment, systems, and the reactor in place; and decontamination (usually standard) and conservation of unit equipment, systems, and civil structures. In this stage the operability of the unit's radiological inspection system should be ensured, and the system should be optimized for the specific nature of the work to be done (Section 10) and the condition of the reactors and its structures. Unit equipment and systems supporting long-term safe reactor storage and subsequent work should remain operable.

Clean, slightly contaminated, and low-radioactivity equipment and systems may be dismantled and removed, after which the equipment may be recycled and the radwastes processed, packaged, and stored in an organized fashion at the unit site.

The long-term storage stage includes surveillance of the unit equipment, systems, and civil structures. The duration of this stage depends on many factors, namely, the service life of the civil structures housing the localized reactor equipment and systems, the decline in the radioactivity of the structures and equipment as a result of natural radionuclide decay, the dismantling equipment required, and others.

Dismantling the reactor and unit structures includes dismantling the localized equipment, systems, reactor, and unit civil structures; processing, packaging, and temporarily storing radwastes on site followed by their removal from the site; and completing specific procedures to restore the site. The time required and the criteria for completing each stage would be defined in a unit's decommissioning project. On the basis of current estimates, it would take up to 5 years to prepare for long-term storage, 30 to 70 years for long-term storage, and up to 5 years for dismantling.

Analysis of the change in the radioactivity of RBMK-1000 reactor structures as a function of storage time after final reactor shutdown shows (Section 6) that a unit should be held for 50 to 100 years before dismantling. Calculations show the lower limit for this period is the point at which reactor structures begin to exhibit a slight reduction in radioactivity. The upper limit for the period is related to the time required for the main dose-forming radionuclide, ${ }^{60} \mathrm{Co}$, to decay to an acceptable level, which is about 100 years. In this case the gamma dose rate near the structures when they are dismantled will be $1-5 \mathrm{mrem} / \mathrm{hr}$-about $10^{-6}$ times the initial radioactivity of the cobalt. The exterior gamma dose rate near reactor structures will permit them to be dismantled without specialized equipment. After the structures are dismantled and segmented, they may even be classified as moderately radioactive radwastes in terms of specific beta activity. 


\subsection{Substantiation of the Proposed Decommissioning Alternative and Final Condition}

The preceding description of decommissioning alternatives and analysis of the feasibility of their use to decommission an RBMK-1000 unit shows that SAFESTOR is the most acceptable and suitable near-term alternative for decommissioning Leningrad Unit \#1. Theoretically, the ENTOMB alternative may also be used with RBMK-1000 units, provided that several highly radioactive structural elements containing long-lived radionuclides, e.g., zirconium fuel channel tubes, are dismantled and removed from the reactor before the localization stage.

In this case, however, the entombment alternative will have disadvantages that make it unrealistic. First, estimates (Section 6) show that even if the highly radioactive structural elements are extracted and removed, the radioactivity of the remaining reactor structures will still be rather high throughout the reactor entombment period of 100 to 150 years, which equals the maximum operating life of the engineering structures. Second, as noted above, dismantling, removing and subsequently entombing or storing the highly radioactive structural elements is still a technically difficult task. Third, if the entombment period is 100 to 150 years, the entombment alternative becomes essentially the same as the SAFESTOR alternative, since the radiological parameters of the reactor structures in these alternatives are similar.

As the preceding description of the alternatives shows, decommissioning NPP units is a technically complicated, multi-staged, protracted process requiring thorough planning and regulation, the appropriate technological, material, and financial support, and personnel training in the appropriate skills.

Analysis of the factors (Section 2) now delaying the development of full-scale work to decommission shutdown Russian units shows that in the near future, the SAFESTOR alternative is more suitable for decommissioning RBMK-1000 units since this alternative has the following advantages:

- It provides extra time to

- develop comprehensive regulations including national standards for reusable materials

- complete the required basic research and experimental design work to study the decommissioning process and provide the necessary equipment

- build the required NPP radwaste storage facilities and repositories.

- It permits a significant reduction in the amounts of radwastes formed and in personnel dosages during dismantling as a result of partial decay of radionuclides.

In addition, in view of the current economic situation in Russia, the problem of finding the required funding is less acute-it does not require large initial expenditures, and it may be possible to obtain and spend the funding gradually. All of this applies to LNPP, which makes the SAFESTOR alternative appear the most advantageous and acceptable alternative for decommissioning Unit \#1. 
Correct definition of the final condition of the facility being decommissioned helps increase the efficiency and economic acceptability of the chosen decommissioning alternative. Therefore, choosing the optimal final NPP unit condition when it is being decommissioned is an integral part of planning the decommissioning work.

A major problem in decommissioning a unit is processing the radwastes formed when the reactor and unit civil structures are dismantled and then removing them for storage or burial. The pace of the dismantling and the economic parameters of the decommissioning work in general will depend on the readiness and timeliness of the solutions to this problem and their economic acceptability.

Russia, especially the Northwest economic region, has no storage facilities or repositories for the radwastes that form when nuclear power plants are decommissioned, nor is their construction planned in the near future. The lack of these facilities will obviously delay full-scale work to dismantle equipment and civil structures when Leningrad Unit \#1 is decommissioned. Consequently, the processing and removal of the radwastes that will form when Leningrad Unit \#1 is decommissioned is a major problem.

One possible solution to this problem and to the general problem of NPP radwaste in Russia may be to build radwaste processing and long-term storage facilities right on the site of the NPPs. In terms of decommissioning Leningrad Unit \#1, it would be economically more acceptable if the alternative of building on-site radwaste processing and storage facilities had the capacity to handle the waste that will arise from the decommissioning of not only Unit \#1, but both Phase I units or all LNPP units.

There are two alternatives for selecting a site for a radwaste processing and storage facility: locate the complex either in a special separate building at the plant site or in the rooms and structures of decommissioned Unit \#1. The analysis of the optimal and most desirable siting alternatives should be the subject of a separate study; but, according to preliminary estimates, the choice of Unit \#1 rooms and structures seems economically preferable. Therefore, this study proposes that the alternative with the radwaste processing and long-term storage complex in Unit \#1 rooms be the final condition of Leningrad Unit \#1.

When Leningrad Unit \#1 is decommissioned, the following procedures should be carried out to achieve its final condition:

- partial dismantling of turbine hall equipment to make room for the specialized radwaste conditioning complex

- localization of the reactor in a concrete cavity and subsequent conversion of the unit's main building into storage for conditioned radwastes (operational radwastes and radwastes produced during decommissioning)

- dismantling of the remaining turbine hall equipment to make room for storing processed radwastes and operable equipment (this equipment may be used at other LNPP units or sold to other NPPs with RBMK-1000 reactors, which will permit partial compensation of decommissioning costs) 
- using the Unit \#1 rooms and structures later as a training base for developing RBMK-1000 unit decommissioning practices and to give personnel the required skills.

Estimating the total material and financial costs and the personnel dose outlays required to implement the recommended Unit \#1 decommissioning alternative and to achieve the proposed final unit condition is a labor-intensive task. It should be done in the next stage of the study.

\subsection{Main Stages and Activities Performed During Leningrad Unit \#1 Decommissioning}

As noted in Section 5.4, efforts to plan and prepare for a unit decommissioning should begin before final shutdown (pre-shutdown stage) and end when the spent nuclear fuel is removed from the unit and the decommissioning license is obtained (decommissioning preparation stage). The proposed Unit \#1 decommissioning alternative includes the following stages:

- pre-shutdown

- unit preparation for decommissioning

- unit preparation for long-term storage

- long-term safe unit storage

- dismantling and demolition of reactor structures.

The goals of, and organizational and technical procedures in, the pre-shutdown stage, which are described in Section 5.4.1 and Table 5.1, fully correspond to the procedures to be performed in the proposed Unit \#1 decommissioning alternative. The goals of preparing the unit for decommissioning, which are described in Section 5.4.2 and Table 5.2, also fully correspond to the procedures to be performed in the proposed Unit \#1 decommissioning alternative. In the latter case, however, the list of organizational, technical, and planning documentation (Table 5.2) to be developed in this stage must be supplemented by a specification for the development of a radwaste processing and storage complex in the unit facilities.

The following must also be performed while preparing the unit for decommissioning:

- The reactor space (reactor stack) nitrogen blowdown system should remain operable. This system will be kept on hold for use as a fire protection system if necessary.

- The main lifting and handling equipment should be kept operable.

- The primary circuit bypass water purification system should remain operable until the nuclear fuel is completely removed from the reactor. Then the equipment in this system may be used to prepare decontamination solutions for unit spaces, the forced circulation circuit, the CPS cooling circuit, and other process circuits and to purify the coolant once these circuits are drained. The primary circuit water purification system may be dismantled after this work is done.

- After the nuclear fuel is removed from the unit, the gaseous waste processing unit may be refurbished for use as a dust suppression and gas purification system during dismantling. 
- After the nuclear fuel is removed from the unit, the heating and ventilation systems will operate with reduced air flow to maintain the required temperature.

- The industrial and potable water supply, fire extinguishing, and industrial and special sewage systems will remain operable in this stage.

- All unit systems remaining operable are to be regularly inspected and maintained to ensure that they perform their functions.

\subsubsection{Unit Preparation for Safe Storage}

The primary goal of this stage is to localize the reactor and several highly radioactive systems in place. This is done to ensure their long-term safe storage within existing or additional civil and protective structures. The reactor is localized by isolating the interior holding radioactive equipment from the outside as much as possible by erecting additional protective barriers on the path by which radionuclides might escape to the environment. Structure elements obstructing reactor localization are dismantled and removed.

In order to erect a lower protective barrier in the reactor bottom room, some of the equipment must be dismantled, the room's thermal insulation must be removed, and special waterproofing materials with high radionuclide adsorptivity must be used. Group distribution headers, lower water lines, and supply mains should also be dismantled.

To erect an upper protective barrier in the concrete cavity, steam-water lines and the equipment at the top of the reactor must be dismantled. After this work is completed, the ventilation, cable, and pipe runs from the reactor cavity are sealed. The merit of extracting and removing fuel channels from the graphite stack requires special consideration in this stage. A great deal of experience extracting and removing fuel channels was gained when LNPP units were rebuilt. This experience showed that:

- In the first two years after reactor shutdown, the dose rate from the zirconium portion of the channels drops by a factor of about 100; calculations show that in the subsequent 30 years the channels' dose rate decreases by only about half. Thus the radiological situation when channels are removed after two years differs little from that after 30 years.

- At present it is impossible to reliably assess the effects of corrosion and strength of the zirconium portion of the channels after long-term storage. It seems obvious, however, that corrosion processes will continue and may lead to a decline in the strength of channel welds.

- Holding channels in the graphite stack for a long period may cause the channels to jam in the stack, increasing the forces needed to extract them. This may complicate dismantling because of the higher probability that channels will break when they are removed.

These circumstances point to the advantages of extracting and removing fuel channels from the reactor graphite stack in this stage.

Non-radioactive and low-radioactivity equipment is also dismantled in this stage. If necessary, unit equipment and systems that may be used in later stages of decommissioning are reserved. Building the radwaste storage and processing complex in the unit facilities must begin at the same time, and radwaste processing must continue. Several unit rooms must be cleared of 
equipment to make room for this complex. Reactor section rooms must be decontaminated if this is found to be necessary and cost-effective; reactor section rooms must be brought into compliance with required radiological and health codes.

Unit equipment and systems required for decommissioning must be inspected in this stage: dosimetry and radiological inspection systems, standard heating and ventilation, power supply, sewage, fire safety, and other necessary systems. These systems must be optimized and used according to the specific nature of the work to be performed.

Specific research and experimental design work must be done to facilitate the next stage (longterm storage): analysis of the long-term reliability of the reactor's load-bearing metal structures, development of methods for checking the long-term performance of concrete structures and unit buildings, and several other studies. Table 11.1 summarizes work to be done to prepare Unit \#1 for long-term storage and provides estimates of the time required to complete the work.

\subsubsection{Long-Term Safe Storage}

The main objective of this stage is to keep the localized reactor and highly radioactive systems in a safe condition to prevent the radioactivity in them from escaping into the environment. For this purpose the unit's protective engineering barriers, civil structures, and physical protection systems are regularly inspected. Access to the unit and to the area where the reactor and highly radioactive systems are localized must be restricted.

The radwaste processing and storage facility is built and installed in this stage. Places for warehousing and temporary storage of wastes approved for restricted and unrestricted use are prepared. As radioactivity declines, the equipment and systems of the reactor section outside the localization area are dismantled and turbine hall equipment will be dismantled. The spent nuclear fuel and radwaste storage facilities are operated. The unit's operating equipment and systems are regularly inspected and serviced, and systems and equipment necessary for work in the next stage are inspected and readied according to previously developed plans. Table 11.2 lists the work to be done during long-term storage of Unit \#1 and provides estimates of the time required to complete this work.

\subsubsection{Dismantling and Demolition of Reactor Structures}

The goals of this stage are the dismantling and demolition of reactor structures and completion of specific measures to bring the Unit \#1 site to the condition specified in the decommissioning project. In this stage, unit equipment, systems and structures are taken out of storage, the required dust suppression and gas purification equipment is installed, and reactor structure dismantling equipment is installed.

If necessary, the protective engineering structures are opened, and structures obstructing access to the reactor and structure dismantling work are removed. Then the reactor is dismantled and the radioactive structure elements are segmented and packaged. The reactor assemblies created as a result of dismantling and segmentation and the reactor's metal structure elements and graphite stacks undergo radiological inspection and sorting in terms of radioactivity category. All wastes accepted for restricted or unrestricted use and sent for temporary storage undergo radiological inspection and sorting. 
Table 11.1. List of Work Required to Prepare Unit \#1 for Safe Storage

\begin{tabular}{|c|c|c|}
\hline \multirow[b]{2}{*}{ Stage and List of Required Procedures } & \multicolumn{2}{|c|}{ Time Required, yr } \\
\hline & Start & End \\
\hline Prepare unit for storage under surveillance & 5 & 10 \\
\hline 1. Deactivation of systems and equipment not required for decommissioning & 5 & 5.5 \\
\hline 2. Inspection of unit equipment and systems required for decommissioning & 5 & 6 \\
\hline $\begin{array}{l}\text { 2.1. Rebuild standard heating and ventilation, power supply, sewage, fire and } \\
\text { radiation safety, and other necessary systems }\end{array}$ & & \\
\hline 2.2. Upgrade dosimetry and radiological inspection systems (if necessary) & & \\
\hline $\begin{array}{l}\text { 2.3. Reserve equipment and systems that may be used for later unit } \\
\text { decommissioning work }\end{array}$ & & \\
\hline $\begin{array}{l}\text { 3. Bringing reactor section rooms into compliance with radiological and health } \\
\text { requirements so that they can be subsequently used as temporary processed radwaste } \\
\text { storage facilities }\end{array}$ & 5 & 6 \\
\hline 3.1. Decontaminate reactor section equipment and rooms for subsequent work & & \\
\hline 3.2. Remove thermal insulation from equipment and piping & & \\
\hline $\begin{array}{l}\text { 3.3. Dismantle equipment, low- and non-radioactive systems that will not be } \\
\text { used in later stages in rooms designated for radwaste storage }\end{array}$ & & \\
\hline 4. Construction of the radwaste storage and processing complex & 5 & 10 \\
\hline 4.1. Prepare to refurbish unit rooms to store conditioned radwastes & & \\
\hline $\begin{array}{l}\text { 4.2. Partially dismantle turbine hall equipment to make room for the radwaste } \\
\text { processing complex }\end{array}$ & & \\
\hline 5. Localization of the reactor in place to prevent radionuclides from escaping & 6 & 8 \\
\hline $\begin{array}{l}\text { 5.1. Dismantle reactor system elements and structures obstructing reactor } \\
\text { localization }\end{array}$ & & \\
\hline 5.2. Localize the reactor & & \\
\hline 5.3. Seal ventilation, cable, and pipe runs from the reactor cavity & & \\
\hline 6. Handling of operational radwastes & 5 & 10 \\
\hline 6.1. Condition operational radwastes & & \\
\hline 6.2. Transport radwastes to temporary storage site & & \\
\hline 7. Operations and maintenance & 5 & 10 \\
\hline $\begin{array}{l}\text { 7.1. Operate monitoring, heating and ventilation, sewage, fire and radiation } \\
\text { safety, and other systems }\end{array}$ & & \\
\hline 7.2. Operate the spent nuclear fuel storage facility & & \\
\hline 7.3. Operate the radwaste storage facility & & \\
\hline $\begin{array}{l}\text { 8. Preparation of systems and equipment necessary for the next stage (including } \\
\text { necessary experiment and design work) }\end{array}$ & 9 & 10 \\
\hline
\end{tabular}


Table 11.2. List of Work Required During Long-Term Storage of Leningrad Unit \#1

\begin{tabular}{|c|c|c|}
\hline \multirow[b]{2}{*}{ Stage and List of Required Procedures } & \multicolumn{2}{|c|}{ Time required, yr } \\
\hline & Start & End \\
\hline Long-term storage of Unit \#1 & 10 & 80 \\
\hline $\begin{array}{l}\text { 1. Preparation of places for warehousing and temporary storage of } \\
\text { wastes permitted for restricted and unrestricted use }\end{array}$ & 10 & 15 \\
\hline 2. Operations and maintenance & 10 & 80 \\
\hline 2.1. Inspect and repair operating equipment and systems & & \\
\hline $\begin{array}{l}\text { 2.2. Regularly inspect equipment, structures, protective } \\
\text { engineering barriers, and the physical protection system }\end{array}$ & & \\
\hline 2.3. Operate the radwaste storage facility & & \\
\hline 2.4. Operate the spent nuclear fuel storage facility & & \\
\hline 3. Dismantling of equipment and systems outside the localization area & 10 & 20 \\
\hline 3.1. Completely dismantle turbine hall equipment & & \\
\hline $\begin{array}{l}\text { 3.2. Dismantle reactor section equipment and systems (as } \\
\text { radioactivity declines) }\end{array}$ & & \\
\hline 4. Construction and installation of the radwaste processing complex & 10 & 15 \\
\hline $\begin{array}{l}\text { 5. Preparation of systems and equipment necessary for the next stage } \\
\text { (including necessary experiment and design work) }\end{array}$ & 78 & 80 \\
\hline
\end{tabular}

After dismantling and demolition of the reactor structures, the surface of the concrete cavity may, if necessary, be decontaminated or cleaned by some other method. In this stage all radwastes formed during dismantling are processed, and the processed radwastes are transported to storage. After dismantling is completed, all equipment used in the work is decontaminated and dismantled. The unit civil structures left according to the decommissioning project are brought into compliance with radiological and health requirements. If the processed radwastes must be removed from the NPP site, work should first be done to build regional repositories for off-site burial of processed radwastes

In conclusion, there is no benefit in going into further detail at this stage. Our perceptions are based on our current understanding of this work and current experience, but this work will be done 50 or more years after the reactor is shut down. In this period, about two generations hence, a higher technological level will be achieved (e.g., new dismantling, radwaste handling and burial equipment, etc.) and regulatory requirements may change. The list of procedures to implement the proposed Unit \#1 decommissioning alternative presented above is based on our current 
understanding of personnel and environmental safety and the current capacities for technological. support of the work. Table 11.3 lists the work that must be done during dismantling of Unit \#1 reactor structures and provides estimates of the time required to do so.

\subsection{Certain Problems to be Solved During Implementation of the Unit \#1 Decommissioning Alternative}

Specific research and experimental design work must be performed in order to implement the proposed Unit \#1 decommissioning alternative. This work includes verification of the strength of the reactor's metal structures and the unit's concrete structures during long-term storage; solution of the problem of final handling of the irradiated reactor graphite stack; and other work.

\subsubsection{Long-Term Durability of Unit Structures}

Because of the duration of long-term storage, which may exceed the unit's design operating life, the condition of the reactor structures and unit civil structures must be reliably predicted. The following circumstances must be considered in making this prediction.

First, the temperature in the reactor rooms will drop after a unit is shut down. Subsequent temperature change may depend on a change in ambient (air and soil) temperature, and the humidity in these rooms will be determined by the tightness and impermeability of the waterproofing of the unit rooms. Under these conditions the reliability of the reactor's load-bearing metal structures will be governed by corrosion processes and by the conditions under which the structures performed while the reactor was operating and which affect the cold brittleness threshold of carbon steels.

Estimates show that the fast neutron fluence $(\mathrm{E}>0.5 \mathrm{MeV})$ for reactor metal structures after 30 years of operation is rather high: $5 \times 10^{18} \mathrm{n} / \mathrm{cm}^{2}$ for the upper plate of the bottom load-bearing structure; $2 \times 10^{18} \mathrm{n} / \mathrm{cm}^{2}$ for the lower plate of the top load-bearing structure and graphite stack liner; and $1 \times 10^{18} \mathrm{n} / \mathrm{cm}^{2}$ for the inside wall of the water protection tank. Neutron fluence clearly exceeds $10^{18} \mathrm{n} / \mathrm{cm}^{2}$. It seems appropriate, therefore, to do some experimental studies on the brittle strength of reactor structures to predict their behavior while the unit is in long-term. storage.

The overall corrosion rate for carbon steels in a humid atmosphere is a function of the rate of air exchange and may range from 5 to $100 \mu \mathrm{m} / \mathrm{yr}$. Daily and seasonal pressure, temperature, and humidity fluctuations will cause moisture to accumulate in slits and cracks and at the bottoms of the structures of the shutdown reactor. Since ambient moisture is enriched with carbon dioxide, pitting corrosion may occur, especially in the reactor's lower bearing structures.

The most suitable preventive methods and devices must be found to control corrosion. For example, spraying the vertical surfaces of the metal structures with several coats of an aqueous solution of lime $\left[\mathrm{Ca}(\mathrm{OH})_{2}\right]$ and spreading quenched lime on the bottoms of the reactor spaces, biological shield tanks, and the spaces between the tanks and concrete walls and between the metal structures and concrete, or by some other means. 
Table 11.3. List of Required Work During Dismantling of Unit \#1 Reactor Structures

\begin{tabular}{|c|c|c|}
\hline \multirow[b]{2}{*}{ Stage and List of Required Procedures } & \multicolumn{2}{|c|}{ Time required, yr } \\
\hline & Start & End \\
\hline Dismantle and demolish reactor structures & 80 & 85 \\
\hline 1. Taking equipment, systems and structures out of storage & 80 & 81 \\
\hline 2. Dismantling reactor structures & 82 & 84 \\
\hline $\begin{array}{l}\text { 2.1. Install required equipment and special dust suppression } \\
\text { and gas purification systems }\end{array}$ & & \\
\hline 2.2. Install equipment to dismantle reactor structures & & \\
\hline $\begin{array}{l}\text { 2.3. Open protective engineering barriers and remove structures } \\
\text { obstructing access to reactor }\end{array}$ & & \\
\hline $\begin{array}{l}\text { 2.4. Dismantle, segment, and package radioactive reactor } \\
\text { structure elements }\end{array}$ & & \\
\hline $\begin{array}{l}\text { 2.5. Complete radiological inspection and sorting of reactor } \\
\text { assemblies, metal structure fragments and graphite }\end{array}$ & & \\
\hline 2.6. Condition radwastes created during dismantling & & \\
\hline $\begin{array}{l}\text { 3. Completion of radiological inspection and sorting and } \\
\text { temporarily store wastes accepted for restricted and unrestricted use }\end{array}$ & 83 & 84 \\
\hline $\begin{array}{l}\text { 4. Cleaning or decontamination of the surface of the concrete } \\
\text { reactor cavity (if necessary) }\end{array}$ & 84 & 85 \\
\hline 5. Operations and maintenance & 80 & 85 \\
\hline $\begin{array}{l}\text { 5.1. Operate monitoring, heating and ventilation, power supply, } \\
\text { sewage, fire and radiation safety, and other necessary systems }\end{array}$ & & \\
\hline 5.2. Operate the spent nuclear fuel storage facility & & \\
\hline 5.3. Operate the radwaste storage facility & & \\
\hline $\begin{array}{l}\text { 6. Decontamination and dismantling of equipment used in } \\
\text { dismantling }\end{array}$ & 84 & 85 \\
\hline $\begin{array}{l}\text { 7. Putting remaining unit civil structures into compliance with } \\
\text { radiological and health requirements }\end{array}$ & 84 & 85 \\
\hline
\end{tabular}


Second, localization of the reactor in a concrete cavity while the unit is being prepared for longterm storage should prevent air from reaching the reactor, the reactor's graphite stack from oxidizing, and radionuclides from escaping the reactor cavity into the environment-processes that may be intensified by fluctuations in atmospheric pressure. To prevent these processes, the spaces in the reactor cavity and reactor space may need to be filled with special loose materials. Otherwise, experts estimate that about $20 \%$ of the reactor's graphite stack may oxidize over a storage period of 100 years. Research should therefore be performed to select fill materials with the properties required to retard radionuclide migration through them and that are easy to remove before reactor dismantling.

Third, the properties of the concrete structures will also deteriorate during long-term storage. Therefore, a reliable prediction of the condition of the concrete is also important. Since certain Unit \#1 reactor rooms are to be used for long-term storage of processed radwastes, requirements for monitoring the change in the properties of the concrete should be increased. Methods must be developed to check the tightness of the unit's concrete rooms and to determine the seepage of gas-aerosol and liquid radioactive media between rooms and their leakage out of the unit. A comprehensive procedure must therefore be developed for estimating the lifespan and stability of reactor metal structures and unit concrete structures kept in long-term storage.

\subsubsection{Final Handling of the Reactor's Graphite Stack Blocks}

A unique feature of the decommissioning of NPP units with RBMK reactors is the presence in the core of a large amount of radioactive graphite. Russia now has about 50,000 metric tons of irradiated graphite at graphite-uranium reactors used for various purposes. Nuclear power plant units account for about 25,000 metric tons of this amount.

The development of suitable technologies for dismantling and for processing, recycling, or burial of this rather large amount of specific radioactive material requires special attention. The following factors must be considered in developing these technologies:

- The long-term action of neutrons causes considerable radioactivity to develop in the graphite, where radionuclides with long half-lives (thousands of years or more) form.

- While reactors are operating, fission products and nuclear fuel may enter the core's graphite stack because of fuel failures. These products are sources of strong radiation and migrate throughout the entire stack. Specialized remote equipment is required to dismantle graphite stacks.

- While reactors are operating, the stack's graphite blocks swell and distort, leading to partial cracking and crumbling and a general loss of integrity that will complicate subsequent dismantling.

The following additional factors make final handling of irradiated graphite an even more pressing problem in decommissioning RBMK units at NPPs:

- First, RBMK units do not have containment, which would be an additional barrier protecting the environment from radionuclides, especially during long-term storage. 
- Second, if the reactor's graphite stack and metal structures are localized, their mechanical properties and the radiological situation must be reliably predicted when localization zones are opened. This requires study of the changes in the radiological and physicomechanical condition of the irradiated graphite stack over time.

- Third, the accumulation of a rather large amount of ${ }^{14} \mathrm{C}$ and tritium radionuclides in the graphite of the reactor stack represents a serious environmental hazard. The radioactivity of these radionuclides is estimated to be 4.0 and $17.5 \mathrm{Ci}$ per metric ton, respectively. They constitute a potential threat of global contamination of the Earth's ecosystems and, if they enter the human body, a threat of increased somatic and genetic damage.

Nevertheless, Russia has done no systematic analysis on the nuclide composition and condition of graphite stacks, nor are there any consistent and metrologically certified research methods. Therefore, there are discrepancies between experimental and theoretical results, as well as errors. Analysis of data on the nuclide composition of radioactive graphite shows that there is significant variation in the composition of impurities in the original graphite, which affects estimates of graphite stack radioactivity by various authors here and abroad.

Moreover, Russia still has not developed a national concept for regulatory requirements for safe handling of irradiated graphite. A comprehensive program to find and implement radiologically safe technologies for dismantling and final handling of irradiated graphite must therefore be developed during the decommissioning of Leningrad Unit \#1. We must keep in mind that the results of such a comprehensive program may necessitate amendments, revisions, or corrections to the list of work under the proposed decommissioning alternative.

\subsubsection{Radiological Inspection During Dismantling and Segmentation of Reactor Structures}

The unique nature of the large-scale work to dismantle and segment radioactive structures when NPP units are decommissioned (Section 10) raises doubts about the reliability of aerosol radioactivity suppression systems and radiological inspection devices at NPPs, although they have demonstrated high efficiency under operating conditions.

The physicochemical properties of the aerosols formed as a result of the dismantling and segmentation of radioactive structures during decommissioning will differ from the properties of aerosols formed while the units are operating. Our ignorance of the basic principles by which aerosols form during these processes causes inefficiency in filtration units and low efficiency in personal protection devices.

The formation of aerosol "hot particles" is unavoidable when protective barriers and process circuits are opened, when radioactive structures are dismantled and segmented, and when the resulting radwastes are processed, but standard equipment used in NPP operation is not efficient enough to record them. The radioactive decay of the benchmark radionuclide ${ }^{60} \mathrm{Co}$ during longterm storage of highly radioactive reactor structures before they are dismantled and segmented also makes radiological inspection with traditional devices inefficient. 
For these reasons, research must determine the physiochemical properties of aerosols formed by the various methods used in dismantling radioactive equipment and civil structures; optimum designs for the required filtration units and personal protection devices must be studied; and new equipment for effective monitoring of low-energy beta and gamma radiation and detection of aerosol hot particles must be developed. 


\subsection{Summary}

Strategy is the art of planning and directing the achievement of a goal through actions based on predictions of their results and consequences. In accordance with this definition, the strategy for decommissioning a unit or an NPP is the sequence of actions and solutions to problems carried out to achieve the ultimate goal. In this study, the ultimate goal in developing a decommissioning strategy for Leningrad Unit \#1 was to choose the decommissioning alternative and final unit status most suitable given Russia's socioeconomic situation.

The sequence of specific actions and solutions may be determined as a result of multi-parameter analysis of the problems that arise and must be solved during decommissioning of an NPP unit. This report covered the following basic problems related to the decommissioning of Leningrad Unit \#1:

- the existence of national laws and regulations on NPP unit decommissioning

- the possibility of prompt removal of spent nuclear fuel from the unit and of bringing the unit to the required state of nuclear safety

- the technological support for decontaminating and dismantling radioactive structures required to decommission the unit

- the problem of processing, storing and/or burying radwastes (those accumulated during operation and formed during decommissioning)

- safety assurance, including environmental safety, in completing the decommissioning work with regard to the specific design of the RBMK and the construction of the unit

- the ability to finance the decommissioning.

Existence of national laws and regulations: legal regulation of the decommissioning of nuclear power plants in Russia is based on the provisions of the federal law, "On the Use of Nuclear Energy," and the Russian Federation laws, "On Environmental Protection" and "On Public Radiation Safety."

The federal law, "On the Use of Nuclear Energy," ratified October 20, 1995, mandated that all Russian NPPs are federal property and that the government will make the decision to decommission them. This law made the operating organization fully responsible for safety during decommissioning and during nuclear material and radwaste handling. The operating organization must obtain a decommissioning license from GAN. According to "On Environmental Protection," project materials must undergo environmental (state and public) review.

Russia does not have a complete set of regulations covering the decommissioning of NPP units. Moreover, existing codes and regulations must be fully reconciled with Russian Federation laws.

Russian regulations on the procedure for decommissioning NPP units differ from those in the West in several ways. In particular, regulations state that operating requirements must be met until an NPP's nuclear fuel is removed from the unit. Five years before the end of the unit's design life, the decommissioning program must be developed and submitted to GAN for review. 
Decommissioning work must be preceded by comprehensive (radiation and engineering) inspection. The decommissioning project materials must include a report demonstrating the safety of the work and a report ensuring no adverse environmental impacts.

However, requirements for the content of the documents listed above are not fully defined. Regulations do not detail various specific aspects of decommissioning work, including safety assurance, and there are no requirements to justify the time required for decommissioning work. Nevertheless, one might say that current Russian laws and regulations covering decommissioning are not the factor delaying planning and preparation for decommissioning NPP units.

Prompt removal of spent nuclear fuel from the unit: spent nuclear fuel from Russian nuclear power plants with RBMK reactors is now stored on site. This is because funding is unavailable for obtaining the technologies required for handling spent nuclear fuel from RBMK reactors and for the long-term storage or burial of highly radioactive radwastes.

To facilitate storage of spent nuclear fuel at LNPP, a separate building for storage of all the plant's spent nuclear fuel was built in 1981. Its design operating life is 30 years, and its design capacity is 17,520 spent fuel assemblies. Spent fuel assemblies are stored in water in ponds in the storage facility.

The operation of Leningrad units has resulted in the accumulation of about 26,000 spent fuel assemblies. Unit \#1 accounts for more than 8,200 , of which 870 are stored in two cooling ponds, each with a capacity of 850 assemblies; the rest were taken to the spent fuel storage facility. Clearly the spent fuel storage facility and cooling ponds at Leningrad are almost out of space. Therefore, work to upgrade the spent fuel storage facility and cooling ponds under a program developed by the plant has been ongoing since 1995 to ensure high-density storage of spent fuel assemblies and increase the facilities' capacity.

The main goal of the work to increase the capacity of the spent fuel storage facility and cooling ponds at the plant is to provide conditions for continued normal operation of the units. With all four Leningrad units operating normally, and high-density storage, the anticipated capacity of the cooling ponds and spent nuclear fuel storage facility will meet operating demands for no more than $13-15$ years.

In 1995, work began on developing the design of metal-concrete casks (MCCs) to ensure stable and safe unit operation for a longer term, as well as for expected decommissioning in the future. The casks will be used for long-term "dry" storage (for at least 50 years) and transport of spent nuclear fuel assemblies. The design capacity of one cask is about 60 assemblies. Before they are loaded into the casks, the assemblies must be kept in spent nuclear fuel storage ponds for at least 10 years. It is anticipated that spent nuclear fuel assemblies will be broken down and loaded at a maximum rate of 3,500 per year.

Russian regulations require that decommissioning a shutdown unit may begin only after the spent nuclear fuel has been removed from the unit and the unit has been brought to a state of nuclear safety. After final shutdown of the Unit \#1 reactor, there will be 1,600 usable spent nuclear fuel assemblies in the core and about 2,900 in the cooling ponds. 
To start decommissioning, spent nuclear fuel must be removed from the reactor core, held in cooling ponds, removed from the cooling ponds, and transported for storage to the spent nuclear fuel storage facility. The spent nuclear fuel storage and transport systems existing at LNPP will be used within the limits of their standard operating modes.

The sequence of operations for handling spent nuclear fuel when Unit \#1 is permanently shut down will not differ from that used or planned at LNPP. It will include the following steps: preliminary holding of the spent nuclear fuel (in the reactor or cooling ponds); removal of the spent nuclear fuel and its transport to the storage facility; storage at the facility; transfer of the spent nuclear fuel to casks and on-site storage of the casks.

One might speculate that successful completion of the spent fuel handling program and cask production project developed at LNPP will solve the problems of prompt removal of the fuel from the unit and its later placement and storage in the facility. But, the following problems should also be solved: removal of failed spent fuel assemblies from the cooling ponds; justification of the continued operation of the spent nuclear fuel facility beyond its design life; organization of transportation to remove spent nuclear fuel from the plant site.

Technologies to support dismantling of radioactive structures: analysis of the radiation conditions of Unit \#1 reactor structures and of radiation conditions near the equipment and fuel circuits while RBMK units are in operation, or if repair shows that dismantling and segmentation of reactor metal structures exposed to radiation (top and bottom load bearing structures, cylindrical liner, and circular tank) and disassembling and removing the reactor's graphite stack will be the most complicated and time-consuming jobs.

Estimates of the decline in the radioactivity of the metal structures over time indicate that in the next 30-70 years work to dismantle these reactor structures will require the use of specialized equipment, e.g., remote-controlled equipment installed in the central reactor hall. It is possible that the remote-controlled equipment or other technologies will have to be used to disassemble and remove the blocks in Unit \#1's graphite stack.

Russia does not have practical experience in full-scale dismantling and segmenting of highly radioactive NPP unit structures during decommissioning. The reactor structure of shutdown Russian units is not dismantled, but work is being done to find and develop efficient, safe technologies for dismantling and segmenting. Russia has experience repairing and rebuilding RBMK units and plutonium production graphite-uranium reactors without the use of robots and other remote technologies. The resulting total personnel radiation dose during repair and reconstruction was rather high. Nevertheless, the analysis done in this study shows that Russia has definite technical resources, both in terms of the methods and technologies for decontaminating fuel circuits and equipment in RBMK units and in developing remote technologies to dismantle them. Using these technologies may theoretically permit Unit \#1 to be decommissioned using the DECON option-immediate dismantling of the reactor and unit structures. However, refining these technologies to the point where they can be used requires research, planning, design, and experimental work, as well as personnel training. It will also take time and money.

Radwaste processing and burial: Russia's policy on NPP radwaste handling calls for processing and long-term storage of processed radwastes on site at the NPPs. 
Like other Russian NPPs, LNPP does not have the necessary facilities to process solid radwastes to reduce their volume or to convert them into forms suitable for transport and burial in compliance with regulations. The plant's facilities for processing (bituminization) liquid radwastes must be upgraded.

The plant's operational liquid and metal radwastes are in on-site storage facilities. Liquid radwastes, a large quantity of which has accumulated, are stored in tanks with capacities from 500 to $3,200 \mathrm{~m}^{3}$. Sediment have formed at the bottom of some of the tanks, and others contain large quantities of ion-exchange resins and perlite.

LNPP has built bituminization facilities to process operational liquid radwastes. All bituminized liquid radwastes are stored in an on-site storage compound comprising 12 specialized canyons, each with a capacity of $2,000 \mathrm{~m}^{3}$. Perlite, ion-exchange resins, sediment, and other new wastes are stored in tanks.

From the time Unit \#1 was started up until recently, the operational solid radwastes created at LNPP were sent for burial at Lenspetskombinat, a specialized enterprise that collects, processes, and buries radwastes for the city of St. Petersburg, Leningrad Oblast, and certain other adjacent oblasts. Since 1996, however, Lenspetskombinat has accepted only combustible solid radwastes from LNPP. The space assigned to the power plant in Lenspetskombinat's solid radwaste storage facilities is only $330 \mathrm{~m}^{3}$, which does not meet the plant's needs. About $100 \mathrm{~m}^{3}$ of highly radioactive solid radwaste is now in temporary storage at the plant.

A program for handling operational liquid radwastes at LNPP has been developed based on experience operating the plant's chemical waste treatment department. The provisions of the program define the basic directions in the development (reducing volume, conditioning homogeneous and heterogeneous liquid wastes and those containing surfactants) and upgrading of liquid radwaste processing equipment. Presumably the equipment will be upgraded in view of the requirements for decommissioning LNPP units. The operational solid radwaste handling program calls for construction of an on-site storage facility with a capacity of about $18,000 \mathrm{~m}^{3}$ and for upgrading existing equipment and developing a solid radwaste processing facility.

When Unit \#1 is decommissioned, the radwastes will consist of operational liquid (solidified) and solid wastes, liquid and solid wastes formed during decommissioning and operation of the radwaste processing facilities, and solid wastes from the dismantling unit equipment and structures. The maximum estimates of the total volume of wastes in these categories show that the planned capacities and facilities for processing operational radwastes may not be sufficient and that the amount of wastes to be processed will require additional specialized storage sites. In undertaking the decommissioning of Unit \#1 and other LNPP units, the need to build processed waste storage facilities is becoming a significant problem. The required radwaste processing facilities must be built and commissioned before Unit \#1 decommissioning begins.

Uncertainty about the construction of a regional radwaste repository and the growing amount of wastes at the plant make it necessary to provide for long-term storage of processed radwastes on site. Russia, however, does not have the necessary regulations for design and construction of long-term radwaste storage facilities on site at nuclear power plants. 
The decommissioning of Unit \#1 will also result in the formation of a significant amount of wastes classified as materials for reuse (limited or unlimited). These materials are distinguishable because their specific radioactivity is below the threshold for low-level radwastes but above the level of materials that may be used without restriction. By weight they account for more than $90 \%$ of the total amount of wastes expected during unit decommissioning. Radiation control of such a large amount of materials will be one of the critical control problems when Unit \#1 is decommissioned. Solving this problem involves not only possible technical difficulties and financial outlays but also the need to ensure environmental safety during the handling of limiteduse materials. There is no concept for the safe handling of these materials.

Safety assurance during decommissioning: The major problems in safety assurance during the Unit \#1 decommissioning are

- nuclear safety of spent fuel handling

- physical protection of long-term, on-site spent nuclear fuel storage

- radiation safety of personnel and the public

- environmental safety.

Nuclear safety of spent fuel handling after final shutdown of Leningrad \#1, including all necessary transportation, is ensured by a set of procedures that use existing spent fuel storage and transportation systems.

Physical protection of long-term spent nuclear fuel storage on site will be provided by the physical protection system (PPS) at LNPP. This system is an integral part of the plant-wide system of technological, nuclear, and radiation safety procedures that constitute a set of organizational, engineering, and technological practices aimed at preventing theft of nuclear materials.

LNPP's physical protection system meets requirements for controlling the movement of nuclear materials, storage of spent nuclear fuel, nuclear fuel cycle wastes, and other materials that represent a radiation hazard both across and within the perimeter of the plant. LNPP's physical protection system is organized to meet required standards.

Radiation safety of personnel and the public during Unit \#1 decommissioning must comply with radiological limits (permissible radiation dose limits) established by the Russian Federation law "On Public Radiation Safety." Under this law an annual worker effective dose of 2 rem (0.02 Sv) must not be exceeded during unit decommissioning; for the public, the required average annual effective dose is $0.1 \mathrm{rem}(0.001 \mathrm{~Sv})$.

The primary hazard in unit decommissioning will be radionuclides that formed in the nuclear fuel during reactor operation, in corrosion products in the primary coolant circulation circuit, and in reactor structural materials. These radionuclides will define radiation conditions near the equipment and in unit rooms.

Dismantling and demolition during decommissioning will be accompanied by intense dust formation, resulting in a significant amount of radioactive aerosols and hot aerosol particles that will spread throughout the unit structures and rooms. Therefore, internal radiation may be more significant than that of external personnel radiation. 
Environmental safety. From the standpoint of natural and human environmental safety, the Unit \#1 decommissioning should be no more hazardous than other industrial activities in the region where a nuclear power plant is located.

According to the requirements of current Russian laws, decommissioning work requires the development of a concept for ensuring environmental safety and supporting environmental materials that must undergo public and state environmental review.

The following circumstances should be kept in mind in planning the decommissioning of Leningrad Unit \#1:

- This will be the first decommissioning at LNPP.

- Implementing the Russian concept for NPP radwaste handling, which calls for radwaste processing and storage on site, requires that care be taken to ensure that the process maintains environmental safety.

- LNPP units are located in a rather complicated mountainous region on the shore of a large body of water, which requires careful analysis of the possible environmental consequences of unit decommissioning.

Therefore, the Unit \#1 decommissioning project must be accompanied by ecological monitoring. However, ecological monitoring has not been organized at a single Russian NPP. Therefore, the region in which LNPP is located does not have the required ecological monitoring service.

The following may be one sequence for organizing ecological monitoring: observation of the condition of the natural surroundings and human habitat - assessment of the observed condition forecast of the anticipated condition - assessment of the anticipated condition - condition control and decommissioning process adjustment (if necessary). The procedure for preparing for and carrying out the Unit \#1 decommissioning process may be organized according to the sequence shown in Figure 10.2.

Financing the decommissioning: LNPP, which has the status of an independent operating organization, is a state enterprise. The nuclear power plant is completely self-supporting and receives no government financial support for reconstruction to ensure an adequate level of safety.

LNPP has recently established a special decommissioning fund to finance the decommissioning of LNPP units that have reached the end of their design lives. Begun in 1997, this fund will receive money from fees on the primary operation of an NPP (on the salable products of nuclear power plants-electricity and heat). However, the mechanism by which the special decommissioning fund is being formed and will accumulate and spend money does not take into account possible requirements for decommissioning LNPP units as well as the financial and politicoeconomic aspects of Russia.

The Russian nuclear power industry's problem of consumer failure to pay for electricity generated by nuclear power plants has a negative impact on the current financial position of LNPP. Therefore, even procurements associated with operating its units are not being fully satisfied. The problem of non-payment and the instability of LNPPs financial position make it impossible 
to accumulate money in the special fund. This threatens not only the financing of future decommissioning work but also basic research and experimental design required to start this work. The problem of financing the decommissioning of Leningrad Unit \#1 is a major one and requires special attention to find suitable solutions.

Leningrad Unit \#1 decommissioning alternative: in view of the results of the analysis of the main problems to be solved in developing a decommissioning strategy, analysis of the suitability of possible decommissioning alternatives, and Russia's socioeconomic conditions, this study proposed the SAFESTOR decommissioning alternative (deferred reactor dismantling).

The analysis of radioactivity decay for Unit \#1 structures as a function of storage time showed that the unit should be held for 50 to 100 years before reactor dismantling (see Tables $6.11,6.13$ ) begins to ensure reduced total reactor radioactivity and gamma radiation dose rates. Estimates indicate that the lower limit for the storage time is the point at which the total radioactivity of reactor structures will reach a plateau; i.e., storing the reactor structures longer will lower their radioactivity only slightly.

The upper limit for the storage time is the time required for ${ }^{60} \mathrm{Co}$, the primary dose-forming radionuclide, to decay to an acceptable level, which is about 100 years. In this case the gamma radiation dose rate near the structures when they are dismantled will be $1-5 \mathrm{mrem} / \mathrm{hr}$, which is about $10^{-6}$ times cobalt's initial dose rate. When the gamma radiation dose rate near the reactor structures reaches this level, they may be dismantled without special remote equipment. However, after these structures are dismantled, their specific beta-radioactivity will require that they be classified as medium-level radwastes.

Decommissioning Leningrad Unit \#1 according to the DECON alternative is not feasible for the following reasons:

- First, dismantling the highly radioactive structures and graphite stack of an RBMK requires special equipment, including robotics that Russia does not have.

- Second, storing highly radioactive wastes, including the irradiated graphite that will form in large quantities when the RBMK is dismantled, requires repositories or storage facilities. Russia does not have these facilities, and there are problems with their construction in the near future. Moreover, a concept has not been developed for environmental safety in handling irradiated RBMK graphite, which poses a potential hazard because of the genetically significant ${ }^{14} \mathrm{C}$ and tritium radionuclides that accumulate in it. If this option were to be chosen, significant financial and material outlays would be required from the very beginning, and LNPP does not have the resources.

In case of long-term entombment for 100 to 150 years, burying Leningrad Unit \#1 (the ENTOMB alternative) is almost the same as the SAFESTOR option, since the radiation parameters of the reactor structures when they are dismantled will be similar.

The merit of the Leningrad Unit \#1 decommissioning alternative proposed in this study is also supported by further advantages, since this alternative

- provides extra time to 
- develop comprehensive regulations including national standards for re-usable materials

- complete the required basic research and experimental design work to study the decommissioning process and provide the necessary equipment

- build the required NPP radwaste storage facilities and repositories

- permits a significant reduction in the amounts of radwastes formed and in personnel dose loads during dismantling as a result of partial decay of radionuclides

- makes the problem of finding the required funding less acute-it does not require large initial expenditures and it may be possible to acquire and spend the money gradually.

All these make the SAFESTOR option the most advantageous and acceptable option for decommissioning the plant's Unit \#1 according to the proposed schedule.

Final condition of Leningrad Unit \#1: Processing the radwastes formed during dismantling of unit equipment and structures and removing them for later storage or burial and controlling and storing the resulting wastes will be fundamental problems during unit decommissioning. The availability and timeliness of solutions to these problems and their economic acceptability will have a considerable impact both on the rate of dismantling and on total costs to decommission Unit \#1.

The correct choice of the final condition of Unit \#1 when it is decommissioned will help make the problem of waste handling less acute (e.g., by reducing the amount of waste) and increase the efficiency of and economic acceptability of the decommissioning option. Finding an optimal final condition of Unit \#1 should therefore be an integral part of the planning for unit decommissioning.

One possible final condition that deals with the NPP radwaste handling situation in Russia is to build a radwaste processing and long-term organized storage facility in the Unit \#1 facilities. Various approaches aimed at maximum compliance with decommissioning requirements were analyzed for implementing this building proposal, not only for Unit \#1, but for both units in Phase I and all LNPP units.

In this study, the recommended final condition of the decommissioned Leningrad Unit \#1 is the placement of a radwaste processing and long-term organized storage facility on the site. To bring Leningrad Unit \#1 to the final condition described above, the following steps should be taken when it is decommissioned:

- partial dismantling of turbine hall equipment to make room for the specialized radwaste conditioning complex

- localization of the reactor in a concrete cavity and subsequent conversion of the unit's facilities for storage of processed radwastes (operational radwastes and radwastes produced during decommissioning)

- dismantling of the remaining turbine hall equipment to make room for processed radwastes and dismantled equipment (this equipment may be used for other LNPP units or sold to other NPPs with RBMK-1000 reactors, which will partially cover decommissioning costs) 
- using the Unit \#1 facilities as a training base for developing RBMK-1000 unit decommissioning practices and to provide personnel with the required skills.

The basic steps and kinds of work necessary to implement the recommended decommissioning alternatives and bring Unit \#1 to the proposed final condition have been described in more detail in Tables 5.1, 5.2, 11.1, 11.2, and 11.3.

In order to implement the Leningrad Unit \#1 decommissioning alternative, a program of research and experimental design must verify the strength of the reactor metal structures and unit concrete structures. A comprehensive procedure for estimating the longevity and durability of the reactor metal structures and unit concrete structures must be developed to do this.

Neither a national concept of nor regulatory requirements for safety in the final handling of irradiated graphite nor technologies for dismantling irradiated graphite have been developed. The specifics of the large-scale work required to dismantle Unit \#1's radioactive structures necessitate the development of new equipment for real-time monitoring of low-energy beta and gamma radiation and for detecting hot aerosol particles. Theoretically, the ultimate goal of this comprehensive research and experimental design program should be to prove the safety of the Leningrad Unit \#1 decommissioning alternative proposed in this study. 


\subsection{General Conclusions and Recommendations}

\subsection{Results of the Study}

1. The objective of this joint study was to lay the groundwork for a safe, technically feasible and economically acceptable strategy for decommissioning Leningrad Unit \#1, an RBMK-1000 reactor. The ultimate goal in developing a decommissioning strategy was to choose the unit decommissioning option most acceptable given Russia's socioeconomic situation and the unit's end state.

2. The strategy was developed on the basis of a preliminary analysis of regulations and technical requirements for decommissioning NPP units and on experience repairing, rebuilding, and dismantling graphite-uranium nuclear reactors.

The results of this analysis, which appear in Appendixes B and C to this report (to be published as a separate document), made it possible to identify and develop the strategy with regard to current legal and regulatory requirements and restrictions and the infrastructure for decontaminating and dismantling radioactive structures of graphite-uranium reactors, including the RBMK.

3. The study encompassed the following basic issues, which had to be taken into account in developing a decommissioning strategy for Leningrad Unit \#1:

- national laws and regulations

- prompt removal of spent nuclear fuel from the unit and processing, storing, and/or burying radwastes

- the availability of technologies required to decontaminate and dismantle the unit's radioactive structures

- safety assurance, including environmental safety, during unit decommissioning

- the availability of financing for the decommissioning.

4. Scientific, technical, and technological information was gathered on handling spent nuclear fuel and radwastes at LNPP; on the radioactivity of reactor structures, equipment, rooms, and main circuits of Unit \#1; and on existing decontamination and dismantling technologies. These data were systematized and analyzed against the basic issues to find acceptable solutions. In addition, restrictions on the choice of a decommissioning strategy for Unit \#1 and its end state were identified.

5. The alternative recommended as a result of this study is SAFESTOR (deferred reactor and graphite stack dismantling). This choice was made based on the analysis of the issues above, the applicability of other possible options to decommissioning a unit with an RBMK- 1000 reactor, and assessments of socioeconomic conditions in Russia. The recommended alternative has several advantages. It provides extra time to develop the regulations required to perform the necessary basic research and experimental design activities and to build the radwaste storage facilities and repositories; it also permits a significant reduction in the amounts of radwastes formed and in personnel dose rates 
during decommissioning. Finally, this option makes the problem of finding the required funding less acute because it does not require large initial expenditures.

6. To increase the economic acceptability of the proposed Unit \#1 decommissioning alternative, various ways to accomplish it were analyzed with regard to providing for the decommissioning not only of this unit but also of both Phase I Units and the entire NPP. As a result it has been proposed that a processing and long-term storage complex for radwastes (both operational and those created during decommissioning) be built in Unit \#1 facilities.

7. A list of sequenced actions required to achieve the proposed final condition of the unit was compiled for the proposed Unit \#1 decommissioning alternative. This list is summarized in Tables 11.1, 11.2, and 11.3 of this report.

8. The preliminary list of basic research required to accomplish the Unit \#1 decommissioning alternative was developed. The primary topics of this research are substantiating the long-term strength of unit metal and concrete structures during long-term storage; developing technologies for final handling of irradiated graphite; and developing instruments for real-time monitoring of low-level beta and gamma radiation and for detecting hot aerosol particles.

9. The results of this study may lay the foundation for developing a program and project for decommissioning Leningrad Unit \#1. These results may also be used in planning the decommissioning of other NPP units with RBMK reactors.

10. The objective of this study was to develop a strategy for decommissioning Leningrad Unit \#1. Nevertheless, the combination of process equipment and auxiliary systems used for the construction of the Phase I and II units makes it worthwhile to consider whether the service life of Phase I Unit \#1 might be extended at least until the end of Unit \#2's service life.

This question is worth considering from the standpoint of decommissioning the entire Phase I units, which is made easier by the short time between the planned dates for the shutdown of these units and the possibility of reducing total costs to decommission them.

\subsection{Proposed Projects}

Estimates of the monetary costs and the personnel dose rates required to achieve the chosen Unit \#1 decommissioning alternative and proposed end state have not been undertaken at this stage. Cost and dose estimates are a rather labor-intensive task and should be the subject of separate studies.

The following projects are offered as specific proposals for further joint study to facilitate the development of the Leningrad Unit \#1 decommissioning strategy that is optimal in terms of safety, technical feasibility, and economic acceptability:

a) Detailed analysis of the proposed alternative and Unit \#1 end state when it is decommissioned in order to estimate costs. 
b) Development of a technical and economic data base for preparing cost estimates and for optimizing costs to decommission units with RBMK-1000 reactors.

Other possible projects for later joint study, whose results are necessary to plan for and carry out the decommissioning of units with RBMK reactors of Soviet design, might be

a) Development of a standard program for decommissioning units with RBMK-1000 reactors.

b) Development of a project for decommissioning Leningrad Unit \#1 with RBMK-1000 reactors according to the proposed option and with regard to its construction as part of Phase I.

c) Development of a strategy for combined decommissioning of first-generation units with RBMK-1000 reactors at Leningrad and VVER-440 reactors at Kola, both of which are in the northwestern region of Russia.

d) Analysis of the design basis accidents that may occur during long-term storage and decommissioning of RBMK-1000 reactors.

It is recommended that LNPP use the outlines presented in Appendix D for the planning and license submittal for the Unit \#1 decommissioning. Initial planning may be started, but much of the planning effort will require the results of the recommended projects.

Other recommendations related to the Russian Federation are

a) Continue development of regulations for decommissioning and handling of SNF.

b) Analyze the possibility of non-safety threatening decommissioning activities (e.g., general cleanup and dismantling of non-safety related equipment and systems) after shut down but prior to licensing, and modify current regulations.

c) Construct state radwaste sites for management of NPP operational and decommissioning waste.

d) Initiate a program for joint NPP funding of basic research and development required for decommissioning of units with RBMK-1000 reactors. 